\title{
DESIGN OF VERTICAL BREAKWATERS
}

\section{By Shigeo TAKAHASHI}

PORT and AIRPORT RESEARCH INSTITUTE, JAPAN

August 31, 1996 (Revised in Jully, 2002 Version 2.1)

Revised Version of Reference Document No.34, PHRI 



\section{INTRODUCTION}

2. TYPES OF BREAKWATERS AND THEIR HISTORICAL DEVELOPMENT

\subsection{Structural Types}

2.2 Historical Development of Breakwaters

\section{RECENT FAILURES OF VERTICAL BREAKWATERS}

4. DESIGN OF CONVENTIONAL VERTICAL BREAKWATERS

4.1 Example of Vertical Breakwaters

4.2 Wave Transmission and Reflection of Vertical Walls

4.3 Wave Forces on Vertical Walls

4.4 Design of Rubble Mound Foundations

4.5 Evaluation of Sliding Distance

5. DESIGN OF NEW VERTICAL BREAKWATERS

\subsection{Perforated Walls}

5.2 Inclined Walls

6. DESIGN OF HORIZONTALLY COMPOSITE BREAKWATERS

6.1 Typical Cross Section of Horizontally Composite Breakwaters

6.2 Wave and Block Forces on a Vertical Walls

6.3 Stability of Wave Dissipating Concrete Blocls

7. PERFORMANCE DESIGN OF COPMOSITE BREAKWATERS

7.1 History and Definition of Performance Design

7.2 New Framework for Performance Design

7.3 Deformation-Based Reliability Design

7.4 Extended Performance Design

REFERENCES

* A lecture note for Coastal Structures Short Course, 25 ${ }^{\text {th }}$ International Conference on Coastal Engineering, Orlando, USA, September 31, 1996. Revised as the version 2.1 for Short Course of Hydraulic Response and Vertical Walls, 28 $8^{\text {th }}$ International Conference on Coastal Engineering, Cardiff, Wales, UK, July 7, 2002

** Director of Marine Environment and Engineering Department, Port and Airport Research Institute, Independent Administrative Agency, Japan, 3-1-1, Nagase, Yokosuka, Japan 239-0826 Phone+81·468-44-5036 Fax+81-468-44-1274, email: takahashi_s@pari.go.jp 


\section{INTRODUCTION}

Breakwaters are constructed to provide a calm basin for ships and to protect harbor facilities. They are also sometimes used to protect the port area from the intrusion of littoral drift. In fact, for ports open to rough seas, breakwaters play a key role in port operations.

Since sea waves have enormous power, the construction of structures to mitigate such power is not easily accomplished. The history of breakwaters, therefore, can be said to be one of much damage and many failures. On the other hand, maritime technology has progressed a great deal, especially since 1945, and this has gradually made it possible to construct breakwaters having high stability against waves.

There are two main types of breakwaters: rubble mound and composite breakwaters. Rubble mound breakwaters have a rubble mound and an armor layer that usually consists of shape-designed concrete blocks. Due to the development of these blocks, modern-day rubble mound breakwaters can strongly resist the destructive power of waves, even in deepwaters. Composite breakwaters consist of a rubble foundation and vertical wall, and are therefore classified as vertical breakwaters. By using caissons as the vertical wall, composite breakwaters provide an extremely stable structure even in rough, deep seas. Such strength has led to their use throughout the world.

In this book, different types of breakwaters are introduced and their historical development is described in order to understand the advantages and disadvantages associated with each type of breakwater. The failures of breakwaters are then discussed to demonstrate crucial points in their stability design. Finally, the design methods used for vertical are explained including a new design concept of performance design for vertical breakwaters. Since the design methodology for rubble mound breakwaters has been addressed in many textbooks, the design of vertical breakwaters will be concentrated on here.

Sincere gratitude is extended to the authors of many references, especially the following:

1) Ito, Y. : A treatise on historical development of breakwater design, Technical Note of Port and Harbour Research Institute, No. 69, 1969, 78 p. (in Japanese).

2) Horikawa, K. : Coastal Engineering, University of Tokyo Press, 1978, $402 \mathrm{p}$.

3) Goda Y. : Random Seas and Design of Maritime Structures, University of Tokyo Press, 1985, 323 p.

4) Tanimoto, K. et al.: Structures and Hydrodynamic Characteristics of Break waters, Report of Port and Harbour Research Institute, Vol. 25, No. 5. 1987, pp. 11·55.

5) Burcharth, H. F. The Design of Breakwaters, Coastal and Harbour Engineering Reference Book (edited by M. B. Abbott and W. A. Price), Chapter 28, E \& FN SPON, 1993.

6) Brunn P. : Design and Construction of Mound for Breakwater and Coastal Protection, Elsevier; $1985,938 \mathrm{p}$.

7) Proceedings of International Workshop on Wave Barriers in Deepwaters, Port and Harbour Research Institute, 1994, $583 \mathrm{p}$.

8) Proceedings of International Workshop on Advanced Design of Maritime Structures in the 21st 
Century (ADMS21), Port and Harbour Research Institute, 2001, 392 p.

9) Technical Standards for Port and Harbour Facilities in Japan: The Overseas Coastal Area Development Institute of Japan (OCDI), 2002, 599p.

10) Manual on the Use of Rock in Coastal and Shoreline Engineering, CIRA special publication 83 , CUR Report 154, 1991, $607 \mathrm{p}$.

11) Shore Protection Manual: Coastal Engineering Research Center, U.S. Army Corps of Engineers, 1984.

12) Losada, M. A. : Recent Developments in the Design of Mound Breakwaters, Handbook of Coastal and Ocean Engineering (edited by J. B. Herbich), Chapter 21, Gulf Publishing Co., 1990.

13) Tsinker, G.P.: Handbook of Port and Harbor Engineering,Chapman \&Hall, 1996,1054p. 


\section{TYPES OF BREAKWATERS AND THEIR HISTORICAL DEVELOPMENT}

\subsection{Structural Types}

There are many types of breakwater structures used throughout the world. As shown in Table 2.1, breakwaters can be classified into three structural types: (1) the sloping or mound type, (2) the vertical type which includes the basic (simple) vertical type and the composite and horizontally composite types, and (3) special types. Figure 2.1 shows conceptual diagrams of the different types of breakwaters.

Table 2.1 Structural types of breakwaters

\begin{tabular}{|l|l|}
\hline Sloping (mound) type & $\begin{array}{l}\text { Rubble mound breakwaters } \\
\text { Rubble mound breakwaters (multi-layer) } \\
\text { Rubble mound breakwaters armored with blocks } \\
\text { Concrete block breakwaters } \\
\text { Reshaping rubble mound breakwaters (berm breakwaters) } \\
\text { Reef breakwaters (submerged breakwaters) }\end{array}$ \\
\hline Vertical (upright) type & $\begin{array}{l}\text { Monolith concrete breakwaters } \\
\text { Block masonry breakwaters } \\
\text { Cellular block breakwaters } \\
\text { Concrete caisson breakwaters } \\
\text { New caisson breakwaters }\end{array}$ \\
\hline Special (non-gravity) type & $\begin{array}{l}\text { Curtain wall breakwaters } \\
\text { Steel pile breakwaters } \\
\text { Horizontal plate breakwaters } \\
\text { Floating breakwaters } \\
\text { Pneumatic breakwater } \\
\text { Hydraul ic breakwater }\end{array}$ \\
\hline
\end{tabular}

(1) Sloping or mound type

The sloping or mound type of breakwaters basically consist of a rubble mound as shown in Fig. 2.1(1). The most fundamental sloping type breakwater is one with randomly placed stones (a). To increase stability and decrease wave transmission, as well as to decrease material costs, the multi-layered rubble mound breakwater was developed having a core of quarry run (b). The stability of the armor layer can be strengthened using shape-designed concrete blocks, while wave transmission can be reduced using a superstructure (wave screen or wave wall), which can also function as an access road to the breakwater (c).

Breakwaters comprised of only concrete blocks (d) are also being constructed, especially for use as a detached breakwater providing coastal protection. Although wave transmission is not reduced so much for this breakwater type, its simple construction procedure and the relatively high permeability of the breakwater body are advantageous features. Recently, reef breakwaters or submerged breakwaters (e) have been constructed for coastal protection, while not to interrupting the beautiful "seascape." 
Reshaping breakwaters (f) utilize the basic concept of establishing an equilibrium between the slope of the rubble stone and wave action, i.e., the rubble mound forms an $\mathrm{S}$-shape slope to stabilize itself against wave actions. This breakwater has a large berm in front, which will ultimately be reshaped due to wave actions, and therefore it is called the berm breakwater or dynamically stable breakwater. It should be noted that this concept is not new, since ancient rubble mound breakwaters were all of this type, being naturally reshaped by damage and subsequent repairs.

\section{(2) Vertical type}

(composite and horizontally composite types)

The original concept of the vertical breakwater was to reflect waves, while that for the rubble mound breakwater was to break them. Figure 2.1(2) shows four vertical type breakwaters having different mound heights. The basic vertical wall breakwater is shown in (a), while the others are composite breakwaters with a rubble mound foundation, namely, the low-mound (b) and high-mound composite breakwaters (d). By convention, the high-mound composite breakwater has a mound that is higher than the low water level (L.W.L.). The former breakwater does not cause wave breaking on the mound, while the latter one does. Since the high-mound composite type is unstable due to wave-generated impulsive pressure and scouring caused by breaking waves, composite breakwaters with a lowmound are more common. The composite breakwater with a relatively high mound (c) that is lower than L.W.L. occasionally generates impulsive wave pressure due to wave breaking.

To reduce wave reflection and the breaking wave force on the vertical wall, concrete blocks are placed in front of it. This is called a composite breakwater covered with wavedissipating concrete blocks, which is now called the horizontally composite breakwater. Such breakwaters are not new, however, since vertical wall breakwaters suffering damage to the vertical walls were often strengthened by placing large stones or concrete blocks in front of them so as to dissipate the wave energy and reduce the wave force, especially that from breaking waves. Modern horizontally composite breakwaters employ shape-designed concrete blocks such as tetrapods. (a)
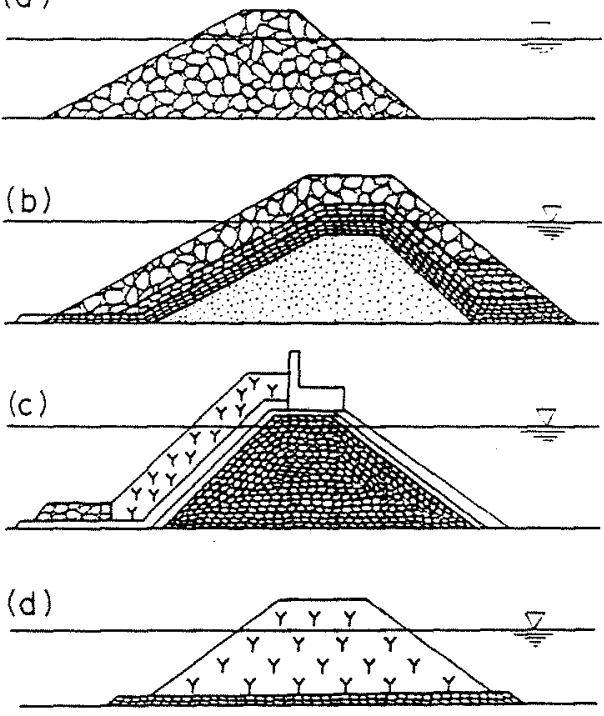

(e)

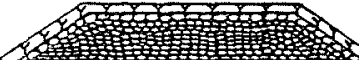

(f)

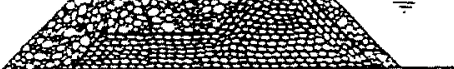

Fig. 2.1 (1) Sloping type breakwaters
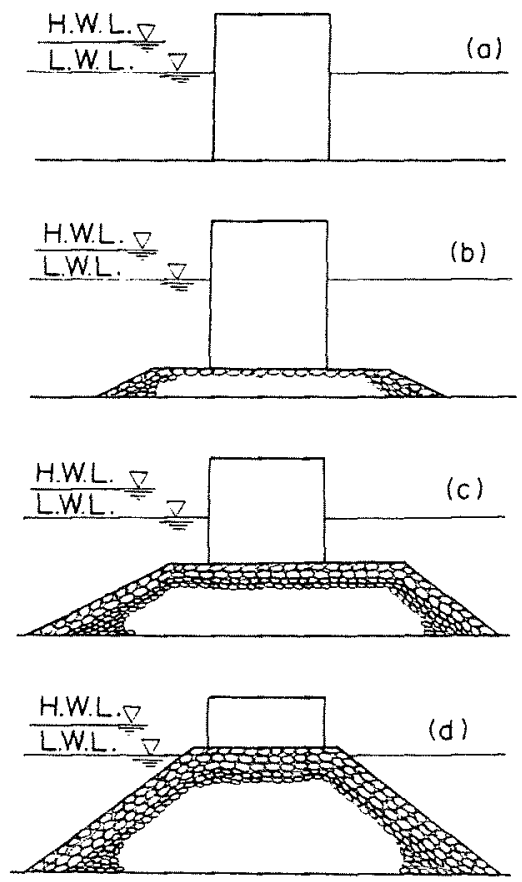

Fig. 2.1 (2) Vertical type breakwaters 
The horizontally composite breakwater is very similar to a rubble mound breakwater armored with concrete blocks. Figure 2.1(3) shows how its cross section varies with mound height, where as the mound height increases, the breakwater becomes very similar to rubble mound breakwaters. In particular, a breakwater with core stones in front of the vertical wall (d) is nearly the same as the rubble mound breakwater. They are basically different, however, since the concrete blocks of the rubble mound breakwater act as the armor for the rubble foundation, while the concrete blocks of the horizontally composite breakwater function to reduce the wave force and size of the reflected waves. Thus, horizontally composite breakwaters are considered to be an improved version of the vertical types.

Figure 2.1(4) shows several kinds of composite breakwaters having different upright sections. An upright wall with block masonry (b) was initially most popular, in which many different methods were applied to strengthen the interlocking between the blocks. Cellular blocks (c) have also been used to form the upright wall of vertical breakwaters. However, the invention of caissons (d) made these breakwaters more reliable, and many were subsequently constructed around the world. Caisson breakwaters have been improved using sloping top caissons (e) or perforated walls (f).

It should be noted that the rubble mound/rubble foundation of composite breakwaters is vital to prevent the failure of the upright section by scouring, as well as stabilizing the foundation against the wave force and caisson weight.

\section{(3) Special types}

Special type breakwaters are those employing some kind of special feature. Although they are not commonly used, their history is long, and in fact, some were constructed in ancient times. Special breakwaters, however, do not always remain special, because some of them later become a standard breakwater, e.g., the perforated caisson breakwater has become very popular in some countries and is now considered to be a standard breakwater there.
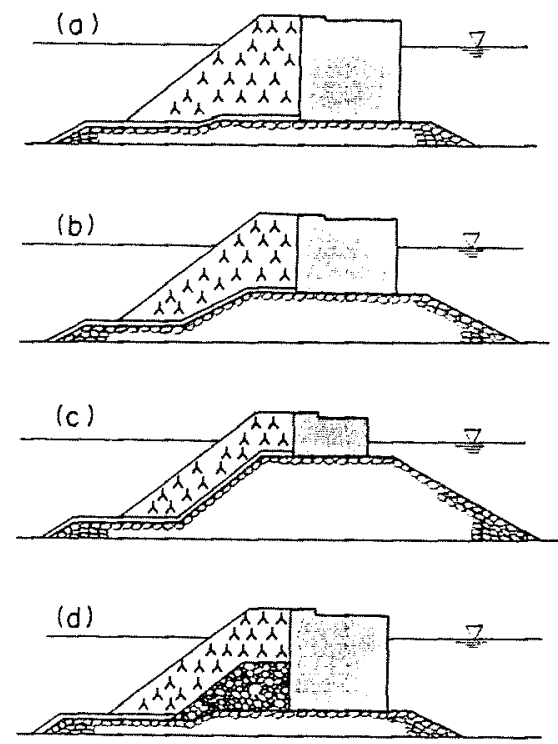

Fig. 2.1 (3) Horizontally composite breakwaters
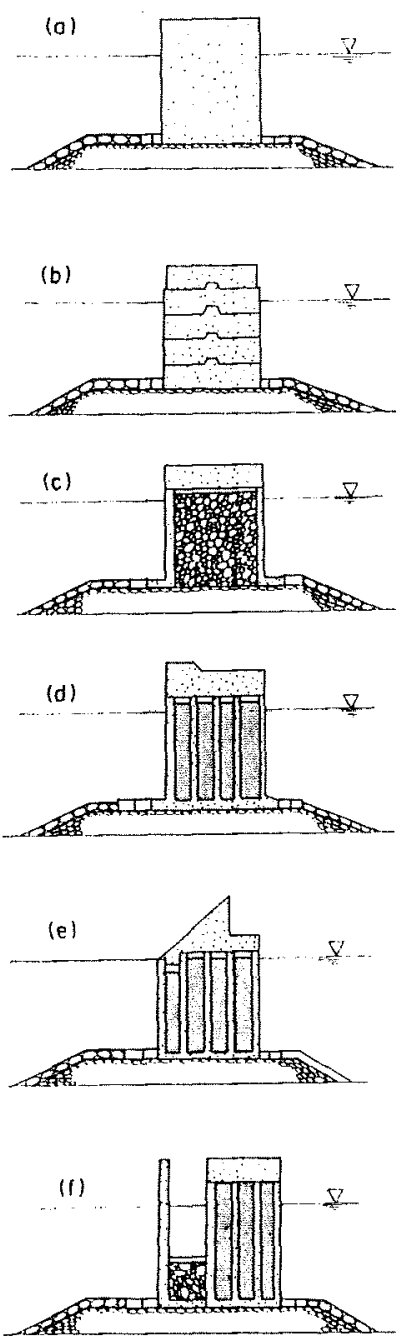

Fig. 2.1 (4) Composite breakwaters 
Common special type breakwaters are non-gravity type ones, such as the pile, floating, or pneumatic types. These breakwaters also have a long history, and some are still being currently employed. Their uses though, are limited to special conditions.

Figure 2.1(5) shows some special breakwaters. The curtain wall breakwater (a) is commonly used as a secondary breakwater to protect small craft harbors, and the vertical wall breakwater having sheet piles or continuous piles (b) is sometimes used to break relatively small waves. A horizontal plate breakwater (c) can reflect and break waves, and as shown, it is sometimes supported by a steel jacket. A floating breakwater (d) is very useful as a breakwater in deepwaters, but its effect is limited to relatively short waves. The pneumatic breakwater (e) breaks the waves due to a water current induced by air bubble flow, and it is considered effective for improving nearby water quality, though only being effective for waves having a short length.

\section{(4) Breakwater selection}

Breakwaters are selected based on considering the items listed in Table 2.2. Their influence on the surrounding topography due to wave reflection and on the environmental water conditions also help determine which type of breakwater structure should be used.

(5) Comparison of sloping and vertical types Each type of breakwater has advantages and disadvantages. Lamberti and Franco (1994) discussed the advantages and disadvantages of using a caisson breakwater (composite breakwater) in comparison with a rubble mound breakwater armored by concrete blocks. The advantages are summarized as follows:
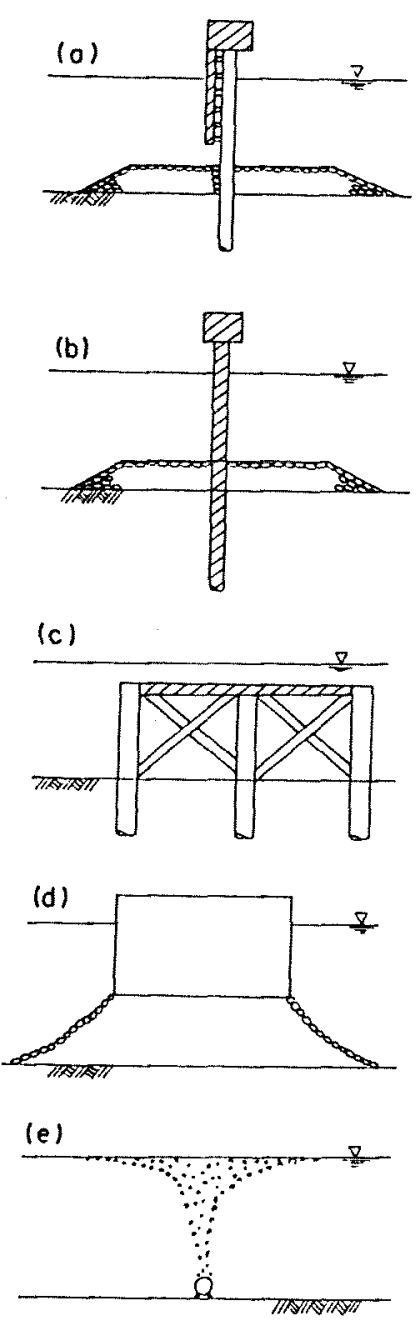

Fig. 2.1 (5) Special breakwaters

Table 2.2 items to be considered in the selection of breakwaters

(1) Layout of breakwaters

(2) Environmental conditions

(3) Utilization conditions

(4) Executive conditions

(5) Costs of construction

(6) Construction terms

(7) Importance of breakwaters

(8) Available construction materials

(9) Maintenance

a) A smaller body width/quantity of material

This is one of the biggest advantages of using a composite breakwater, which makes the breakwater construction more economical, especially in deep water. In addition, a small breakwater width limits the impact on seabed life and increases the usable water area.

b) Reduced maintenance 
The composite breakwater requires less maintenance because the blocks of rubble mound breakwaters require relatively frequent maintenance efforts.

c) Rapid construction, reduction of failure during construction, and smaller environmental impact during construction

The composite breakwater can be rapidly constructed and is fully stabilized once its caissons are filled with sand. In comparison, the rubble mound breakwater is more unstable since a longer period occurs in which its inner layers may be subjected to the damage during construction. In addition, since not much quarry work or damping is required, the general public is not disturbed as much and the environment is damaged less.

\section{d) Miscellaneous}

Reuse of the dredged material, potential removability, and fewer underwater obstacles are also considered to be advantages of using composite breakwaters. Moreover, use of a vertical breakwater may be only the choice if the availability of rubble stones is limited.

The advantages associated with using rubble mound breakwaters are summarized as follows:

a) Use of natural material

The use of natural material is a big advantage for the rubble mound breakwater since this reduces material costs, especially when a large supply of rubble stones is readily available.

b) Use of smaller construction equipment

The construction of rubble mound breakwaters can be done from land, and does not usually require large-scale construction equipment such as work barges.

c) Less environmental impact due to smaller reflected waves and more water exchange Waves are absorbed by the rubble mound breakwater and long period waves such as tidal waves are transmitted through it, which reduces the harm done to the environment.

d) Creation of a natural reef

The slope of the rubble mound breakwater provides an suitable place for sea life to live.

It should be noted that some of the disadvantages of composite breakwaters can be improved by using horizontally composite breakwaters or perforated wall caissons. 


\subsection{Historical Development of Breakwaters}

The value of "lessens learned" in actual breakwater design and construction methodology cannot be stressed enough. It is for this reason that the historical development of breakwaters will be described next, being a brief review of the work by Ito (1969) concerning the history of breakwaters, as well as including additional recent developments.

\subsubsection{Historical Breakwaters}

(1) Breakwaters in ancient times

Breakwaters constructed in ancient times were presumably simple mounds made from stones. However, as early as 2000 B.C., a stone masonry breakwater was constructed in Alexandria, Egypt. Figure 2.2 shows a rubble mound breakwater located in Civitavecchia, Italy, which was constructed by the Roman Emperor Trajanus (A.D. 53-117) and is recognized as being the oldest existing rubble mound breakwater. This breakwater reached its equilibrium slope after a long history of damage and subsequent repairs.

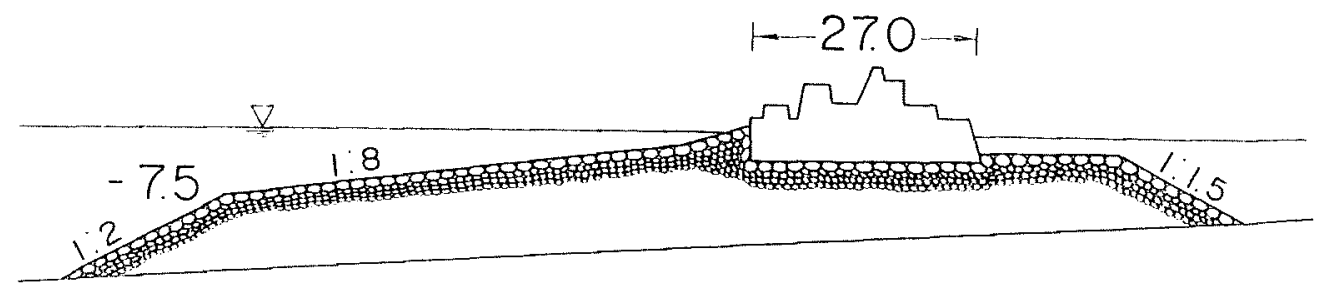

Fig. 2.2 Rubble mound breakwater in Civitavecchia

(2) Modern breakwaters

The age of modern breakwaters is thought to have started in the latter half of the 18 th century, corresponding to the industrial revolution. The breakwaters built in Cherbourg, Plymouth, and Dover are considered to be the pioneers of modern-day breakwaters.

\section{a) Breakwater at Cherbourg}

The construction of a bay-mouth breakwater at Cherbourg Port, France, which faces the mainland U.K. began in 1781. The breakwater's initial design was a rock-filled breakwater with a 50-m cone-shaped crib. However, the large cones failed soon after installation, and so in 1978 its design was changed to a rubble mound breakwater. The slope was $1 / 3$ in the initial plan, although after frequent damage and repairs, it leveled out at 1/8. The upper part, above L.W.L., suffered frequent damage, and in 1830 a vertical wall was erected above this level. It is probably the first high-mound composite breakwater. Changes in the breakwater's cross section are shown in Fig. 2.3.

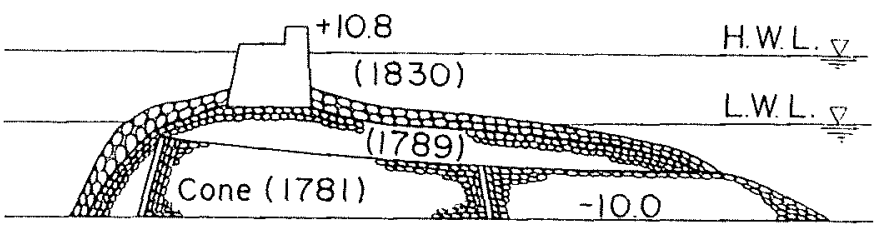

Fig. 2.3 Cherbourg breakwater 
(3) Rubble mound breakwater at Plymouth

The breakwater in Plymouth Port, U.K., which runs along the English Channel facing Cherbourg Port, was started in 1812. It was a rubble mound type which copied the rubble mound breakwater at Cherbourg. The initial cross section is shown in Fig. 2.4, where the crown elevation is $+3 \mathrm{~m}$ and the slope $1 / 3$. The crown elevation was later changed to $+6 \mathrm{~m}$ to reduce wave overtopping.

The cross section of the breakwater was changed after suffering various damage and repairs. The slope was leveled to $1 / 5$ in 1824 , and stone pitching was added above L.W.L. Its cross section in 1841 is also shown in Fig. 2.4, having a berm near L.W.L. and a width of $110 \mathrm{~m}$. This breakwater continued to require a great amount of additional stones even after the work done in 1841 . The slope reached 1/12 in 1921, which is close to the equilibrium slope. Dedicated maintenance has ensured the breakwater's existence.

(a)

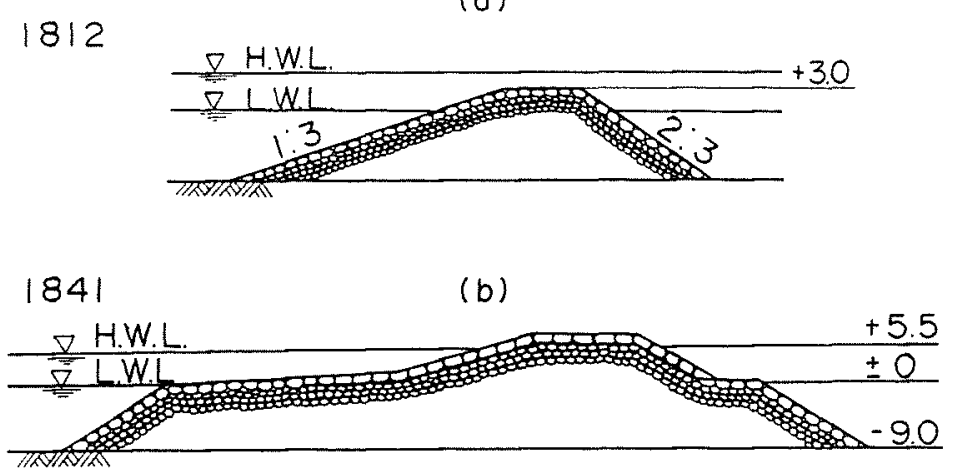

Fig. 2.4 Plymouth breakwater

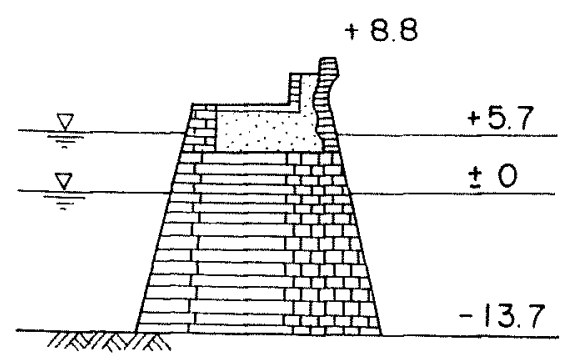

Fig. 2.5 Dover breakwater

(4) Vertical wall breakwater at Dover

Figure 2.5 shows the original design (1847) of the vertical wall breakwater located at Dover, U.K. Factored into the design were the lessens learned from the Cherbourg and Plymouth rubble mound breakwaters, as well as the limited supply of quarry-stones available near Dover. Erection of this vertical wall breakwater was extremely difficult; thus its construction was slow and performed at great expense. This appeared to "pay off" since the breakwater experienced only slight damages after completion. A half century later, the construction speed was significantly improved when another vertical wall breakwater was built in the adjacent area.

\subsubsection{Composite Breakwater (from high- to low-mound)}

Many high-mound composite breakwaters were built after the construction of the Cherbourg breakwater. In the U.K., composite breakwaters were also built in places such as St. Catherine and Alderney.

Wave action on the rubble mound causes scouring of the mound and makes the vertical wall unstable. To avoid this type of damage, the scouring area may be covered with large stones or blocks, or the wall may be placed at a lower level. The breakwater in Alderney was changed 
from a high-mound breakwater to a lowmound one, while the river-mouth breakwater in Tyne was also changed from a high - to a low-mound composite breakwater, and finally in the 1890 's, to a vertical breakwater without a rubble foundation. The breakwater in Peterhead is a very lowmound composite breakwater with a mound level of $-13.1 \mathrm{~m}$. Figure 2.6 shows cross sections of these breakwaters.

Such composite breakwater technology was applied throughout the world, with lowmound composite breakwaters being subsequented erected in the ports of British colonies, e.g., Karachi, Colombo, and Madras.

\subsubsection{Rubble Mound Breakwater Armored with Blocks}

In parallel with the development of composite breakwaters, rubble mound breakwaters showed very impressive developments owing to the invention of concrete blocks. The primitive cement that appeared around 3000 B.C. was significantly improved in the 18th and 19th centuries. One major improvement occurred in 1824 when J. Aspdin invented portland cement.

\section{(1) Breakwaters in Algeria}

The historical port of Algiers dates back to the 16 th century. The port's breakwater was a rubble mound breakwater which required continu-

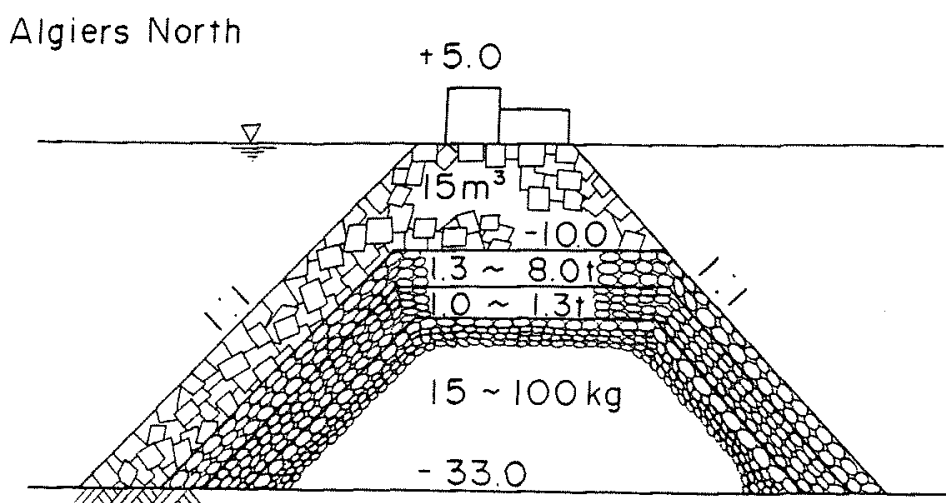

Fig. 2.7 Algiers north breakwater ous maintenance. In 1833, a French engineer, Poirel, carried out reinforcement work using 6000 $\mathrm{m}^{3}$ of 2 - to $3-\mathrm{m}^{3}$ stones, but the stones ended up being unstable. The breakwater was later successfully reinforced using $20-\mathrm{m}^{3}$ rectangular concrete blocks.

Figure 2.7 shows the cross section of the north breakwater in Algiers in 1840. Its cross section then was similar to modern breakwaters, having core stones armored with $15-$ $\mathrm{m}^{3}$ concrete blocks. The concrete blocks, with a slope of $1 / 1$, saved much materials compared to the Plymouth type of rubble mound breakwaters. 
Rubble mound breakwaters armored with concrete blocks were built in ports in Algeria (Algers, Oran, Philippeville, etc.) from the middle to the end of the 19th century. These breakwaters, however, suffered from damage due to the steep slope, insufficient weight of concrete blocks, insufficient depth of the armor layer, and rough placing of blocks.

Figure 2.8 shows changes in the cross section of the breakwater at Oran, which suffered from damage in 1869 because its armor layer was not extended to a sufficient depth. Even though the armor layer depth was changed to $-9.5 \mathrm{~m}$ in the improved cross section, the breakwater still experienced much subsequent damage. A Marseille type cross section was therefore adopted as the extension part, which will be described later.

Figure 2.9 shows changes in the cross section of the breakwater built at Philippeville. It experienced much damage, even during construction, which gradually led to improving the cross section. To increase its stability, a large superstructure was incorporated.

(2) Marseille type

Extension of the outer port of Marseille, France, started in 1845. Both vertical and rubble mound breakwaters were constructed there. Its rubble mound breakwater (Fig. 2.10) was very strong and included the following special features:

a) The stones of the breakwater core vary in weight, with lighter stones being placed in the inner core.

b) An armor layer of concrete blocks is included and extends to a sufficient depth. The armor layer above sea level has a gentle slope that dissipates waves, and the superstructure is placed at distance away from the water with most of it being covered with armor blocks.
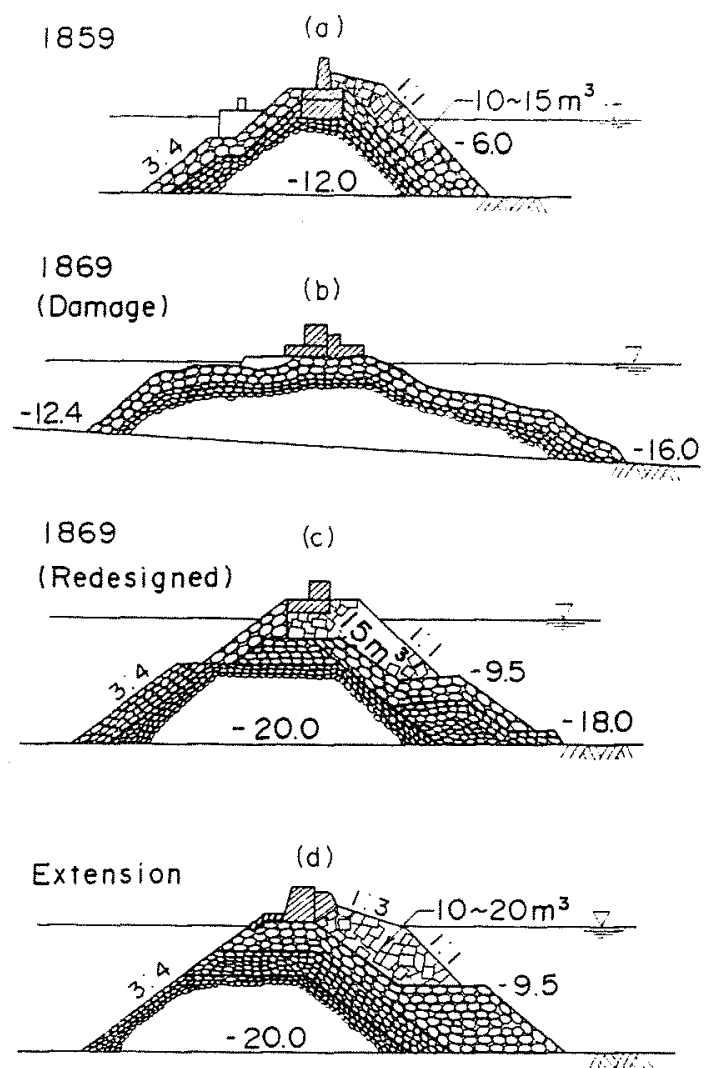

Fig. 2.8 Breakwater at Oran
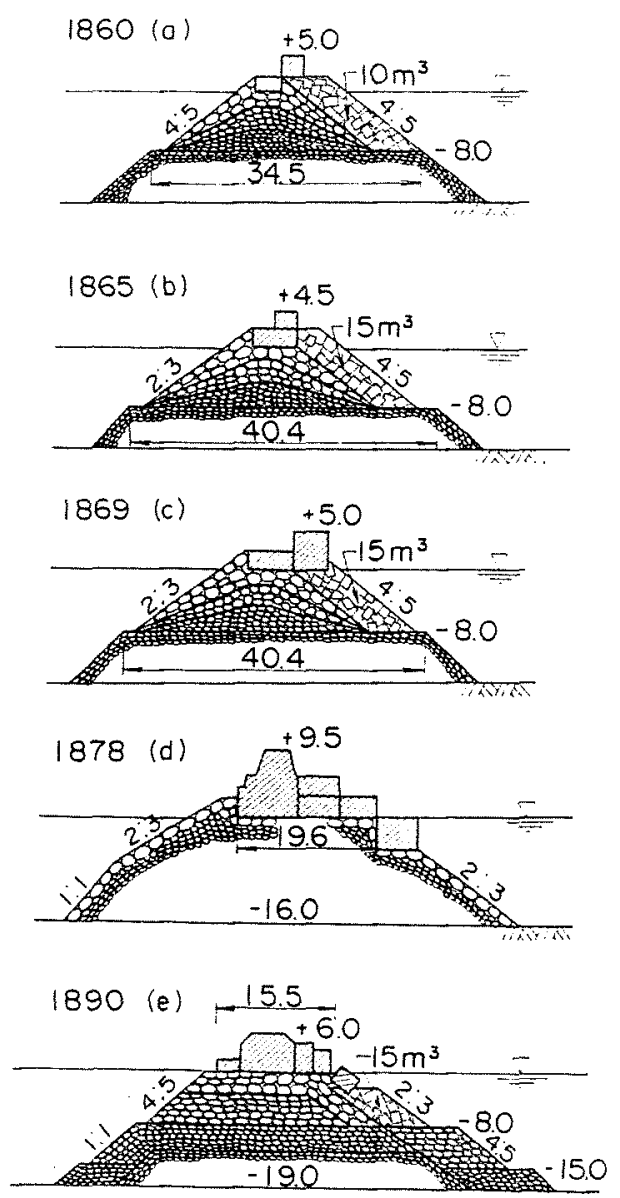

Fig. 2.9 Breakwater at Phillippeville 


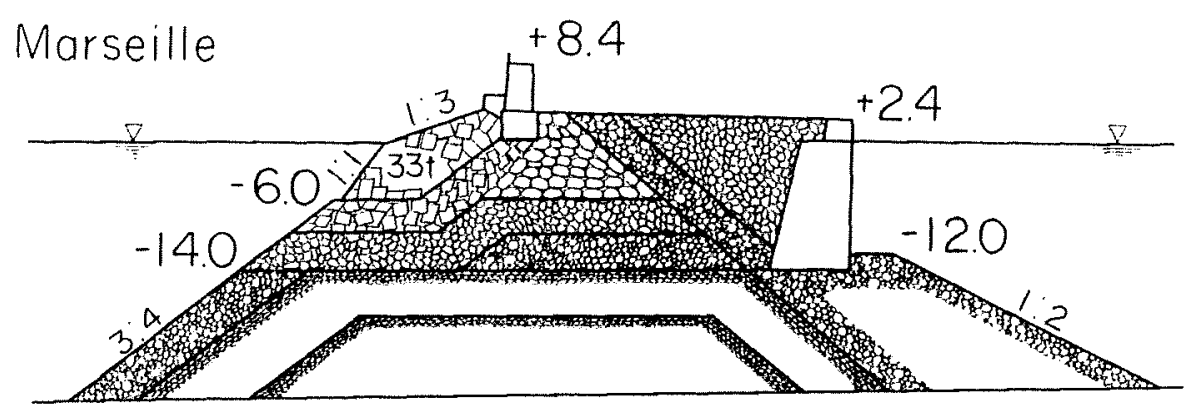

Fig. 2.10 Marseille breakwater

c) The slope of the lower level is relatively steep.

d) The armor blocks are installed carefully.

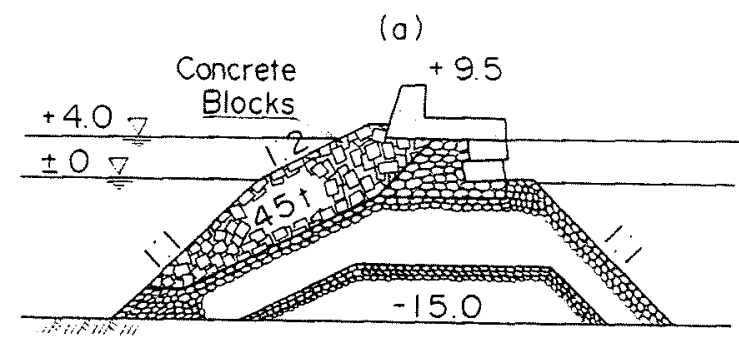

(3) Shape-designed concrete blocks

The Marseille type breakwater was not only popular for use in the Mediterranean but also in other seas. Its design, however, has drawbacks, e.g., the armor concrete (rectangular) block is very heavy and the cross section tends to be large because of the mild slope above sea level. Shape-designed concrete blocks such as the tetrapod, which was conceived by P. Danel in 1949, were subsequently invented to improve the

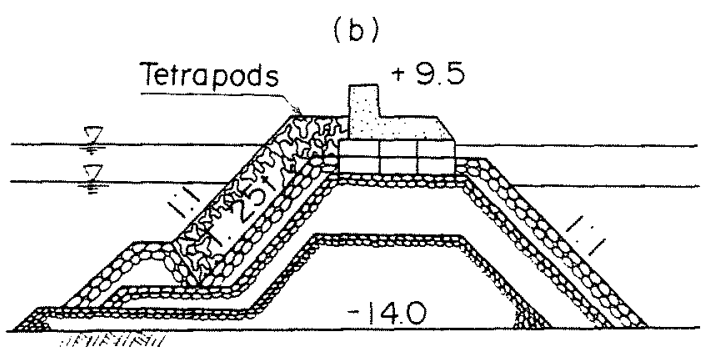

Fig. 2.11 Change of armor blocks at Safi rubble mound breakwater.

Figure 2.11 shows cross sections of the Marseille type rubble mound breakwater and a rubble mound breakwater in Safi, Morocco, armored with 25-t tetrapods. It is considered that the latter breakwater reduced the required amount of concrete by $70 \%$ and stones by $5 \%$. This breakwater showed its solid construction when it withstood a heavy storm in 1957 that produced $9-\mathrm{m}$ waves.

\subsubsection{Step-Type Breakwater and Composite Breakwater}

(1) Step-type and composite breakwaters in Italy

Another type of rubble mound breakwater was developed in Italy (Fig. 2.12), namely, a rubble mound breakwater having a step-type armor layer was designed by Parodi and constructed as the Galliera breakwater in Genoa, Italy. This step-type armor layer was considered to be more stable owing to the interlocking network of uniformly piled concrete blocks. Many breakwaters of this type were built in the 1880's and 1890's, but they were not so successful. In fact, the Galliera breakwater suffered damage in 1898, with one of the causes being due to settlement, especially differential settlement of the rubble mound. 


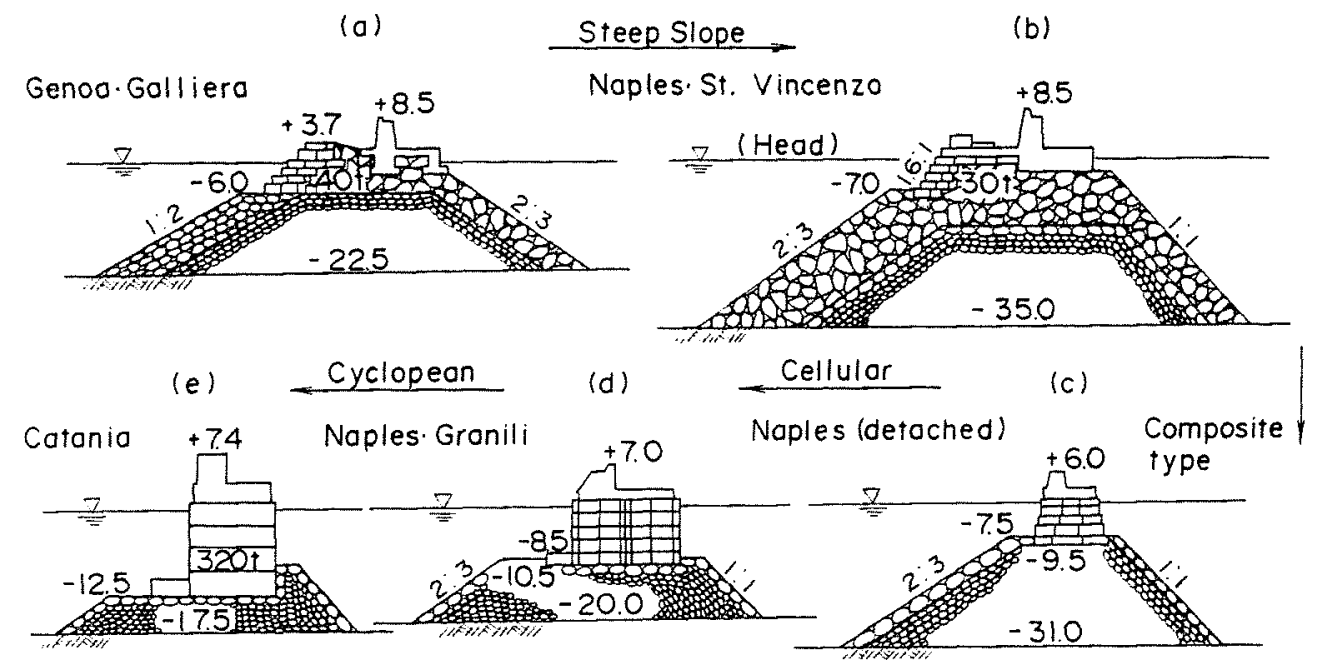

Fig. 2.12 Change from step-type to composite breakwater

In Naples, a step-type breakwater was adopted as the breakwater head of the St. Vincenzo breakwater. The breakwater had a steep stepped wall to increase stability. If the step becomes very steep, it looks similar to the vertical wall of a composite breakwater. Many composite breakwaters were constructed at that time in the U.K., and the associated technology was transferred to Italy; thereby making this composite breakwater the predominant one after 1900. One noteworthy composite breakwater was a detached (island) breakwater erected in Naples (Fig. 2.12).

(2) Cyclopean blocks and caissons

To increase the stability of the vertical wall, large blocks were used to build it. The Granill breakwater in Naples employed cellular blocks, but their installation led to problems. For example, these blocks were not stable during installation, and therefore, rapid construction was required.

The composite breakwater at Catania, Italy, adopted huge 330-t Cyclopean concrete blocks as the vertical wall. The word "Cyclopean" comes from "Cyclops," who according to Greek mythology was a giant with a single eye in the middle of his forehead.

The composite breakwater built in Italy affected later designs of other breakwaters in the Mediterranean. The Mustafa breakwater constructed in Algiers in 1923 adopted the composite breakwater design with cyclopean blocks. Sainflou designed a cyclopean block composite breakwater design to be used as the outer breakwater in Marseille (Fig. 2.13), with each cyclopean block weighing $450 \mathrm{t}$ and interlocking with

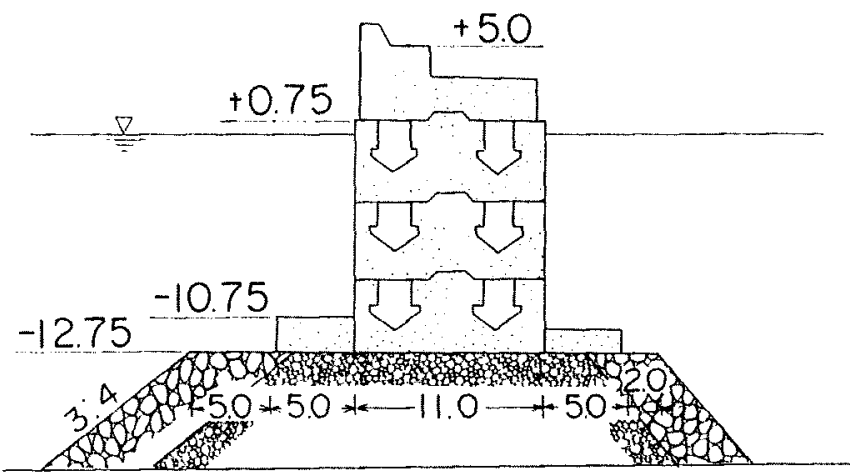

Fig. 2.13 Cyclopean block breakwater designed by Sainflou 
each other through projections. This design, however, was not adopted, although a similar type composite breakwater was built from 1930 to 1953 in Marseille. Figure 2.14 shows changes in the cross section of this breakwater. The interlocking network was further reinforced as a design improvement.

The vertical wall of a composite breakwater can be constructed using a caisson, which increases its stability. Walker proposed the use of a caisson in the 1840 's, and in 1886, Kinipple proposed using a concrete caisson reinforced by iron members. A metal caisson was employed in Bilbao, Spain, in 1894, and was later adopted in several other ports. Concrete caissons were also erected in Barcelona, Spain, and other ports, while reinforced concrete caissons were employed, vice using a rock-fill crib, around 1901 in America's Great Lakes. In Japan, the reinforced concrete caisson was used for the first time in Kobe in 1907. It is clear that the caisson promoted further development of composite breakwaters throughout the world.
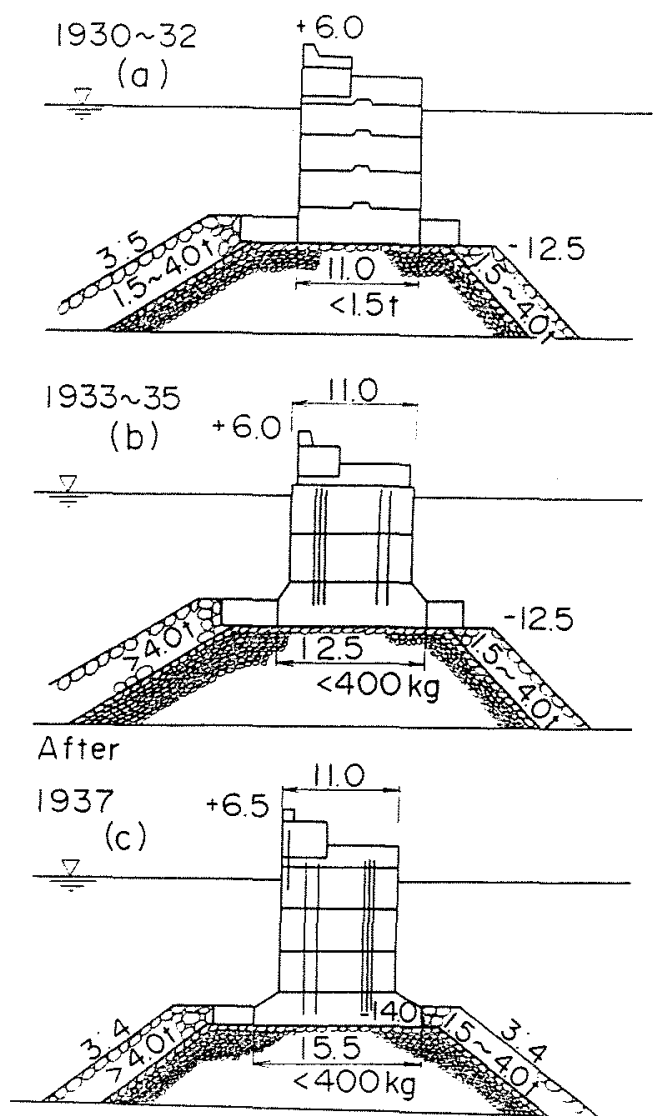

Fig. 2.14 Cyclopean block breakwater at Marseille

(3) Wave-dissipating blocks

The composite breakwater can be reinforced by placing wave-dissipating blocks in front of the vertical wall, with Fig. 2.15 showing such breakwaters. The wave-dissipating blocks are rectangular concrete blocks which are the same as those used for the armor layer of the rubble

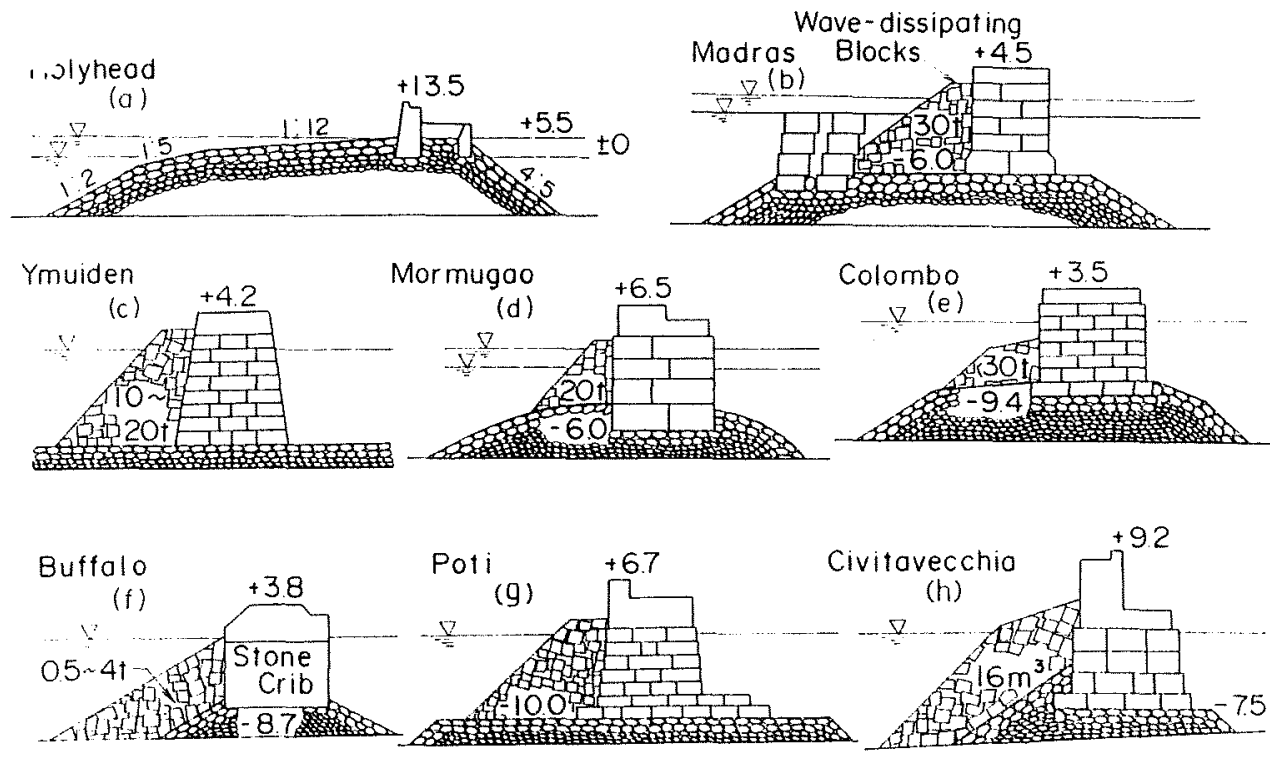

Fig. 2.15 Breakwaters with wave-dissipating blocks 
mound breakwater. Therefore, the breakwater cross section looks similar to rubble mound breakwaters armored with concrete blocks. Although the concrete blocks were usually placed after breakwater damage occurred, in some breakwaters they were incorporated into the initial design.

Figure 2.16 shows the Agha breakwater in Algiers, which has a wave screen, i.e., a vertical wall that reduces wave transmission through the breakwater. This breakwater and a composite breakwater with wave-dissipating blocks are nearly identical, but based on its design concept, this type of breakwater is considered to be a rubble mound breakwater having a large wave crown (screen).

\subsubsection{Revival of the Rubble Mound Breakwater}

The development of breakwaters, which started with the mild-slope rubble mound breakwater, led to the prevailing worldwide construction of the low'mound composite

breakwater. However, low-mound breakwaters suffered from various types of damage, and in Europe, damaged composite breakwaters were changed into rubble mound breakwaters.

\section{(1) Failure of the Catania breakwater}

The composite breakwater built at Catania, Italy, (Fig. 2.17) failed during construction between 1930 to 1931: a failure caused by insufficient inter locking of the cyclopean blocks. The breakwater was subsequently reconstructed as a Marseille type rubble mound breakwater.

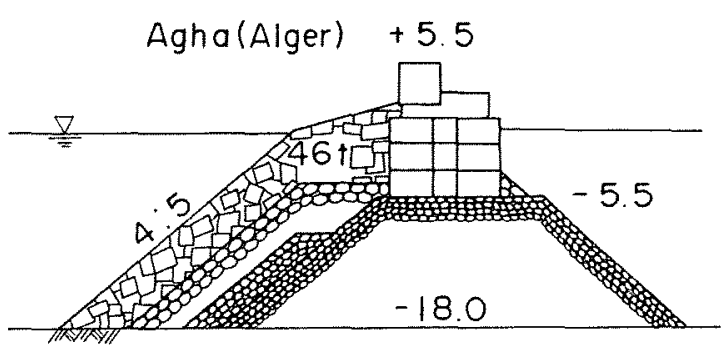

Fig.2.16 Wave screen at Agha breakwater

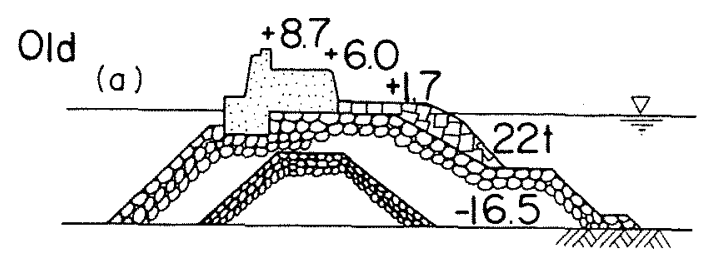

\section{Damage}

1933
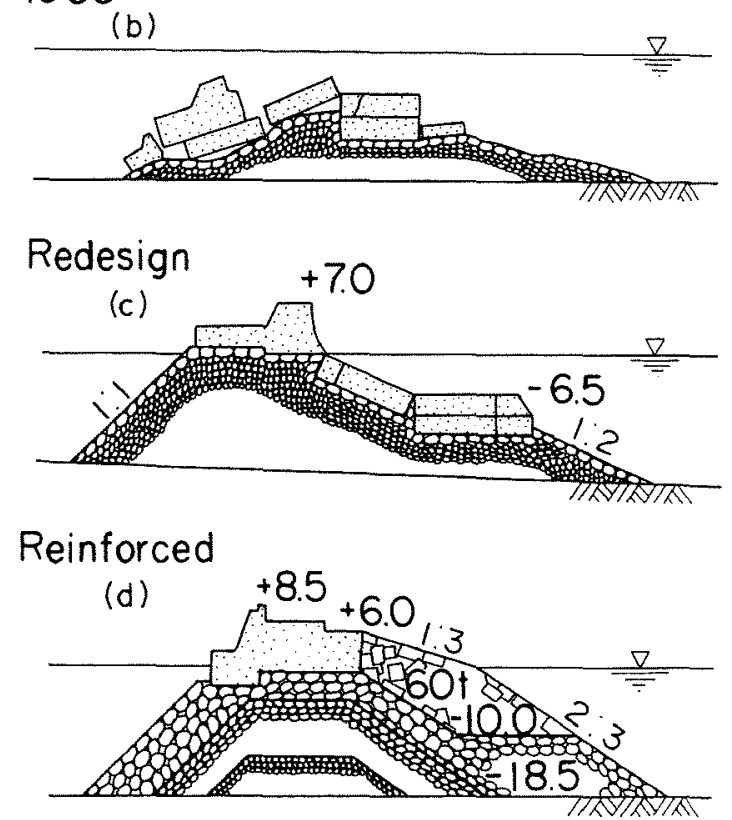

Fig.2.17 Revival of rubble mound breakwater at Catania 
(2) Failure of the Leixoes breakwater

Figure 2.18 shows changes in the breakwater at Leixoes, Portugal. The original breakwater was a Marseille type rubble mound breakwater. The breakwater, designed in 1932, was a composite type breakwater which failed during construction between 1934 to 1936 . The redesigned breakwater was still a Marseille type, but the constructed breakwater was a rubble mound breakwater having large concrete blocks

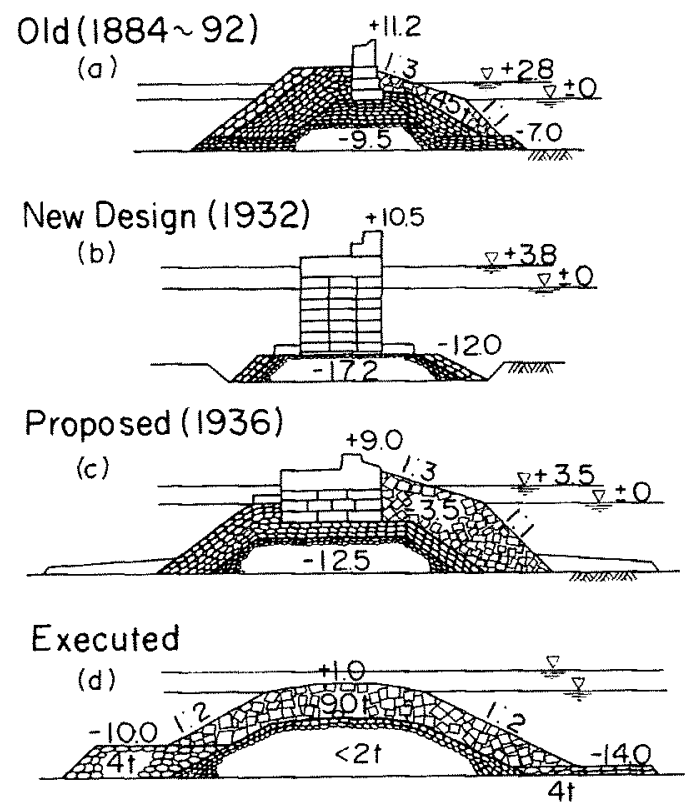

Fig.2.18 Revival of rubble mound breakwater at Leixoes

\subsubsection{Recent Development of Rubble Mound Breakwaters}

(1) Rubble mound breakwaters armored with shape-designed concrete blocks

The development of breakwaters up to the middle of the 20th century has been described. Recent developments in rubble mound breakwaters are largely based on using shape-designed concrete blocks. Many successful rubble mound breakwaters were made using armor layers comprised of such blocks. The design methods for rubble mound breakwaters were established and summarized in books and manuals; e.g., the Shore Protection Manual, in which the Hudson formula was introduced as the standard design method for the armor layer. In addition, high-speed, computer-assisted numerical analysis and physical model experiment technology has also supported the enhanced development of rubble mound breakwaters.

Figure 2.19(a) shows the cross section of the Sines breakwater built in Portugal. This is a typical rubble mound breakwater constructed with shape-designed concrete blocks. Note that the cross section is quite small even though the water depth is deeper than $30 \mathrm{~m}$ and the design significant wave height is higher than $10 \mathrm{~m}$. The employed shape-designed concrete block is the Dolos block, which has high interlocking strength, and enables a more economical design by reducing the amount of required materials.

It was very surprising that this breakwater suffered serious damage in 1978. The break down of Dolos blocks is thought to be one of the main causes of failure, since they are relatively weak 
although their interlocking strength is high. Several failures of rubble mound breakwaters also occurred during those ages.

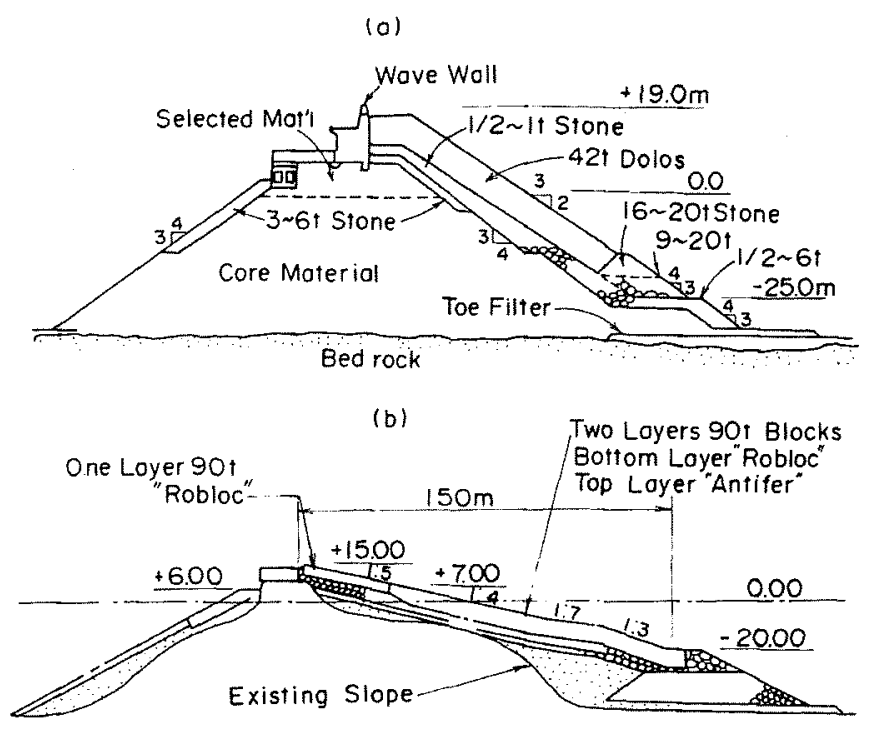

Fig.2.19 Sines breakwater (Brunn, 1985)

The redesigned cross section of the Sines breakwater has an armor layer made from low-interlocking blocks and a mild slope (Fig. 2.19(b)). Its cross section is very similar to that of 19 th-century rubble mound breakwaters armored with concrete blocks.

After such failures, major efforts were directed at improving the design method of the rubble mound breakwaters, as well as associated experimental techniques. These succeeded in reestablishing the design method, which is summarized in recently published books and manuals, e.g., CIRA/CUR(1991), and includes van der Meer's new formula for designing the armor layer.

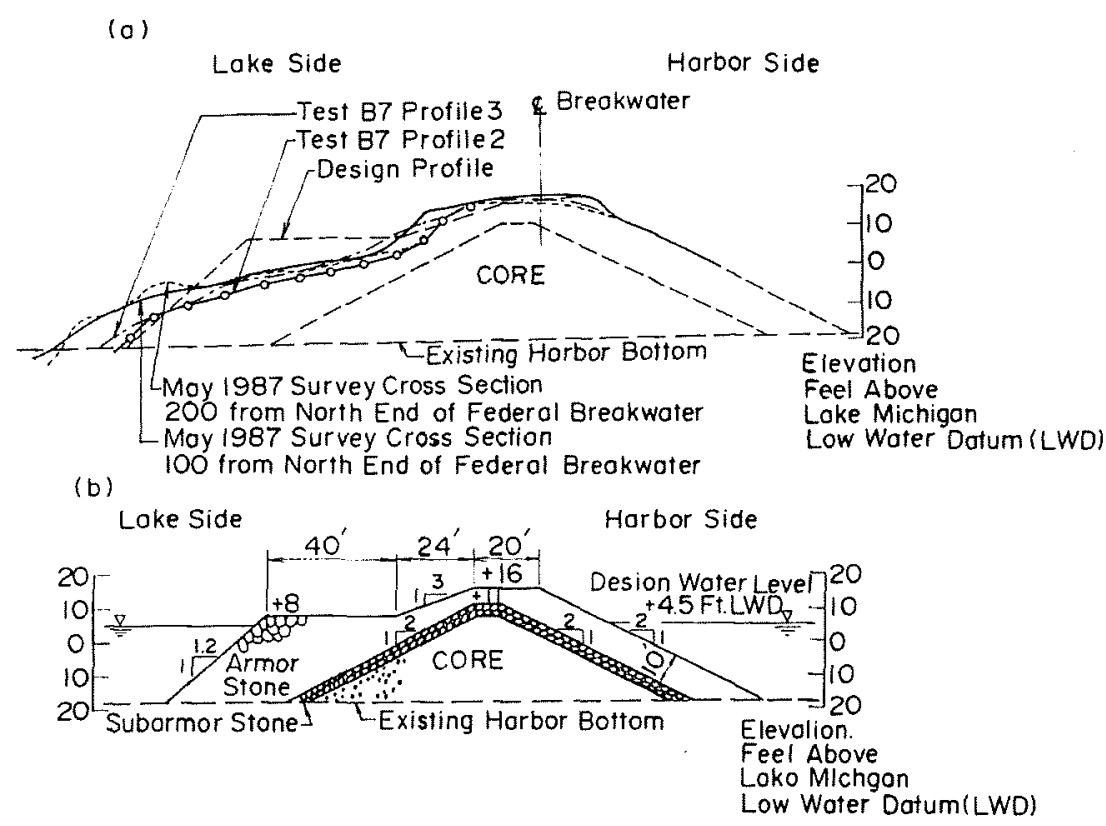

Fig.2.20 Berm breakwater at Rachine, Michigan (Montgomery et al., 1987) 


\section{(2) Berm breakwaters}

Figure 2.20 shows the cross section of a breakwater built in Racine, Michigan. This breakwater has a large berm in the front part of the breakwater, though the quarry stones are not very large. Such a design allows for berm deformation which will end up forming an equilibrium slope. Berm breakwaters like these have been built in North America, Europe, and other places, and many studies have been carries out on them (Willis et al., 1987; Baird and Hall, 1984; Fournier et al., 1990; Burcharth et al., 1987, 1988). Note that the berm breakwater resembles much older rubble mound breakwaters, e.g., the Plymouth breakwater.

\subsubsection{Recent Developments in Composite Breakwaters}

Figure 2.21 shows one of the first modern breakwaters built in Japan in 1897: the north breakwater at the Port of Otaru designed by Hiroi. Many breakwaters constructed in Europe around this time were rubble mound breakwaters or composite breakwaters with block masonry. The technology introduced into Japan was primarily related to the composite breakwater, which has been developed into the currently used caisson composite breakwater. In Italy and other countries facing the Mediterranean Sea, caisson breakwaters were gradually being developed based on the technology available at the end of the 19th century. The development of composite breakwaters following 1945 was rapid due to the advancement of the design technology for concrete structures and that of in-sea construction technology using large working vessels.

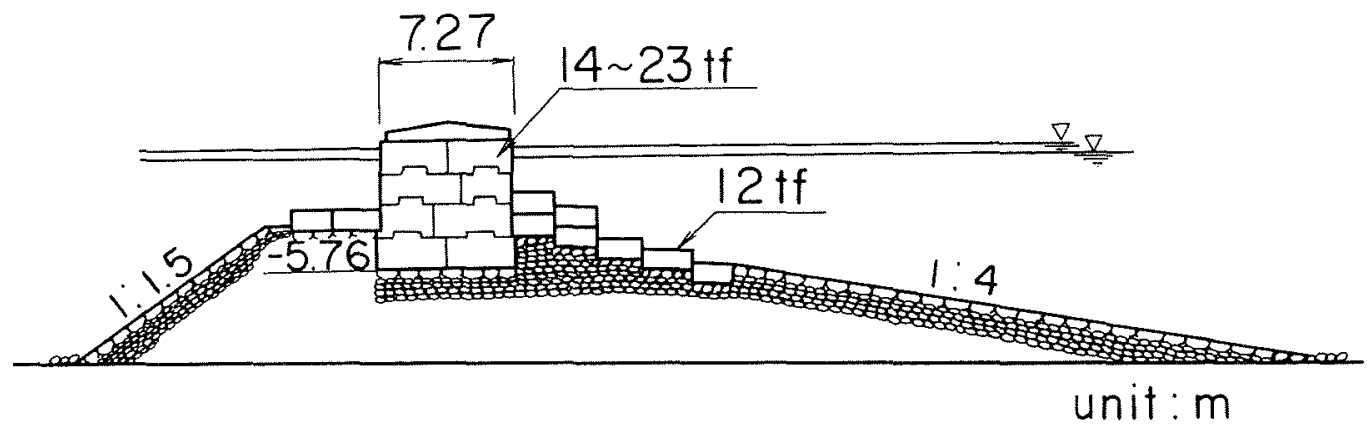

Fig.2.21 Otaru breakwater

The current status of composite breakwater technology is summarized as follows (Tanimoto et al., 1994):

(1) Design method of conventional composite breakwaters

The design technique for composite breakwaters is nearly established, and includes the calculation method for determining the wave forces acting on the breakwater and the design method used for its caisson members.

(2) Horizontally composite breakwaters

The composite breakwater covered with wave-dissipating blocks is an improved version of the conventional composite breakwater, and is now frequently being constructed, especially in breaker zones. 
(3) New caisson breakwaters

Many new types of breakwaters have been invented and commercialized in order to mitigate the drawbacks associated with conventional composite breakwaters.

\section{a)Perforated wall}

One new caisson breakwater is the perforated wall caisson breakwater invented by Jarlan (1961). Figure 2.22 shows this type of breakwater in Comoeau bay(Cote and Simard 1964). The caisson dissipates wave energy by the front perforated wall and wave chamber. Therefore the caisson is also called the wave dissipating caisson. The perforated wall caisson breakwater is usually employed with in a bay having relatively small waves since the forces on the caisson members are relatively small in such area. This type of construction also meets the need for providing low reflectivity.

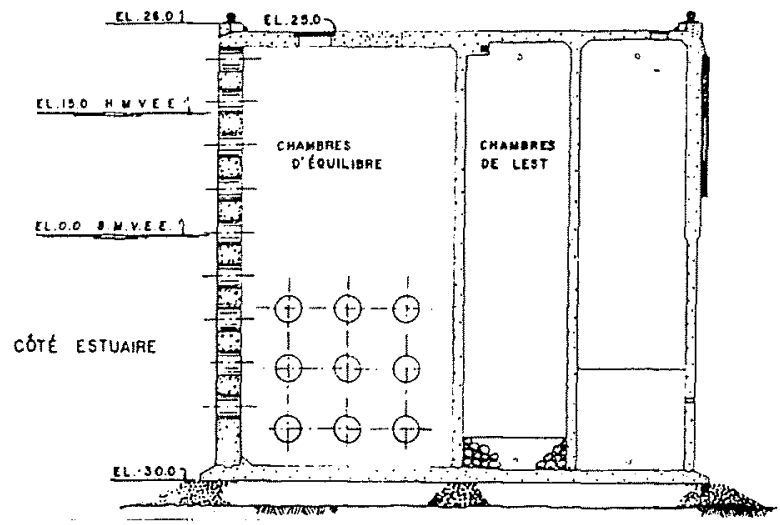

Fig.2.22 Perforated wall caisson breakwater in Comeau bay

Many breakwaters of this type were subsequently constructed throughout the world. The first perforated wall breakwater in Japan was constructed at Takamatsu Port in 1970(Fig. 2.23) Since then, perforated wall caissons have often been employed as breakwaters or quaywalls, with much effort having been made to improve their stability and function in breakwater applications(Okada et al. 1990) Establishing the design method has also been a key study area.

Figure 2.24 shows a perforated wall caisson breakwater incorporating a vertical slit wall. This caisson was constructed at the Port of Yobuko, Japan, and is a modified version of a perforated wall caisson having an opening that passes from the front to rear side; thus improving the efficiency of seawater exchange.

Figure 2.25 shows the curved slit caisson breakwater at Funakawa Port. The caisson has a curved slit wall as a perforated wall which is reinforced by prestressed concrete to be able to resist against severe storm waves.

Figure 2.26 shows a cross section of the baymouth breakwater constructed in Kamaishi Bay. The maximum depth at the bay-mouth is $63 \mathrm{~m}$, making the breakwater there the deepest in the world. The lower part of the caisson has a trapezoidal shape to obtain a wide bottom, which decreases the eccentric load on the rubble mound. Its upper part has a wave-dissipating structure consisting of double horizontal slit walls. In general, the trapezoidal caisson suits deep water sites.

Figure 2.27 shows the dual cylinder caisson breakwater being constructed at the Port of Shibayama, which also has deep water, as well as large waves. This breakwater caisson consists of inner and outer cylinders. The cylinder wall is a kind of shell structure that can withstand large forces with 
a relatively small cross section. Since the caisson is cylindrical as a whole, the total amount of required construction material is reduced. The upper part of the outer cylinder consists of a perforated wall, and the sections between the inner and outer cylinders constitutes a wave chamber that forms the wave-dissipating structure. The design method for the dual cylinder caisson breakwater is almost fully established, with much data being obtained from a demonstration experiment carried out at Sakaiminato (Tanimoto et al. 1992). Figure 2.28 shows the dual cylinder caisson breakwater at Nagashima, where the calm water area behind the breakwater is used for recreational and aquaculture purposes.

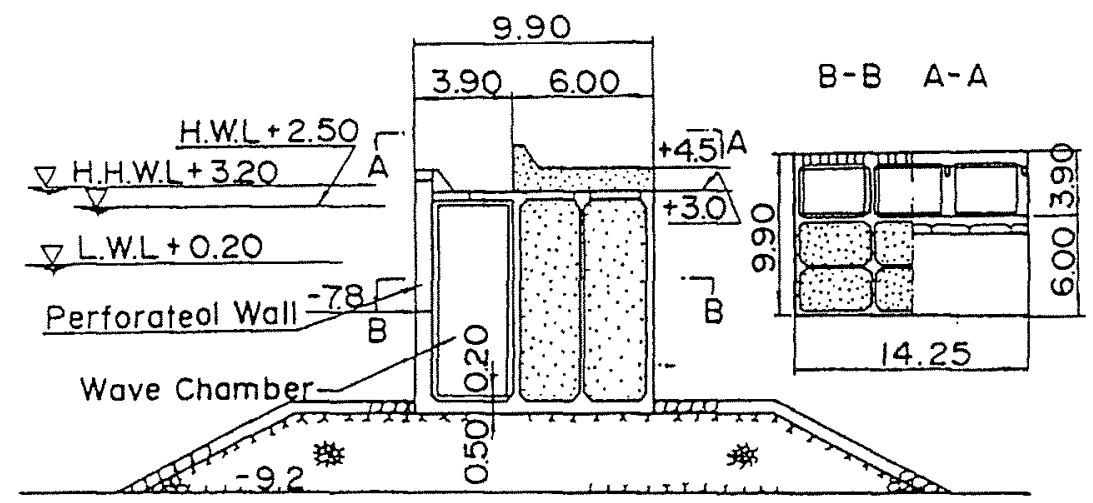

Fig.2.23 Perforated wall caisson breakwater at Takamatsu Port

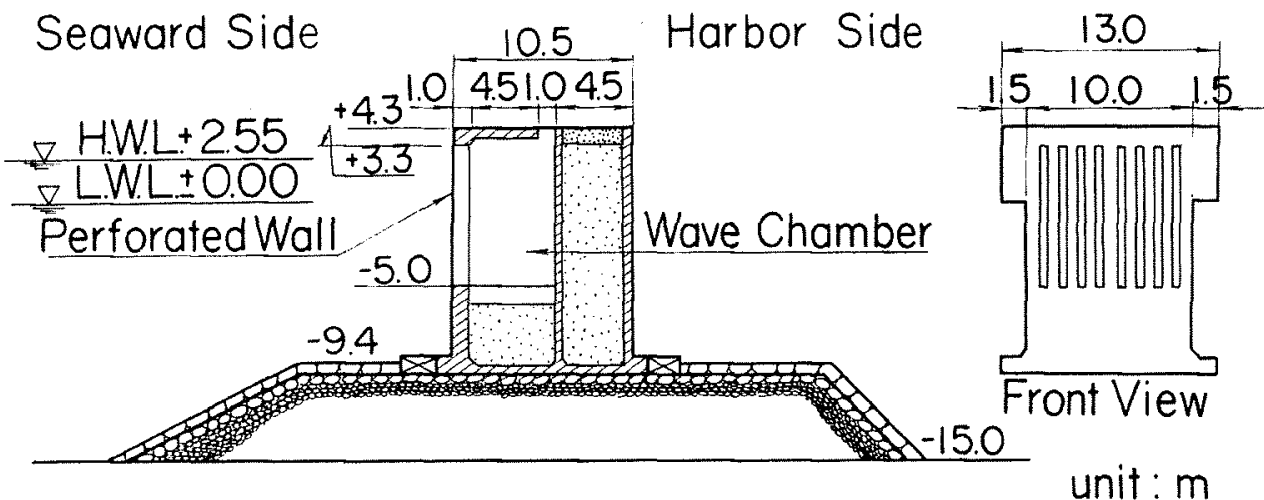

Fig.2.24 Perforated wall caisson breakwater at Yobuko Port

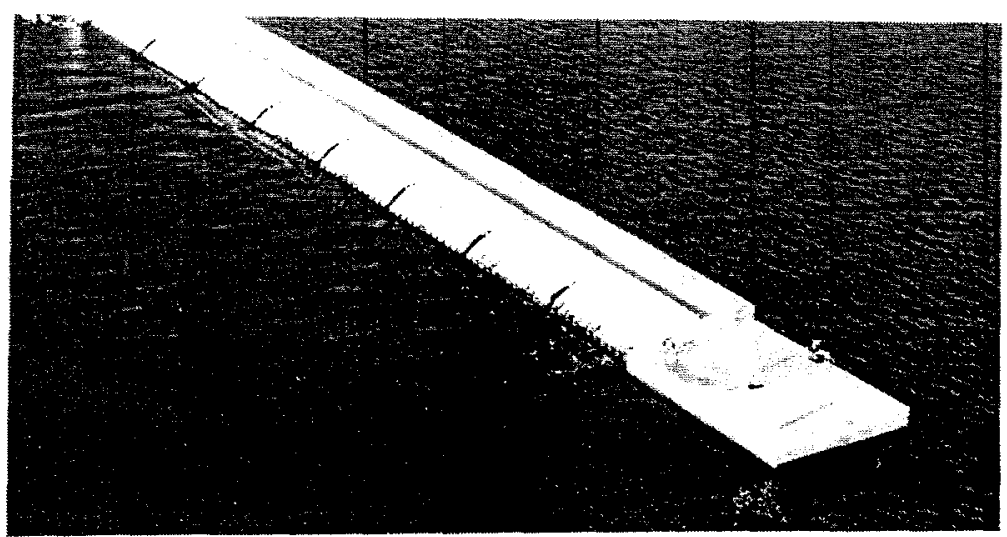

Fig.2.25 Curved slit wall caisson breakwater at Funakawa Port 


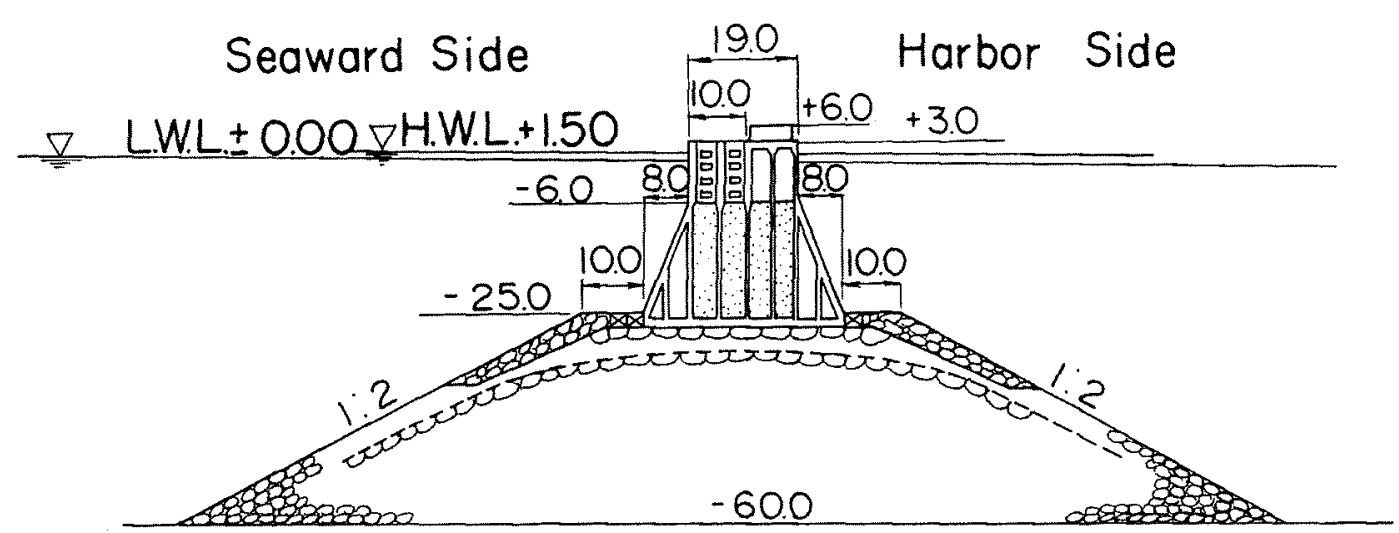

Fig.2.26 Deepwater breakwater at Kamaishi Port

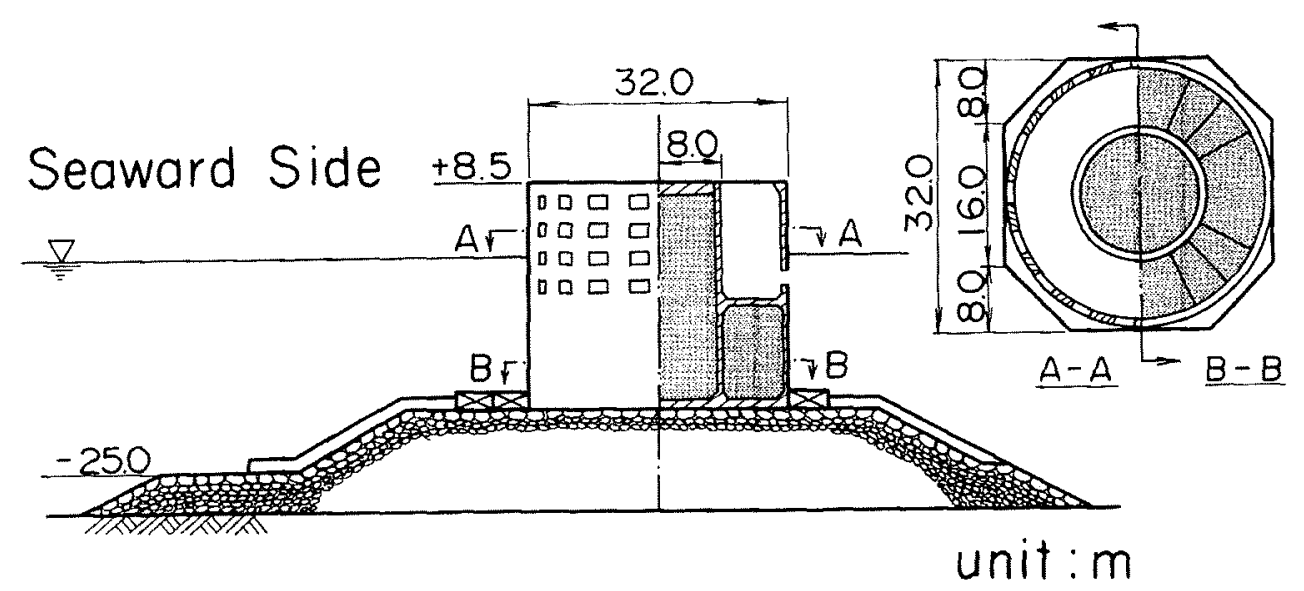

Fig.2.27 Dual cylinder caisson breakwater at Shibayama Port

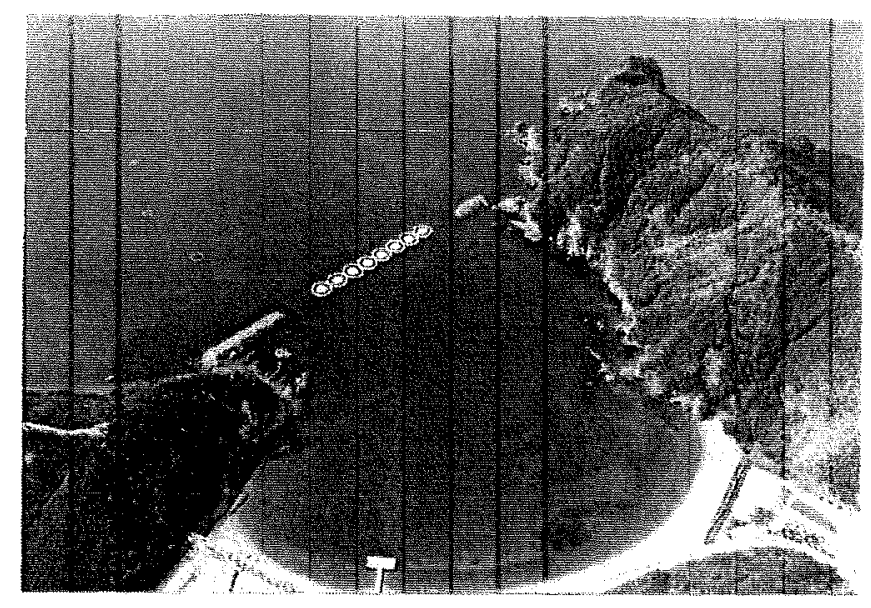

Fig.2.28 Dual cylinder caisson breakwater at Nagashima Port 


\section{b) Sloping wall}

Another type includes those incorporating a sloped front wall, e.g., the sloping top, trapezoidal, and semicircular caissons.

Figure 2.29 shows a conceptual drawing of a sloping-top caisson breakwater, having a super structure that is sloped to increase the caisson stability, i.e., the downward force on the slope increases the caisson's stability. The sloping top breakwater has been used for many years as a breakwater against very rough seas (see Chapter 5). Figure 2.30 shows another sloping top caisson breakwater which is undergoing construction at Naha Port. The upright section of the caisson is covered with concrete blocks to reduce wave reflection from the breakwater. The water depth here is very deep, being more than $25 \mathrm{~m}$, and therefore this cross section is very economical compared with conventional ones.

The trapezoidal caisson breakwaters which was conceived in ancient timesis also another highly stable structure against wave action. The offshore breakwater in Onahama Port (Fig. 2.31) was recently made with trapezoidal caissons placed at a depth of more than $25 \mathrm{~m}$ so as to reduce the load on its relatively week foundation.

Figure 2.32 is a conceptual drawing of a semicircular caisson breakwater in which the vertical downward component of the wave force increases breakwater stability. A particular advantage of this type of breakwater is that the wave force vector passes thorough the center of the circle; thereby increasing the resistance to caisson turnover. It is expected to exhibit high performance in sea areas with relatively shallow water yet high waves.

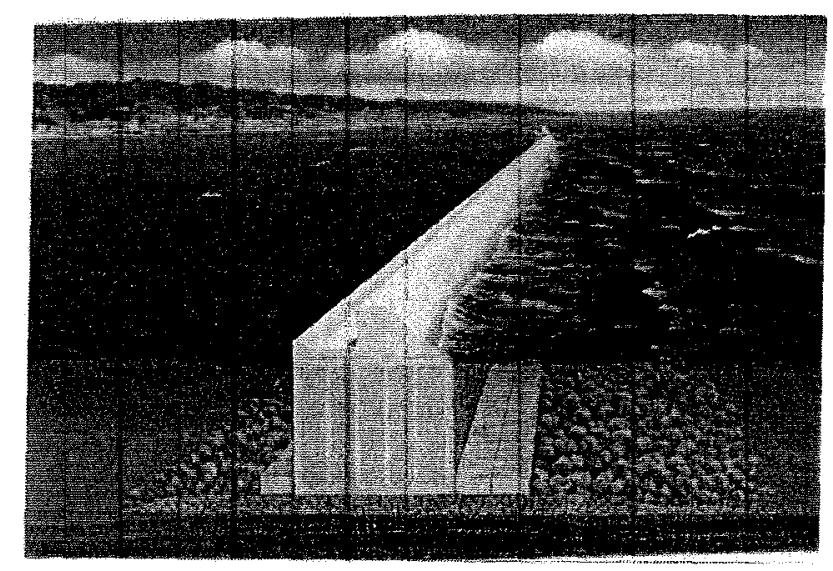

Fig.2.29 Sloping top caisson breakwater

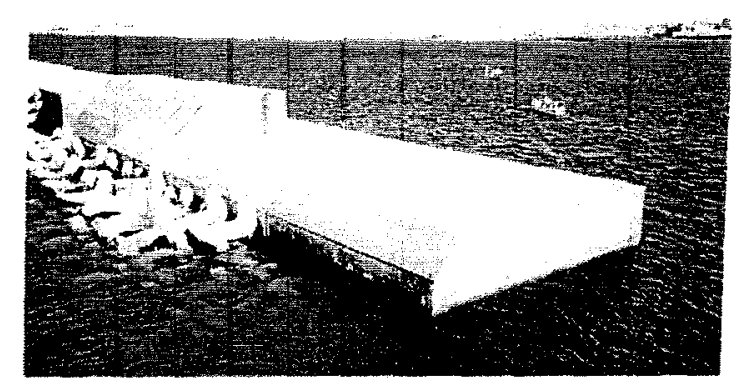

Fig.2.30 Sloping top caisson covered with concrete blocks

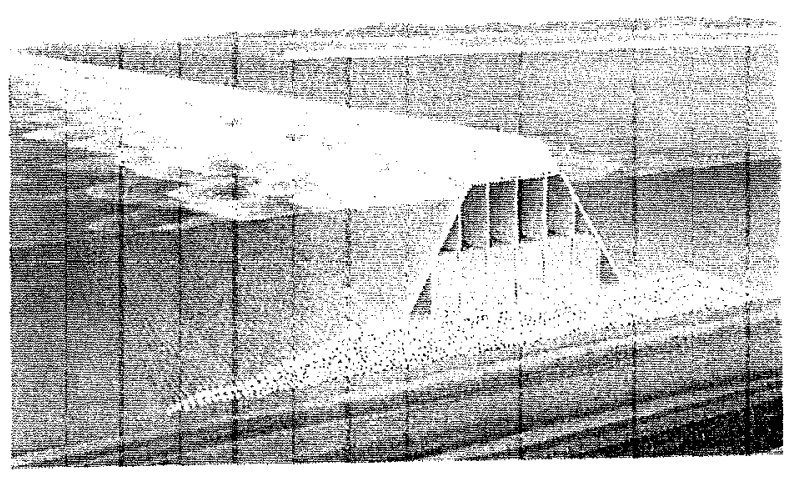

Fig.2.31 Trapezoidal caisson breakwater at Onahama Port 
c) Other caissons

In 1992, the longest caisson in Japan was used as a temporary breakwater at Kochi Port. One unit of the caisson is $100 \mathrm{~m}$ in length. Figure 2.33 shows the caisson being towed to the site, arriving following a $370 \mathrm{~km}$ travel from the ship dock where it was fabricated. It will be removed form the present site and be reinstalled as a part of an offshore breakwater. This long caisson is similar to (i) the phoenix caisson; namely temporary steel caisson used in D-Day landing operations at Normandy during World War II and to (ii) the sunken ship breakwater used after World War II in Japan. The caisson design allows rapid construction and increases the stability in oblique seas by the wave-force averaging effect (see 4.3.7). The caisson was designed to incorporate steel frames and prestressed concrete walls, being another aspect of caisson development.

Instead of just dissipating wave energy, the wave energy can be converted into usable energy. After the oil crisis in 1973, many studies concerning wave energy conversion system have been made. In Sakata Port, a wave power-extracting caisson breakwater was built to demonstrate the feasibility of converting wave power, being a unique concept in breakwater development (Takahashi et al., 1992). Figure 2.34 shows the breakwater with the air chamber where the oscillation of the water surface compresses and expand the air, which activates the turbine-generator in the machine room.

Public access to breakwaters is usually prohibited due to the potential danger. However; some of the breakwaters are designed for public access, e.g., the breakwater in Briton Marina, U.K., was designed to have a promenade deck on top of

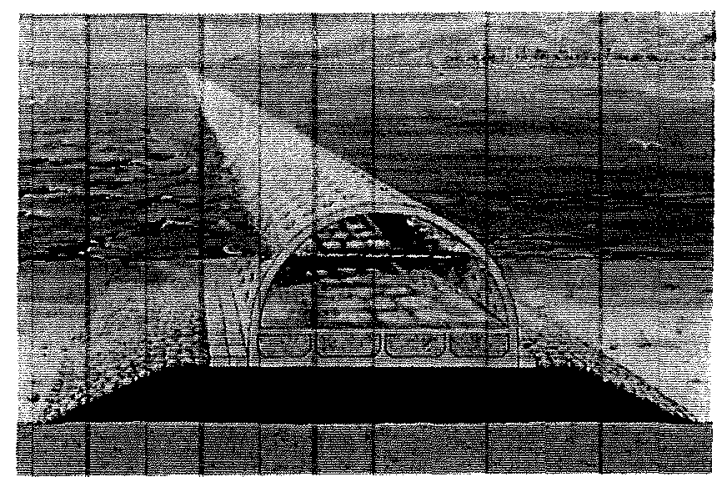

Fig.2.32 Semicircular caisson breakwater i at Miyazaki Port

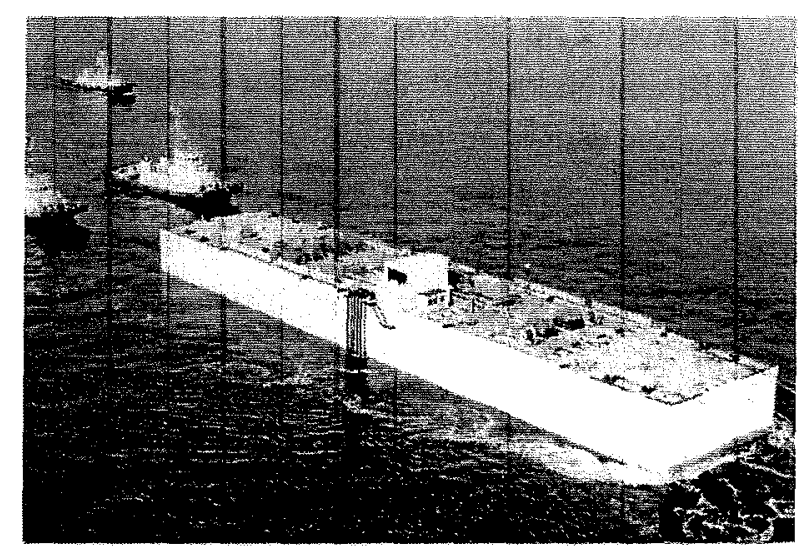

Fig.2.33 Long caisson at Kochi

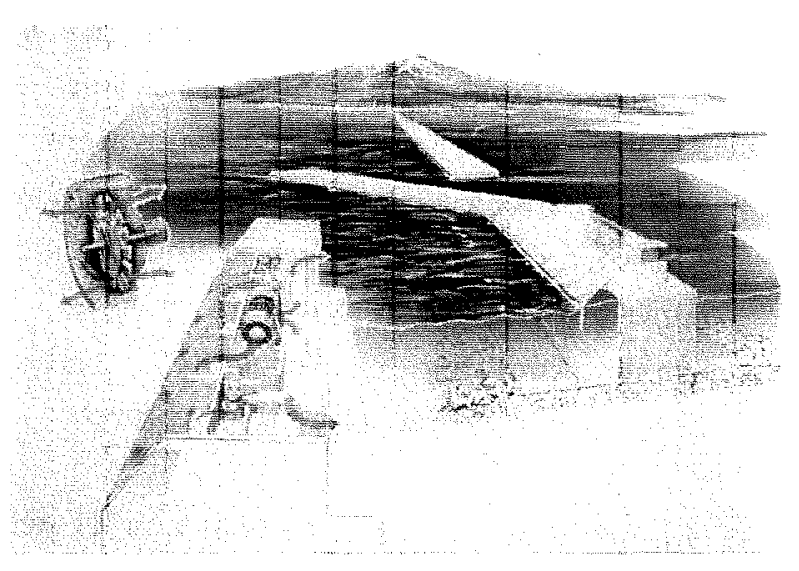

Fig.2.34 Wave Power extracting caisson at Sakata Port 
it. Figure 2.35 shows a promenade breakwater erected in Wakayama Marina City, which was specifically designed in consideration of enhancing the amenity and landscape. In parallel with the design of promenade breakwaters, personnel safety is being investigated (Endo and Takahashi, 1994), with the future design of such breakwaters being expected to include these items.

(4) Port Construction in Japan and Hitachnaka Port Project

Figure 2.36 shows recent construction of Hitachi Naka Port. An offshore breakwater is under construction. Figure 2.37 shows the caisson yard for the offshore breakwater of composite type. Many composite breakwaters have been built along with the development of Japanese ports especially from the 60's. This has resulted in significantly advancing composite breakwater technology in Japan.

The introduction of concrete caissons for the vertical walls of the composite breakwaters has especially encouraged the development of composite breakwaters. In fact, the total length of Japanese breakwaters is more than $800 \mathrm{~km}$ and the major breakwaters are caisson breakwaters, a half of which is ordinary composite type and another half is mostly caisson breakwaters covered with wave-dissipating concrete blocks (horizontally composite breakwaters).

Figure 2.38 shows a distribution of design offshore wave heights of Japanese breakwaters. Due to typhoons, the wave height is very high in southern part of Japan; about 8 to $12 \mathrm{~m}$ high. Due to winter storms, the waves are also high in the northern part of Japan. The design wave heights are quite

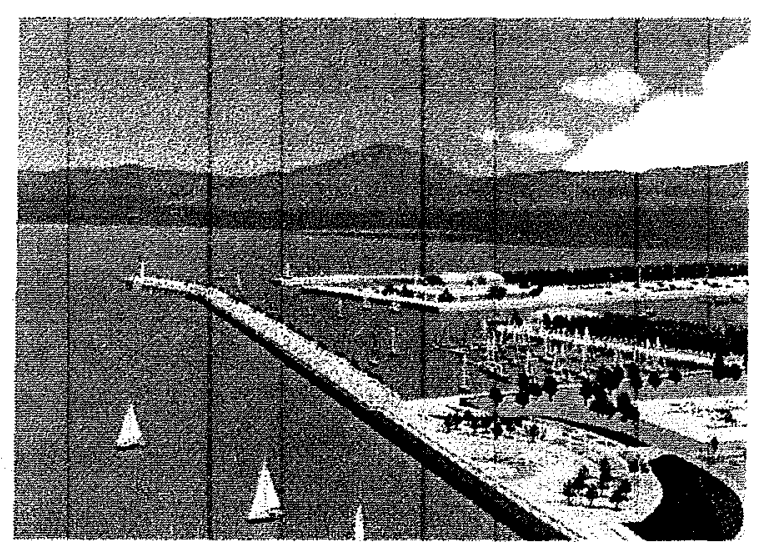

Fig.2.35 Promenade breakwater at Wakayama

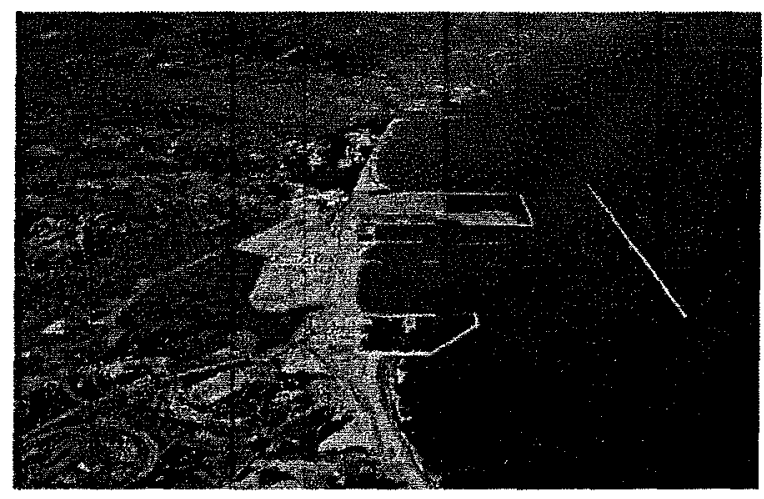

Fig.2.36 Hitachinaka Port

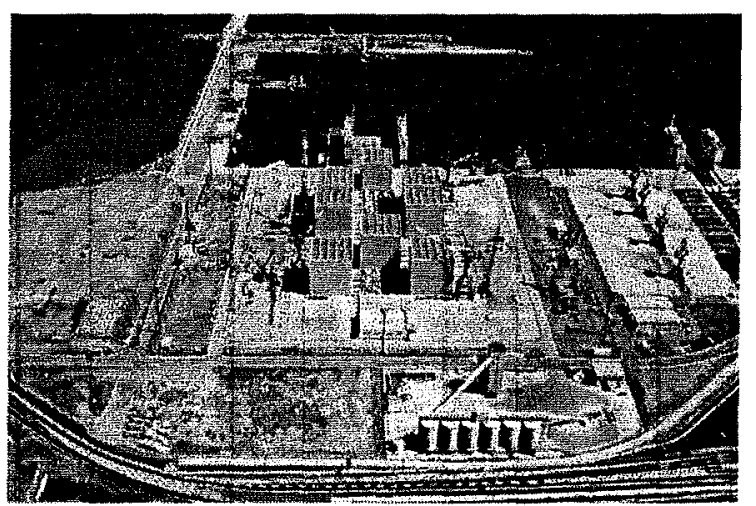

Fig.2.37 Caisson Yard at Hitachinaka

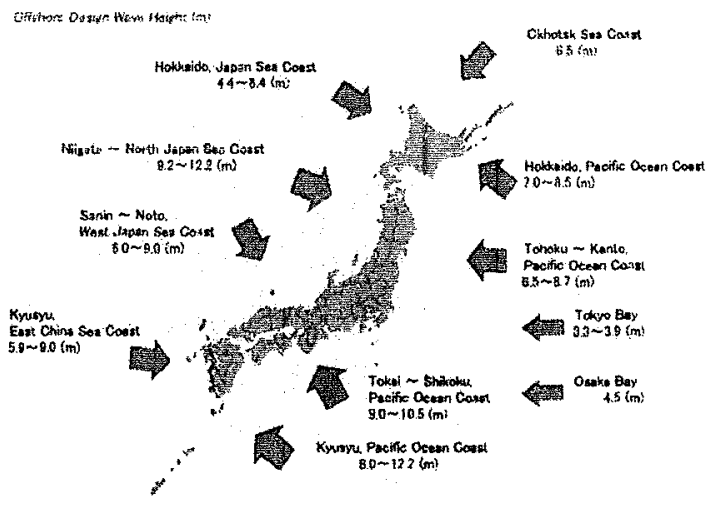

Fig.2.38 Wave Height Distribution around Japan 
large as shown in the figure, but the actual storms sometimes exceed even the design wave. Breakwater failures have occurred sometimes, although the frequency is very low.

\subsubsection{Summary of Breakwaters History}

Table 2.3 summarizes the history of breakwaters, especially that during the 19th and 20th century. Important aspects to note are as follows:

1) The trend of breakwater development is from mild slope breakwaters to upright ones, i.e., from mild-slope rubble mound breakwaters to steep slope ones, and from high-mound composite breakwaters to low-mound ones, as well as from rubble mound breakwaters to composite breakwaters.

2) Breakwater development was strongly affected by the development of new technologies.

3) The failure of new breakwaters always resulted in returning to old breakwater designs.

It should be noted that the lessens learned in breakwater design, construction, and operation/failure, in combination with recent extensive investigations, have demonstrated that both the sloping and vertical types of breakwaters can be designed with high reliability.

Table 2.3 Summary of historical development of breakwater

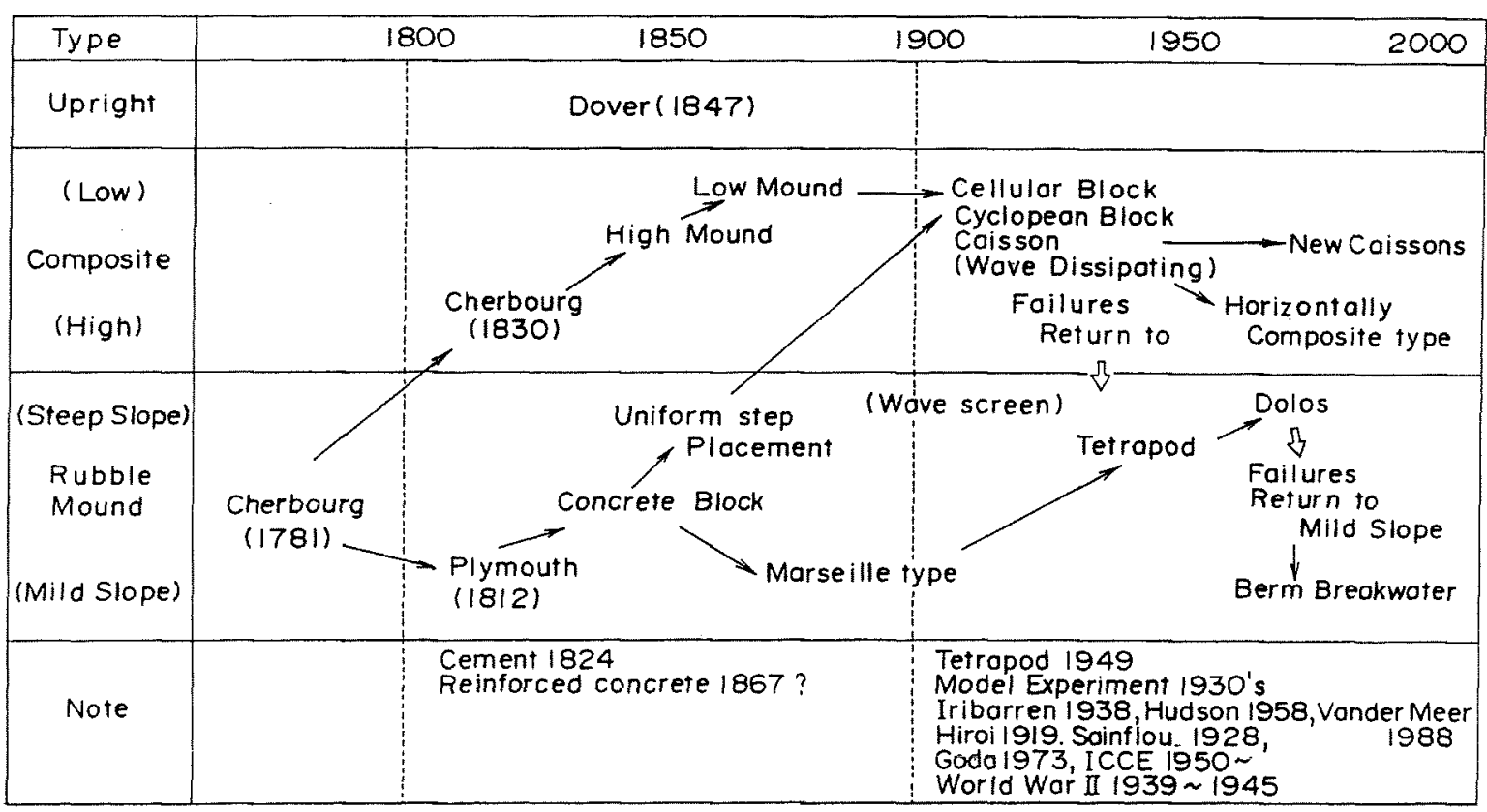




\section{RECENT FAILURES OF VERTICAL BREAKWATERS}

Development of the design and construction methods used for composite breakwaters has prevented them from suffering total failure. However, some damage has been caused by heavy storms. Since breakwaters are designed to withstand wave heights having a particular return period, such as 50 years, a high probability exists that higher waves than the design wave will attack them. Consequently, in the near future a probabilistic design method will be introduced to enable quantitative evaluation of the failure probability during the design stage (Burcharth, 1989; Takayama et al., 1991).

Another reason that breakwater damage has occurred is that improvements are needed in portions of the design and construction methods. Damage of composite breakwaters is introduced next to illustrate the problems associated with current design methodology.

\subsection{Failure of Offshore Breakwater in Mutsu·Ogawara Port}

A typical caisson failure of a composite breakwater recently occurred in February 1991 at Mutsu-Ogawahara Port, Japan (Hitachi, 1994). This port is located in the northern part of Japan and faces the Pacific Ocean. Figure 3.1 shows a plane view of the composite type caisson breakwater, where two wings of the breakwater form a concaved corner portion which is covered with wave-dissipating blocks to reduce the wave pressure there, i.e., the concaved part of the breakwater is the horizontally composite type.

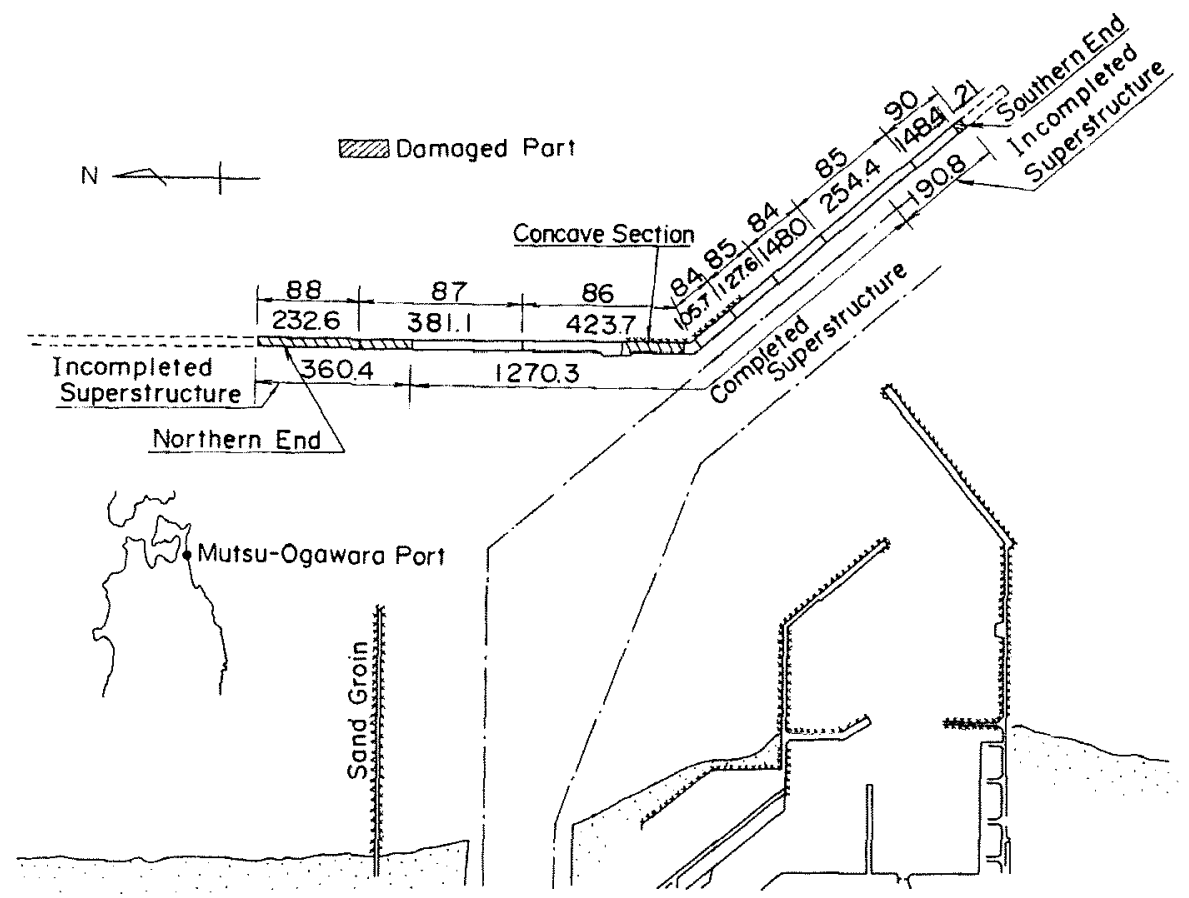

Fig.3.1 Plane view of Mutsu-Ogawara Port (Hitachi, 1994) 
On February 16, 1992 at 16:00, the largest-ever significant wave height of $9.94 \mathrm{~m}$ was recorded during a storm that attacked northern Japan. The wave exceeded the design wave. Four kinds of damage were found following the storm, all of which are typical damage suffered by composite breakwaters:

1) large scale-scouring in front of the breakwater

2) meandering sliding at the northern end

3) scattering of wave-dissipating concrete blocks and caisson failure at the concaved section due to impulsive breaking pressures

4) scouring underneath the caisson at the southern breakwater head

(1) Scouring in front of the breakwater

The sand sea bottom in front of the breakwater was deepened 1 to $2 \mathrm{~m}$ due to the storm, which caused settlement and deformation of the rubble mound toe, though no direct damage to the main caisson body. However, two deteriorative consequences should be noted:

1) The design wave was a breaking wave which was limited by the initial water depth. Due to the change in water depth, however, the design wave height for the caissons is increased.

2) Due to settlement and deformation of the rubble mound, the interlocking of concrete blocks in the concaved section was probably loosened, which may be one of the reasons that the blocks were scattered there.

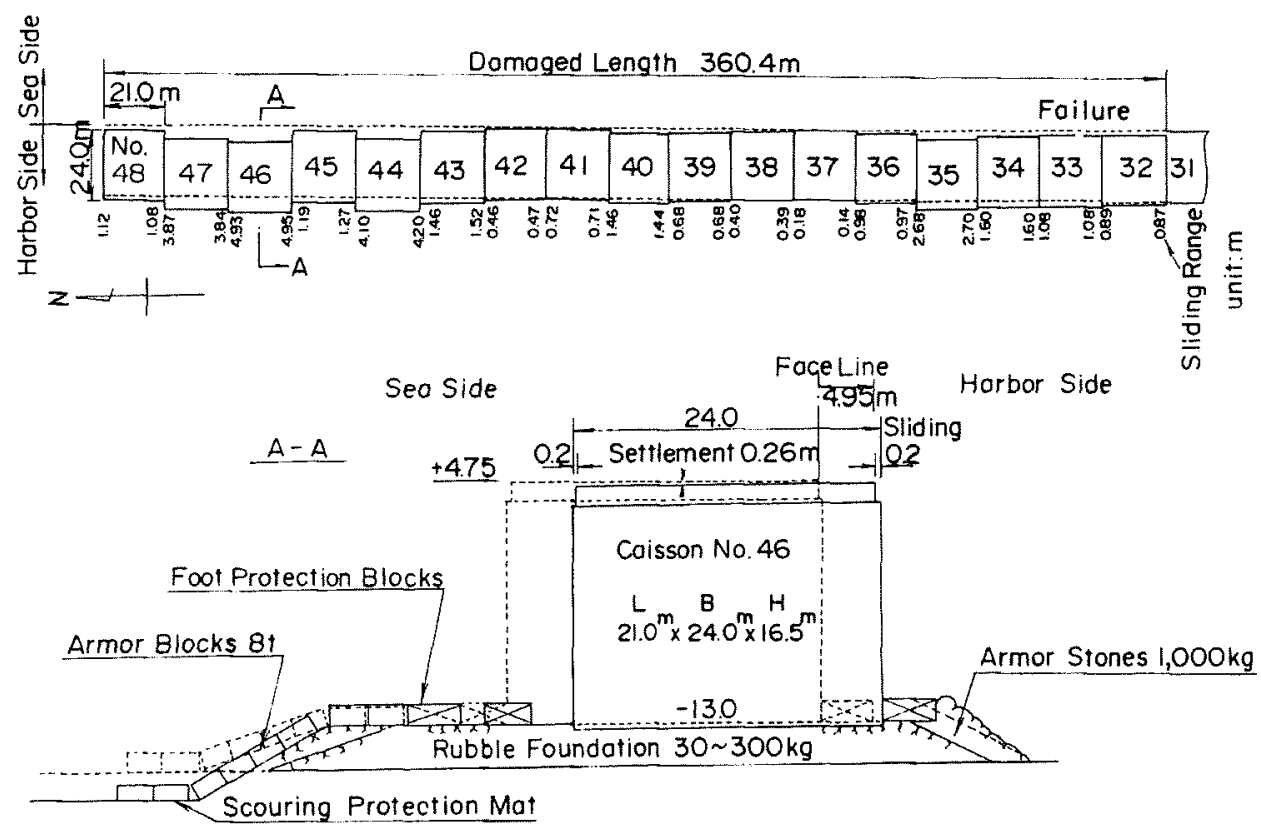

Fig.3.2 Meandering sliding of caisson at the northern end (Hitachi, 1994)

(2) Meandering sliding at the north end

Seventeen caissons having a total length of $360.4 \mathrm{~m}$ slid from 0.14 to $4.95 \mathrm{~m}$, forming a plane view similar to a meandering river (Fig. 3.2). The caissons slid because the waves exceeded the design 
wave height. A meandering shape in the breakwater alignment is very typical in sliding failures, being caused by the refracted waves produced at the breakwater head, which will be described in Section 4.3.7.

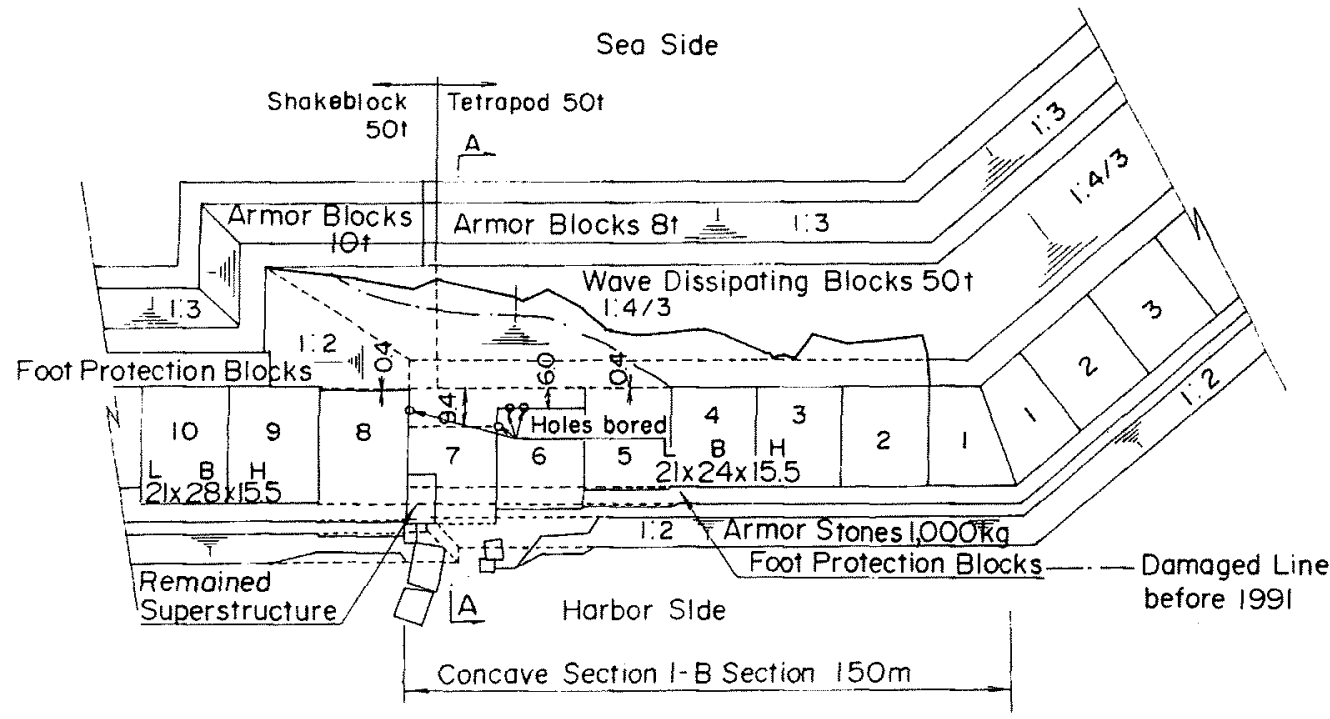

$\underline{A-A}$

Seo Side

Harbor Side

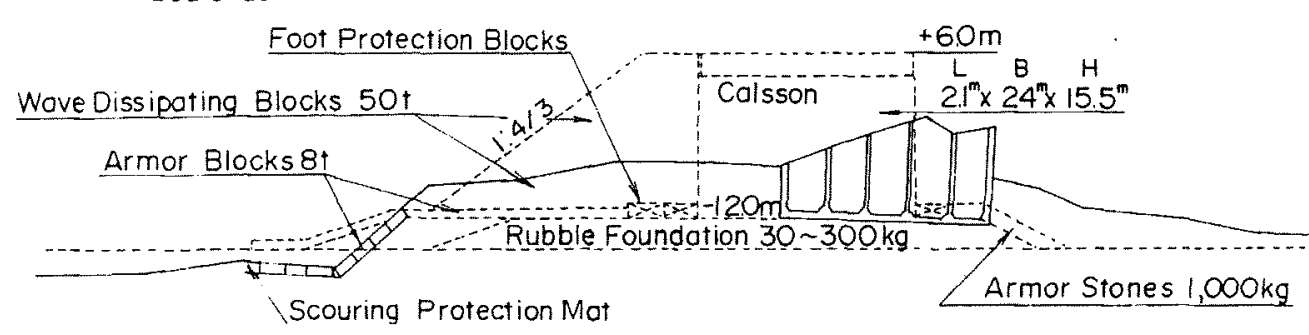

Fig.3.3 Scattering of artificial blocks and damage to the caisson (Hitachi, 1994)

(3) Scattering of wave-dissipating concrete blocks and caisson failure at the concaved section due to impulsive breaking pressures

The place where a breakwater contains a transition from a conventional composite type to block covered type (horizontally composite type) is usually weak, and if waves break on the covering blocks, a caisson that is insufficiently covered will be subjected to impulsive pressures. Consequently, caisson No. 8 was designed to withstand larger wave forces than its neighboring caissons.

However, a previous storm in 1990 had scattered the blocks, which were further scattered by this storm. The transition portion was then extended toward caisson No. 7, which slid about $10 \mathrm{~m}$ and had its upper walls completely destroyed. Caisson No. 8 slid only about $1 \mathrm{~m}$ (Fig. 3.3). This failure was obviously caused by impulsive wave pressures resulting from an insufficient block covering of the caisson. 
The damage at this section also demonstrates the weakness of concrete blocks (50-ton tetrapods) at a transition (as at a breakwater head section). In contrast, the concrete blocks at the breakwater trunk held firmly even though the significant wave was much higher than the design wave.

(4) Scouring underneath the caisson at the southern breakwater head

The foot protection blocks at the breakwater head were scattered and the rubble stones were washed out from underneath the caisson (Fig. 3.4). This damage was probably caused by waves coming from a nearly west direction, where the caisson edge on the harbor side acted as an edged corner against the waves. As will be described in Section 4.4.1, the armor of the rubble mound at this edge has a high probability to suffer from scattering and scouring, which in the worst case, will result in tilting and/or sliding the caisson.

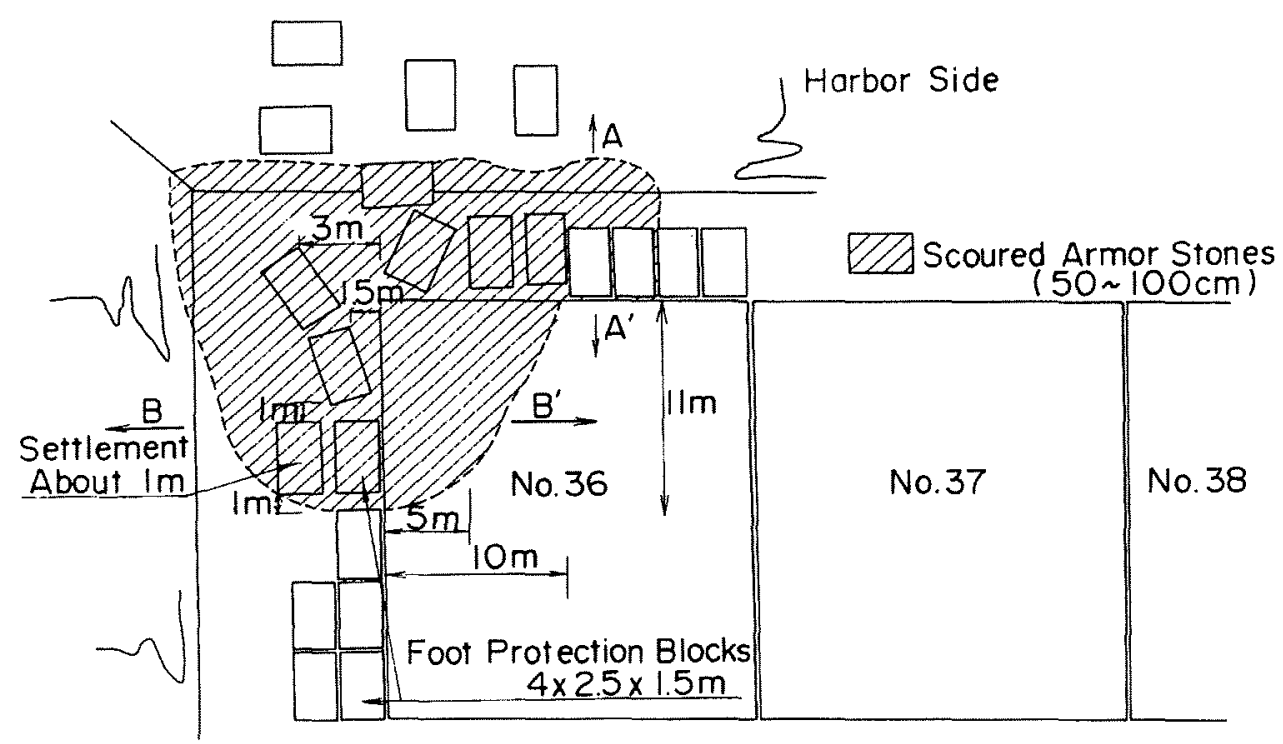

A-A' Section

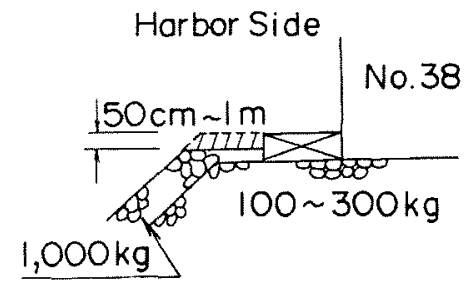

$\underline{B-B^{\prime}}$ Section

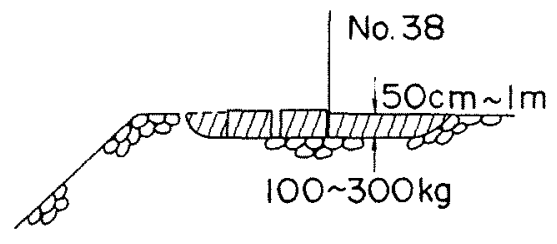

Fig.3.4 Scouring underneath the caisson (Hitachi, 1994) 


\subsection{Typical Failures of Caisson Breakwaters}

(1) Meandering Failures.

Figure 3.5 shows an offshore breakwater at Sendai Port after Typhoon 9119 hit causing several caissons to slide. The length of the breakwater is $700 \mathrm{~m}$. Although the attacking waves were estimated to be about $20 \%$ higher than the design wave height, only caissons at particular locations suffered sliding. This is called "Meandering Sliding".

The breakwater is consisted of caissons of $11.8 \mathrm{~m}$ wide on $6 \mathrm{~m}$ thick rubble foundation. The water depth is $21 \mathrm{~m}$, and the estimated incident wave was $\mathrm{H}_{1 / 3}=6.8 \mathrm{~m}$ and $\mathrm{T}_{1 / 3}=12 \mathrm{~s}$, with an incident wave angle 65 degrees. The waves attacking the caisson were not breaking waves but non-breaking waves. This meandering sliding is a typical sliding phenomenon due to non breaking waves. This is caused by refracted waves from breakwater heads in an oblique wave condition as discussed in 4.4 .

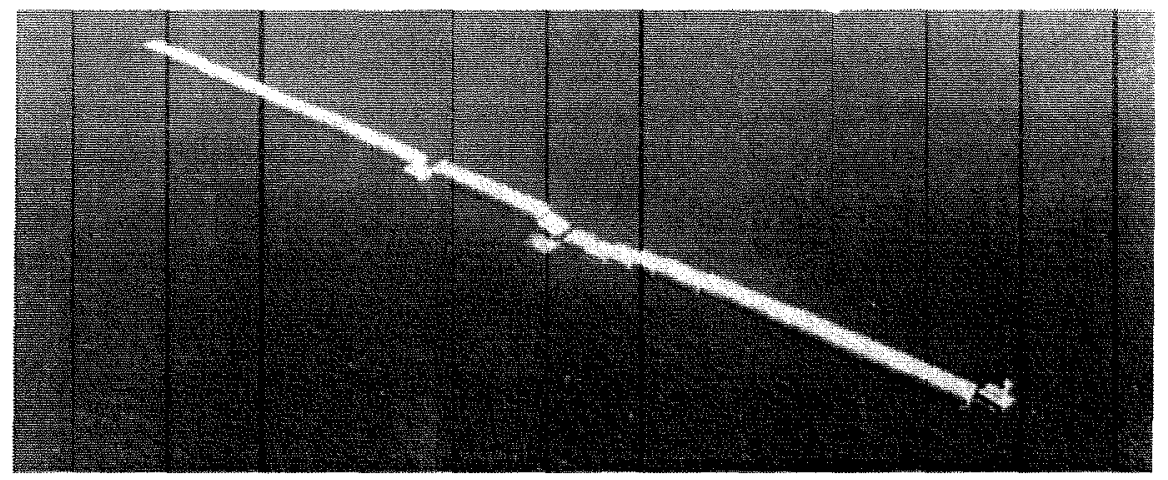

Fig.3.5 Meandering sliding of caissons

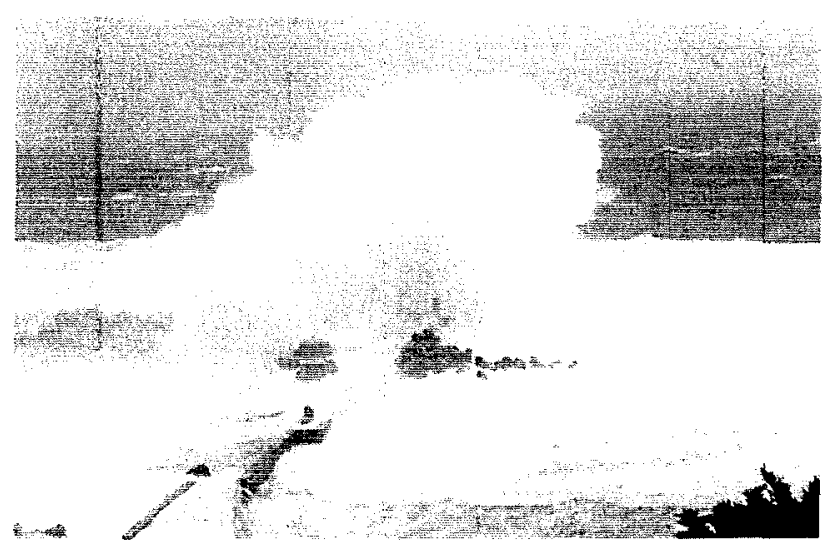

Fig.3.6 Breaking wave impacting a caisson

(2) Impulsive Wave Pressures.

Figure 3.6 shows a wave hitting the offshore side of a caisson at Minamino hama Port. Big splash in the photo is typical, when an impulsive breaking wave force act on the vertical wall. The breakwater forms a jetty type breakwater designed to protect small ferryboats, with its rear side to be used as a quay wall. 
During a typhoon, waves equivalent to the design wave or larger attacked the breakwater head caisson from the breakwater alignment direction. Plunging breakers almost completely destroyed the caisson at the breakwater head. Caisson damage started when the sidewall of the caisson began breaking, then progressed to the whole caisson. Such caisson breakage was caused by impulsive wave pressures acting on a caisson installed on a steep seabed slope. Actually the breakwater was under construction and the damaged caisson was going to be protected by another caisson which was designed considering such severe wave pressures.

Similar failure due to impulsive wave pressure occurs due to breaking waves acting on a caisson installed on a high/wide rubble foundation. Impulsive wave pressures occur when the vertical wall is attacked by vertical water surface, and therefore larger vertical wave front due to plunging or surging breakers gives larger impact pressures. Such caisson failures due to impulsive pressures have recently been greatly reduced using accumulated knowledge about impulsive wave pressures including impulsive pressure coefficient as discussed in 4.3 .

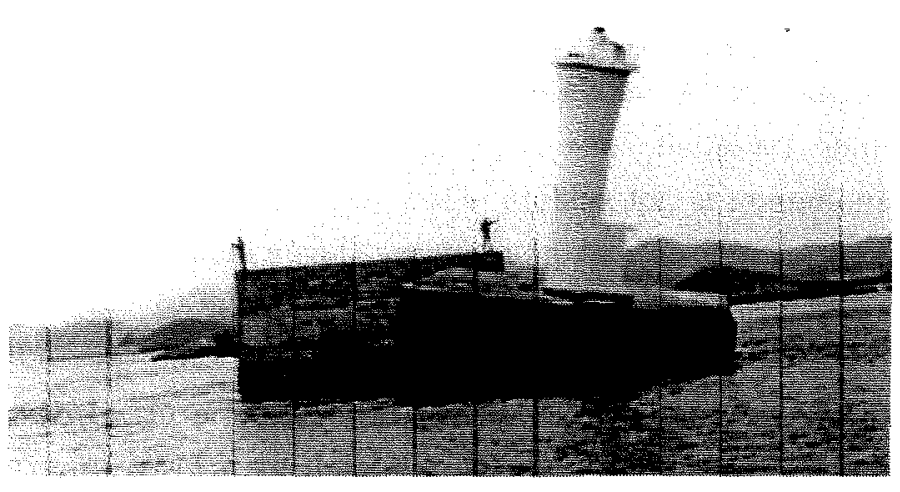

Fig.3.7 Inclined caisson at a Breakwater Head

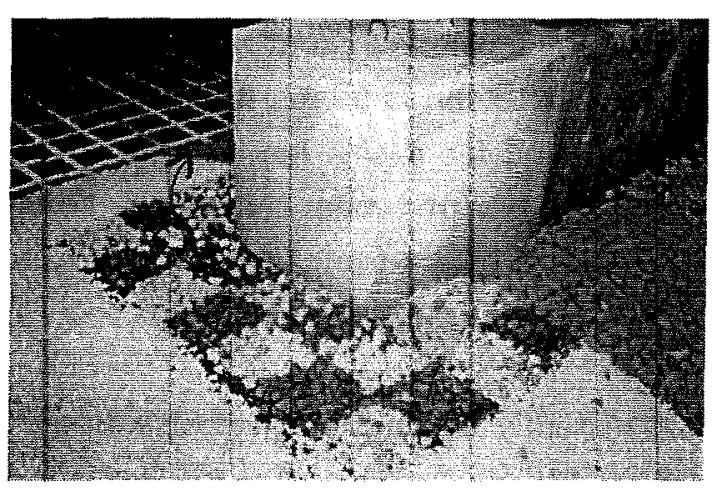

Fig.3.8 Scattering of armor stone around breakwater head

(3) Scattering of Armor for Rubble Foundation.

Figure 3.7 shows a typical caisson failure at a breakwater head, where the caisson moved toward the harbor side. It should be noted that the caisson was not moved by wave force, rather by scouring of the rubble foundation.

Figure 3.8 shows scouring of the rubble foundation at the breakwater head in a model experiment. It is known that very strong wave-induced current occurs at the corner of the breakwater head caisson. Scattering of armor stones occurs when the weight of armor stones was insufficient against very high water particle velocity around the breakwater head. Then the scouring of the rubble mound and the sandbed under the rubble mound occurs.

This type of failure can particularly occur during the construction period, although the design method against such high water particle velocity is well established as explained in 4.4.

(4) Scouring of Rubble Stones and Seabed Sand due to Oblique Waves.

Figure 3.9 shows the inclined caisson in a relatively calm harbor. This is due to the scouring of rubble mound stones and the sandbed under the rubble mound. Oblique waves caused strong wave-induced current along the breakwater caissons, although the wave height is not large. 
An estimation method of the wave-induced current in front of the caisson due to normal as well as oblique waves was already proposed and was included in the current design (Kimura, 1998).

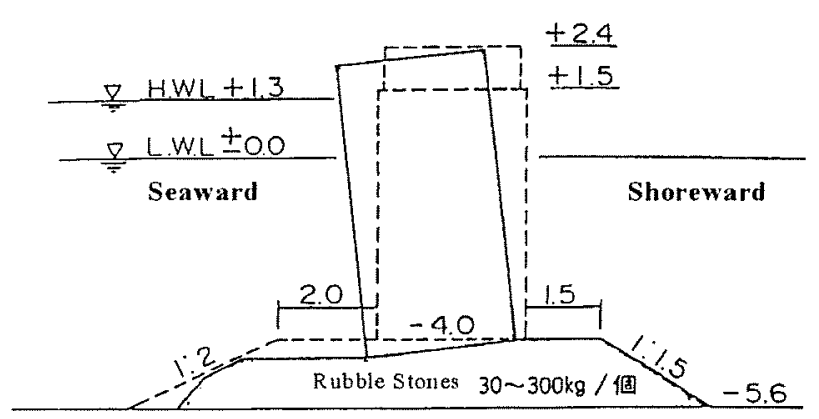

Fig.3.9 Inclined caisson due to front scouring

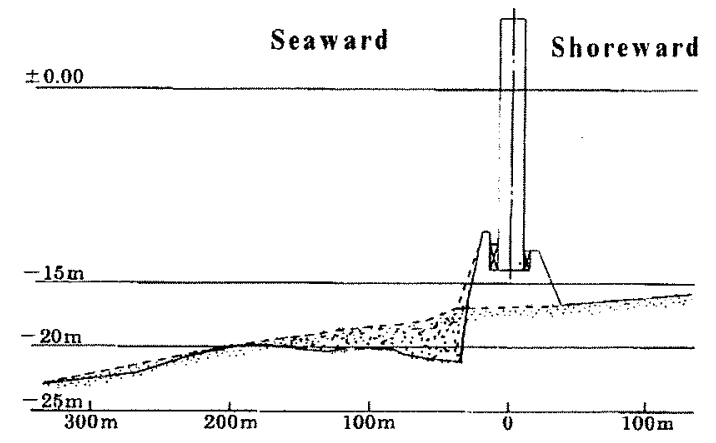

Fig.3.10 Erosion at rubble mound toe

(5) Erosion of Front Seabed (Scouring of Mound Toe).

Figure 3.10 shows a cross section of a large composite breakwater which suffered severe erosion of the mound toe area. Due to high waves, which exceeded $7 \mathrm{~m}$ in significant wave height, the front area was scoured more than $3 \mathrm{~ms}$. This phenomenon is not seldom when such high waves attack a breakwater. The front erosion of breakwaters comprises two phenomena; large'scale sea bottom change and local front scouring.

It is really difficult to protect a breakwater from such front erosion although Irie et. al.(1984) described its fundamental mechanism. Only empirical countermeasures such as a gravel mat or asphalt mat are usually adopted to reduce such scouring as discussed in 4.4. It should be noted that protecting the caisson is essential even though some part of the rubble foundation is scoured. The rubble foundation is usually designed with an enough length considering its deformation due to front erosion.

(6) Seabed Through-Wash.

Figure 3.11 shows settlement of a breakwater due to through 'wash of the sandbed under it (Suzuki et. al., 1998). The relatively fine sand under the rubble mound was washed away by severe wave actions. This type of damage is normally prevented by placing a geotextile sheet under the rubble foundation as discussed in 3.6. If, however, high waves hit the breakwater during construction, this may lead to improper placement of the geotextile sheet, which results in settlement as shown here.

(7) Rubble Foundation Failure.

Breakwater failure due to foundation failure is seldom seen since the current design method seems to be a little conservative which evaluates the bearing capacity of rubble mound and seabed foundation using the Bishop method (Kobayashi et. al., 1987) as explained in 4.3.6.

Figure 3.12 shows a special case of that due to rubble mound failure. An asphalt mat was placed under the caisson to increase the friction coefficient between the caisson and the rubble foundation. Due to high waves exceeding the design wave, sliding took place, which did not occur at the caisson bottom, rather in the foundation. It was thought this sliding occurred between the rubble mound 
and sandbed.

Use of an asphalt mat is very effective in reducing the necessary width of the caisson, and has been widely applied in recent designs. Care must be taken to check foundation stability, however.

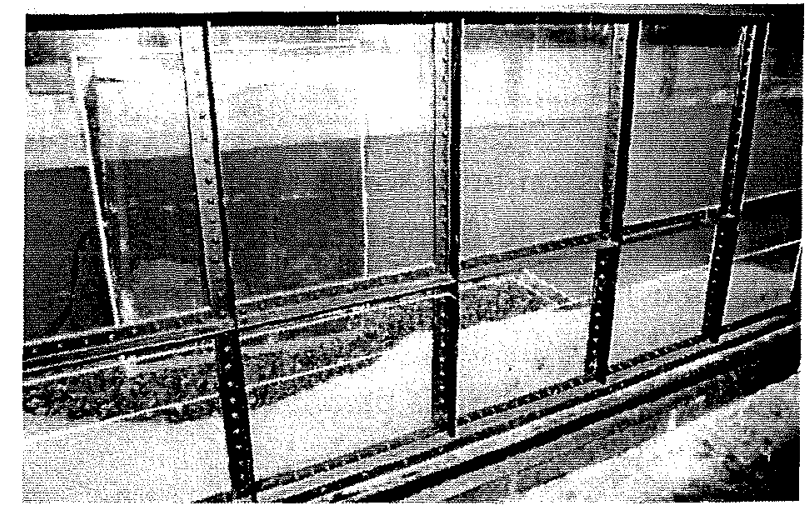

Fig.3.11 Settlement of caisson due to through-wash

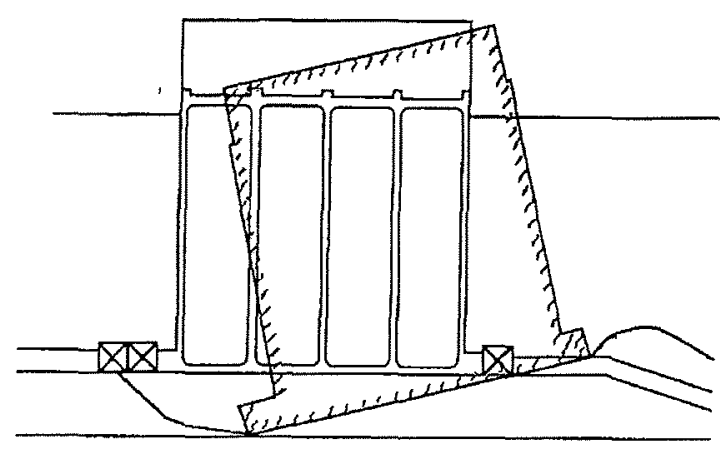

Fig.3.12 Rubble Foundation Failur

\subsection{Failure Path Diagram.}

Figure 3.13 is a failure path diagram of composite breakwaters. It shows the weaker parts of breakwaters and major causes of failures that were already explained above. For example, due to wave wave-induced strong current around the breakwater head, scattering of armor blocks around the head occurs, which results in settlement of mound and therefore the settlement of the caisson. Then caisson can easily slide.

It should be noted that damage to breakwaters seldom occurs even when storm waves exceed the design wave. Typically, only a part of the breakwater weaker than other parts suffers damage due to storm wave heights less than the design wave height. The failure can be reduced by more careful design especially against armor layer scattering and seabed scouring. It will be also effective to reduce failures to include the wave height increase along the breakwater alignment. Most of the design methods against such failures are already established but more precise method should be further developed to reduce the cost of breakwaters.

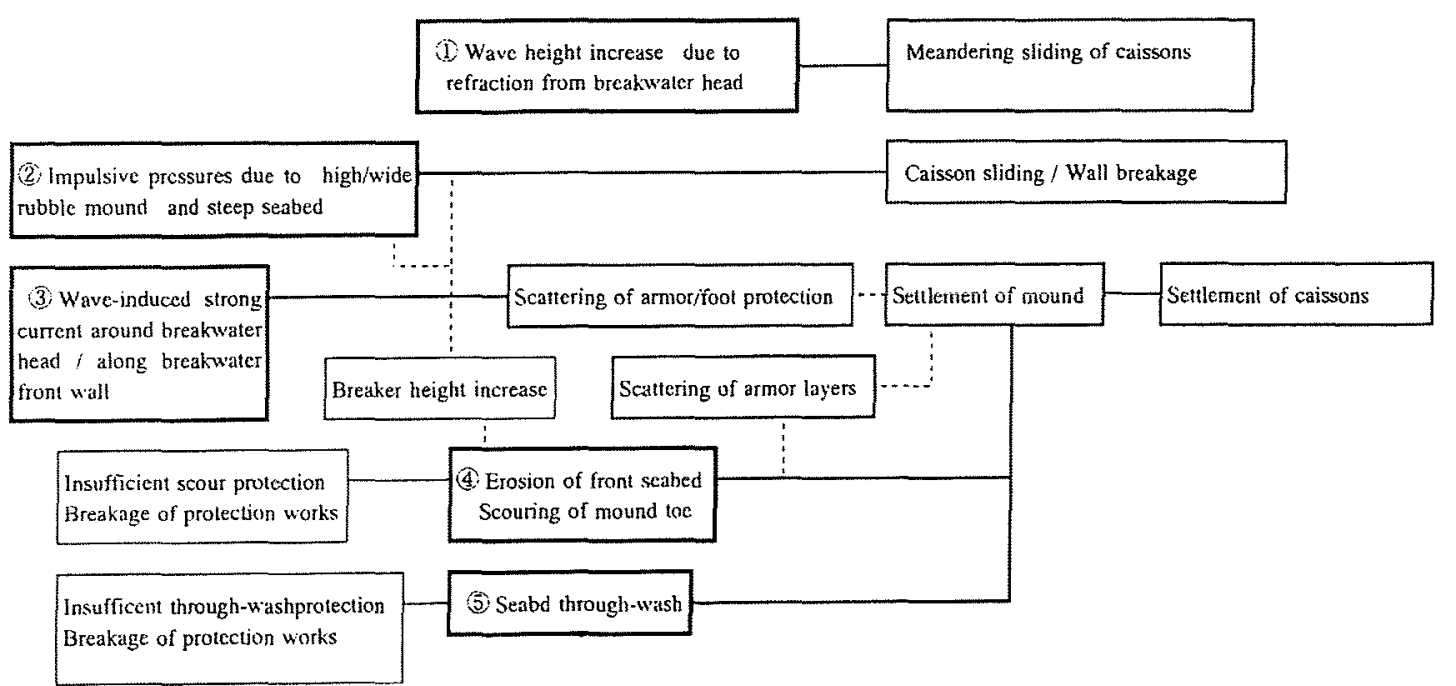

Fig.3.13 Failure Path diagram of composite breakwaters 


\section{DESIGN OF CONVENTIONAL VERTICAL BREAKWATERS}

\subsection{Example of a Conventional Vertical Breakwater}

\subsubsection{Caisson Breakwater}

Figure 4.1 shows a typical cross section of a conventional caisson breakwater. The upright section is a $21.5 \mathrm{~m} \mathrm{x} 27 \mathrm{~m}$ caisson installed on a $3.5-\mathrm{m}$-thick rubble foundation. The depth of the caisson $h^{\prime}$ is $12.5 \mathrm{~m}$ and the height of the crown $h_{c}$ is $6.1 \mathrm{~m}$ at L.W.L. The caisson is divided into $5 \times 6$ chambers by $20-\mathrm{cm}$-thick inner walls and $40-\mathrm{cm}$-thick outer walls. The chambers are filled with sand, capped by concrete, and a concrete superstructure is placed on the caisson.

Foot protection blocks are placed to prevent through-wash of the rubble foundation and the sand below, while shape-designed concrete blocks are installed to act as the armor layer of the rubble foundation. The water depth $\mathrm{d}$ above the rubble mound including the armor layer is $10 \mathrm{~m}$ at L.W.L., and the berm width $\mathrm{B}_{\mathrm{M}}$ of the rubble mound is $12.8 \mathrm{~m}$. For scour protection, additional gravel is placed, being called a "gravel mat." A vinyl sheet is also used to prevent scouring of the sand under the rubble foundation.

This breakwater is designed to withstand a wave of $\mathrm{H}_{\mathrm{D}}=11.6 \mathrm{~m}$ (significant wave height $\mathrm{H}_{1 / 3}=$ $6.66 \mathrm{~m}$ ), significant wave period $T_{1 / 3}=13 \mathrm{~s}$, and wave angle $\theta$ of $22^{\circ}$ at a water depth $\mathrm{h}$ of $21 \mathrm{~m}$. The design significant wave in deepwater $\mathrm{H}_{0}$ is $12.2 \mathrm{~m}$ at a return period of 50 years. The design wave at the breakwater site was evaluated using a wave transformation calculation, with wave pressures on the caisson being evaluated by the extended Goda pressure formula.

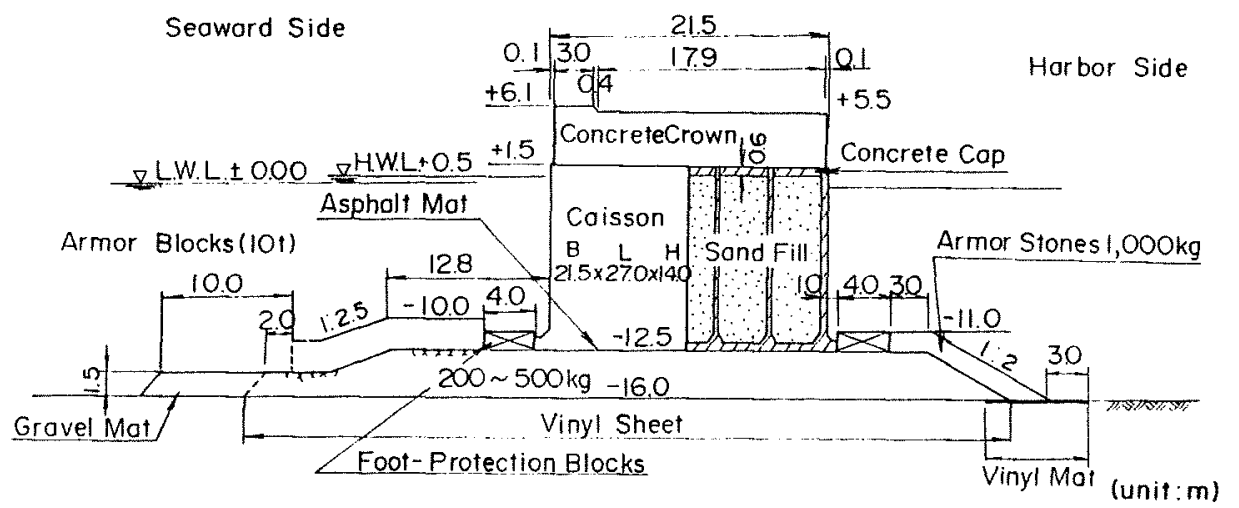

Fig. 4.1 Typical cross section of a vertical breakwater, Noshiro Port (Kataoka, 1986)

\subsubsection{Block Masonry Breakwater}

Figure 4.2 shows a typical cross section of a block masonry breakwater. The rubble foundation of this breakwater is made by excavating the sand bed, and three concrete blocks are installed with a superstructure of in-situ concrete. The design wave of the breakwater is small, i.e., $\mathrm{H}_{1 / 3}$ $=1.8 \mathrm{~m}$ and $T_{1 / 3}=14 \mathrm{~s}$, because it is a secondary breakwater placed behind an offshore breakwater. 


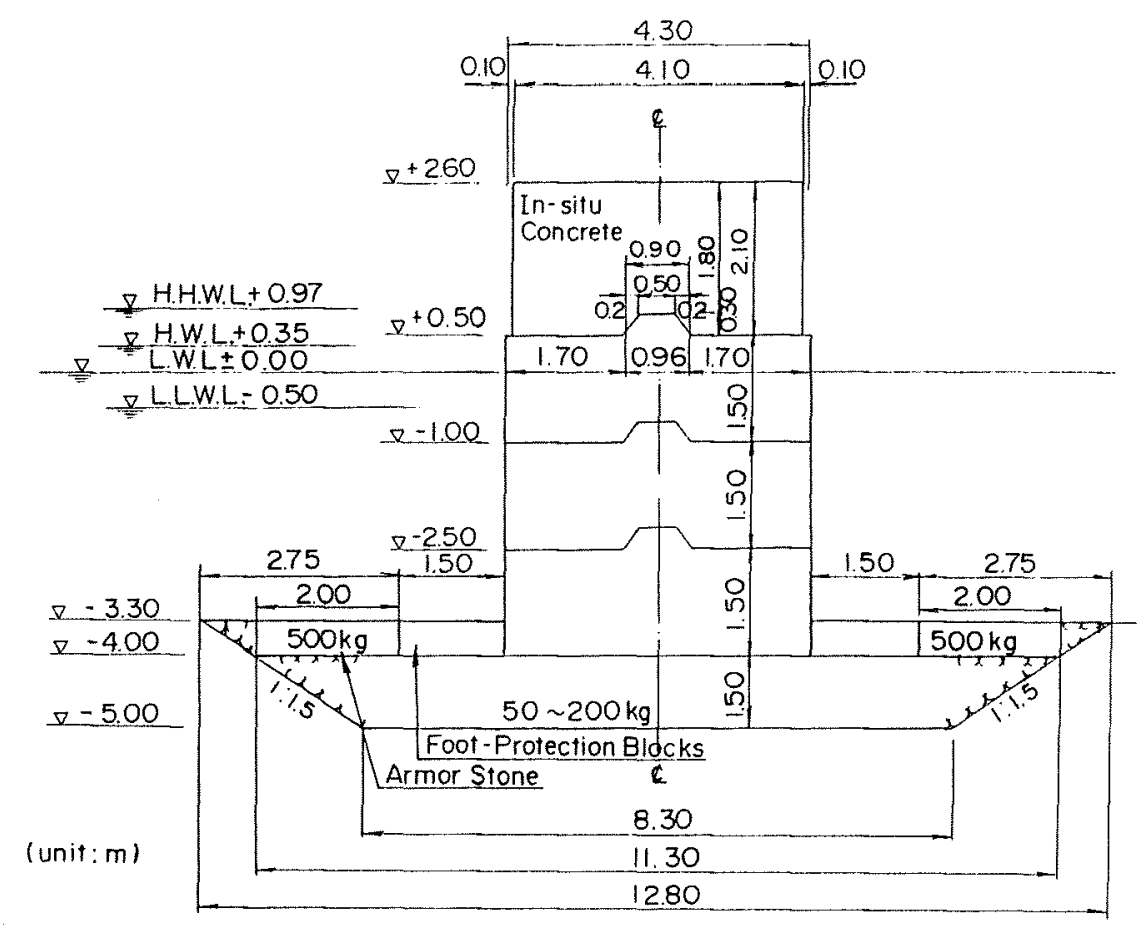

Fig. 4.2 Typical cross section of a block masonry breakwater, Akasaki Port (Kataoka, 1986)

\subsection{Wave Transmission and Reflection of Vertical Walls}

When waves act on breakwaters, some of the incident wave energy is dissipated. Some of the remaining energy, however, is reflected and generates reflected waves in front of the breakwaters. The rest is transmitted and yields transmitted waves behind them. Wave reflection is sometimes a problem because it creates additional agitation. Minimization of wave transmission is especially important in breakwater design since the principal function of breakwaters is to prevent wave propagation from occurring; thereby creating a calm water area behind them.

The amount of wave reflection and transmission are usually measured by the reflection coefficient $\mathrm{K}_{\mathrm{R}}$ and transmission coefficient $\mathrm{K}_{\mathrm{T}}$, being defined by the following relations:

$$
\begin{aligned}
& K_{R}=H_{R} / H_{1} \\
& K_{T}=H_{T} / H_{1}
\end{aligned}
$$

where $H_{I}$ is the incident wave height, $H_{R}$ the reflected wave height, and $H_{T}$ the transmitted wave height, all of which usually correspond to the significant wave.

\subsubsection{Wave Transmission}

Transmitted waves are caused by wave transmission through the structure and overtopping. The transmission coefficients by both causes are respectively denoted as $\mathrm{K}_{\mathrm{Tt}}$ and $\mathrm{K}_{\mathrm{To}}$, with the total 
transmission coefficient $\mathrm{K}_{\mathrm{T}}$ being expressed as

$$
K_{T}=\left(K_{T t}^{2}+K_{T o}^{2}\right)^{0.5}
$$

Because wave transmission by overtopping waves is produced by waves generated at the lee, which result due to the impact from the fall of the overtopping mass, the transmitted waves have a complicated form with high frequency components. Therefore, in general, not only the wave height but also the wave period of transmitted waves are different from those of incident waves, i.e., the wave period of transmitted waves is generally smaller.

Another interesting phenomenon is that transmitted irregular waves change characteristics as they propagate over a long distance, e.g., the distributions of wave height and period vary with the distance away from the breakwater.

Wave transmission of vertical wall breakwaters is mainly by overtopping, and therefore, the ratio of the breakwater's crest height $h_{c}$ to the incident wave height $H_{I}$ is the principal parameter governing the wave transmission coefficient. Based on regular wave tests, Goda (1969) proposed the following equations to represent the transmission coefficient for vertical breakwaters:

$$
\begin{array}{ll}
K_{T}=\left[0.25\left\{1-\sin \left((\pi / 2 \alpha)\left(h_{c} / H_{1}+\beta\right)\right)\right\}^{2}+0.01\left(1-h^{\prime} / h\right)^{2}\right]^{0.5} \\
; \beta-\alpha<h_{c} / H_{1}<\alpha-\beta \\
K_{T}=0.1\left(1-h^{\prime} / h\right) \quad ; h_{c} / H_{1} \geq \alpha-\beta
\end{array}
$$

where $\alpha=2.2$ and $\beta$ is obtained using Fig. 4.3. The term $h^{\prime}$ is the distance from the design water level to the bottom of the caisson.

Although Eq. (4.3) is based on regular wave tests, the relations are still applicable to the transmission coefficient of irregular waves with a significant wave height. Most breakwaters in Japan are designed with a relative crest height $h_{c} / H_{1 / 3}=0.6$, where $\mathrm{H}_{1 / 3}$ is the design significant wave height. The transmission coefficient calculated by Eq. (4.3) is then about 0.2 for the typical conditions of $d / h=$ 0.6 and $h^{\prime} / h=0.7$. Figure 4.4 shows the transmission coefficient for vertical wall breakwaters using

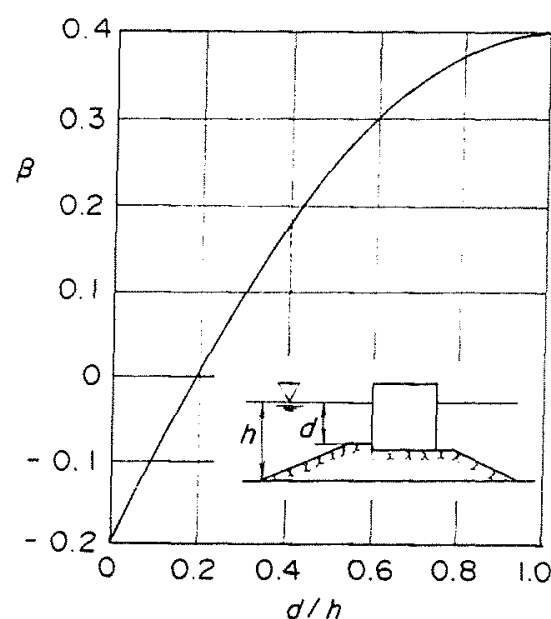

Fig. 4.3 Nomograph for determining $\beta$ Eq. (4.3). 


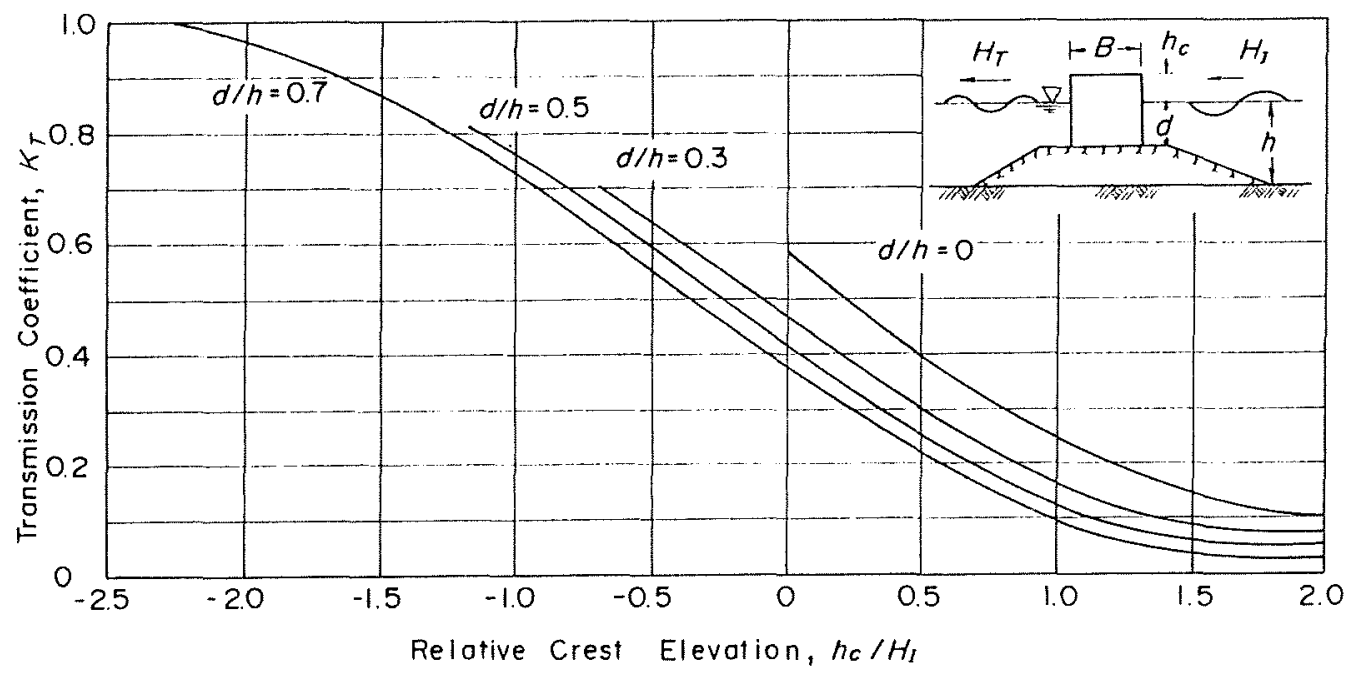

Fig. 4.4 Transmission coefficient for a vertical breakwater (Goda 1969)

\subsubsection{Wave Reflection}

The waves in front of the vertical breakwaters are standing waves, being reflected by the wall. The reflection coefficient $\mathrm{K}_{\mathrm{R}}$ of vertical wall breakwaters is therefore generally high, though less than 1.0 due to the effects of the rubble mound foundation and wave overtopping. In particular, $\mathrm{K}_{\mathrm{R}}$ is considerably reduced when breaking waves act on the breakwaters. Figure 4.5 shows the results from two series of experiments using various wave conditions which are represented by the incident significant wave height $\mathrm{H}_{1 / 3}$ and the wavelength $\mathrm{L}_{1 / 3}$ corresponding to the significant wave period $\mathrm{T}_{1 / 3}$ (Tanimoto et al., 1987). In the first series, the relative thickness of the rubble mound foundation to the water depth, $d / h$, is primarily changed, whereas the relative crest height of the upright sections to the water depth, $h_{c} / h$, is changed in the second series.

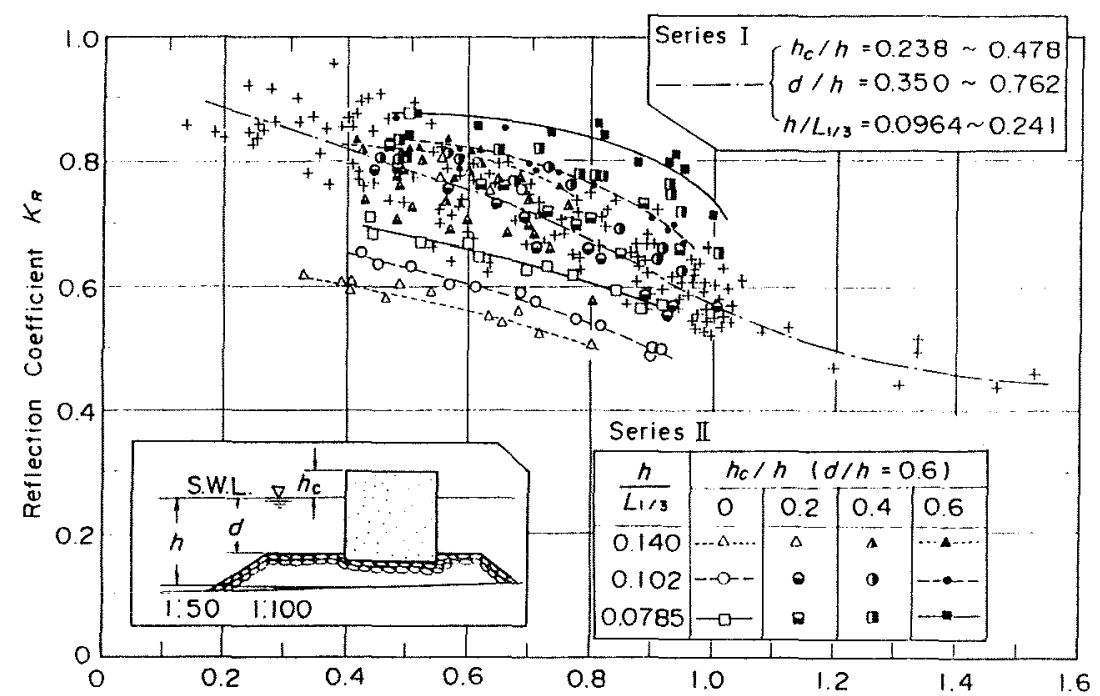

Fig. 4.5 Reflection coefficients of vertical breakwaters (Tanimoto et al., 1987)

The $\mathrm{x}$-axis in Fig. 4.5 is taken as the ratio of the incident significant wave height to the depth in front of the upright section above the armor layer, $\mathrm{H}_{1 / 3} / \mathrm{d}$, which is considered to be a principal factor representing the degree of wave breaking. The average relation from Series I data is indicated, as are the upper and lower limits of Series II data obtained using different values of the 
relative water depth $h / L_{1 / 3}$. Results indicate that $K_{R}$ tends to decrease with increases in $\mathrm{H}_{1 / 3} / \mathrm{d}$. Another important parameter is the relative crest height to the incident significant wave height, $\mathrm{h}_{\mathrm{d}} / \mathrm{H}_{1 / 3}$, since it strongly influences wave overtopping. Series II results reflects this, although the crest height is expressed in the dimensionless form using h vice $\mathrm{H}_{1 / 3}$.

\subsection{Wave Forces on Vertical Walls}

\subsubsection{Standing Wave Pressure}

(1) Small amplitude wave theory

The wave pressure on a vertical wall (Fig. 4.6) can be simply estimated by small amplitude wave theory for a standing wave, i.e.,

$$
p_{(z)}=w_{0} H[\{\cosh k(h+z)\} / \cosh k h] \cos \sigma t
$$

where

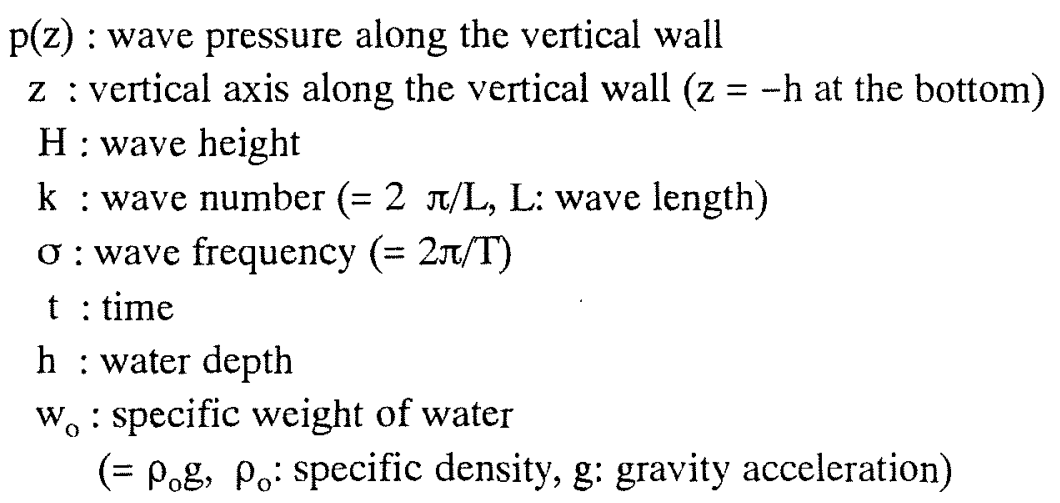

Equation (4.4) indicates that the nondimensional value of positive peak pressure (nondimensional pressure intensity $\mathrm{p} / \mathrm{w}_{0} \mathrm{H}$ ) is 1.0 at the water surface and decreases along the vertical wall down to the bottom, being $1 /$ cosh $\mathrm{kh}$ there. Obvious then, for shallow water waves, the wave pressure is constant along the vertical wall in the direction of water depth. The equation also implies that longer waves give a larger wave

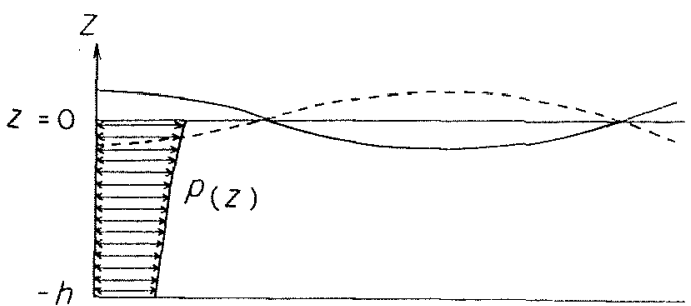

Fig. 4.6 Standing wave on a vertical wall force on the vertical wall when the water depth and wave height are the same. It is important to understand Equation(4.4) because it expresses a basic though essential concept regarding wave pressure on a vertical wall.

(2) Nonlinear wave theory

Figure 4.7 shows the time history of wave pressure on a vertical wall obtained from a model experiment, where the wave pressure is not sinusoidal, instead having double humps at positive pressure and a relatively flat profile at negative pressure due to nonlinearity. Goda and 
Kakizaki (1966) calculated the profile of nonlinear wave pressures using a fourth-order perturbation method, with Fig. 4.8 showing the nondimensional averaged wave forces at the positive peak (wave crest) and negative peak (wave trough), $\mathrm{P}_{\max } / \mathrm{w}_{0}$ Hh and $\mathrm{P}_{\min } / \mathrm{w}_{\mathrm{o}} \mathrm{Hh}$ respectively. Interesting features of the wave pressure are as follows:

1) The average pressure intensities clearly vary with respect to the wave height, and in

some conditions exceed the values obtained by small amplitude wave theory, especially when $h / L$ is small.

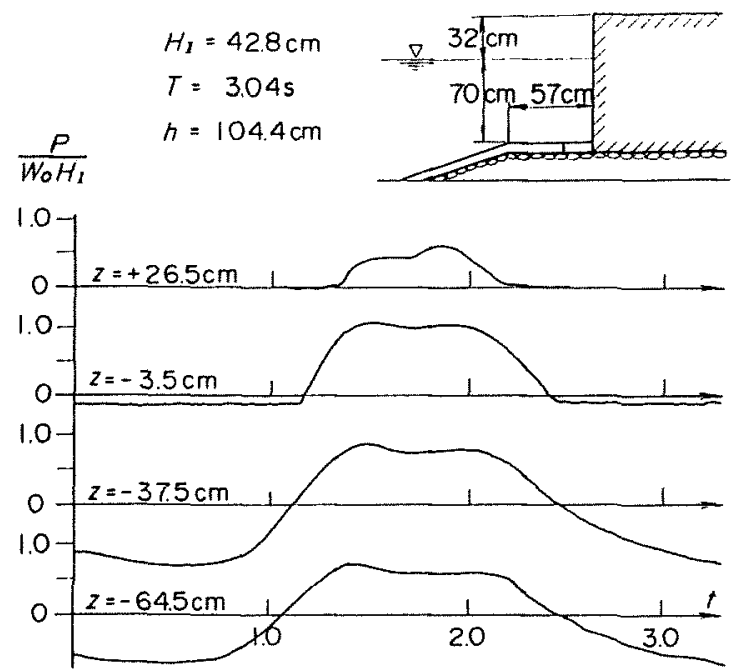

Fig. 4.7 Typical sample analogue results showing standing wave pressures

2) In general, the average pressure intensity at the wave crests increases first, then decreases and finally increases with increases in wave height.

3) As commonly accepted, the absolute value of the pressure intensity at wave trough is usually smaller than that at wave crest. However, when the relative water depth $\mathrm{h} / \mathrm{L}$ is larger than 0.25 , the opposite occurs, being a unique feature of wave pressure in deep waters.

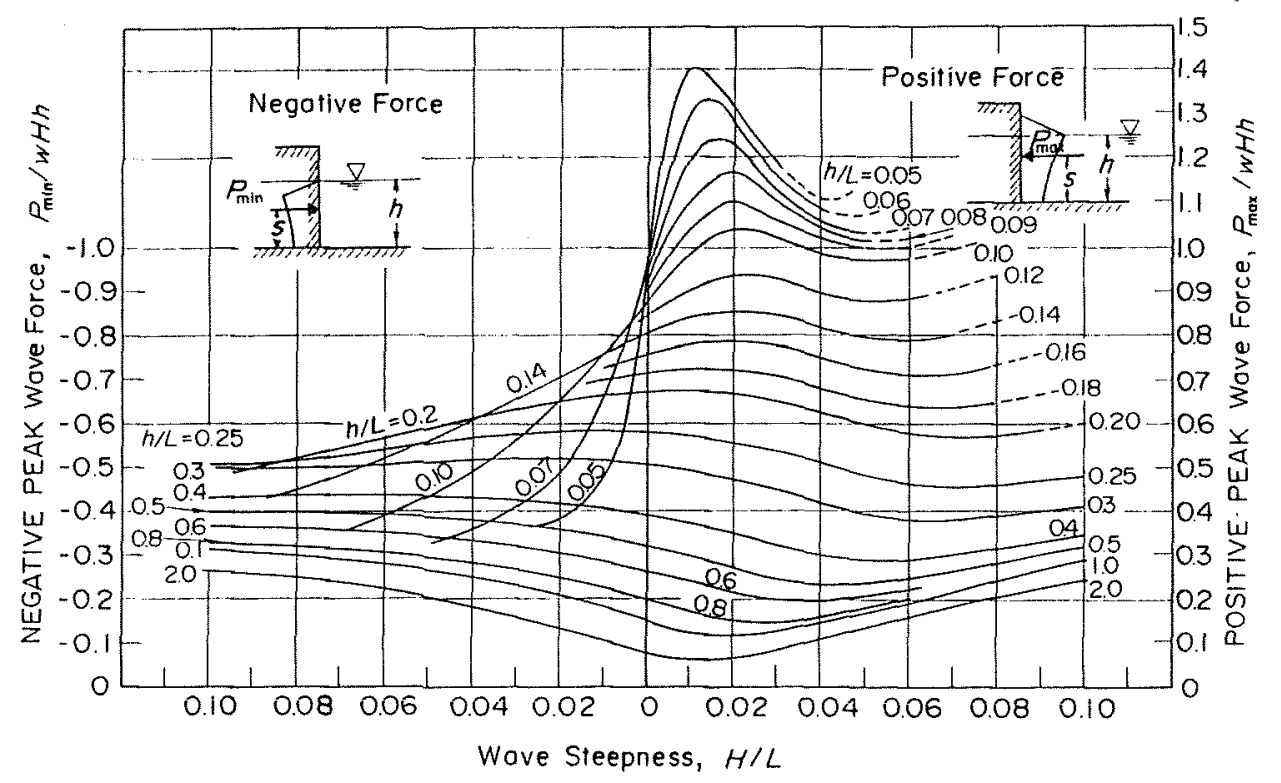

Fig. 4.8 Forces generated by a nonlinear standing wave forces (Goda, 1966)

\subsubsection{Limitations of Wave Pressure Calculations}

Although small and finite amplitude wave theory can directly evaluate wave pressure on a simple vertical wall, the wave pressure on the vertical wall of breakwaters is not easily determined due 
to following reasons:

(1) Wave breaking and sea bottom slope

Wave breaking has not been included in wave theories, and the design wave of breakwaters is usually a breaking wave. In particular, when the sea bottom slope is steep, impulsive pressures will be generated due to wave breaking.

(2) Rubble mound

A rubble foundation is used for composite breakwaters and increases the wave pressure intensity, which in the worst cases, generates impulsive pressure by causing wave breaking on the mound.

\section{(3) Overtopping}

The crown of vertical breakwaters is usually lower than the crest elevation of the design wave, and therefore the breakwaters allow overtopping, which usually reduces the wave pressure intensity, especially when the wave pressure is impulsive.

Due to (1) - (3), wave pressures on vertical wall breakwaters are determined by model experiments or by empirical formulas formulated from model experiments.

Another problem in the design calculation of wave forces concerns the irregularity of waves. Up until recently, wave pressure has been evaluated using the significant wave height, which usually gives a smaller value than the actual wave pressure. It is presently popular, however, to employ the maximum wave height when calculating the design wave pressure, assuming that the highest wave gives the highest wave pressure. It should be realized though, that even when the wave height is the same, the wave pressure may be different due to a different wave profile. This phenomenon requires further investigation.

The wave direction is another important parameter in wave pressure calculations. If a wave is non-breaking, the wave pressure in oblique seas can be calculated. However, the effect of wave direction becomes especially pertinent when the wave is breaking, which is normally evaluated experimentally. In addition to the wave direction, the plane configuration of breakwater causes complex phenomena associated with wave actions, which will be discussed in Section 4.3.7.

\subsubsection{Impulsive Pressure and Dynamic Response of a Caisson}

\section{(1) Impulsive wave pressure}

Figure 4.9 shows a photograph of a boy doing a "belly flop." Since his body is almost parallel to the water surface, his chest and stomach severely slap against the water. Such a collision between the water surface and body produces a strong impulsive water pressure on the body. Impulsive wave pressure due to a breaking wave is similar to this phenomenon, i.e., the collision of the wave surface with the vertical wall. Impulsive wave pressure is one of the biggest problems in design of the vertical breakwaters, being regarded as an inherent disadvantage. On the other hand, if the nature and the generation conditions of this pressure are understood, it can be avoided. 
pressure; thereby indicating the pressure at this angle is similar to the Bagnold type pressure described next.

b) Bagnold type pressure

Bagnold type pressure is very popular to represent impulsive wave pressures. Bagnold (1939) discussed this air compression pressure and Mitsuyasu (1966) derived a pressure calculation method that includes damping due to air leakage (Figure 4.13). This pressure is characterized by a damping oscillation of air pressure, and sometimes only a single pressure peak occurs when the air leakage is large. Note that the pressure travels at $c_{w}$ and acts simultaneously on the vertical wall, appearing even at a distance away from the vertical wall.

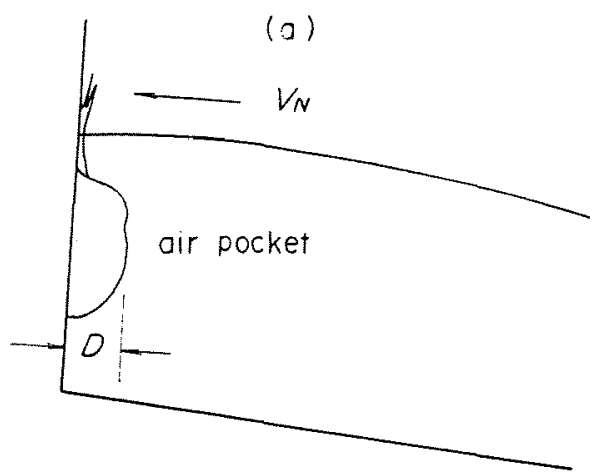

(b)

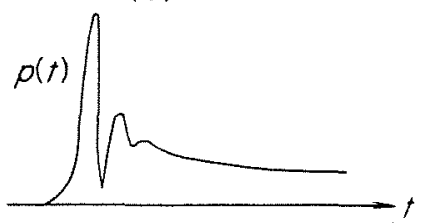

Fig. 4.13 Air compression with leakage (Bagnold type pressure)

The peak value of the Bagnold pressure increases with an increase in the wave front speed or with a decrease of the air layer thickness. It is a common misconception that the air layer contributes to inducing high impulsive pressure similar to that occurring in an explosion process. In actuality, the air layer act as a cushion to reduce the impact pressure.

Many studies on impulsive pressures are still being made (Arami et al., 1990; Partensky, 1988; Kirkgoz, 1991; Oumeraci et al. 1991, Oumeraci and Kortenhaus 1992, Chan 1994)

c) Calculation model of impulsive pressure

Figure 4.14 shows three impulsive wave pressure models developed by Takahashi et al. (1983, 1992). When the attacking angle $\beta$ of the wave front is larger than the curvature angle $\delta$ of the wave front, Wagner type pressure acts on the wall. When $\beta$ is negative, Bagnold type pressure arises. When $\beta$ is between these values, a transition type pressure acts generating an impulsive pressure similar to the Bagnold type. The wave pressure can be evaluated using $\beta$, the curvature angle $\delta$, wave front height 1 , and hitting speed $V_{N}$.

The maximum average wave pressure intensity $\mathrm{p} / \mathrm{w}_{\mathrm{o}} \mathrm{H}$ appears in the transition region and its peak value and duration time $\tau$ are approximated as

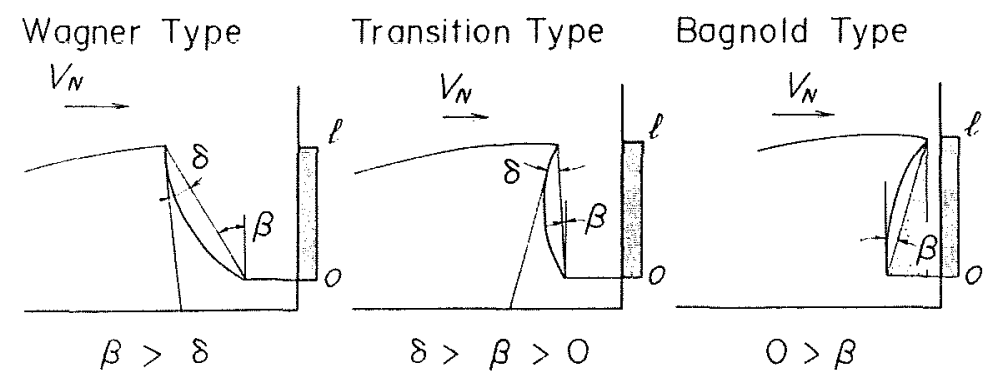

Fig. 4.14 Three types of impulsive pressure 


$$
\begin{aligned}
& p /\left(w_{0} H\right)=\left\{\left(0.4 \pi \kappa_{m}^{2} \kappa_{l}\right) / \kappa_{a}\right\}\left\{(h+0.75 H) /\left(h^{\prime}+h_{c}\right)\right\} \\
& \tau=\pi \quad\left\{\left(\pi w_{0} \kappa_{m}^{2} \kappa_{l}^{2} \kappa_{a} H^{2}\right) /\left(4 \gamma g p_{0}\right)\right\}^{0.5}
\end{aligned}
$$

where $\gamma$ : specific heat ratio $(=1.4)$

$\kappa_{\mathrm{a}}$ : air thickness coefficient

$\kappa_{1}$ : impulsive height coefficient

$\kappa_{\mathrm{m}}$ : added mass correction factor

$\gamma:$ specific heat ratio $(=1.4)$

$\mathrm{h}:$ water depth

$\mathrm{H}$ : wave height

$\mathrm{p}_{\mathrm{o}}$ : atmospheric pressure

$h^{\prime}:$ water depth at the bottom of wall

$h_{c}$ : crest elevation of wall

g: gravity acceleration

$\mathrm{w}_{\mathrm{o}}$ : specific weight of water

$\kappa_{1}$ is the ratio of the wave front height $l$ to the wave height $H$, and theoretically ranges from 0 to 1 , though it is usually approximated as 0.4 to $0.9 . \kappa_{\mathrm{a}}$ is related to $\beta$ and $\delta$, and its minimum value is approximately on the order of 0.01 to $0.1 . \kappa_{\mathrm{m}}$ is assumed to be 0.83 .

From Eq. (4.5), it is obvious that the pressure intensity increases as the wave front height increases and the amount of entrapped air decreases. For example, when $\mathrm{h}=22.5 \mathrm{~m}, \mathrm{~h}^{\prime}=17.5 \mathrm{~m}$, $\mathrm{h}_{\mathrm{c}}=5 \mathrm{~m}, \mathrm{H}=8 \mathrm{~m}, \kappa_{\mathrm{a}}=0.06$, and $\kappa_{1}=0.5$, the maximum average pressure intensity is about 8 $\mathrm{w}_{\mathrm{o}} \mathrm{H}$ and the duration time is $0.2 \mathrm{~s}$.

(2) Impulsive pressure due to a steep sea bottom slope

Waves traveling across a steep sea bottom generate impulsive pressure by forming a vertical wave front when they break. Mitsuyasu (1961) performed a series of experiments to measure wave pressure on a vertical wall placed on a steep slope. Figure 4.15 shows typical results of nondimensional pressure as a function of $\mathrm{h} / \mathrm{H}_{\mathrm{o}}$, the ratio of the water depth at the wall to the wave height in deepwater. In this case, $h$ is from 5 to $18 \mathrm{~cm}, \mathrm{H}_{\mathrm{o}}$ is nearly $10 \mathrm{~cm}$, the wave period is from 1.02 to $2.57 \mathrm{~s}$, and the slope is $1 / 15$. When these results are considered together with those at slopes of $1 / 30$ and $1 / 50$, the following conclusions can be drawn:

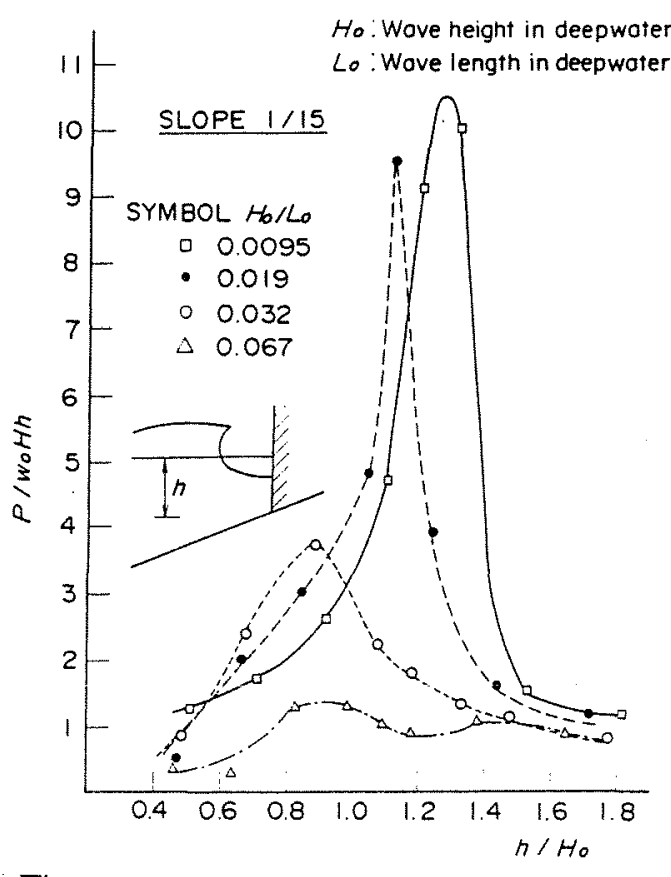

Fig. 4.15 Impulsive pressure due to breaking on a steep slope (Mitsuyasu 1961) 
1) The smaller $H_{o} / L_{o}$ and the larger the slope, the larger the nondimensional pressure intensity. These factors obviously affect the type of wave breaking (breaker). Figure 4.16 shows different breaker types arising as the wave steepness and slope angle are varied. Note that in the region of a spilling breaker, no significant impulsive pressure occurs, whereas in those of plunging or surging breakers, impulsive pressures are generated. Clearly the impulsive pressures are dependent on the wave front of a breaker hitting the vertical wall. The breaker type can also be classified by the so-called surf-similarity parameter (Iribarren number, Ir $=\tan \alpha$ $\left./\left(\mathrm{H}_{\mathrm{o}} / \mathrm{L}_{\mathrm{o}}\right)^{1 / 2}\right)$, with a plunging breaker occurring when Ir > 0.46 (Battjes, 1974).

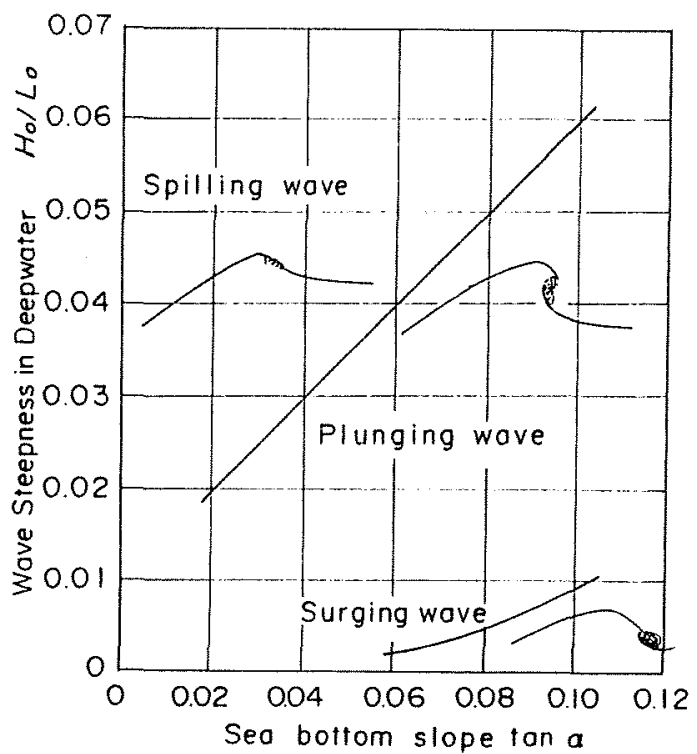

Fig. 4.16 Breaker types due to sea bottom slope and wave steepness

2) When $H_{o} / L_{o}$ is the same value, the pressure intensity peaks at the critical water depth $h_{M}$, which is dependent on the slope angle tan $\alpha$ and $\mathrm{H}_{\mathrm{o}} / \mathrm{L}_{\mathrm{o}}$, i.e.,

$$
h_{M} / H_{0}=(0.59-3.2 \tan \alpha)\left(H_{0} / L_{0}\right)
$$

3) When h is deep enough, non-breaking wave pressure appears, and when it is a little larger than the critical depth $h_{M}$, i.e., $\left(1.0-1.2 h_{M}\right)$, Wagner type impulsive pressure occurs. When $h$ is slightly less than $h_{M}$, i.e., $\left(0.7-1.0 h_{M}\right)$, then Bagnold type pressure appears.

Based on these results, impulsive pressure may occur under the following conditions:

$$
\begin{aligned}
& \left.\mathrm{I}_{\mathrm{r}}=\tan \alpha /\left(\mathrm{H}_{0} / \mathrm{L}_{0}\right)^{0.5}\right)>0.46 \\
& 0.7<\mathrm{h} / \mathrm{h}_{\mathrm{M}}<1.2
\end{aligned}
$$

(3) Impulsive pressure due to a high and/or long mound

When wave forces act on an upright section having a high and/or long rubble mound foundation, the wave pressure becomes strongly impulsive. For example, Fig. 4.17 shows the variation in the wave pressure intensity $p$ averaged over the total height of the upright section, where the $x-$ axis represents the berm width of the rubble mound foundation relative to the water depth, and the $y$-axis represents the thickness of the rubble mound foundation, including the armor layer, relative to the water depth.

Data for $\mathrm{p}$ are obtained using sliding tests of an upright section in which different sizes of the rubble mound foundation are employed. The following relation is used to obtain $p$ from the sliding tests results (Tanimoto et al., 1981): 


$$
p\left(h^{\prime}+h_{c}\right)=\mu W_{O c} /\left(1+\mu U_{G} / P_{G}\right)
$$

where $\mu$ is the coefficient of friction, $\mathrm{W}_{\mathrm{oc}}$ the threshold weight in water against sliding (determined experimentally for a given wave condition), and $\mathrm{U}_{\mathrm{G}}$ and $\mathrm{P}_{\mathrm{G}}$ are respectively the total uplift force and total horizontal wave force calculated by the Goda formula. Therefore, $p$ is not the actual wave pressure, but rather an equivalent static wave pressure intensity which allows examination of the stability against sliding. $p$ actually represents the shear force at the bottom of the upright section including the dynamic response effect.

The variation of the pressure intensity $\left(\mathrm{p} / \mathrm{w}_{0} \mathrm{H}\right)$ in Fig. 4.17 is shown by the equalvalue-lines for the wave condition in which $\mathrm{h} / \mathrm{L}=0.0712$ and $\mathrm{H} / \mathrm{h}=0.719$. This example illustrates how strongly the wave pressure

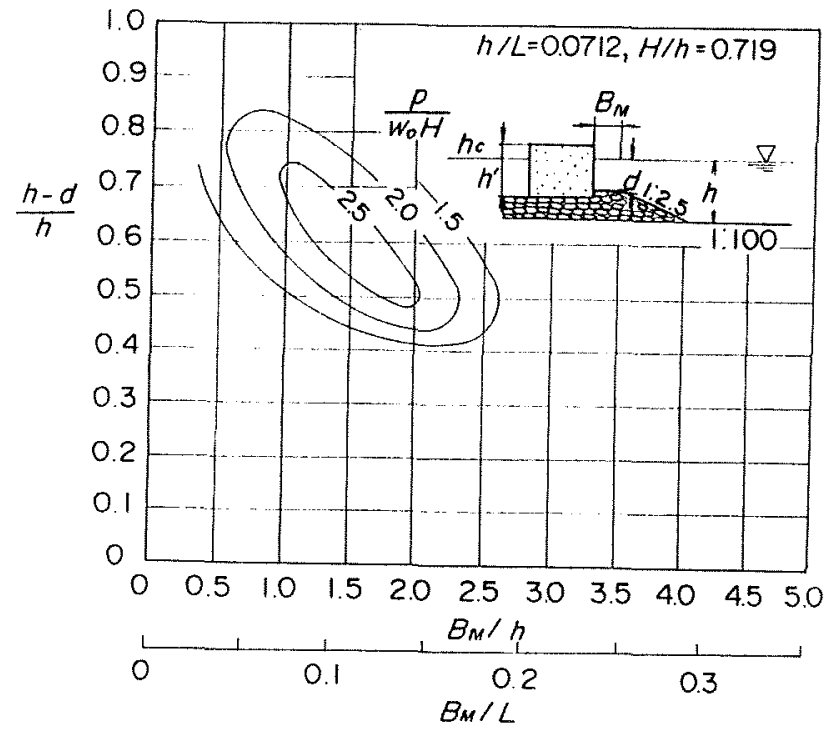

Fig. 4.17 Horizontal wave pressure intensity obtained from sliding tests intensity is influenced by both the height of the rubble mound foundation and the berm width, and also that the breaking wave forces become very large when the rubble mound foundation is too high and/or wide. Under these wave conditions, the horizontal wave pressure (equivalent static pressure) exceeds $2.5 \mathrm{w}_{0} \mathrm{H}$ and reaches a maximum when $(h-d) / h=0.6$ and $B_{M} / L=0.12$. Figure 4.17 represents results generated by conducting extensive sliding tests in a wave tank.

The impulsive pressure coefficient $\alpha_{I}$ was derived from these experimental results. $\alpha_{I}$ can be used to determine the dangerous level of impulsive pressure, includes the effect of dynamic response of the caisson, and is used together with the extended Goda formula described in Section 4.3.5.

(4) Dynamic response of a caisson

Even though the impulsive pressure acts on an upright wall such as a caisson, the wall dynamically responds in conjunction with the rubble mound and soil bed, which significantly reduces the actual shear force that causes sliding (Hayashi et al., 1964; Horikawa et al., 1975; Ito et al., 1966, Shimosako et al., 1994).

Figure 4.18 shows calculated results of the dynamic response of a caisson. The finite element method (FEM) was used with Biot's equations, where an impulsive pressure acts on a caisson that is $22.5 \mathrm{~m}$ high, $20 \mathrm{~m}$ wide, and placed on a 5-m-thick mound above an ordinary sand bed at a water depth of $22.5 \mathrm{~m}$. The input force $\mathrm{F}_{\mathrm{H}}$, inertia force $\mathrm{mx}_{\mathrm{G}}$, shear force $\mathrm{F}_{\mathrm{s}}$, and horizontal displacement $x_{G}$ are indicated along with values of the impulsive component $P_{p}$ and static component $P_{s}$ of the input force $F_{H}$, and the duration time $\tau$ of the impact. The intensity of $P_{p}$ in 

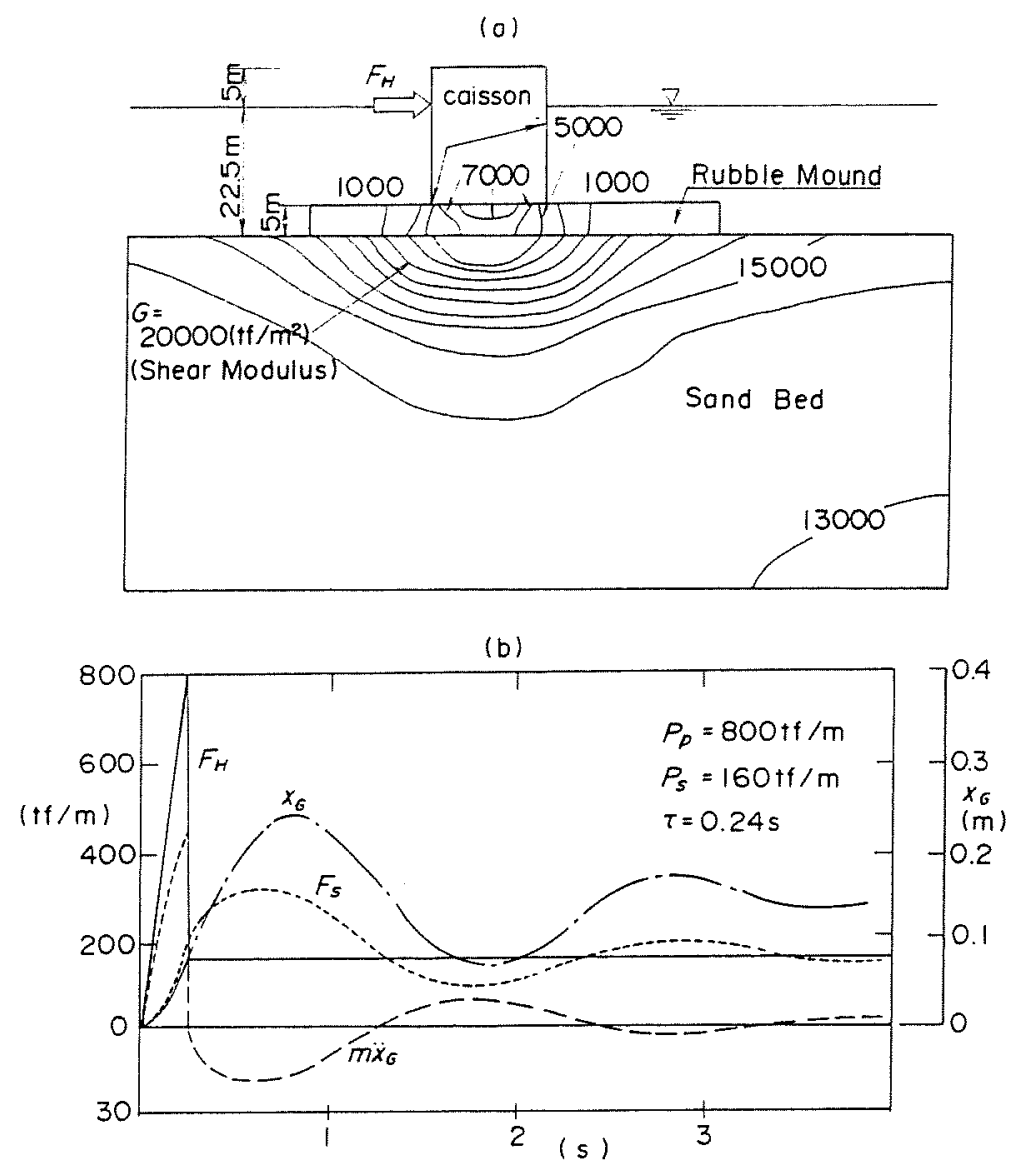

Fig. 4.18 Calculation results of a caisson's dynamic response (Shimosako, 1994)

the calculation is $800 \mathrm{tf} / \mathrm{m}$, approximately about $5 \mathrm{w}_{\mathrm{o}} \mathrm{H}$ if the wave height is assumed to be $8 \mathrm{~m}$. It should be noted that $\mathrm{F}_{\mathrm{s}}$ peaks at about $300 \mathrm{tf} / \mathrm{m}$, being only $40 \%$ of $\mathrm{P}_{\mathrm{p}}$, having been reduced to a great extent. Of interest, the caisson moves significantly at a relatively low frequency.

The shear force is reduced due to the inertia force, and peaks at the negative peak of the inertia force. This is the so-called dynamic response of the caisson. From these numerical experiments, the sliding force is expected to be less than $3 w_{0} \mathrm{H}$ as previously shown by Goda (1973a). Also, the sliding force is almost the same if the momentum of the impact is the same.

(5) Countermeasures for impulsive pressure

a) Design prevention of dangerous conditions

The best countermeasure against impulsive pressure is to have the design prevent the occurrence of dangerous conditions, which can be judged by Eqs. (4.8) and (4.9), or by using the impulsive pressure coefficient described in Section 4.3.5(2). If possible, the breakwater should be situated on a gentle-slope sea bottom, vice a steep bottom, or at a location that is sufficiently deep. The caisson mound must also have its height and length optimized, and it is recommended that the water depth $\mathrm{d}$ in front of the caisson be deeper than $0.6 \mathrm{~h}$.

The incident wave angle $\theta$ to the breakwater's alignment is also an important factor affecting the impulsive pressure. In fact, if the breakwater is planned such that $\theta$ is greater than $30^{\circ}$, then 
impulsive pressure barely occurs (Takahashi et al., 1992).

b) Adoption of alternative breakwater structures

If the rubble foundation has an unavoidably large height and length and/or the sea bottom slope is steep, then breakwater structures should be selected which do not cause impulsive pressures. One such alternative structure is a horizontally composite breakwater, e.g., a composite breakwater having its front covered with wave dissipating concrete blocks. This design results in a completely different wave profile hitting the breakwater, such that the impulsive pressure is remarkably reduced by the covering blocks. The design of horizontally composite breakwaters is described in Chapter 6.

Another alternative structure uses a perforated wall caisson called the wave-dissipating caisson. Although the wave action on its front wall is the same as that on a conventional caisson, a perforated wall having a wave chamber significantly reduces the impulsive pressure. The design of a perforated wall caissons is described in Chapter 5. In addition, sloping top caissons can also reduce the destructive effect on the structure.

\subsubsection{Wave Pressure Formulas}

(1) Sainflou Formula

In 1928, Sainflou introduced a wave pressure formula for standing waves that was based on trochoidal theory. His formula improved the existing wave pressure formula proposed by Benezit (1923). The Sainflou formula was simplified such that it provided the wave pressure distributions at the wave crest and trough (Fig. 4.19). The wave pressure at wave crest can be evaluated using

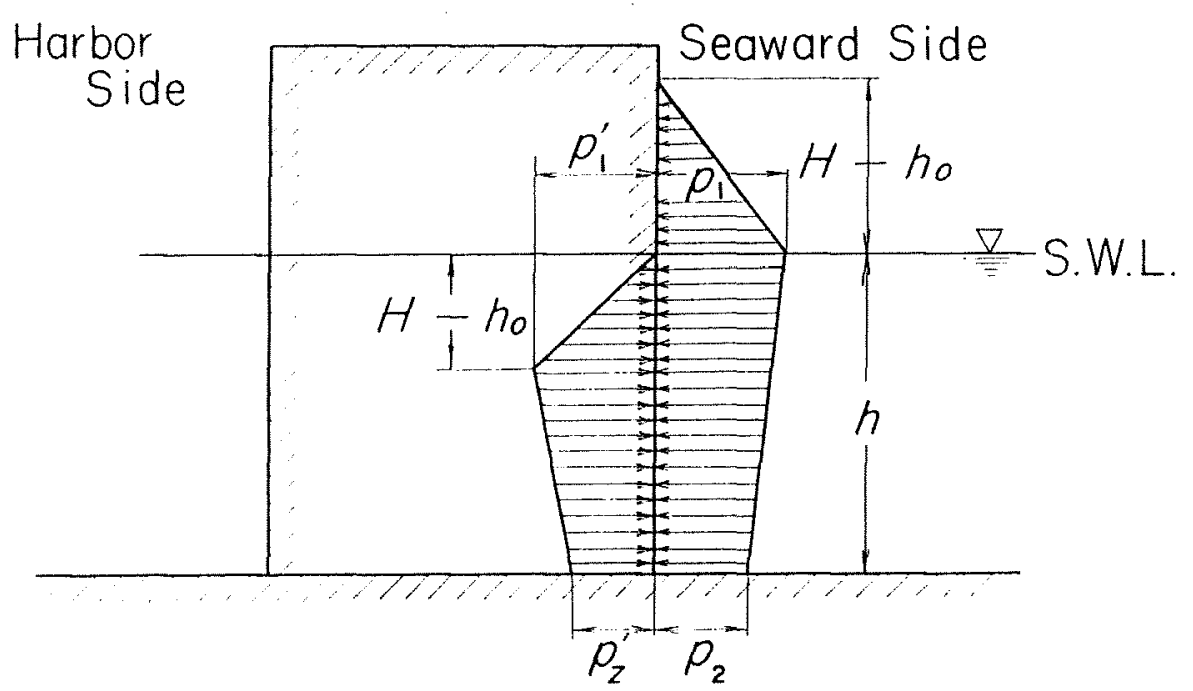

Fig. 4.19 Simplified Sainflou pressure formula 


$$
\begin{aligned}
& p_{1}=\left(p_{2}+w_{0} h\right)\left\{\left(H+h_{0}\right) /\left(H+h+h_{0}\right)\right\} \\
& p_{2}=w_{0} H /\{\cosh (2 \pi h / L)\}
\end{aligned}
$$

whereas that at the wave trough by

$$
\begin{aligned}
& p_{1}^{\prime}=w_{0}\left(H-h_{0}\right) \\
& p_{2}^{\prime}=p_{2}=w_{0} H /\{\cosh (2 \pi h / L)\} \\
& h_{0}=\left(\pi H^{2} / L\right) \operatorname{coth}(2 \pi h / L)
\end{aligned}
$$

The Sainflou formula properly describes the standing wave pressure and has been used throughout the world for many years. It was also applied in Japan prior to the development of the Goda formula. One should realize that when the Sainflou formula is employed in Japan the design wave $\mathrm{H}$ is $\mathrm{H}_{1 / 3}$, while $\mathrm{H}_{1 / 10}$ in some other countries. In any case, it is recommended that the maximum wave height be applied for the design wave.

\section{(2) Hiroi Formula}

Hiroi (1919) developed a wave pressure formula using an analogy of the hydrodynamic pressure. His formula was based on field measurements obtained by Setevenson type pressure gauges (Stevenson, 1886), and it applies to breaking waves in relatively shallow seas. The pressure distribution is assumed to be uniform along the vertical direction as shown in Fig. 4.20, and the wave pressure $p$ at the wave crest is

$$
p=1.5 w_{0} H
$$

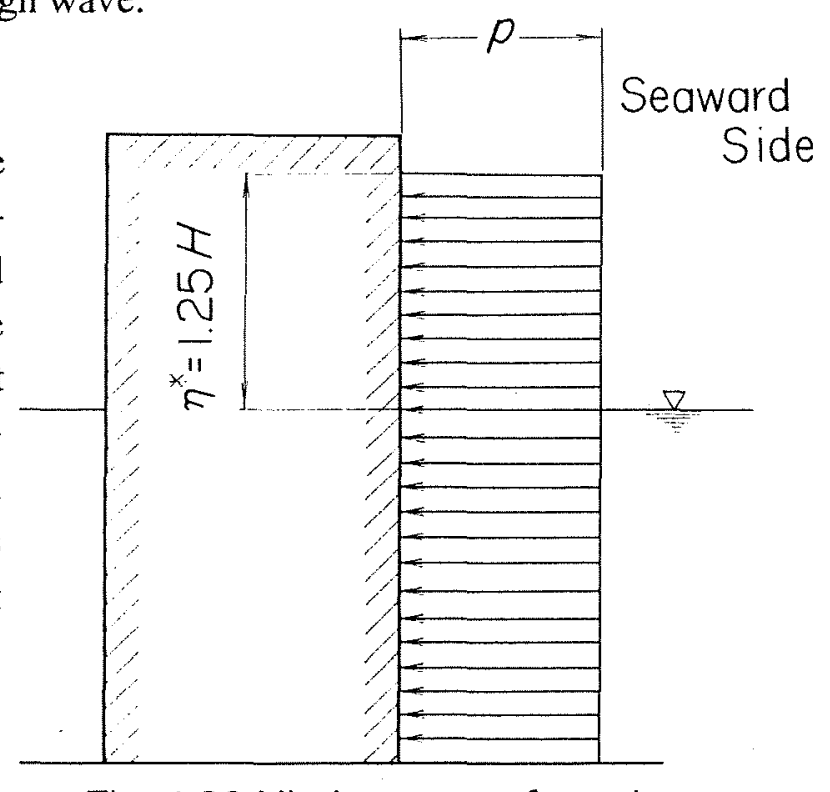

Fig. 4.20 Hiroi pressure formula

where $\eta^{*}$ is the wave crest elevation and $p$ is assumed to act up to $\eta^{*}$ from the still water level.

The Hiroi formula is very simple, yet it reasonably describes the design pressure and was used for many years in Japan until development of the Goda formula. When the Hiroi formula is employed, the design wave is usually $\mathrm{H}_{1 / 3}$. However, the difference between the maximum wave height and the significant wave height is small in shallow seas. In fact, it is believed that the water depth was used instead of the wave height when Hiroi designed the breakwater built in Hakodate.

(3) Minikin formula

Minikin (1950) proposed a breaking wave pressure formula that includes impulsive pressures. 
However, it cannot properly describe changes in the impulsive pressures due to the shape of the rubble foundation.

(4) Nagai formula

Nagai and Kurata (1974) elaborated on developing a comprehensive wave pressure formula, which indicates the importance of the depth $d$ in front of the upright section relative to the site's water depth $h$ and berm width $B_{M}$.

\subsubsection{Extended Goda Formula}

(1) Goda formula and its extension

In 1973, Goda used his own theoretical and laboratory studies (Goda, 1972) to establish a comprehensive formula to calculate the design wave forces. After a later modification to account for the effect of oblique wave incidence, this formula was successfully applied to the design of vertical breakwaters built in Japan.

The original Goda formula (Goda, 1973b) has many advantageous features, with the main ones being as follows:

1) It can be employed for all wave conditions, i.e., both for standing and breaking waves.

2) The formula's design wave is the maximum wave height and can be evaluated by given diagrams and/or equations.

3) It is partially based on nonlinear wave theory and can represent wave pressure

characteristics by considering two pressure components: the breaking and slowly-varying pressure components. Consequently, it is relatively easy to extend the Goda formula in order to apply it to other vertical wall-type structures.

4) The Goda formula clarifies the concept of uplift pressure on the caisson bottom, since the buoyancy of the upright section in still water and its uplift pressure due to the wave action are defined separately. The distribution of the uplift pressure has a triangular shape.

The Goda formula was subsequently extended to include the following parameters:

1) the incident wave direction (Tanimoto et al., 1976)

2) modification factors applicable to other types of vertical walls

3) the impulsive pressure coefficient (Takahashi et al., 1994).

In the extended Goda formula, the wave pressure acting along a vertical wall is assumed to have a trapezoidal distribution both above and below the still water level, while the uplift pressure acting on the bottom of the upright section is assumed to have a triangular distribution as shown in Fig. 4.21. The buoyancy is calculated using the displacement volume of the upright section in still water at the design water level. Asindicated, $h$

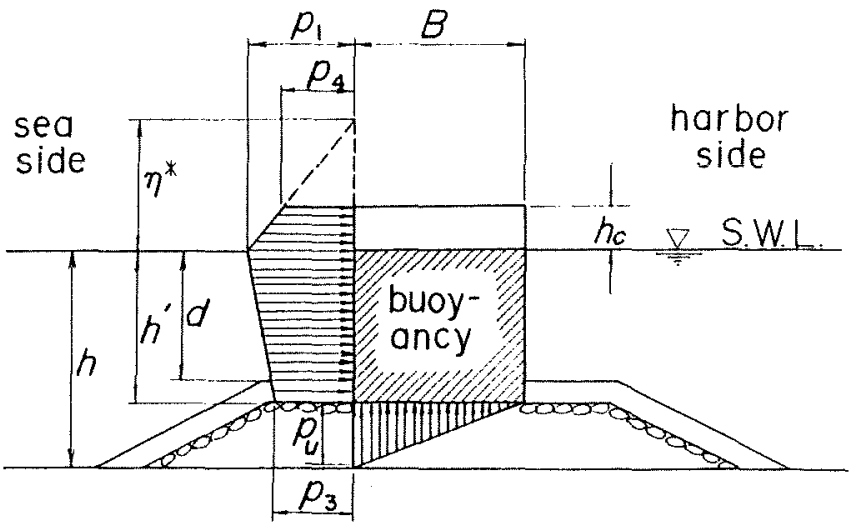

Fig. 4.21 Goda pressure formula 
denotes the water depth in front of the breakwater, $d$ the depth above the armor layer of the rubble mound foundation, $h^{\prime}$ the distance from the design water level to the bottom of the upright section, and $h_{c}$ the elevation of the breakwater above the design water level. The elevation at which the wave pressure is exerted, $\eta^{*}$, and the representative wave pressure intensities $p_{1}, p_{3}$, $\mathrm{p}_{4}$, and $\mathrm{p}_{\mathrm{u}}$ can be written in a generalized form as

$$
\begin{aligned}
& \eta^{\star}=0.75(1+\cos \theta) \lambda_{1} H_{D} \\
& p_{1}=0.5(1+\cos \theta)\left(\lambda_{1} \alpha_{1}+\lambda_{2} \alpha^{\star} \cos ^{2} \theta\right) w_{0} H_{D} \\
& p_{3}=\alpha_{3} p_{1} \\
& p_{4}=\alpha_{4} p_{1} \\
& p_{u}=0.5(1+\cos \theta) \lambda_{3} \alpha_{1} \alpha_{3} w_{0} H_{D}
\end{aligned}
$$

in which

$$
\begin{aligned}
& \alpha_{1}=0.6+0.5\left\{\left(4 \pi h / L_{D}\right) / \sinh \left(4 \pi h / L_{D}\right)\right\}^{2} \\
& \alpha^{*}=\max \left\{\alpha_{2}, \alpha_{1}\right\} \\
& \alpha_{2}=\min \left\{\left(1-d / h_{b}\right)\left(H_{D} / d\right)^{2} / 3,2 d / H_{D}\right\} \\
& \alpha_{3}=1-\left(h^{\prime} / h\right)\left\{1-1 / \cosh \left(2 \pi h / L_{D}\right)\right\} \\
& \alpha_{4}=1-h_{c}^{*} / \eta^{*} \\
& h_{c}^{*}=\min \left\{\eta^{*}, h_{c}\right\}
\end{aligned}
$$

where

$\theta$ : angle between the direction of wave approach and a line normal to the breakwater

$\lambda_{1}, \lambda_{2}, \lambda_{3}$ : modification factors dependent on the structural type

$H_{D}, L_{D}$ : wave height and wave length applied to calculate design wave forces

$\alpha_{I}$ : impulsive pressure coefficient

$w_{o}$ : the specific weight of sea water $\left(=\rho_{\mathrm{o}} \mathrm{g}\right)$

$h_{b}$ : offshore water depth at a distance five times the significant wave height $H_{1 / 3}$

$\min \{a, b\}:$ the minimum of $a$ and $b$

$\max \{a, b\}$ : the maximum of $a$ and $b$

(2) Pressure component and pressure coefficients $\left(\alpha_{1}, \alpha_{2}\right.$, and $\left.\alpha_{1}\right)$

Figure 4.22 shows the transition of wave pressure from nonbreaking to impulsive pressure, where the pressure component is indicated by coefficient $\alpha_{1}, \alpha_{2}$, and $\alpha_{\mathrm{I}}$. $\alpha_{1}$ represents the 
where the pressure component is indicated by coefficient $\alpha_{1}, \alpha_{2}$, and $\alpha_{1}$. $\alpha_{1}$ represents the slowly-varying pressure component and $\alpha_{2}$ the breaking pressure component, while $\alpha_{1}$ represents the impulsive pressure component, which includes the dynamic response effect on the caisson sliding.

$\alpha_{1}$ increases from 0 to 1.1 as the relative depth decreases, and $\alpha_{2}$ increases as $d / h_{b}$ decreases, though it peaks and then decreases as $d / h_{b}$ decreases, ranging 0 to 1.0. The value of $\alpha_{I}$ is described next in more detail.

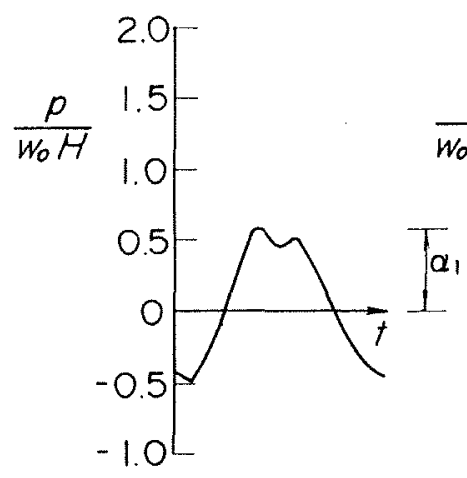

(a) Standing Pressure (b)Breaking Pressure

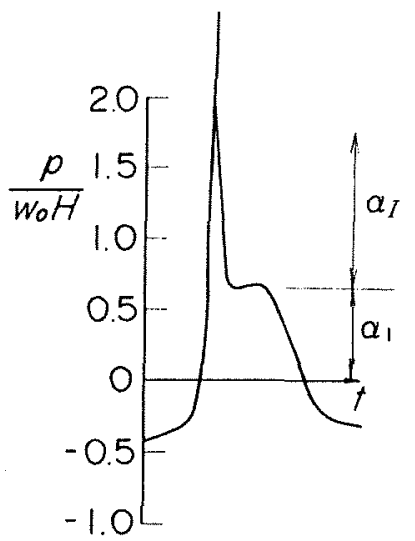

(c) Impulsive Pressure

Fig. 4.22 Transition of wave pressure

(3) Impulsive pressure coefficient $\alpha_{I}$

$\alpha_{\mathrm{I}}$ was obtained by reanalyzing the results of comprehensive sliding tests (Takahashi, 1994), being a non-dimensional value representing the impulsive pressure component, which should be regarded as an additional effect to the slowly-varying pressure component. The effect of the dynamic (impulsive) pressure indicated by $\alpha_{2}$ in Goda's formula does not under all conditions accurately estimate the effective pressure (equivalent static pressure) due to impulsive pressure, and therefore, $\alpha_{\mathrm{I}}$ was introduced.

Figure 4.23 shows a calculation diagram for $\alpha_{\mathrm{I}}$, in which it is expressed by the product of $\alpha_{\mathrm{I}}$ and $\alpha_{\mathrm{I} 1}$, where $\alpha_{\mathrm{IO}}$ represents the effect of wave height on the mound, i.e.,

$$
\begin{array}{rlrl}
\alpha_{1} & =\alpha_{10} \alpha_{11} & \\
\alpha_{10} & =H / d & H \leq 2 d \\
& =2 & H>2 d
\end{array}
$$

and $\alpha_{I 1}$ represents the effect of the mound shape (shown by the contour lines). This term can be evaluated using

$$
\begin{aligned}
& \alpha_{11}=\cos \delta_{2} / \cosh \delta_{1} \quad \delta_{2} \leq 0 \\
& =1 /\left\{\cosh \delta_{1}\left(\cosh \delta_{2}\right)^{0.5}\right\} \quad \delta_{2}>0 \\
& \delta_{1}=20 \delta_{11} \quad \delta_{11} \leq 0 \\
& =15 \delta_{11} \quad \delta_{11}>0
\end{aligned}
$$




$$
\begin{aligned}
\delta_{2} & =4.9 \delta_{22} & & \delta_{22} \leq 0 \\
& =3 \delta_{22} & & \delta_{22}>0
\end{aligned}
$$

$$
\begin{aligned}
& \delta_{11}=0.93\left(B_{M} / L-0.12\right)+0.36\{(h-d) / h-0.6\} \\
& \delta_{22}=-0.36\left(B_{M} / L-0.12\right)+0.93\{(h-d) / h-0.6\}
\end{aligned}
$$

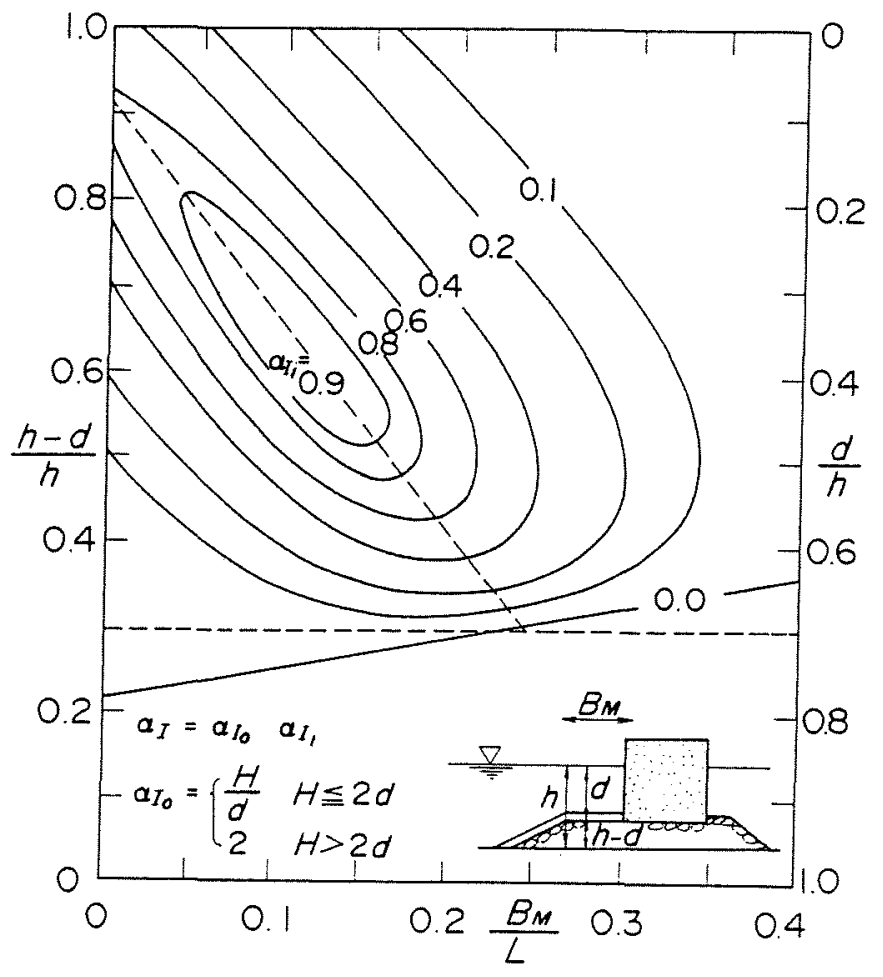

Fig. 4.23 Calculation diagram of impulsive pressure coefficient

(Takahashi et al., 1994)

The value of $\alpha_{\mathrm{I}}$ reaches a maximum of 2 at $\mathrm{B}_{\mathrm{M}} / \mathrm{L}=0.12, \mathrm{~d} / \mathrm{h}=0.4$, and $\mathrm{H} / \mathrm{d}>2$. When $\mathrm{d} / \mathrm{h}>$ $0.7, \alpha_{1}$ is always close to zero and is less than $\alpha_{2}$. It should be noted that the impulsive pressure significantly decreases when the angle of incidence $\theta$ is oblique.

(4) Modification factors $\left(\lambda_{1}, \lambda_{2}\right.$, and $\left.\lambda_{3}\right)$

For the ordinary vertical breakwater, $\lambda_{1} \lambda_{2}$, and $\lambda_{3}$ are taken as unity since the Goda formula was originally proposed to describe this type of breakwater. The modification factor $\lambda_{1}$ represents the reduction or increase of the wave's slowly-varying pressure component, $\lambda_{2}$ represents changes in the breaking pressure component (dynamic pressure component or impulsive pressure component), while $\lambda_{3}$ represents changes in the uplift pressure. These modification factors are explained in Chapters 5 and 6 for other types of caisson breakwaters.

\section{(5) Design wave height}

The wave height and length applied to calculate the design wave forces are those of the highest wave in the design sea state. The height of this wave is taken as $\mathrm{H}_{\mathrm{D}}=\mathrm{H}_{\max }=\mathrm{H}_{1 / 250}=1.8 \mathrm{H}_{1 / 3}$ seaward of the surf zone, or within the surf zone as the largest wave height $\mathrm{H}_{\mathrm{b}}$ of random breaking waves at the water depth $h_{b}$. The term $H_{1 / 250}$ is the average height of the highest one-two hundred fiftieth waves. 
The design wave height can be obtained using the following empirical formulae:

$$
\begin{array}{rlrl}
H_{1 / 3} & =K_{s} H_{0}^{\prime} & : h / L_{0} \geq 0.2 \\
& =\min \left\{\left(\beta_{0} H_{0}^{\prime}+\beta_{1} h\right), \beta_{\max } H_{0}^{\prime}, K_{s} H_{0}^{\prime}\right\} & : h / L_{0}<0.2 \\
H_{\max }=H_{1 / 250}=1.8 K_{s} H_{0}^{\prime} & : h / L_{0} \geq 0.2 \\
& =\min \left\{\left(\beta_{0}{ }^{*} H_{0}^{\prime}+\beta_{1}{ }^{*} h\right), \beta_{\max }{ }^{*} H_{0}^{\prime}, 1.8 K_{s} H_{0}^{\prime}\right\} & : h / L_{0}<0.2
\end{array}
$$

Table 4.1 Coefficients for approximate estimation of wave height within the surf zone (Goda, 1985)

\begin{tabular}{c|c}
\hline Coefficients for $H_{1 / 3}$ & Coefficients for $H_{\max }$ \\
\hline$\beta_{0}=0.028\left(H_{0}^{\prime} / L_{0}\right)^{-0.38} \exp \left[20 \tan ^{1.5} \theta\right]$ & $\beta_{0}{ }^{*}=0.052\left(H_{0}^{\prime} / L_{0}\right)^{-0.38} \exp \left[20 \tan ^{1.5} \theta\right]$ \\
$\beta_{1}=0.52 \exp [4.2 \tan \theta]$ & $\beta_{1}{ }^{*}=0.63 \exp [3.8 \tan \theta]$ \\
$\beta_{\max }=\max \mid 0.92,0.32\left(H_{0}^{\prime} / L_{0}\right)^{-0.29}$ & $\beta_{\max }{ }^{*}=\max \left(1.65,0.53\left(H_{0}^{\prime} / L_{0}\right)^{-0.29}\right.$ \\
$\times \exp [2.4 \tan \theta]]$ & $\times \exp [2.4 \tan \theta]]$ \\
\hline
\end{tabular}

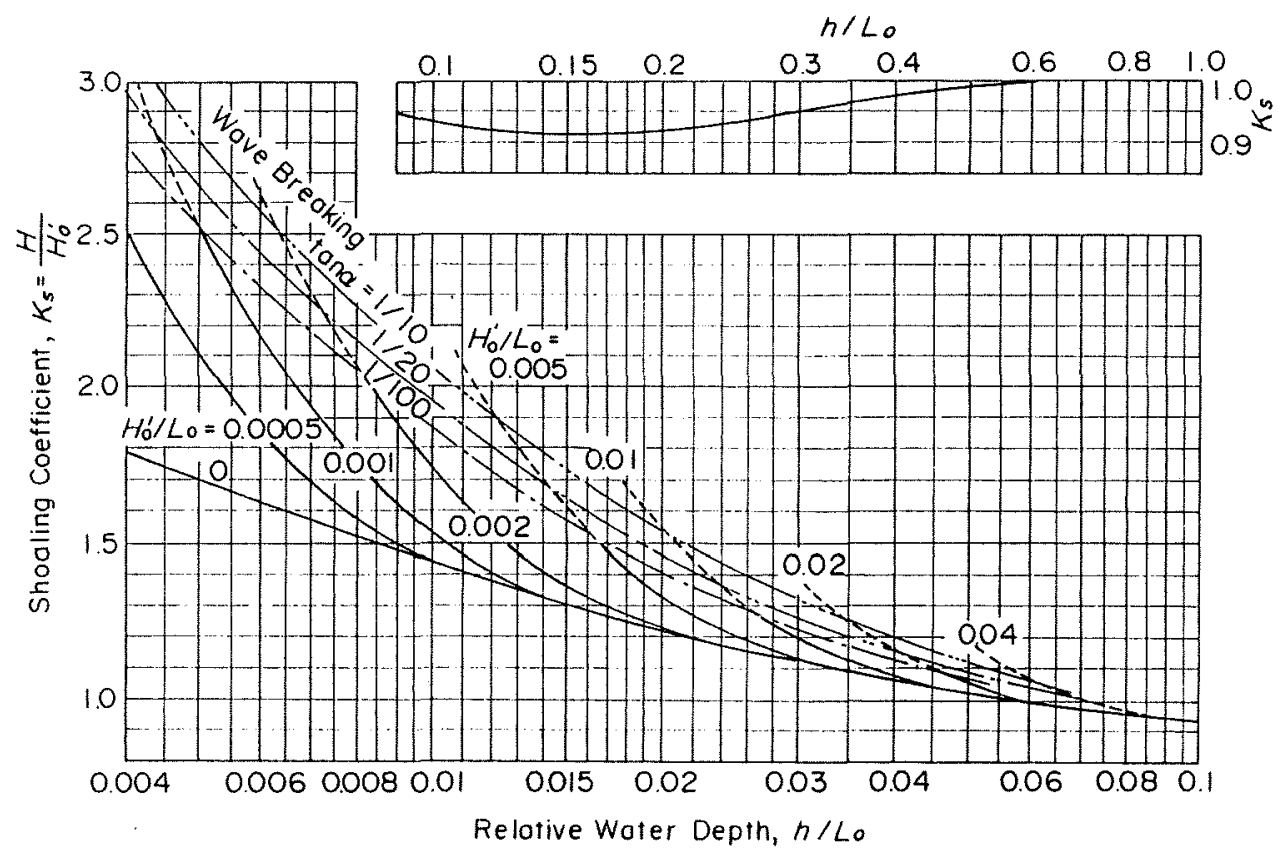

Fig. 4.24 Diagram of nonlinear wave shoaling (Goda, 1985)

where $\min (a, b, c)$ represents the minimum value among $a, b$, and $c$. Other parameters such as $\beta_{o}$ and $\beta^{*}{ }_{0}$ have been formulated as indicated in Table 4.1. The nonlinear shoaling coefficient $K_{s}$ can be read from Fig.4.24, while $\mathrm{H}_{\mathrm{o}}^{\prime}$ is the equivalent deepwater wave which is hypothetically assumed to include the effect of wave transformation due to wave diffraction and refraction. Equations (4.34) and (4.35) are therefore solely used for evaluating the effect of wave transformation due to wave shoaling and breaking. 
It should be noted that the design water depth is not the site's water depth $h$ but the water depth $h_{b}$ at a distance $5 \mathrm{H}_{1 / 3}$ seaward of the breakwater. By using $h_{b}$, the design wave height will increase, especially when the sea bottom slope is steep, and the design wave pressure will to a ceratin extent increase to include the effect on the wave pressure due to the sea bottom slope.

(6) Wave direction

As shown in Fig. 4.25, the wave angle $\theta$ is the angle between the direction of wave approach and a line normal to the breakwater alignment. Starting from its principal direction, the wave direction should be rotated toward the line normal to the breakwater alignment by up to $15^{\circ}$. This adjustment is made to compensate for both the uncertainty in estimating the wave direction and the waves' directional spreading.

\subsubsection{Stability Examination of an Upright Wall}

(1) Sliding and overturning

The design of a breakwater's upright section must be stable against sliding and overturning (Fig. 4.26), and to accomplish this, safety factors against sliding and overturning must be greater than 1.2. In most cases, sliding is more severe than overturning, especially when the breakwater crown is relatively low. The safety factor against sliding due to wave action, $\mathrm{SF}_{\mathrm{s}}$, is defined as follows:

$$
S F_{s}=\mu\left(W_{0}-U\right) / P
$$

where $\mu$ denotes the coefficient of (static) friction between the upright section and rubble mound, $\mathrm{w}_{\mathrm{o}}$ the weight of the upright section per unit extension in still water, $U$ the total uplift force per unit extension, and $\mathrm{P}$ the total horizontal wave force per unit extension calculated by Eqs. (4.17) to (4.27). $\mu$ between a concrete slab and rubble stones is usually taken as 0.6 .

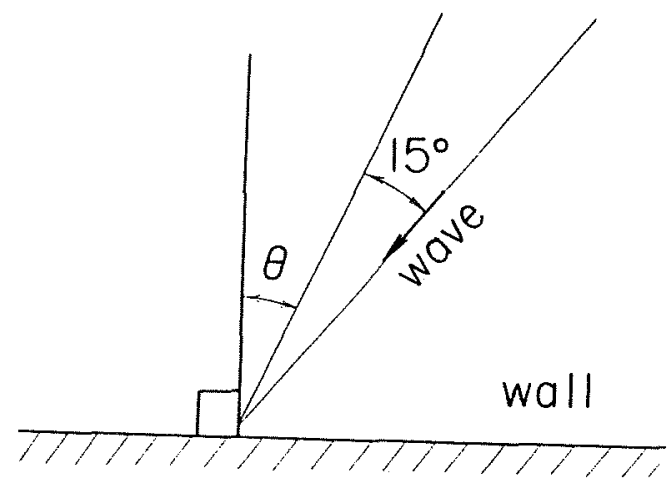

Fig. 4.25 Angle of wave approach

(a)

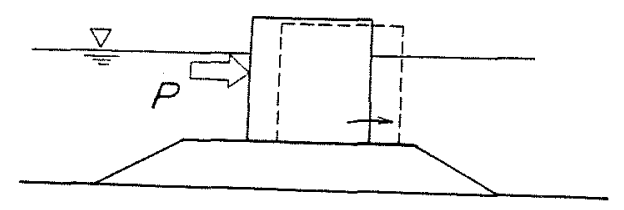

(b)

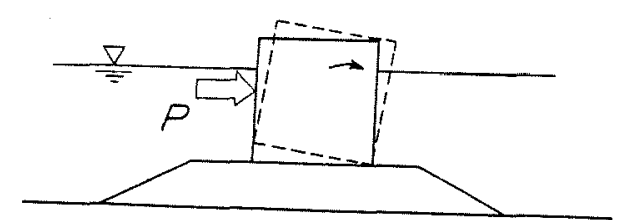

Fig. 4.26 Sliding and overturning of upright section

The safety factor against overturning of the vertical wall section, $\mathrm{SF}_{t}$, is defined as

$$
S F_{t}=\left(W_{0} t-M_{U}\right) / M_{P}
$$


where $\mathrm{t}$ denotes the horizontal distance between the center of gravity and the heel of the upright section, $M_{u}$ the uplift moment around the heel of the upright section, and $M_{p}$ the moment due to the horizontal pressure around the heel of the upright section.

(2) Bearing capacity of the rubble foundation

To fully determine the stability of vertical wall breakwaters, the bearing capacity of the rubble mound and subsoil must be investigated while subjected to inclined and eccentric loads produced by the weight of the upright section and wave forces. In the past, a complex procedure was used to evaluate the stability of a gravity-type structure situated on a rubble mound. In this procedure, a trapezoidal or triangular distribution of bearing pressure is assumed to exist beneath the upright wall as shown in Fig. 4.27, where the total bearing pressure is equal to $\mathrm{W}_{\mathrm{e}}\left(=\mathrm{W}_{\mathrm{o}}-\mathrm{U}\right)$ and the moment due to the bearing pressure should be equal to $M_{e}$ (= $\left.W_{o} t-M_{u}-M_{p}\right)$. The bearing pressures $q_{1}$ and $q_{2}$ can be calculated using

$$
\begin{aligned}
t_{e}>B / 3: q_{1} & =\left(2 W_{e} / B\right)\left(2-3 t_{e} / B\right) \\
q_{2} & =\left(3 W_{e} / B\right)\left(2 t_{e} / B-1\right) \\
t_{e} \leq B / 3: q_{1} & =\left(2 W_{e}\right) / 3 t_{e} \\
q_{2} & =0 \\
t_{e}=M_{e} / W_{e} &
\end{aligned}
$$
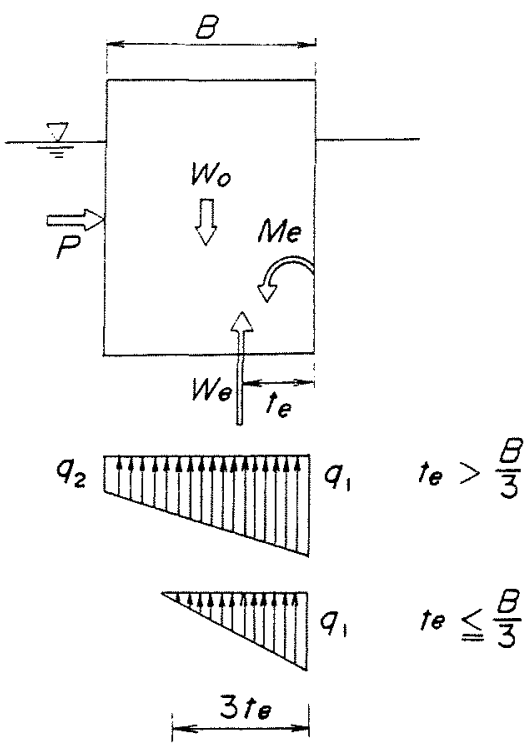

Fig. 4.27 Bearing pressure
The maximum bearing pressure, sometimes called toe pressure, was previously taken as 40 to $50 \mathrm{tf} / \mathrm{m}^{2}$ (400 to $500 \mathrm{kN} / \mathrm{m}^{2}$ ), although this limit was later increased to $60 \mathrm{tf} / \mathrm{m}^{2}$ $\left(600 \mathrm{kN} / \mathrm{m}^{2}\right)$ or greater, especially for deepwater breakwaters.

Kobayashi et al. (1987) proposed a new calculation method for the bearing capacity of gravity-type structures situated on a rubble mound. They used the simplified

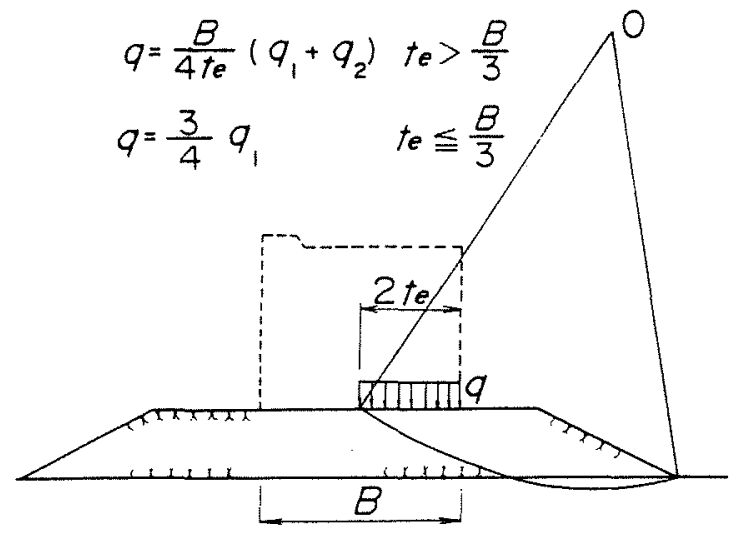

Fig. 4.28 Circular slip failure of rubble mound and sea bed 
Bishop method of circular slip failure analysis (Fig. 4.28), in which the apparent cohesion for rubble is introduced based on the results of large tri-axial tests. The standard values, the apparent cohesion $\mathrm{C}=2 \mathrm{tf} / \mathrm{m}^{2}$, and the angle of shear resistance $\phi=35^{\circ}$, are applied for normal rubble which is predominately used in Japan for harbor construction.

In Japan a common practice exists to evaluate the internal angle of friction in sand $\phi$ from the $\mathrm{N}$ value obtained from a standard penetration test. The applied standard value of $\phi$ is dependent on the $\mathrm{N}$ value, i.e.,

$$
\begin{aligned}
& \phi=40^{\circ} \quad \text { for sand with } N<10 \\
& \phi=45^{\circ} \quad \text { for sand with } N>10
\end{aligned}
$$

The safety factor according to the simplified Bishop method must not be less than 1.0 for a breakwater subjected to wave action.

(4) Stability of the block masonry wall

The stability of the block masonry wall can be determined using the extended Goda pressure formula, and it should be examined at each level of the blocks, namely, the stability of all the blocks above each level should be examined. For example, the stability above the second level of the block can be verified as shown in Fig. 4.29. The pressure existing between blocks, which acts as an uplift pressure on the upper block, can be assumed to be equal to the horizontal pressure occurring at the same level (Tanimoto and Ojima, 1983). It should be noted that the friction coefficient between flat concrete is 0.5 , and that any interlocking effect between the blocks should be considered if present.

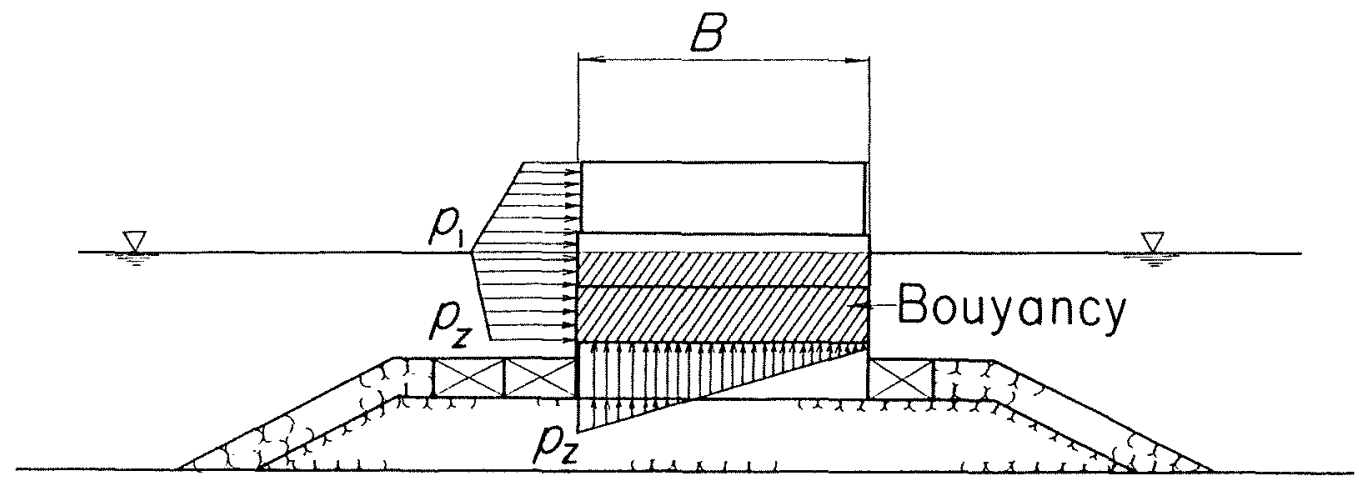

Fig. 4.29 Stability examination for block masonry wall

\subsubsection{Other Problems Related to Wave Forces}

(1) Concave section

Since the breakwater alignment is usually somewhat complex and a vertical breakwater is so reflective, the reflection and diffraction from it should be taken into account in wave force calculations. 
Figure 4.30 shows the calculated distribution of the ratio of the wave height to the incident wave, $\mathrm{K}_{\mathrm{d}}$, in front of a vertical breakwater which has an alignment forming two lines having a concaved shape with respect to the incident waves. Due to the reflection from one of the lines of the breakwater, the wave height along the vertical wall is not simply 2 for standing waves. It is obvious that the value of $\mathrm{K}_{\mathrm{d}}$ exceeds 2.0 . The amplification factor of the incident wave to each part of the breakwater can be obtained by $\mathrm{K}_{\mathrm{d}} / 2$. It should be noted that the amplification factor is limited by standing wave breaking and that its maximum value is recommended to be 1.4 based on carrying out a series of experiments.

(2) Meandering effect

Another problem related to the plane shape of the breakwater is the so-called meandering effect (Ito et al., 1972). Figure 4.31 shows the calculated value of $\mathrm{K}_{d}$ for a single-line detached
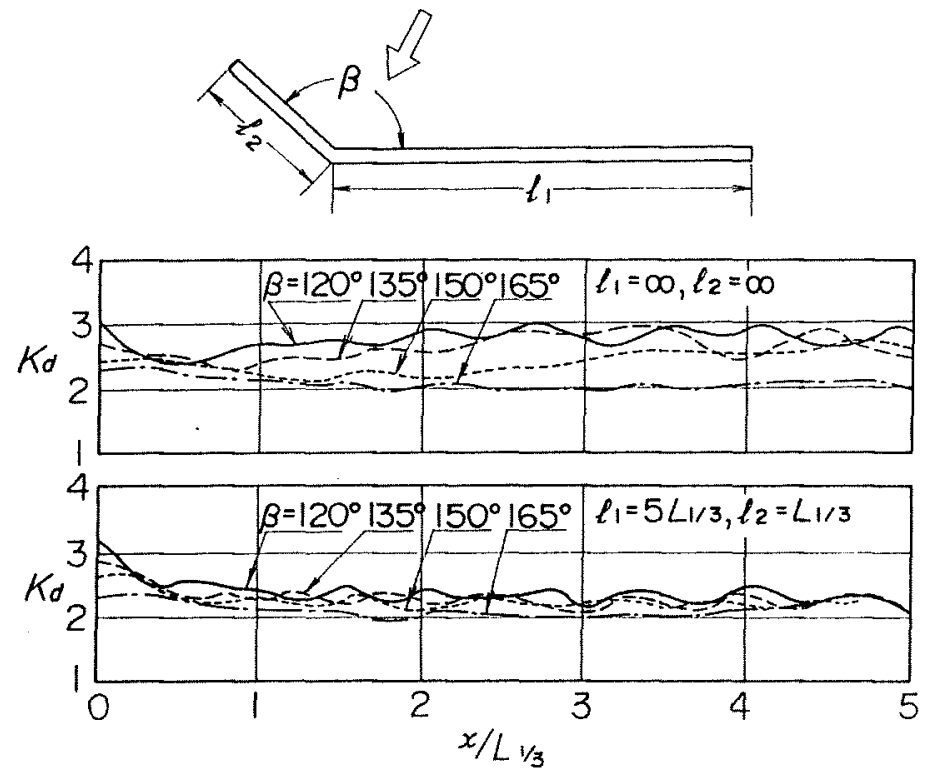

Fig. 4.30 Wave height distribution along concaved breakwater alignment

(Kobune et al., 1976)

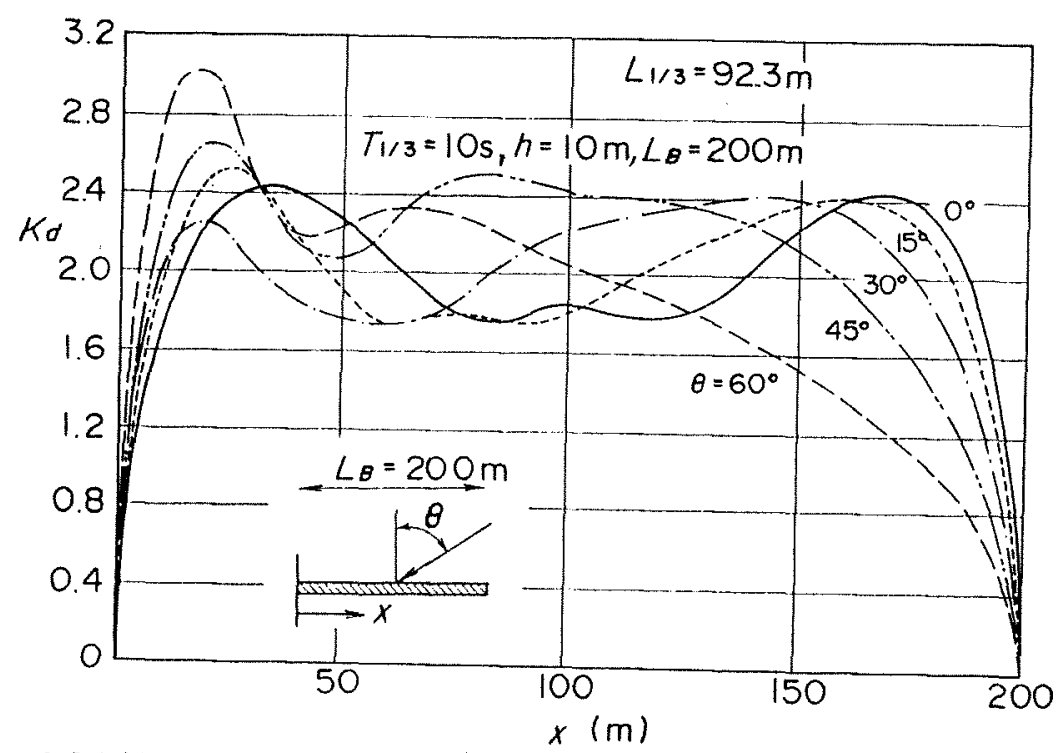

Fig. 4.31 Wave height distribution along detached one-line breakwater

(Goda et al., 1971) 
breakwater with length $L_{B}=200 \mathrm{~m}$ and wave length $L_{1 / 3}=92.3 \mathrm{~m}$, where the wave height fluctuates along the breakwater alignment and significantly increases near the breakwater head. If waves exceeding the design wave height attack the breakwater, and if the breakwater caissons slide, the shape of these caissons will subsequently form a meandering shape.

\section{(3) Long caisson}

When a relatively long caisson is erected in an oblique sea, the wave crest moves along the vertical wall as shown in Fig. 4.32, i.e., the total wave force can be averaged along the breakwater alignment. The solid line shows the averaging factor $\delta_{\mathrm{B}}$ of this caisson as a function of the wave angle and the relative length of the caisson. It is calculated using small amplitude wave theory.

Although $\delta_{B}$ is small when $\theta$ is large and the caisson's relative length is long, the stability against horizontal rotation of the caisson nevertheless becomes crucial. The dotted line shows the limit of $\delta_{\mathrm{B}}$ when considering the stability against rotation, being about 0.8 .

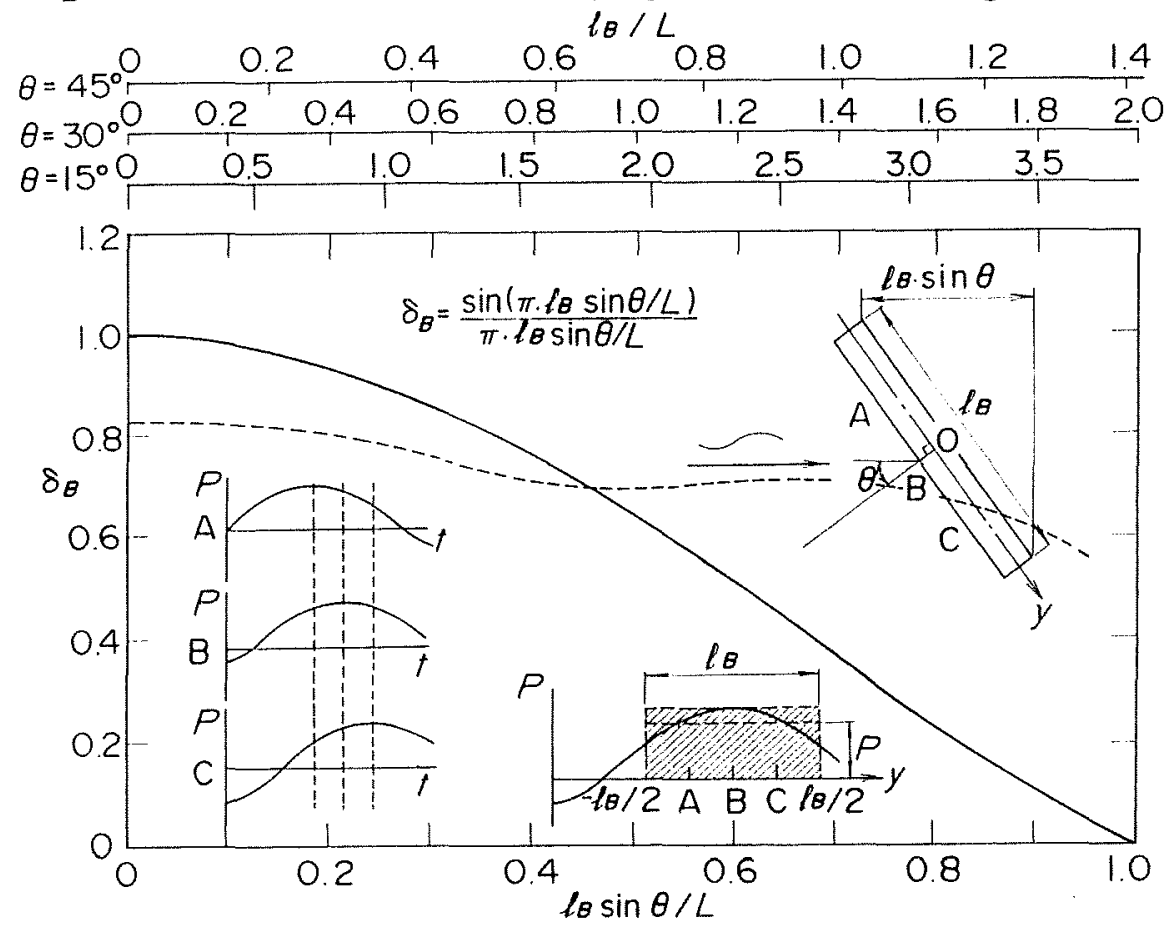

Fig. 4.32 Averaging of wave force by a long caisson (Takahashi et al., 1990)

\section{(4) Coefficient of friction}

The coefficient of friction $\mu$ has been measured in model and prototype measurements, with Table 4.2 showing its recommended values. In order to increase $\mu$, an asphalt mat is sometimes placed underneath the caisson bottom. In such a case, the recommended friction factor is 0.7 . However, it should be noted that if $\mu$ becomes large, failure due to sliding might occur in other places, i.e., betweenthe rubble stones or between the rubble mound and foundation soil.
Table 4.2 various coefficient of friction

\begin{tabular}{|l|l|}
\hline Concrete and concrete & 0.5 \\
\hline Concrete and base rock & 0.5 \\
\hline Concrete and rubble stone & 0.6 \\
\hline Rubble stone and rubble stone & 0.8 \\
\hline
\end{tabular}


(5) High crest or low crest breakwaters

Wave overtopping is allowed for ordinary breakwaters, and therefore, the wave force on the vertical wall is reduced in comparison with that on an infinitely tall vertical wall. The Goda pressure formula, however, still includes this overtopping effect because experiments carried out to establish the formula were done with an ordinary crown height.

Mizuno et al. (1993) conducted a series of experiments and found that a crown height which does not allow wave overtopping creates a larger wave force compared to that determined by the Goda formula. They pointed out that impulsive pressures act even when a spilling-type breaker acts on the vertical wall with a high crown height (Fig. 4.33). This occurs because the vertical wave front induced by the spilling breaker, which is located on the top part of the wave, hits the vertical wall if the crown is

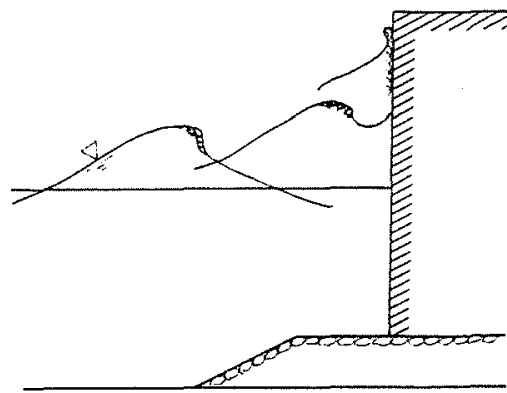

Fig. 4.33 Wave hitting a high crown wall

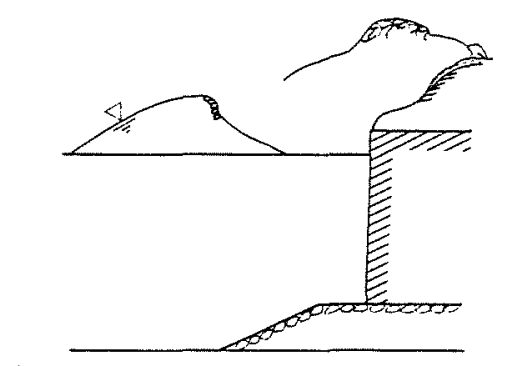

Fig. 4.34 Wave overtopping a low crown wall high, while it does not hit the wall if the crown is at an ordinary height.

On the other hand, the wave pressure on a wall with a very low crown is significantly reduced due to overtopping (Fig. 4.34). Nakada et al. (1984) conducted a series of experiments to investigate the effect of the crown height, and subsequently proposed the use of modification factors for low-crown-height vertical walls.

\subsection{Design of Rubble Mound Foundation}

\subsubsection{Armor for Rubble Foundation}

(1) Wave force on armors

The rubble mound foundation under a vertical wall should be protected to prevent it from scattering due to wave actions. This is accomplished by covering it with armor stones or concrete blocks. Figure 4.35 illustrates the movement of the armor stones in observed sections, where in the upper figure, the stones are scattered from the slope of the mound when incident waves approach perpendicular to the breakwater alignment. Note the occurrence of heavy scattering around the breakwater head. In the middle figure where $\theta=45^{\circ}$, the armor stones not only scatter away from the slope, but in the flat berm near the caisson as well. The stones also scatter around the breakwater head on its downstream side and especially at the caisson edge. In the lower figure with $\theta=60^{\circ}$, the stones on the slope do not move, though they significantly scatter in the flat berm, especially near the caisson. 
It is postulated that the stability of armor stones or blocks is mainly threatened by the water particle velocity induced by the waves, i.e., by the drag and uplift forces produced by the water particle velocity. In Fig. 4.35, the water particle velocity is high where the stones moved, which supports this hypothesis.

Figure 4.36 shows a hodograph of the water particle velocity at the breakwater trunk. When $\theta=0$, a water particle only moves perpendicular to the breakwater alignment and the velocity is almost zero near the vertical walls, being largest at the node of the clapotis (standing wave). As $\theta$ increases, the water velocity component parallel to the breakwater alignment increases, with the velocity near the vertical wall also significantly increasing.

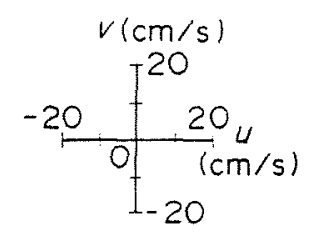

$T=2.92 \mathrm{~s}, H=10.0 \mathrm{~cm}$
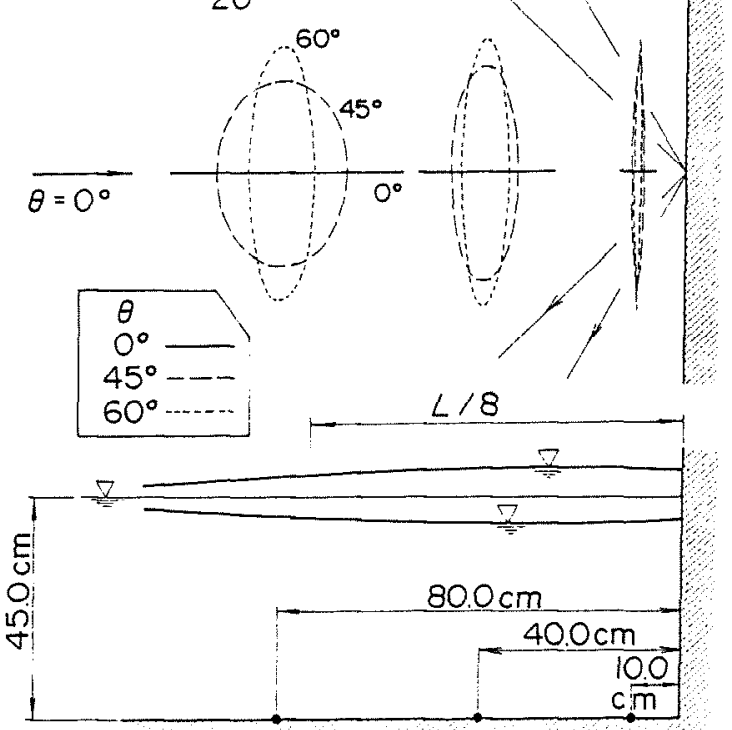

Fig. 4.36 Water particle velocity hodograph near a vertical wall

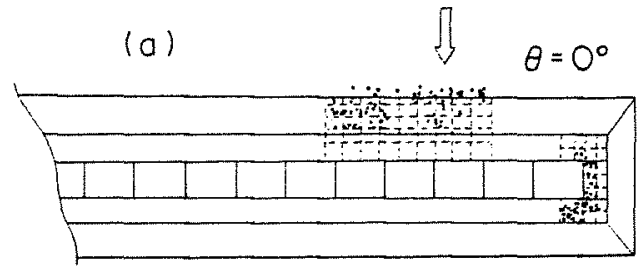

$T_{1 / 3}=2.92 \mathrm{~s}$

$H_{1 / 3}=17.5 \mathrm{~cm}$

(b)

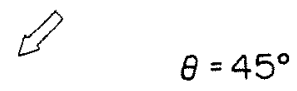

(c)

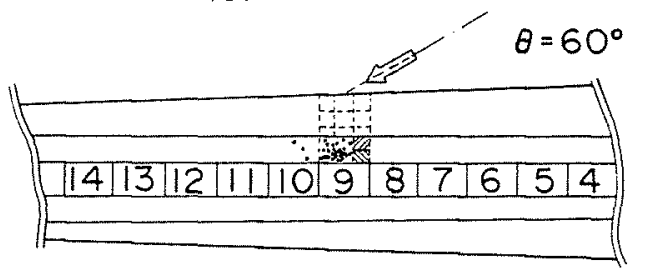

Fig. 4.35 Scattering of armor stones of rubble foundation (Kimura et al., 1990)

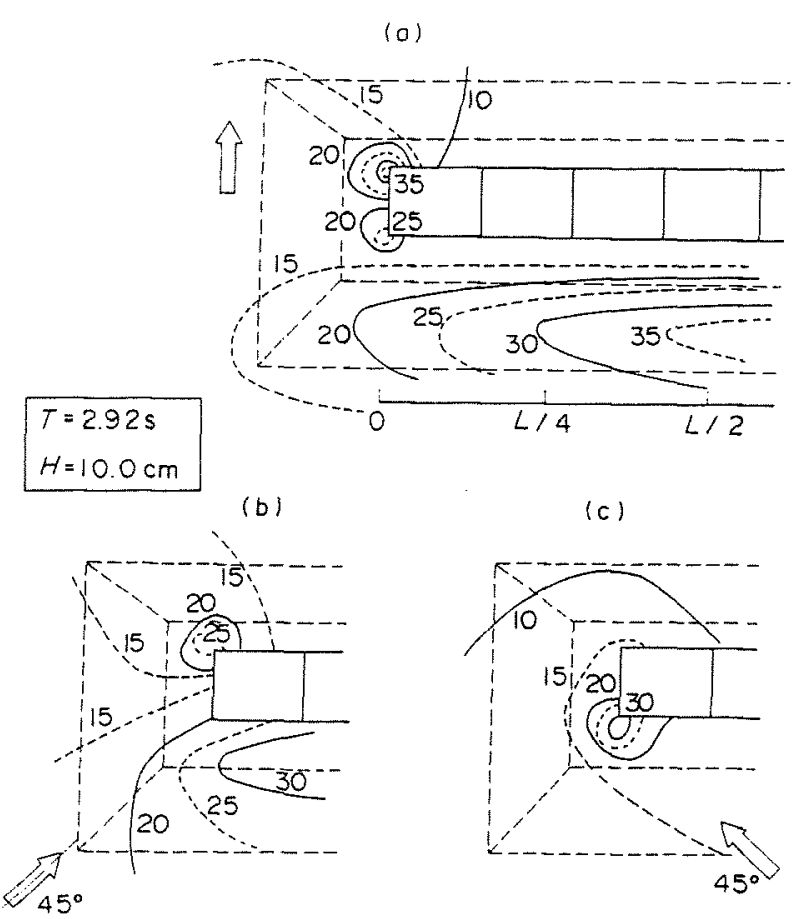

Fig. 4.37 Water particle velocity distribution around the breakwater head 
Figure 4.37 shows the distribution of the peak water particle velocity around the breakwater head, where it is revealed that a high velocity occurs around the edge of the upright section.

To withstand velocity-induced forces, the armor stones or blocks should have enough weight, which can be evaluated using Isbash's equation for stones embedded in the bottom of a sloped channel, i.e.,

$$
W=\left(\pi \gamma_{r} U^{6}\right) /\left\{48 g^{3} y^{6}\left(S_{r}-1\right)^{3}(\cos \alpha-\sin \alpha)^{3}\right\}
$$

where

W : necessary weight of armor stone

$\gamma_{\mathrm{r}}$ : specific weight of armor stone $\left(=\rho_{\mathrm{r}} \mathrm{g}\right)$

$y$ : Ishbash number (1.2 for embedded stones and 0.86 for stones placed on a flat bottom)

$\mathrm{S}_{\mathrm{r}}$ : specific gravity of stone

$\mathrm{U}$ : water particle velocity on the stone

$\mathrm{g}$ : acceleration of gravity

$\alpha:$ bottom slope

(2) Necessary weight of armor

Ishbash's equation relates the stable weight of stones to the water particle velocity. Brebner and Donnelly (1962), however, proposed a method to directly determine the necessary weight from the wave height. In their method, the stable weight of armor units W can be expressed as

$$
W=\left(\gamma_{r} H_{1 / 3}{ }^{3}\right) /\left\{N_{s}{ }^{3}\left(S_{r}-1\right)^{3}\right\}
$$

where $\gamma_{r}$ denotes the specific weight of the armor unit, $\mathrm{H}_{1 / 3}$ the design significant wave height, and $N_{s}$ the stability coefficient. This is a kind of Hudson's equation, which uses $N_{s}$ instcad of $K_{D}$ $\cot \alpha$, such that

$$
H_{1 / 3} /\left\{\left(S_{r}-1\right)\left(W / \gamma_{r}\right)^{1 / 3}\right\}=N_{s}
$$

$\mathrm{N}_{\mathrm{s}}$ depends on variables such as the shape of the armor unit, their manner of placement, the shape of the rubble mound foundation, and wave conditions (height, period, and direction). Tanimoto et al. (1982) proposed a formula to calculate the stability cocfficient for two layers of quarry stones, being based on analytical considerations and the results of random wave experiments. Takahashi et al. (1990) modified Tanimoto's formula so that it can be applied to obliquely incident waves, i.e., 


$$
\begin{aligned}
N_{S}=\max & \left\{1.8,1.3\left\{(1-\kappa) / \kappa^{1 / 3}\right\}\left(h^{\prime} / H_{1 / 3}\right)\right. \\
+ & 1.8 \exp \left[-1.5\left\{(1-\kappa)^{2} / \kappa^{1 / 3}\right\}\left(h^{\prime} / H_{1 / 3}\right)\right]
\end{aligned}
$$

in which

$$
\begin{aligned}
& \kappa=\kappa_{1}\left(\kappa_{2}\right)_{B} \\
& \kappa_{1}=\left(2 k h^{\prime}\right) / \sinh 2 k h^{\prime} \\
& \left(\kappa_{2}\right)_{B}=\max \left\{\alpha_{S} \sin ^{2} \theta \cos ^{2}\left(k B_{M} \cos \theta\right), \cos ^{2} \theta \sin ^{2}\left(k B_{M} \cos \theta\right)\right\}
\end{aligned}
$$

where $\max \{a, b\}$ denotes the maximum of $a$ and $b, h$ the water depth above the rubble mound foundation, $L$ the wavelength corresponding to the significant wave period at the depth $h^{\prime}, k$ the wave number $\left(=2 \pi L^{\prime}\right)$, and $B_{M}$ the berm width as shown in Fig. 4.38. $\alpha_{s}$ is a correction factor obtained using wave tank experiments and is 0.45 .

Equation (4.44) is also extended to include the stability of the rubble mound armor layer in the breakwater head. In the breakwater head, the term $\left(\kappa_{2}\right)_{\mathrm{T}}$ is used instead of $\left(\kappa_{2}\right)_{\mathrm{B}}$ to represent the water particle velocity at the breakwater head, where

$$
\begin{aligned}
& \kappa=\kappa_{1}\left(\kappa_{2}\right)_{T} \\
& \left(\kappa_{2}\right)_{T}=\left(\alpha_{s} \tau^{2}\right) / 4
\end{aligned}
$$

where $\tau$ expresses the ratio of the water particle velocity at the breakwater head to that of the incident wave an is determined to be 1.4 for the wave angle less than $45^{\circ}$.

Figure 4.38 shows sample calculations to determine the necessary weight of armor stones. The shape of the breakwater is indicated and the necessary weight for different wave conditions and water depths in front of the vertical wall are calculated. When $\theta=60^{\circ}$, the weight is the largest, whereas that for $\theta=30^{\circ}$ is the smallest. It is obvious to see that the weight

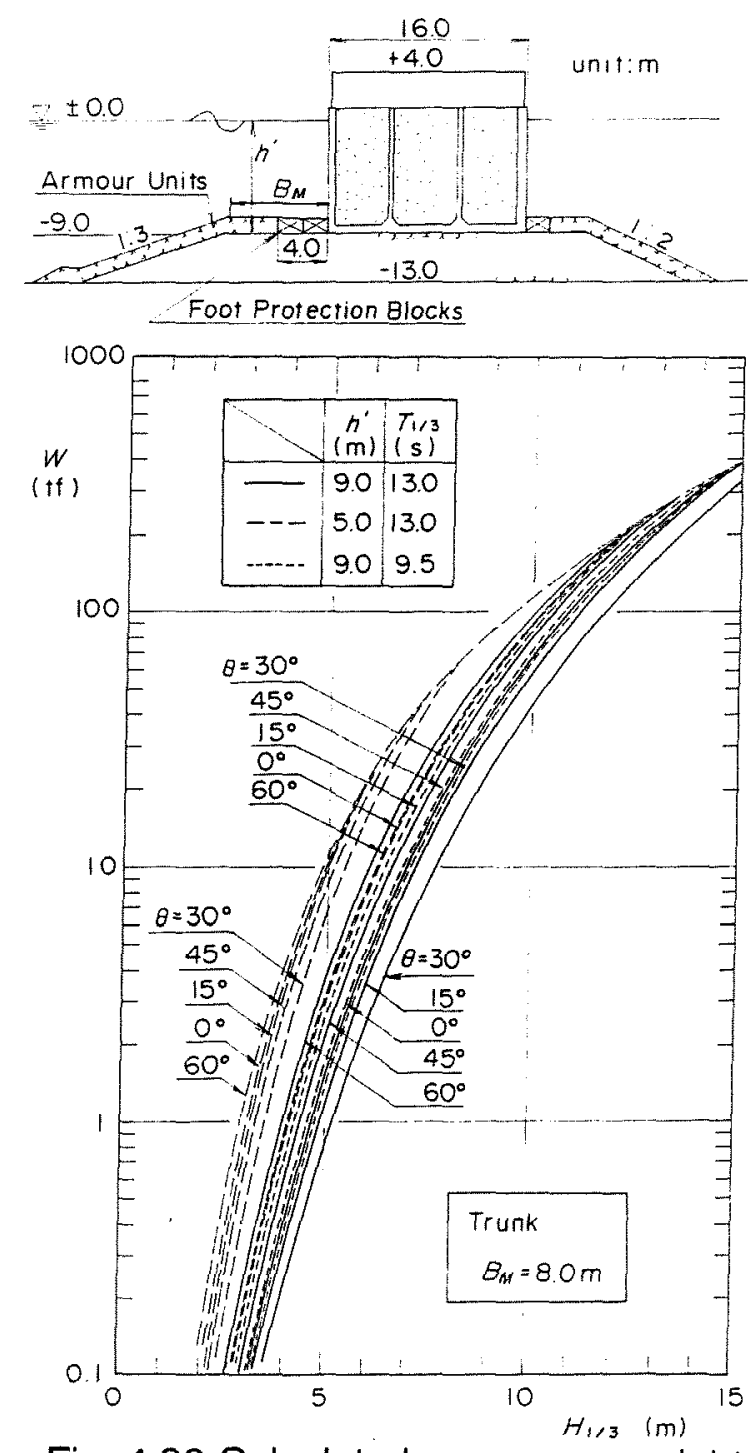

Fig. 4.38 Calculated necessary weight for armor stones for rubble foundation 
increases as the wave period increases or the water depth in front of the wall decreases. When the weight is large, armor concrete blocks must be used to cover the rubble mound.

\subsubsection{Foot Protection of the Upright Wall}

Foot protection concrete blocks are usually placed in front of the upright section. Figure 4.39 shows the failure modes related to such foot protection, where as the foot protection blocks are removed, erosion of rubble mound takes place near the foot of the upright section. Also, through-wash, (rapid current through the rubble mound) will cause scouring of the sand under the rubble mound; thus the foot-protection concrete blocks must prevent the direct intrusion of wave pressure into the rubble mound and also the subsequent pressure-induced current in the mound. These blocks work as a filter and also provide weight for the rubble mound.

The critical force on a foot protection block is that due to the pressure difference between the upper and lower faces of the block. The absolute value of the wave pressure under the block was

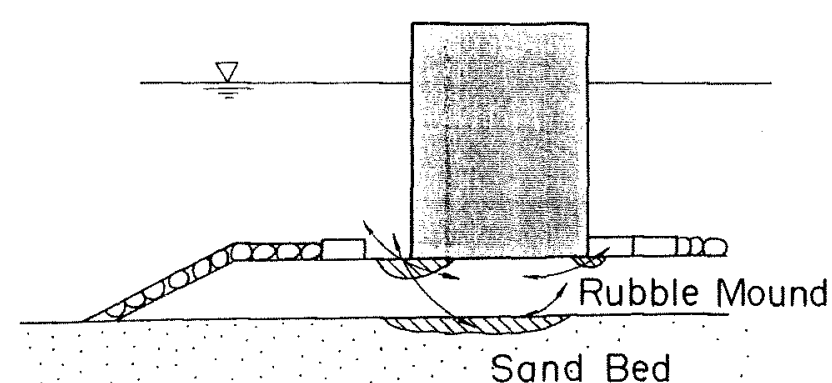

Fig. 4.39 Failure due to damage to toe protection blocks

Table 4.3 Specification of footprotection blocks

\begin{tabular}{|c|c|c|}
\hline$t^{\prime}(\mathrm{m})$ & $1(\mathrm{~m}) \times \mathrm{b}(\mathrm{m}) \times \mathrm{t}^{\prime}(\mathrm{m})$ & $W(\mathrm{t})$ \\
\hline$\sim 0.8$ & $2.5 \times 1.5 \times 0.8$ & 6.2 \\
\hline$\sim 1.0$ & $3.0 \times 2.5 \times 1.0$ & 15.6 \\
\hline$\sim 1.2$ & $4.0 \times 2.5 \times 1.2$ & 24.8 \\
\hline$\sim 1.4$ & $5.0 \times 2.5 \times 1.4$ & 37.0 \\
\hline$\sim 1.6$ & $5.0 \times 2.5 \times 1.6$ & 42.3 \\
\hline$\sim 1.8$ & $5.0 \times 2.5 \times 1.8$ & 47.6 \\
\hline$\sim 2.0$ & $5.0 \times 2.5 \times 2.0$ & 52.9 \\
\hline$\sim 2.2$ & $5.0 \times 2.5 \times 2.2$ & 58.2 \\
\hline
\end{tabular}

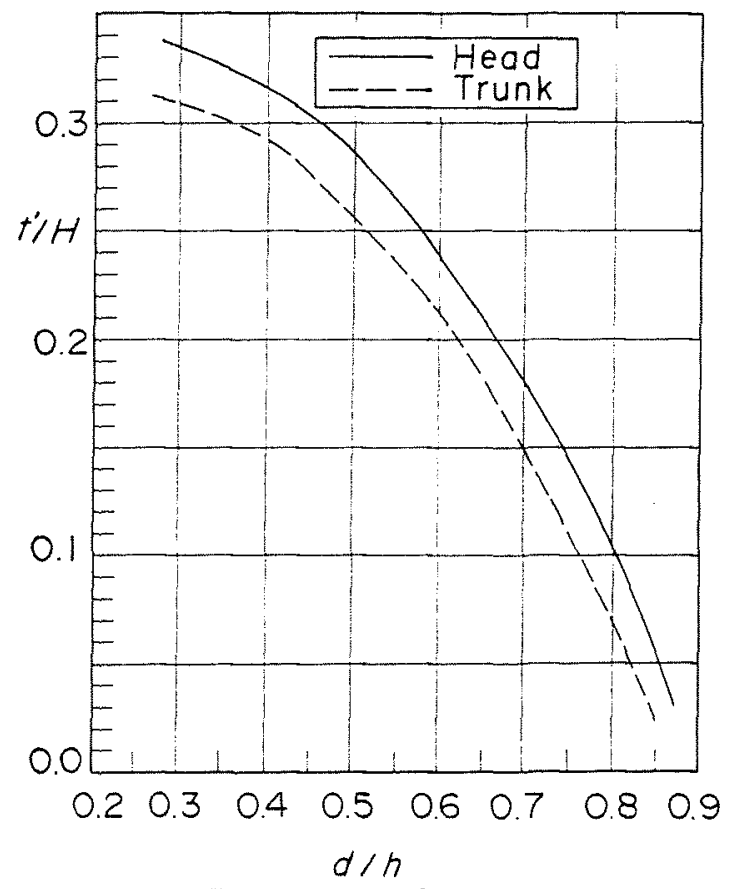

Fig. 4.40 Thickness of foot-protection blocks (Ushijima et al., 1988)

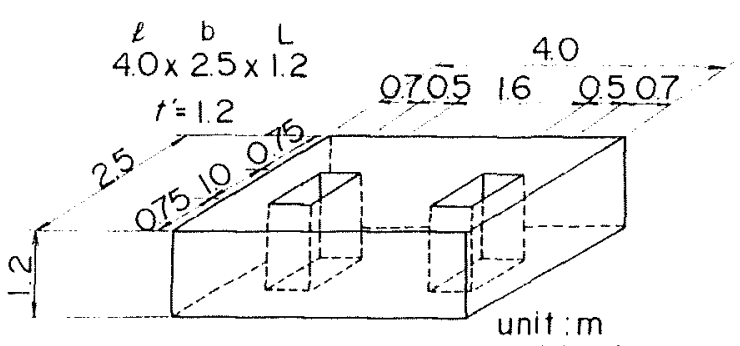

Fig. 4.41 Foot-protection block 
experimentally found to be 5 to $40 \%$ less than that on the upper side. This pressure difference can be reduced and the stability increased by making holes in the blocks, although if the holes are too large, the filtering effect is reduced. An opening ratio of $10 \%$ is therefore recommended by Tanimoto et al. (1982).

Several ways exist to empirically determine the necessary weight. Figure 4.40 shows a diagram to determine the thickness $t^{\prime}$ of concrete blocks having a $10 \%$ opening, with the dimensions of the blocks being subsequently determined and summarized in Table 4.3. Figure 4.41 shows a concrete block with $\mathrm{t}^{\prime}=1.2 \mathrm{~m}$.

It should be noted that the foot protection blocks also act as armor blocks for the rubble mound as discussed in Section 4.4.1, especially in oblique seas and at the breakwater head. Therefore, they should be stable against the velocity-induced force.

Additionally, care should be taken to prevent the occurrence of scouring underneath the rubble foundation. Too thin a rubble mound may cause this type of scouring to occur due to severe wave actions, and consequently, a vinyle sheet is sometimes placed on the sand bed to prevent it.

\subsubsection{Toe Protection Against Scouring}

Figure 4.42 shows scouring damage at the toe of the rubble mound for a composite breakwater situated on a sandy seabed (Funakoshi, 1994). Due to the weight of the caisson, the entire breakwater slightly settles and the toe area is significantly scoured, which deepens the toe area by about 2 or $3 \mathrm{~m}$. Even though this toe erosion occurs, the caisson remains intact and the foot protection blocks and armor blocks of the rubble mound still function as designed. In actuality, one of the primary roles of the rubble mound and the foot protection blocks is to protect the caisson from such scouring.

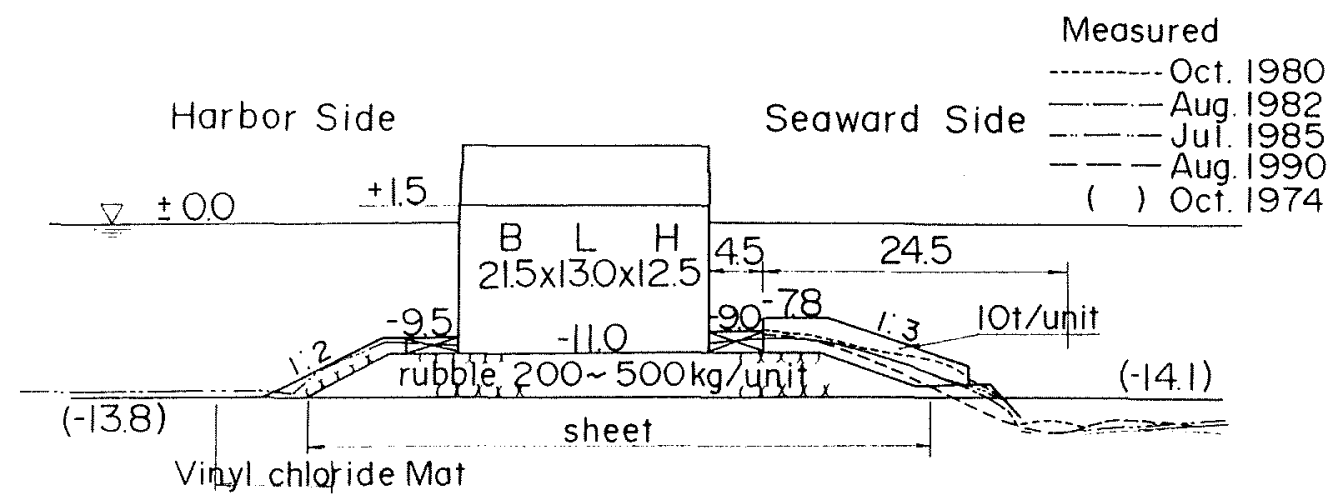

Fig. 4.42 Scour around rubble mound toe (Funakoshi et al., 1994)

The cause of toe area scouring is probably due to the strong wave-induced velocity. These velocities are especially increased by reflected waves from the vertical wall. However, the scouring mechanism is very complicated and has not yet been properly explained. Generally, two types of toe scouring exist: local scouring and large-scale sand movement.

Local scouring was investigated by Xie (1981), Irie et al., (1986), Oumeraci (1994), and others. 
Irie found the occurrence of $\mathrm{N}^{-}$and L-type scours, in which the former type scour is due to suspension of relatively fine sand which causes accretion at the node, while the later type is due to "bed load" of relatively coarse sand that causes erosion at the node and accretion at the loop. L-type scour appears to be predominant in proto type seas where erosion at the node is usually found.

Scour is usually inevitable for vertical breakwaters built on a sandy sea bottom. However, scour is not a fatal problem due to the protection features provided by the rubble mound. Nevertheless, scour protection should be included in breakwaters in which severe scouring is expected. There are several scour protection methods, e.g., the use of gravel, geotextile, or asphalt mats. These methods can prevent scouring to some extent, though no fully sufficient method has yet been realized.

\subsection{Evaluation of Sliding Distance of Caisson}

\section{(1)Equation of motion}

Figure 4.43 shows the forces acting on the caisson while sliding. $\mathrm{M}_{\mathrm{a}}$ is the added mass, $\mathrm{P}$ the horizontal force, $\mathrm{F}_{\mathrm{R}}$ the frictional resistance force, and $\mathrm{F}_{\mathrm{D}}$ the force related sliding velocity including the wave-making resistance force. The equation of motion describing caisson sliding is as follows:

$$
\left(\frac{W}{g}+M_{a}\right) \ddot{x}=P-F_{R}-F_{D}
$$

where $W$ is the caisson weight in the air, g the gravity, and $\ddot{x}$ the acceleration at the center of gravity of the caisson.

In the simplified sliding model, it is assumed that $\left.F_{R}=\mu\left(W^{\prime}-U\right)\right)$ with $\mu$ of a constant value, i.e. represents both the static and dynamic coefficients, and that $F_{D}$ is small enough to be neglected. Consequently, Eq. (4.50) is rewritten as follows:

$$
\left(\frac{W}{g}+M_{a}\right) \ddot{x}=P+\mu U-\mu W^{\prime}
$$

where $U$ the uplift force, the friction coefficient $\square, W^{\prime}$ the caisson weight in water.

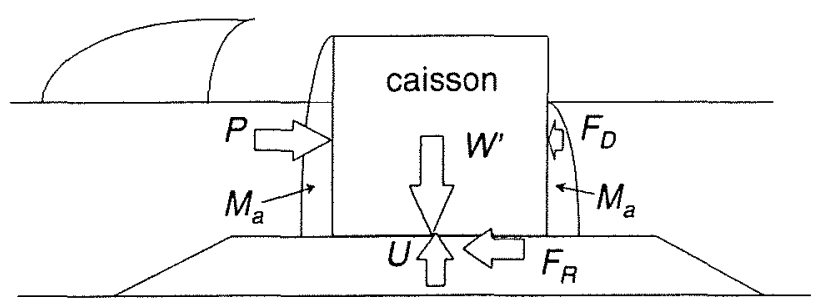

Figure 4.43. Forces acting on caisson during sliding 


\section{(2) Calculation of the sliding distance}

Sliding distance of the caisson can be calculated by integrating the acceleration twice with respect to time. The displacement $\mathrm{x}$ is obtained if the added mass $\mathrm{M}_{\mathrm{a}}$, the horizontal force $\mathrm{P}$, the uplift force $\mathrm{U}$, the friction coefficient $\square$, the caisson weight in water $\mathrm{W}^{\prime}$ and in the air $\mathrm{W}$ are known. In the proposed model, we assumed the added mass Ma is equal to $1.0855 \rho^{\prime} \mathrm{h}_{2}$, where $\square \rho$ is the density of water and h' the water depth in front of the caisson.

Figure 4.44 shows a time series of $\mathrm{P}(\mathrm{t})$ used to simulate caisson displacement, where $\mathrm{P}(\mathrm{t})$ is defined as follows:

$$
P(t)=\max \left\{P_{1}(t), P_{2}(t)\right\}
$$

$P_{1}(t)$ indicates a slowly varying component of the wave force represented by the sinusoidal curve, while $P_{2}(t)$ is an impulsive component represented by the triangular pulse. These are defined as follows:

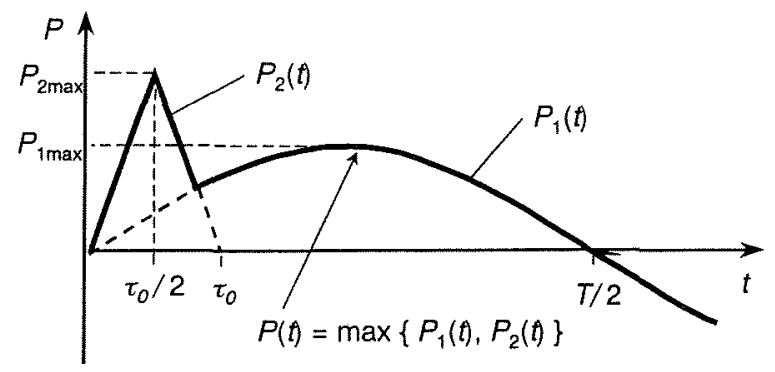

Figure 4.44 Wave force profile for sliding calculation.

$$
\begin{aligned}
P_{1}(t)=\gamma_{P} P_{1 \max } \sin \frac{2 \pi t}{T} & \\
P_{2}(t)=\frac{2 t}{\tau_{0}} P_{2 \max } \quad & :\left(0 \leq t \leq \frac{\tau_{0}}{2}\right) \\
& =2\left(1-\frac{t}{\tau_{0}}\right) P_{2 \max } \quad:\left(\frac{\tau_{0}}{2} \leq t \leq \tau_{0}\right) \\
& =0 \quad:\left(t \geq \tau_{0}\right) \\
\gamma_{P}=1-\frac{\pi}{P_{1 \max } T} \int_{t 1}^{t^{2}}\left(P_{2}(t)-P_{1 \max } \sin \frac{2 \pi t}{T}\right) d t & : P_{2}(t)-P_{1 \max } \sin \frac{2 \pi t}{T} \geq 0
\end{aligned}
$$

where $P_{1 \max }$ denotes the horizontal wave force calculated from the Goda pressure formula considering only the parameter $\alpha_{1}$, while $P_{2 \max }$ the force considering $\alpha_{1}$ and $\alpha^{*}, T$ the wave period and $\tau_{0}$ the duration of $P_{2}(t) . \alpha_{1}$ indicates a standing wave pressure component, while $\alpha^{*}$ an 
impulsive pressure component and defined as follows:

$$
\alpha^{*}=\max \left\{\alpha_{1}, \alpha_{2}\right\}
$$

where $\alpha_{1}$ denotes an impulsive pressure coefficient (Takahashi et al. 1994), while $\alpha_{2}$ a coefficient indicating the effect of impulsive pressure in the Goda formula.

$U(t)$ is also defined as follows:

$$
\begin{aligned}
U(t) & =\max \left\{U_{1}(t), U_{2}(t)\right\} \\
U_{1}(t) & =\gamma_{U} U_{\max } \sin \frac{2 \pi t}{T} \\
U_{2}(t) & =\frac{2 t}{\tau_{0}} U_{\max } \quad:\left(0 \leq t \leq \frac{\tau_{0}}{2}\right) \\
& =2\left(1-\frac{t}{\tau_{0}}\right) U_{\max } \quad:\left(\frac{\tau_{0}}{2} \leq t \leq \tau_{0}\right) \\
& =0 \quad:\left(t \geq \tau_{0}\right) \\
\gamma_{U}=1-\frac{\pi}{U_{\max } T} \int_{t 1}^{2}\left(U_{2}(t)-U_{\max } \sin \frac{2 \pi t}{T}\right) d t & : U_{2}(t)-U_{\max } \sin \frac{2 \pi t}{T} \geq 0
\end{aligned}
$$

where $U_{\text {max }}$ denotes the uplift force calculated from the Goda formula.

The caisson starts sliding when $(P+\mu U)$ becomes larger than $\mu W^{\prime}$. Peak values of $P(t)$ and $U(t)$ can be obtained by the Goda formula, but we still $\tau_{0}$ must be determined to evaluate sliding distance. We used a theoretical analysis and model experiments to determine $\tau_{0}$. Consequently, $\tau_{0}$ becomes as follows:

$$
\begin{aligned}
\tau_{0}=k \tau_{0 F} & \\
k=\left(\frac{1}{(\alpha *)^{0.3}+1}\right)^{2} & \\
\tau_{0 \mid F} & =\left(0.5-\frac{H}{8 h}\right) T \quad:\left(0<\frac{H}{h} \leq 0.8\right) \\
& =0.4 T \quad:\left(0.8<\frac{H}{h}\right)
\end{aligned}
$$


where $H$ denotes the wave height and $h$ the water depth. For a non-breaking wave pressure, $\tau_{0}$ is nearly equal to $\tau_{0 \mathrm{~F}}$, whereas for impulsive wave pressure, $\tau_{0}$ is $0.1 \sim 0.2 \mathrm{~s}$ in the model experiments. Note that $\tau_{0}$ is determined based on the duration of shear force which is the effective force producing caisson sliding. Actually, the duration of impulsive pressure is much smaller than $\tau_{0}$.

Figure 4.45(1) through (3) show sample time histories of the horizontal wave force, the velocity of the caisson, and the displacement for impulsive, breaking and non-breaking wave pressure, respectively.

Note that the sliding distance for the non-breaking wave pressure is much larger than that for the breaking or impulsive one owing to the fact that the duration of the non breaking wave pressure is much longer, although these three cases are designed with the same sliding safety factor S.F. $=0.76$.

(1) Impulsive wave pressure

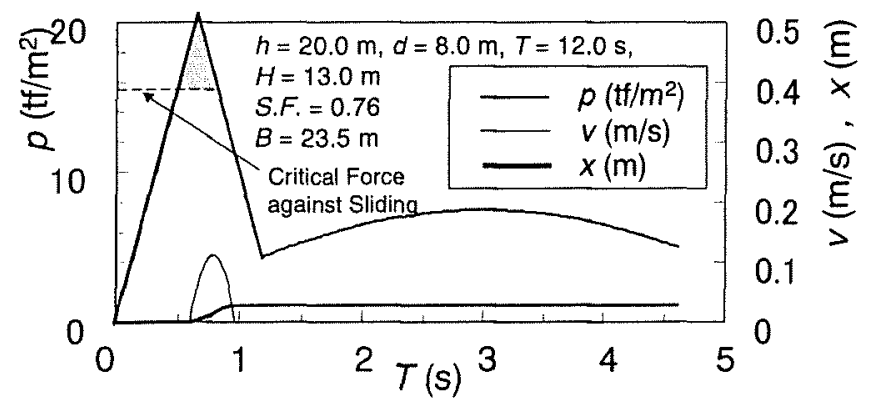

(2) Breaking wave pressure

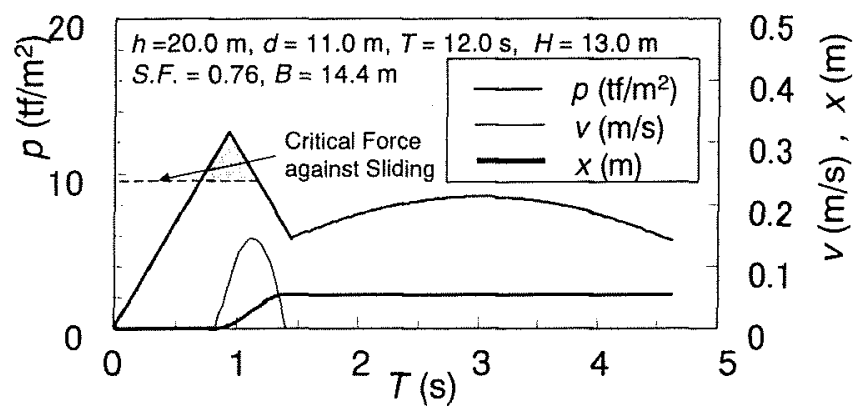

(3) Non-breaking wave pressure

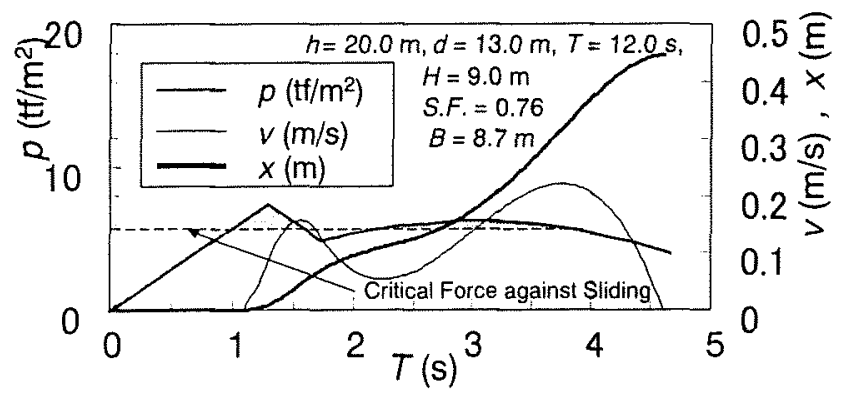

Figure 4.45 Calculated profiles of horizontal wave force, and velocity and displacement of caisson. 


\section{DESIGN OF NEW VERTICAL BREAKWATERS}

\subsection{Perforated Walls}

A perforated wall breakwater employing a perforated front wall and a wave chamber was proposed by Jarlan (1961), and subsequently constructed in 1966 in Comeau Bay, Canada. In Japan, a perforated wall caisson breakwater was constructed in 1970 at Takamatsu Port, while a quaywall with perforated wall caissons was built in Kobe Port in 1969.

Due to their high wave-absorbing ability and high stability against waves, these type of caissons are now being increasingly adopted worldwide as seawalls and breakwaters. Although the perforated wall caisson was initially intended for use in relatively calm seas, it has gradually been employed in heavier, open seas.

Figure 5.1 shows a schematic diagram of structural elements of a perforated wall breakwater. The upright section of the breakwater has a perforated wall, through which waves can enter and leave the wave chamber; thereby dissipating their energy by generating eddies. Energy dissipation is large when the water level difference is large between the inside and outside of the wave chamber, and therefore, it is strongly dependent on the wave length. Perforated wall breakwaters are called wave-dissipating upright breakwaters.

The wave chamber normally has a bottom slab, though a ceiling slab is usually not used to avoid impulsive uplift pressures generated undemeath it. However, to effectively utilize space on the breakwater, a ceiling slab which acts as a water-front promenade can be installed if reinforcement is provided.

Various perforated wall breakwaters exist depending on the type of perforated wall. The most popular one is the vertical-slit wall caisson, while horizontal slit-walls, circular-hole walls, and curved-slit walls are also popular. To widen the range of wave period for wave energy dissipation, more complex perforated wall shapes have been employed, e.g., double-slit walls or a

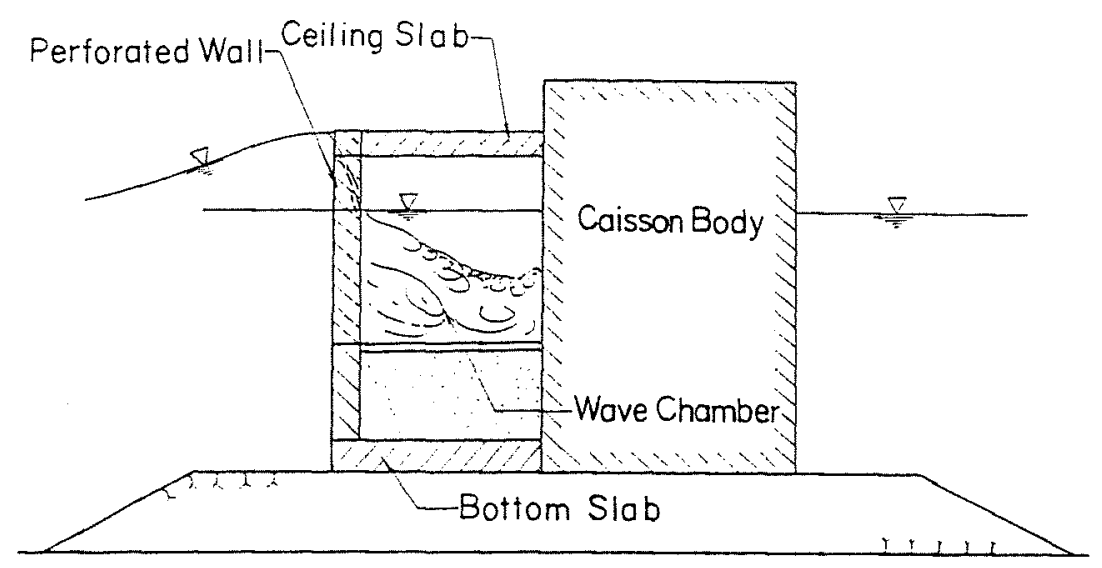

Fig. 5.1 Cross-sectional diagram of a typical perforated wall caisson 
dual-cylinder caisson having a perforated wall with a circular caisson.

The upright section of perforated wall breakwaters can be made by block masonry, where shapedesigned concrete blocks (perforation blocks) are placed to form a perforated wall. This is an innovative and frequently used design, especially in waters that are not so rough.

The slit wall caisson and perforation-block masonry will be described next.

\subsubsection{Vertical Slit Caisson}

(1) Typical cross section

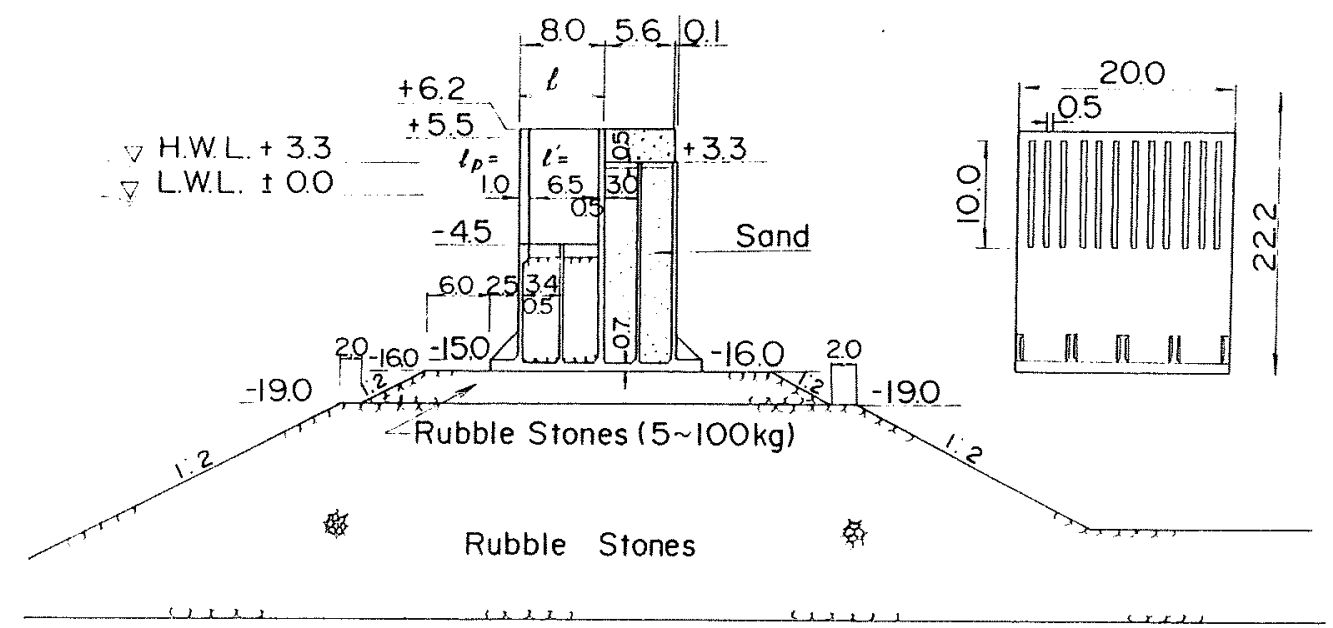

Fig. 5.2 Typical section of a vertical-slit caisson, Nagasaki Port

Figure 5.2 shows a typical cross section of a vertical-slit caisson breakwater, which was constructed in a relatively deep bay $(h=38 \mathrm{~m})$ to withstand a moderate design wave $\left(\mathrm{H}_{1 / 3}=4.8 \mathrm{~m}\right.$, $\mathrm{T}_{1 / 3}=10.4 \mathrm{~s}$ ). The caisson has a slit wall with thickness $l_{p}=1 \mathrm{~m}$ and a wave chamber of width $\mathrm{l}^{\prime}=7 \mathrm{~m}$ (or total width $1=l_{p}+l^{\prime}=8 \mathrm{~m}$ ). The opening ratio of the front wall $\varepsilon$ is 0.135 and the wave chamber depth $\mathrm{d}^{\prime}$ is $4.5 \mathrm{~m}\left(\mathrm{q}=\mathrm{d}^{\prime} / \mathrm{h}^{\prime}=0.28\right)$. No armor stones and foot-protection blocks are installed because of the relatively small wave height and the deep caisson depth $\left(\mathrm{h}^{\prime}=16 \mathrm{~m}\right)$.

(2) Wave reflection and transmission

Tanimoto and Yoshimoto (1982) conducted a series of experiments to investigate the phenomenon of wave reflection of the perforated wall caisson. Figure 5.3 shows the reflection coefficient versus the relative width of the wave chamber l'/L', where $L^{\prime}$ is the wavelength at a water depth of $d^{\prime} . K_{R}$ is reduced to less than 0.4 in the range of $1^{\prime} / L^{\prime}=0.1-0.3$, being smallest around 0.18. Also shown are theoretical

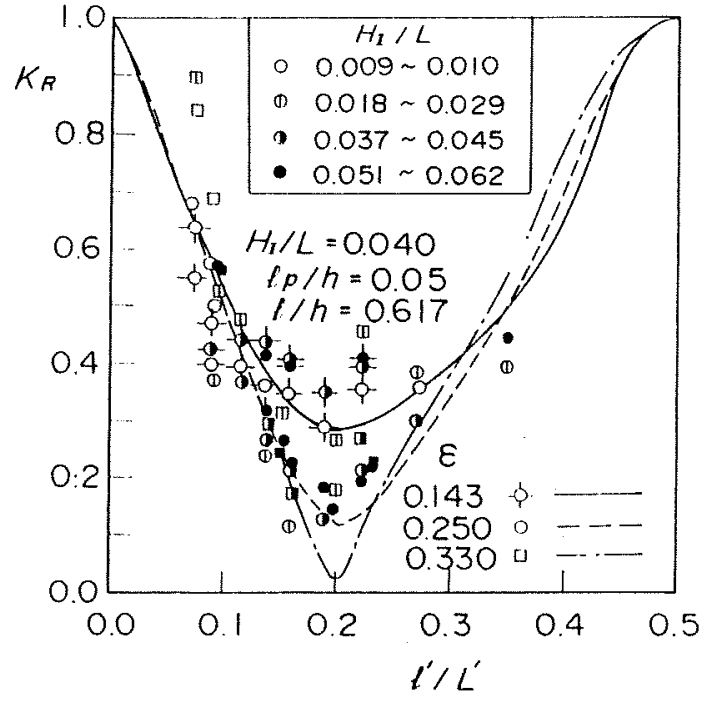

Fig. 5.3 Reflection coefficient of a perforated wall caisson (Tanimoto et al., 1982) 


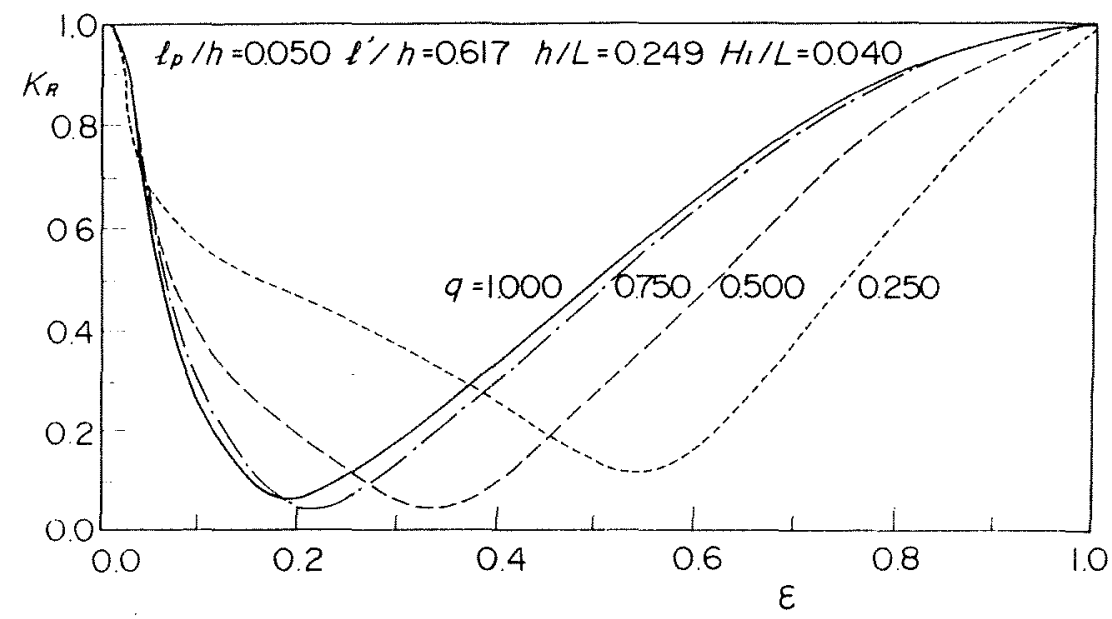

Fig. 5.4 Reflection coefficient versus the opening ratio and wave chamber depth (Tanimoto et al., 1982)

results, that show good agreement with the experimental ones. Based on numerous model experiments carried out to study $\mathrm{K}_{\mathrm{R}}$, it is generally considered that the wave chamber width must be 10 to $20 \%$ of the wave length to significantly dissipate wave energy.

Figure 5.4 shows theoretical predictions in which the reflection coefficient variation is expressed as a function of the opening ratio eand the water depth ratio $q\left(=d^{\prime} / h^{\prime}\right)$ in the wave chamber when $1^{\prime} / \mathrm{L}=0.154,1 / \mathrm{L}=0.166$, and $\mathrm{H} / \mathrm{L}=0.04$. As the water depth in the wave chamber decreases, the optimum opening ratio increases with the minimum reflection coefficient also tending to increase. Such phenomena has been supported by many other model experiments. Consequently, $\varepsilon$ is usually designed to be from 15 to $30 \%$.

From this and other theories (Terett et al., 1968; Richey and Solitt, 1970; Kondo and Takeda, 1983; Allsop and McBride, 1994; Kakuno 1994), the reflection from the perforated wall can be numerically estimated. Although the perforated wall can have numerous shapes, the fundamental characteristics of wave reflection are almost the same.

It should be also noted that "the target waves for wave absorption" must be incorporated in the design of the perforated wall. The target waves are the waves which should be dissipated, and they are usually not heavy storm waves but instead ordinary ones. Reflected waves especially cause problems for small vessels which can enter and leave the harbor when the height of waves is below a certain level.

Due to the wave absorbing behavior of the perforated wall caisson, the wave transmission coefficient $\mathrm{K}_{\mathrm{T}}$ is also reduced. However, since the design wave is longer than the target waves, the reduction of wave transmission is not so significant for the design wave. However, if the flow rate of waves overtopping the perforated wall is compared with that of an ordinary vertical wall, a clear reduction is apparent.

(3) Wave forces

In the design of this type of caisson, the wave pressure distributions at several important phases need to be evaluated, i.e., the forces on the members of the caisson reach their peaks at different 


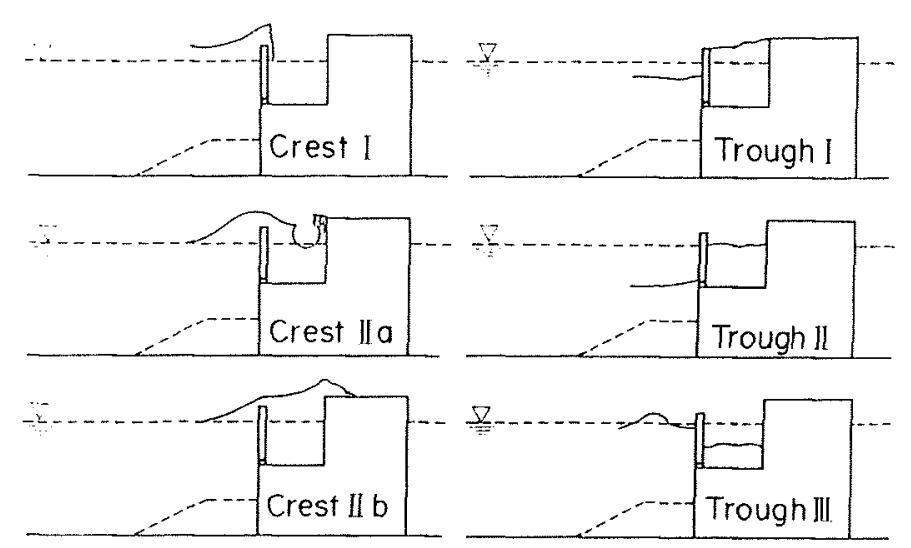

Fig. 5.5 Phases for pressure calculations of perforated wall caissons

(Takahashi et al., 1991)

phases. In fact, the peak in the sliding or overturning force does not necessarily occur when the wave crest is just in front of the caisson.

\section{a) Considered phases}

The forces applied to each structural member of a caisson peak at different wave phases, i.e., crest-I, crest-IIa, crest-IIb, trough-I, trough-II, and trough-III (Fig. 5.5). These six phases are described as follows:

Crest-I: The phase when the wave forces on the front walls (the perforated and impermeable lower front wall) reach their positive peak.

Crest-IIa: The phase when the force on the wave chamber rear wall reaches an impulsive peak. This phase is not always distinct if the wave force is not impulsive.

Crest-IIb: The phase when the force on the wave chamber rear wall reaches a lower peak following the impulsive peak.

Trough-I: The phase when the wave force on the front wall reaches its negative peak.

Trough-II: The phase when the water level in front of the caisson is the lowest.

Trough-III: The phase when the water level in the wave chamber is the lowest.

When the wave force is not so severe, the peak sliding or overturning force usually occurs at crest-IIb. However, when the perforated wall caisson is used as a breakwater in rough seas, where it can be subjected to highly impulsive waves, the peak sliding or overturning force does not always occur at crest-IIb.

b) Design pressure distribution at positive peaks

In the design of perforated wall caissons, the positive pressure distributions at three phases (crest-I, crest-IIa, crest-IIb) should be evaluated, and are calculated based on the Goda pressure formula with modification factors $\lambda_{1}, \lambda_{2}$, and $\lambda_{3}$; where $\lambda_{1}$ is the modification factor of the slowly-varying wave pressure component, $\lambda_{2}$ that for the impulsive wave pressure component of the horizontal pressure, and $\lambda_{3}$ that for the uplift pressure $p_{u}$ as mentioned in Section 4.3.5.

When calculating the impulsive pressure component for the wave chamber rear wall, $\alpha_{1}^{\prime}$ is used 


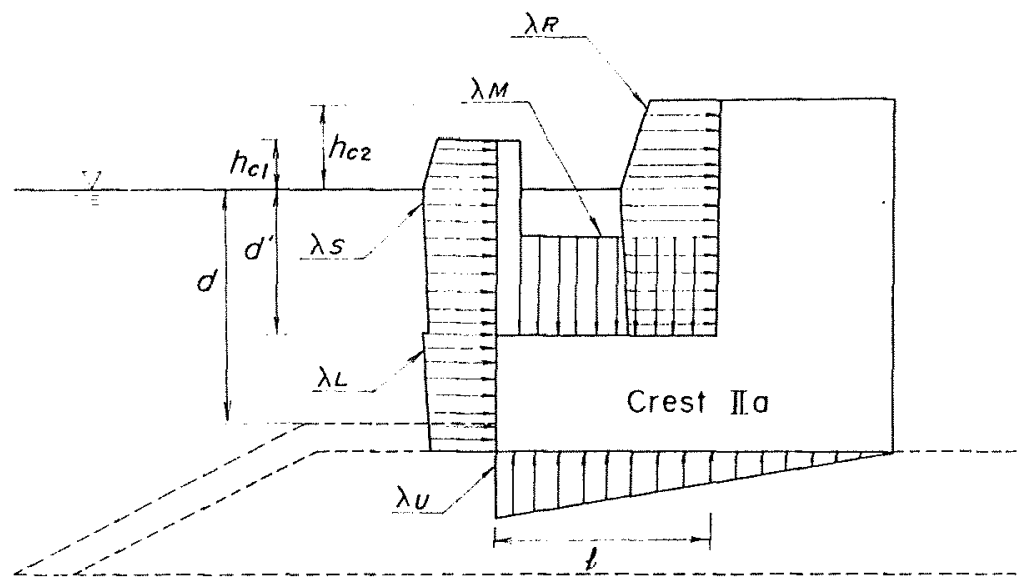

Fig. 5.6 Wave pressure distribution at crest-llb for a perforated wall caisson

Table 5.1 Modification factors for various phases (Takahashi et al., 1991)

\begin{tabular}{|c|c|c|c|c|}
\hline & & Crest-I & Crest-[Ia & Crest-Ilb \\
\hline \multirow[b]{2}{*}{ Slit Wall } & $\lambda_{s 1}$ & 0.85 & 0.7 & 0.3 \\
\hline & $\lambda_{32}$ & $\begin{array}{ll}0.4 & \left(\alpha^{*} \leq 0.75\right) \\
0.3 / \alpha^{*} & \left(\alpha^{*}>0.75\right)\end{array}$ & 0 & 0 \\
\hline \multirow{2}{*}{$\begin{array}{l}\text { Impermeable } \\
\text { Front Wall }\end{array}$} & $\overline{\lambda_{21}}$ & 1 & 0.75 & 0.65 \\
\hline & $\lambda u$ & $\begin{array}{ll}0.4 & \left(\alpha^{*} \leqq 0.5\right) \\
0.2 / \alpha^{*} & \left(\alpha^{*}>0.5\right)\end{array}$ & 0 & 0 \\
\hline \multirow[t]{2}{*}{$\begin{array}{l}\text { Wave Chamber } \\
\text { Rear Wail }\end{array}$} & $\lambda_{R I}$ & 0 & $\begin{array}{cc}201 / 3 L^{\prime} & \left(l / L^{\prime} \leq 0.15\right) \\
1.0 & \left(I / L^{\prime}>0.15\right)\end{array}$ & $\begin{array}{ll}1.4 & \left(H_{0} / h \leqq 0.1\right) \\
1.6-2 H_{0} / h & \left(0.1<H_{D} / h<0.3\right) \\
1.0 & \left(H_{D} / h \geqq 0.3\right) \\
\end{array}$ \\
\hline & $\lambda_{82}$ & 0 & $\begin{array}{ll}0.56 & \left(\alpha^{*} \leqq 25 / 28\right) \\
0.5 / \alpha^{*} & \left(\alpha^{*}>25 / 28\right)\end{array}$ & 0 \\
\hline \multirow[t]{2}{*}{$\begin{array}{l}\text { Wave Chamber } \\
\text { Bottom Slab }\end{array}$} & $\lambda_{m=1}$ & 0 & $\begin{array}{cc}20 l / 3 L^{\prime} & \left(l / L^{\prime} \leq 0.15\right) \\
1.0 & \left(l / L^{\prime}>0.15\right)\end{array}$ & $\begin{array}{cl}1.4 & \left(H_{0} / h \leq 0.1\right) \\
1.6-2 H_{D} / h & \left(0.1<H_{D} / h<0.3\right) \\
1.0 & \left(H_{D} / h \geqq 0.3\right) \\
\end{array}$ \\
\hline & $\lambda_{n, a}$ & 0 & 0 & 0 \\
\hline \multirow[t]{2}{*}{ Upliff Force } & $\lambda_{\mathrm{Ui}}$ & 1 & 0.75 & 0.65 \\
\hline & $\lambda_{u 2}$ & 0 & 0 & 0 \\
\hline
\end{tabular}

vice $\alpha_{\mathrm{I}}$, being obtained by making the following substitutions:

$d$ is replaced by $d^{\prime}$ (wave chamber depth)

$L$ is replaced by $L^{\prime}$ (wave length at $d^{\prime}$ )

$B_{M}$ is replaced by $B_{M}^{\prime}\left(=\max \left\{l-\left(d-d^{\prime}\right), 0\right\}\right)$

where 1 is the wave chamber width.

Figure 5.6 shows the design pressure distribution of the wave pressure at crest-IIb, where the suffixes on $\lambda$ correspond to specific locations on the perforated wall caisson: $S$, slit wall; $L$, impermeable front wall; $R$, wave chamber rear wall; $M$, wave chamber bottom slab; and $U$, uplift force. Table 5.1 shows the modification factors $\left(\lambda_{1}, \lambda_{2}\right.$, and $\left.\lambda_{3}\right)$ used in the extended Goda formula for a typical perforated vertical wall caisson. Note that for this caisson, application of the modification factors reduces both the impulsive pressure and the slowly-varying pressure components. 


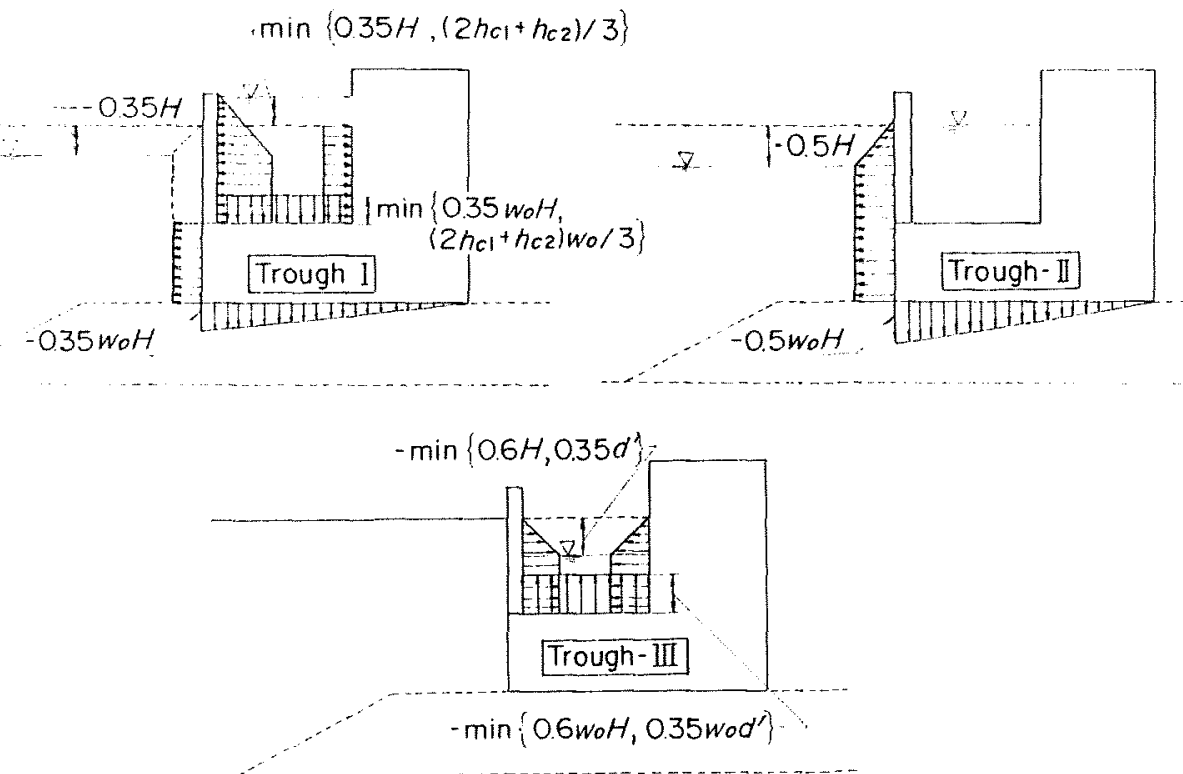

Fig. 5.7 Design pressure distribution at negative peaks

c) Design pressure distribution at negative peaks

The wave pressure from the negative peaks can be determined using the water level in front of the caisson and in the wave chamber. Figure 5.7 respectively shows the distribution of the wave pressure at trough-I, II, and III, where $h_{c 1}$ is the crest elevation of the perforated wall and $h_{c 2}$ that of the wave chamber rear wall. Although the negative wave pressure is not a critical factor affecting the stability of the caisson under normal design conditions, it becomes relatively large in deepwaters, and therefore in this case, it should be more precisely calculated using finite amplitude standing wave theory.

d) Perforated wall caisson vs. conventional solid caisson

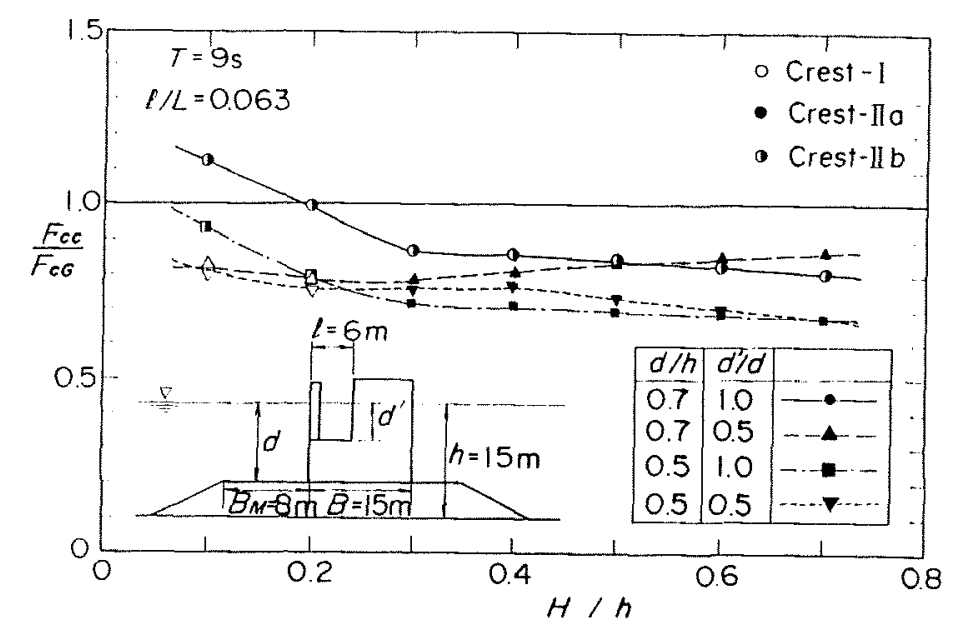

Fig. 5.8 Comparison between perforated wall and conventional caissons

(Takahashi et al., 1991)

The wave forces acting on perforated wall caissons are generally considered to be smaller than those on conventional solid caissons. This can be seen in Fig. 5.8, which compares their calculated necessary caisson weight $F_{C}$ for various indicated conditions, where the results for the perforated wall caisson $\left(\mathrm{F}_{\mathrm{CC}}\right)$ are normalized by those from an equivalent conventional caisson $\left(\mathrm{F}_{\mathrm{CG}}\right)$ using the Goda pressure formula. Note that the front depth $\mathrm{d}$ and wave chamber depth $\mathrm{d}^{\prime}$ 
are varied for the perforated wall caisson. In addition, the phase (crest-I, IIa, and IIb) at which each maximum wave force occurs is indicated.

When the rubble mound is not high $(\mathrm{d} / \mathrm{h}=0.7)$ and $\mathrm{d}^{\prime} / \mathrm{d}=1.0$, the ratio of $\mathrm{F}_{\mathrm{CC}} / \mathrm{F}_{\mathrm{CG}}$ is about 0.8 except when $\mathrm{H} / \mathrm{h}<0.3$, and for all $\mathrm{H} / \mathrm{h}$ values, $\mathrm{F}_{\mathrm{CC}}$ is a maximum, i.e., the sliding stability is critical at crest-IIb. When $\mathrm{d} / \mathrm{h}=0.7$ and $\mathrm{d}^{\prime} / \mathrm{d}=0.5$, this ratio ranges from 0.8 to 0.9 , and the stability is critical at crest-I when $\mathrm{H} / \mathrm{h}<0.2$, whereas at crest-IIa when $\mathrm{H} / \mathrm{h}>0.3$.

When the rubble mound is comparatively higher $(\mathrm{d} / \mathrm{h}=0.5), \mathrm{F}_{\mathrm{CC}} / \mathrm{F}_{\mathrm{CG}}$ is about 0.7 and the stability is critical at crest-IIa for $\mathrm{H} / \mathrm{h}>0.3$, regardless of the value of $\mathrm{d}$ '. This result is noteworthy because it shows that perforated wall caissons have higher stability against wave forces than conventional ones under both low- and high-mound conditions.

e) Wave uplift pressure on the ceiling slab of a wave chamber

When the wave chamber is covered with a ceiling slab, the slab may receive very severe uplift forces depending on the clearance of the slab bottom measured from the still water level. The pressure is usually Bagnold type pressure, which is caused by the compression of the entrapped air in the wave chamber. This occurs due to a lag in phase between the water surface in the wave chamber and that in front of the perforated wall (Fig. 5.9).

The pressure can be evaluated using the upward speed $u_{0}$ of the water surface in the wave chamber and the entrapped air thickness D (Takahashi et al., 1985). In the case of the vertical slit caisson built in Tarumi, Japan, on reclaimed land, the design uplift pressure is $2 \mathrm{w}_{0} \mathrm{H}$ for a design wave of $\mathrm{H}_{1 / 3}=4.6 \mathrm{~m}\left(\mathrm{H}_{\mathrm{D}}=8.3 \mathrm{~m}\right)$ and $\mathrm{T}_{1 / 3}=8 \mathrm{~s}$. It should be noted that in a model experiment the air pressure against the design wave was more than $4 \mathrm{w}_{\mathrm{o}} \mathrm{H}$, which is reduced to $2 \mathrm{w}_{0} \mathrm{H}$ when the scale effect of air compression is taken into account.

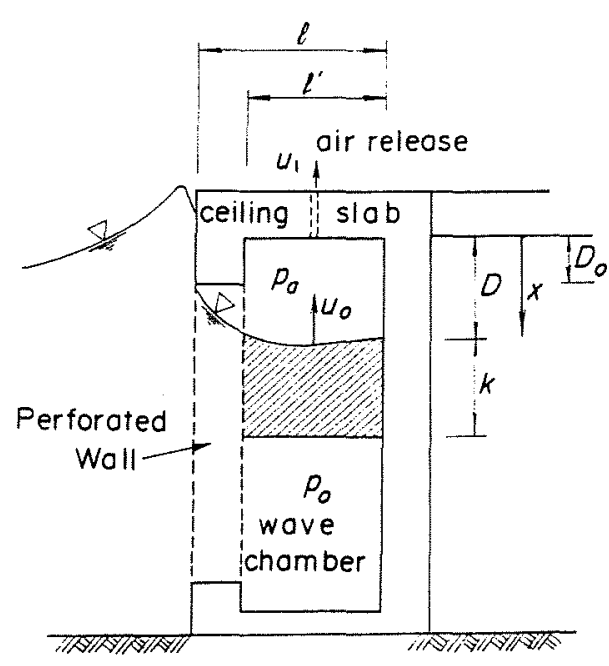

Fig. 5.9 Air compression in wave chamber

\subsubsection{Perforation-Block Masonry}

(1) Typical section

The perforated wall can be made by special masonry blocks as shown in Fig. 5.10, where the wall consists of three perforation blocks. To increase the stability, the blocks are fixed by a large bottom block and a large crown block. The design wave height for the breakwater is $\mathrm{H}_{1 / 3}=2.25$ $\mathrm{m}$ and $\mathrm{T}_{1 / 3}=6 \mathrm{~s}$.

The concrete blocks are called perforation blocks, with several types being shown in Fig. 5.11. These block masonry breakwaters are employed in relatively sheltered areas in which the design significant wave height is less than $3 \mathrm{~m}$. The blocks are also used for quaywalls and seawalls. 


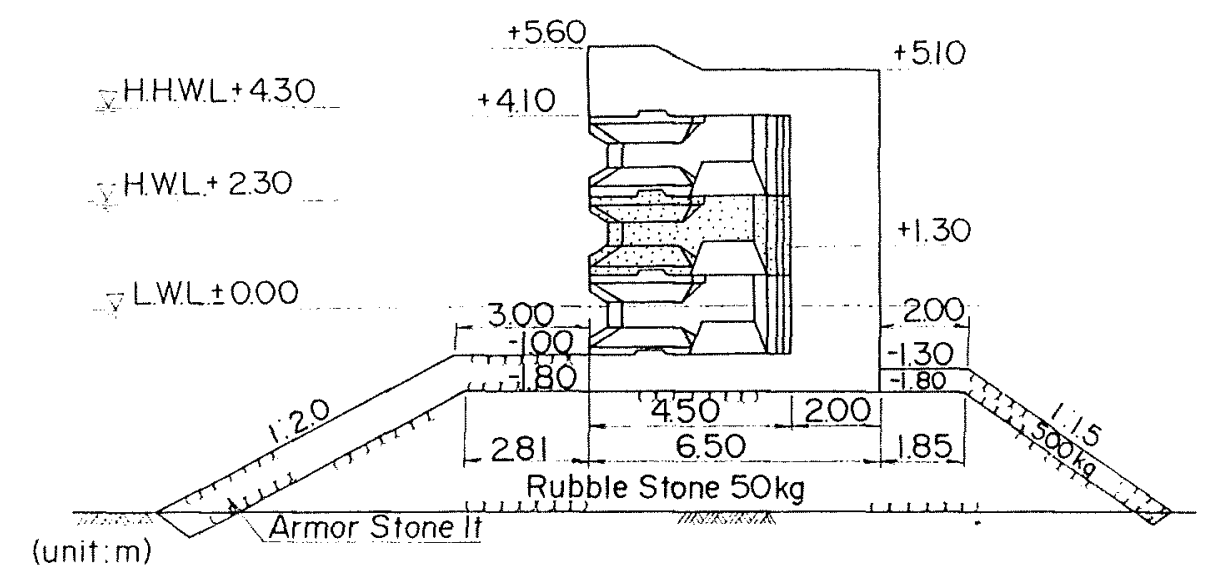

Fig. 5.10 Typical section of a perforation-block masonry breakwater (Kataoka et al., 1986)
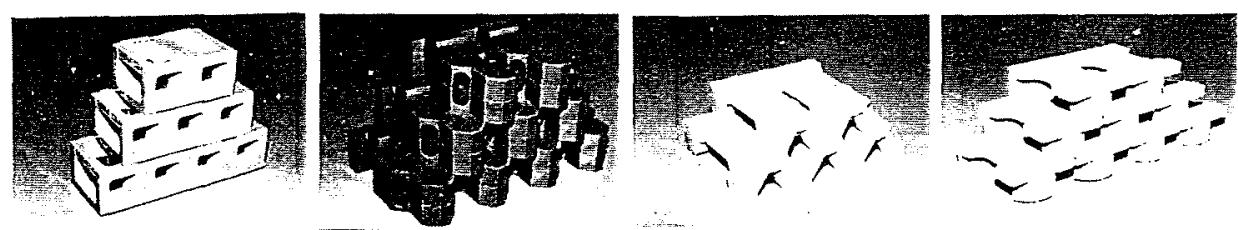

$\triangle N G-L O C K$

CROS S-HOLLOW

DIAER

IGLOO
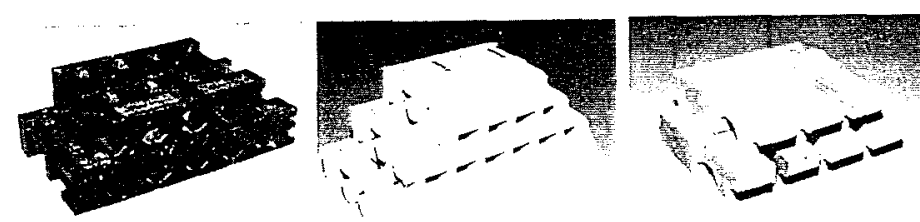

I NE

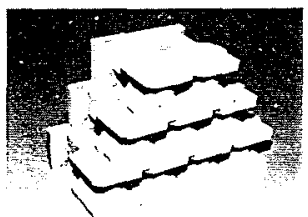

WAROCK

PERFORCEL

P I LOCK

Fig. 5.11 Perforation-blocks

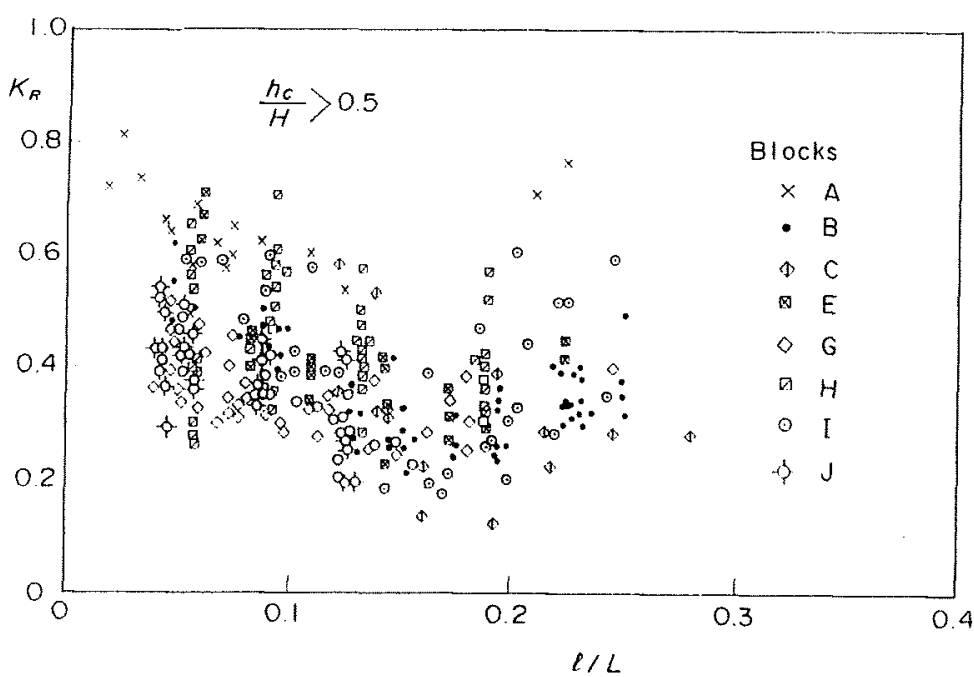

Fig. 5.12 Reflection coefficient of a perforation-block masonry breakwater

(2) Wave reflection and transmission

Since the perforation-block masonry wall is also a perforated wall, it absorbs wave energy. Figure 5.12 shows its reflection coefficient as a function of the relative width $\mathrm{l} / \mathrm{L}$ of the wave chamber part including the front wall to the wave length, which reveals that the reflection coefficient becomes small when $1 / \mathrm{L}=0.05$ to 0.25 . 
Wave transmission of the perforation-block masonry breakwater is quite similar to that of the perforated wall breakwaters, namely, reduction in the transmission coefficient due to the blocks is not significant, though a clear reduction in overtopping occurs in comparison with solid vertical walls.

\section{(3) Wave forces}

Since the block shape is very complex, this makes it difficult to determine wave force on each member. The impulsive uplift pressure underneath the crown block especially complicates wave force determination. Consequently, the stability of the whole upright section as well as that each block should be examined in the design.

Model experiments are recommended to design this type of breakwater. For the preliminary design, the wave pressure distribution of the extended Goda formula can be used with the modification factor of $\lambda_{1}$ and $\lambda_{3}=0.8-1.0$ and $\lambda_{2}=0$. To examine the stability of each block, the same method as used in Section 4.3.6(4) for the block masonry wall can be employed, where the uplift pressure between the blocks is assumed to be the same as the horizontal pressure on the front wall at the same level. However, it should be noted that the uplift pressure on the blocks above the still water level and on the crown block is very impulsive and can be two or three times that calculated using the Goda formula.

\subsection{Inclined Walls}

\subsubsection{Sloping Top Caisson}

Breakwater construction in open deepwaters has become more prevalent in recent years. Large wave heights generate tremendous wave forces acting on a breakwater, and the sloping top caisson has been found to be suitable in this application. The breakwater's caisson has a superstructure that is sloped to reduce the wave forces, i.e., the downward forces on the slope cancel the uplift pressure, thereby increasing the caisson's stability.

The sloping top caisson has been used for many years as a breakwater against very rough seas, with the oldest caisson of this type being constructed in 1906 at Naples Port, Italy. Another one was built at Hanstholm Harbour, Denmark, where the overturning moment and total horizontal force were found to be reduced to about one-half the values of a caisson having entirely vertical walls (Juhl, 1994; Ligteringen, 1994). Sloping top caissons have also been constructed in Taiwan, China, and Libya in deepwater regions where wave conditions are severe (Kuo, 1994 and Xie, 1994).

In Japan, they exist at Niigata, Miyazaki, and Hitachinaka Ports, while in Naha Port, one is under construction which is covered with wave dissipating blocks, being a combination of the sloping top caisson and one with wave-dissipating blocks (Sato et al., 1992). The slope of the caisson is normally above sea level due to construction reasons. However, if the sloping part is extended to below the still water level, this increases the capability to resist waves.

The sloping top caisson is very stable, yet wave overtopping is significantly large, and the crown 
height must be higher than that of the ordinary vertical wall type to obtain the same transmission coefficient.

(1) Typical section

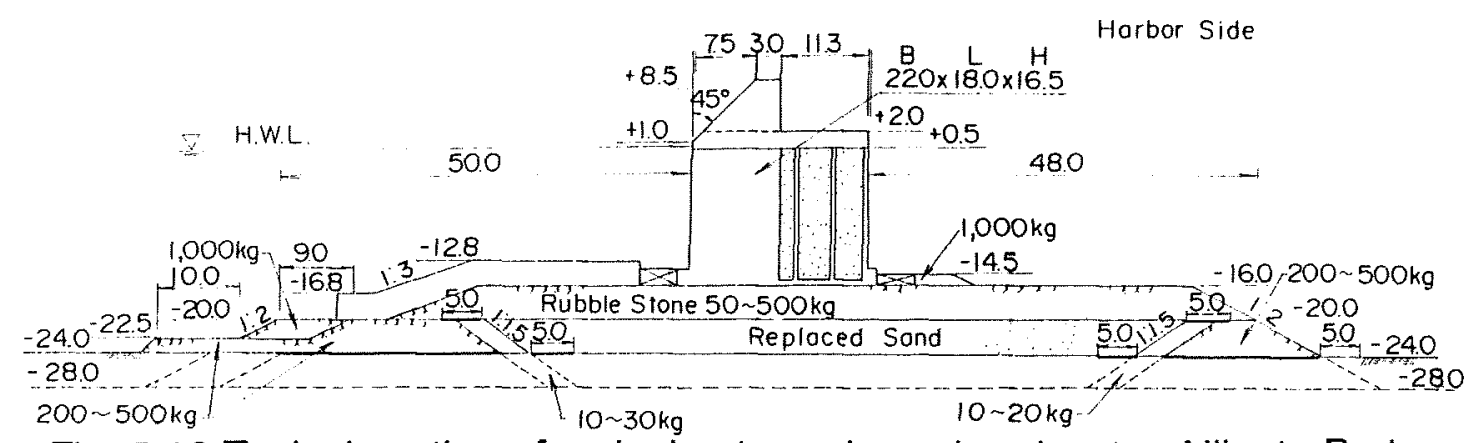

Fig. 5.13 Typical section of a sloping top caisson breakwater, Niigata Port

(Kataoka et al., 1986)

Figure 5.13 shows a cross section of the sloping top caisson at Niigata Port. The slope starts +0.1 $m$ above L.W.L. $\left(d_{c}=+0.1 \mathrm{~m}\right)$ and the sloping angle $\alpha$ is $45^{\circ}$. The crown height $h_{c}$ is $8 \mathrm{~m}$ from H.W.L., which is equal to the design wave height $\left(\mathrm{H}_{1 / 3}=8 \mathrm{~m}, \mathrm{H}_{\max }=14.3 \mathrm{~m}, \mathrm{~T}_{1 / 3}=14 \mathrm{~s}\right)$. The incident wave angle $\theta$ is $21^{\circ}$.

(2) Wave transmission and reflection

Figure 5.14 shows experimental results which were used to investigate the wave transmission coefficient for the six sloping top caisson breakwaters shown in Fig. 5.15 (Takahashi et al., 1994). Type 1 is a standard sloping top caisson, having a slope starting from the still water level $\left(d_{c}=0.0 \mathrm{~cm}\right)$, while Type 2 is a semi-sloping top caisson, having a slope starting above the water level. Types 3-6 are semi-submerged sloping top caissons having a submerged slope that enhances the stability created by the slope. The crest elevation $h_{c}$ is $32 \mathrm{~cm}$ for Types 1-3 and 16 $\mathrm{cm}$ for Types 4-6. The lowest point of Type 5's slope is the deepest, although its $h_{c}$ is the same as that for Type $4 . \alpha$ is $45^{\circ}$ for Types $1-5$ and $56^{\circ}$ for Type 6 . The water depth $h$ in all the experiments was $1.044 \mathrm{~cm}$.

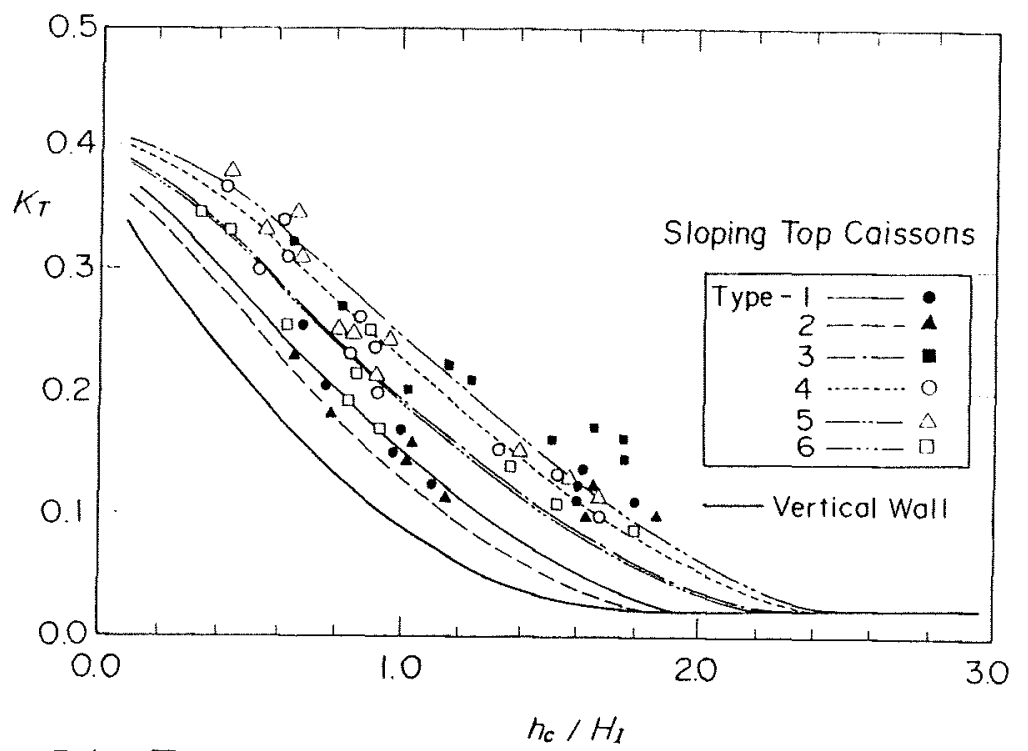

Fig. 5.14 Transmission coefficient for sloping top caissons 


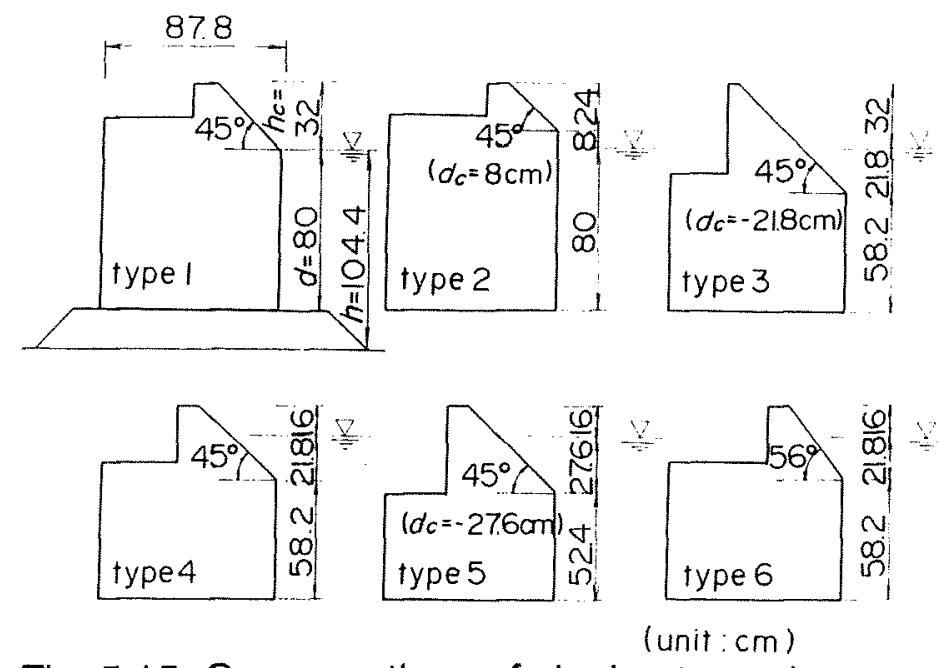

Fig. 5.15 Cross sections of sloping top caissons

It is obvious that the sloping top caisson has a relatively large transmission coefficient $\mathrm{K}_{\mathrm{T}}$ compared to ordinary vertical walls, and also, that $\mathrm{K}_{\mathrm{T}}$ becomes large when either $\alpha$ is small and/or the value of $d_{c}$ is negative and large. Taking such factors into account, $K_{T}$ for a sloping top caissons can be formulated as follows:

$$
\begin{aligned}
& {\left[0.25\left\{1-\sin (\pi / 4.4)\left(h_{c} / H_{1 / 3}+\beta+\beta_{s}\right)\right\}^{2}+0.01\left(1-h^{\prime} / h\right)^{2}\right]^{0.5}} \\
& \mathrm{~K}_{\mathrm{T}}= \\
& : \beta+\beta_{\mathrm{s}}-2.2<h_{\mathrm{c}} / \mathrm{H}_{1 / 3}<2.2-\left(\beta+\beta_{\mathrm{s}}\right) \\
& 0.1\left(1-h^{\prime} / h\right) \\
& : h_{c} / H_{1 / 3}>2.2-\left(\beta+\beta_{s}\right) \\
& \beta_{s}=-0.3\left\{\left(h_{c}-2 d_{c}\right) /\left(H_{1 / 3} \tan \theta\right)\right\}^{0.5}
\end{aligned}
$$

where $\beta$ is obtained from Fig. 4.3. Note that calculated results in Fig. 5.14 using Eq. (5.1) show

good agreement with the experimental results. The crown height $h_{c}$ of the standard sloping top caisson is usually taken as $1.0 \mathrm{H}_{1 / 3}$, while that of the ordinary vertical walls is $0.6 \mathrm{H}_{1 / 3}$.

Figure 5.16 shows the corresponding wave reflection, where the reflection coefficient is smaller than that for conventional vertical walls due to wave overtopping and the eddies generated at the bottom edge of the slope.

(3) Wave forces

The in-use Japanese design method for the sloping top caisson was initially proposed by Morihira and Kunita (1979), who modified the

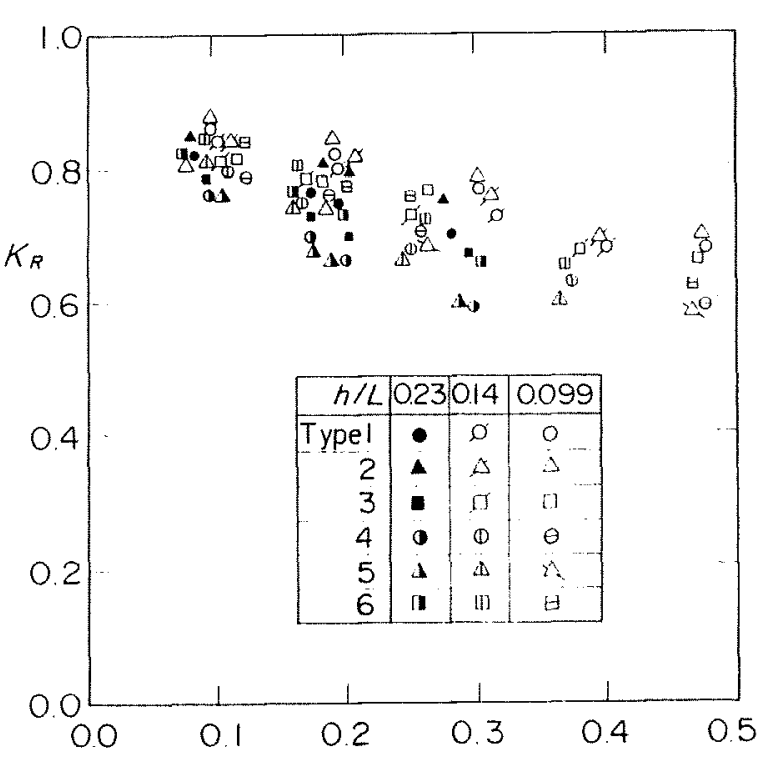

$H_{t} / h$

Fig. 5.16 Reflection coefficient for sloping top caissons (Takahashi et al., 1994) 


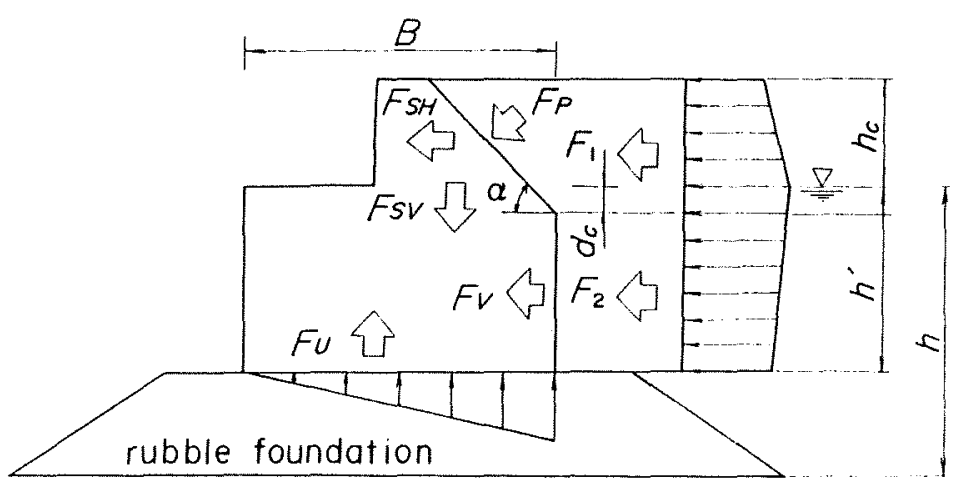

Fig. 5.17 Design wave force on a sloping top caisson

Goda pressure formula for vertical breakwaters. Takahashi et al. (1994) then modified the formula once more to account for force variations due to wave height. Figure 5.17 shows the design wave pressure distribution in which the fundamental pressure distribution is the same as that by the Goda formula.

a) Wave force on the slope

The horizontal component $F_{S H}$ and the vertical downward component $F_{S V}$ are respectively evaluated as

$$
\begin{aligned}
& F_{S H}=F_{p} \sin \alpha=\lambda_{S L} F_{1} \sin ^{2} \alpha \\
& F_{S V}=F_{p} \cos \alpha=\lambda_{S L}{ }^{\prime} F_{1} \sin \alpha \cos \alpha
\end{aligned}
$$

where $F_{1}$ is the horizontal wave force on an equivalent vertical wall which has the same elevation as the slope, $\alpha$ is the slope angle, and $\lambda_{\mathrm{SL}}$ ' is the modification factor. Based on the dependence of $\lambda_{S L}$ ' on $H / L$ and $\alpha$, a design formulation for $\lambda_{S L}{ }^{\prime}$ can be expressed as

$$
\begin{aligned}
& \lambda_{S L}{ }^{\prime}=\min \left\{\operatorname { m a x } \left\{1.0,-23(\mathrm{H} / \mathrm{L}) \tan ^{-2} \alpha\right.\right. \\
&+\left.\left.0.46 \tan ^{-2} \alpha+\sin ^{-2} \alpha\right\}, \sin ^{-2} \alpha\right\}
\end{aligned}
$$

and therefore $\lambda_{\mathrm{SL}}{ }^{\prime} \sin ^{2} \alpha$ becomes

$$
\lambda_{S L}{ }^{\prime} \sin ^{2} \alpha=\min \left\{\max \left\{\sin ^{2} \alpha,-23(H / L) \cos ^{2} \alpha+0.46 \cos ^{2} \alpha+1.0\right\}, 1.0\right\}
$$

$\lambda_{\mathrm{SL}}{ }^{\prime}$ is defined in the following three regions:

1) When $H / L$ is relatively small, $F_{S H}=F_{1}$.

2) When $H / L$ is large, $F_{S H}=F_{1} \sin ^{2} \alpha$.

3) When $H / L$ is between 1) and 2), $F_{S H}$ decreases with increases in $H / L$.

Note that when $\mathrm{H} / \mathrm{L}$ is large and $\alpha=45^{\circ}, \mathrm{F}_{\mathrm{SH}}$ on the sloping superstructure is one half the horizontal wave force on an equivalent vertical wall $F_{1}$. 
b) Wave force on the vertical section

The wave forces on a vertical wall $F_{V}$ and the uplift force on a sloping caisson $F_{U}$ can be calculated from the Goda formula, i.e.,

$$
\begin{aligned}
& F_{V}=\lambda_{V} F_{2} \\
& F_{U}=0.5 p_{U} B
\end{aligned}
$$

where $p_{u}$ is the uplift pressure at the caisson's front toe and $F_{2}$ the wave force on the caisson's upright wall, both of which are calculated using the Goda formula. The modification coefficient $\lambda_{V}$ is defined as

$$
\lambda_{V}=\min \left\{1.0, \max \left\{1.1,1.1+11 d_{c} / L\right\}-5.0 H / L\right\}
$$

where $d_{c}$ is the depth of the slope (height of the starting point of the slope, positive upward). $\lambda_{V}$ indicates the wave pressure is reduced due to the rapid upward velocity induced by the slope.

(4) Stability of sloping top caissons

Figure 5.18 shows experimental results used to determine the weight of the caissons (Types 16) needed to withstand a design wave of $\mathrm{H}=$ $61.9 \mathrm{~cm}$ and $\mathrm{T}=3.5 \mathrm{~s}$ (see Fig. 5.15), where each ratio of the weight $F_{c}$ for the sloping top caisson to that for a conventional caisson is indicated.

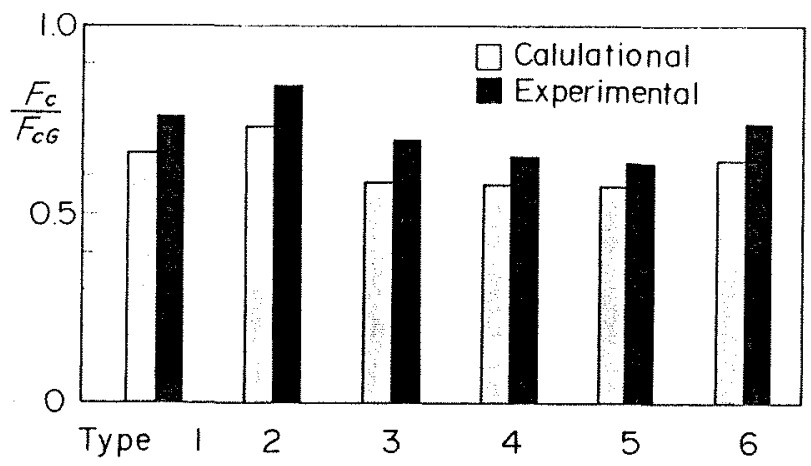

Among Types 1-3 with the same $h_{c}$, the semisubmerged sloping top caisson Type 3 has the minimum weight. Obviously, as either $d_{c}$ or $\alpha$

Fig. 5.18 Necessary weight of sloping top caissons compared with that of a conventional upright caisson

(Takahashi et al., 1994) decreases, caisson stabilization is enhanced. $F_{c}$ for a sloping top caisson is reduced by approximately $60-80 \%$ in comparison with that of the vertical wall caisson. Note the calculated values using the proposed design method are in good agreement with the experimental results; thereby showing that this method is capable of reasonably and safely evaluating the effect of structural variations carried out to enhance stability.

\subsubsection{Trapezoidal Caisson}

Although trapezoidal caissons are also more stable than conventional vertical wall caissons, a trapezoidal wall is a traditional type of vertical wall. Tanimoto and Kimura (1985) carried out a series of model experiments to investigate wave forces on a trapezoidal caisson, with Fig. 5.19 showing the obtained distribution of wave pressure. The pressure is determined by the Goda formula, and it is assumed to act perpendicular to the slope; thus its vertical component con- 


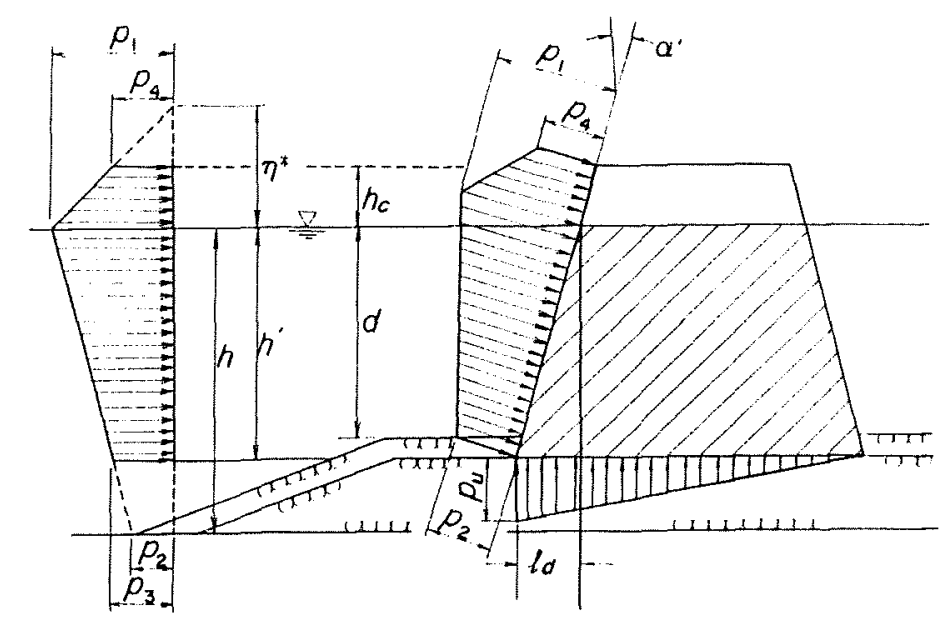

Fig. 5.19 Wave pressure distribution on a trapezoidal caisson (Tanimoto et al., 1985) tributes to stabilize the caisson.

These experiments also demonstrated that the uplift wave pressure on the caisson bottom is reduced due to the upward water particle velocity enhanced by the slope. The modification factor $\lambda_{3}$ for the uplift pressure in the Goda formula is

$$
\lambda_{3}=\exp \left\{\left(-2.26\left(7.2 I_{d} / L\right)^{3}\right)\right\}
$$

where $l_{d}=h^{\prime} \tan \alpha^{\prime}\left(\alpha^{\prime}\right.$ : inclination angle of the front wall).

Equation (5.9) is applicable to a trapezoidal caisson with up to a $20^{\circ}$ inclination and $\mathrm{l}_{\mathrm{d}}<0.1 \mathrm{~L}$.

Another advantage of this caisson is a smaller toe pressure than that occurring on a normal upright section, which is due to the larger width of the bottom plate. The bearing pressure will increase if the water depth increases, though this can be reduced using a trapezoidal shape for the upright section. 


\section{DESIGN OF HORIZONTALLY COMPOSITE BREAKWATERS}

\subsection{Typical Cross Section of Horizontally Composite Breakwaters}

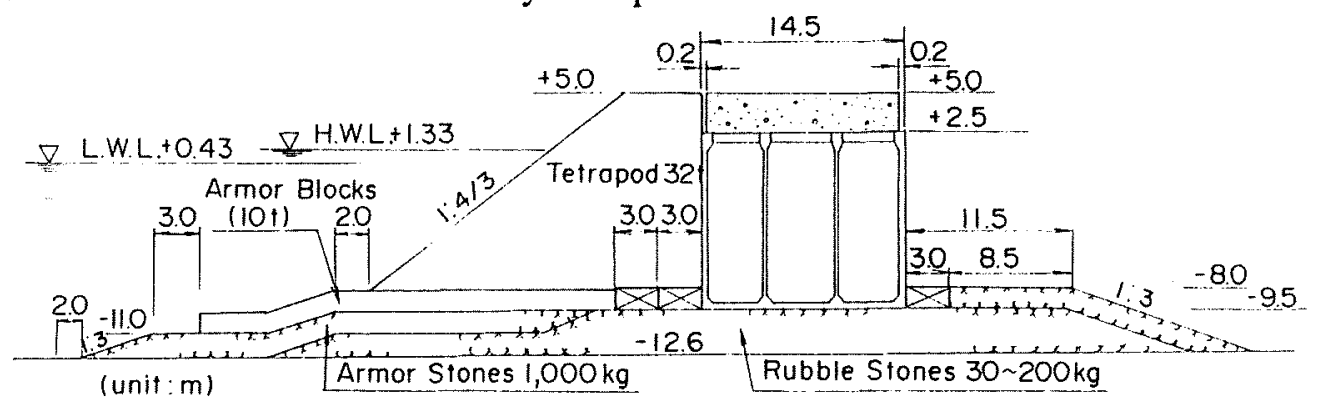

Fig. 6.1 Typical section of a horizontally composite breakwater (Kataoka et al., 1986)

Figure 6.1 shows a typical cross section of a composite breakwater covered with concrete blocks, which is called a horizontally composite breakwater. The breakwater has a $14.5-\mathrm{m}$-wide caisson that is covered with 32-t blocks at a slope of $1: 4 / 3$. These blocks dissipate the wave energy and reduce the wave force of breaking waves. The top level of the block section is at the same height as the caisson crown, and the width of the block section at the top is twice the block height. The design wave is a breaking wave $\left(\mathrm{H}_{1 / 3}=6.01 \mathrm{~m}, \mathrm{H}_{\max }=9.96 \mathrm{~m}, \mathrm{~T}_{1 / 3}=14 \mathrm{~s}\right)$.

\subsection{Wave Transmission and Reflection}

\section{(1) Transmission coefficient}

The transmission coefficient $\mathrm{K}_{\mathrm{T}}$ of a horizontally composite breakwater is slightly influenced by the covering width of the blocks relative to the incident wavelength, as well as by the principal parameter $h_{c} / H_{1 / 3}$.

Figure 6.2 shows experimental results of irregular wave tests (Tanimoto et al., 1987), where the significant wave heights of transmitted waves were measured. The resultant average relation of the experimental data is shown for the different values of $b_{e} / L_{1 / 3}$, where $b_{e}$ is the equivalent covering width defined by

$$
b_{e}=0.5\left(b_{c}+b_{b}\right)
$$

As indicated by these average relations, the value of $\mathrm{K}_{\mathrm{T}}$ ranges from 0.10 to 0.16 for a relative crest height of 0.6 , being less than corresponding values for ordinary vertical walls. It can be easily seen that $\mathrm{K}_{\mathrm{T}}$ decreases as the relative covering increases.

(2) Reflection Coefficient

The reflection coefficient $\mathrm{K}_{\mathrm{R}}$ of horizontally composite breakwaters is contrastingly strongly influenced by the relative covering width, with Fig. 6.3 showing associated experimental results. $B_{e}$ is the equivalent covering width defined by

$$
\left.B_{e}=b_{0}-\left\{\cot \alpha /\left(h+h_{c}\right)\right\}\left[\int_{-h}^{h_{c}}\left\{\cosh ^{2} 2 \pi(h+z) / L\right\} /\left(\cosh ^{2} 2 \pi h / L\right)\right\} z d z+0.5 h_{c}{ }^{2}\right]
$$




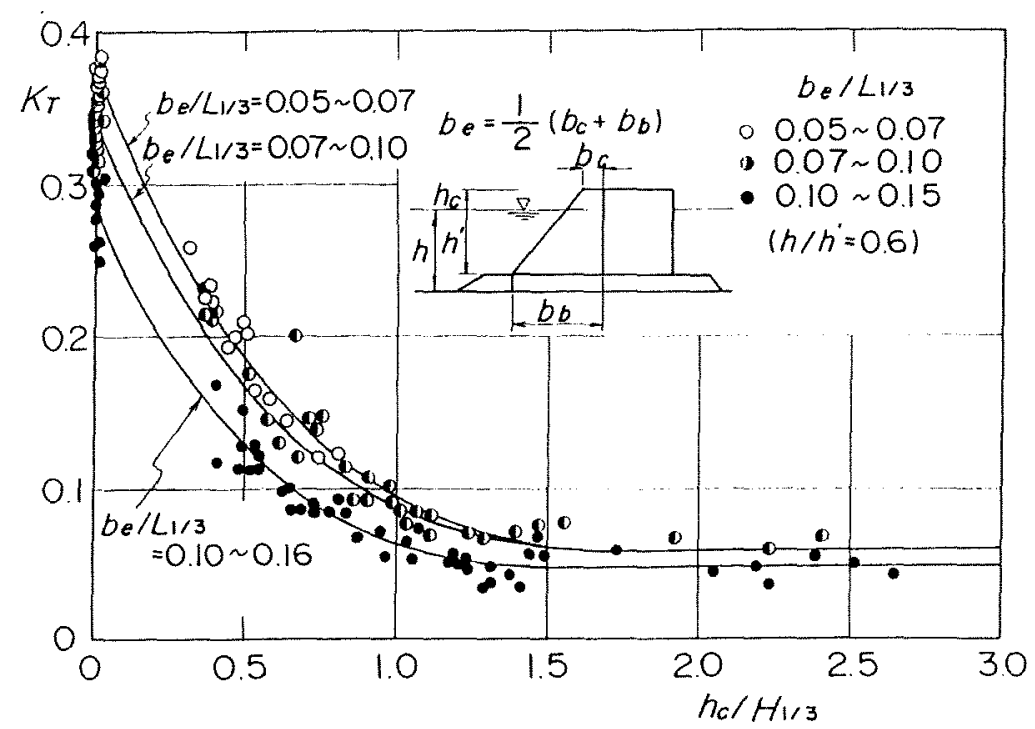

Fig. 6.2 Wave transmission coefficient for horizontally composite breakwaters (Tanimoto et al., 1987)

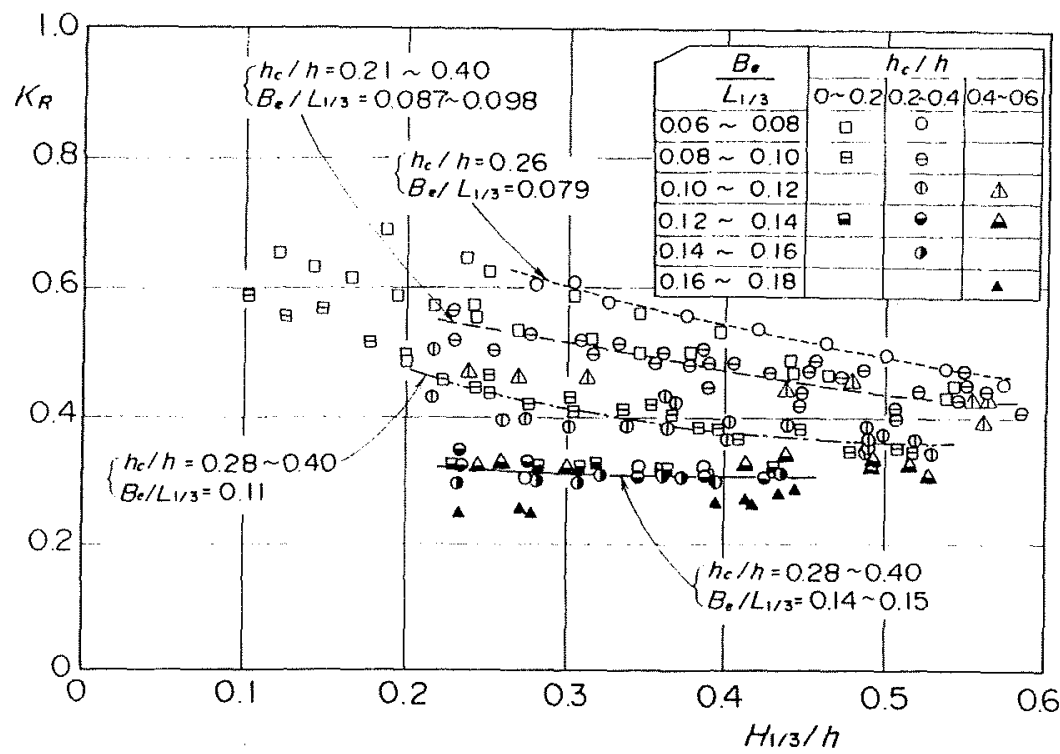

Fig. 6.3 Reflection coefficient of horizontally composite breakwaters (Tanimoto et al., 1987)

where $b_{o}$ is the covering width at the still water level, $\alpha$ the slope angle of the structure measured from horizontal, and $\mathrm{z}$ the upward distance away from the still water level.

In the figure, $K_{R}$ is represented as a function of $B_{e} / L_{1 / 3}, h_{d} / h$, and $H_{1 / 3} / h$. The results of the experiment indicate that value of $K_{R}$ clearly decreases with an increase in $B_{e} / L_{1 / 3}$ value.

\subsection{Wave and Block Forces on a Vertical Wall}

(1) Wave force on a vertical wall

The concrete blocks in front of the upright wall act to reduce the wave force. Figure 6.4 shows the time history of wave pressure obtained from a model experiment, where the pressure profile 
with and without blocks is indicated. These results demonstrate that the pressure component due to breaking is significantly reduced by the blocks, whereas the slowly-varying wave pressure component only slightly changes.

Figure 6.5 shows the ratio of the wave force on the vertical wall with blocks to that without blocks, in which the horizontal axis is the wave height divided by water depth. This ratio tends to decrease with increases in wave height. In fact, when the wave height is close to the water depth, the wave force ratio is reduced to less than 0.8 . Based on these results, it is considered that the design wave force on a vertical wall covered with concrete blocks can be evaluated by the Goda pressure formula after incorporating the following modification factors (Takahashi et al., 1990):

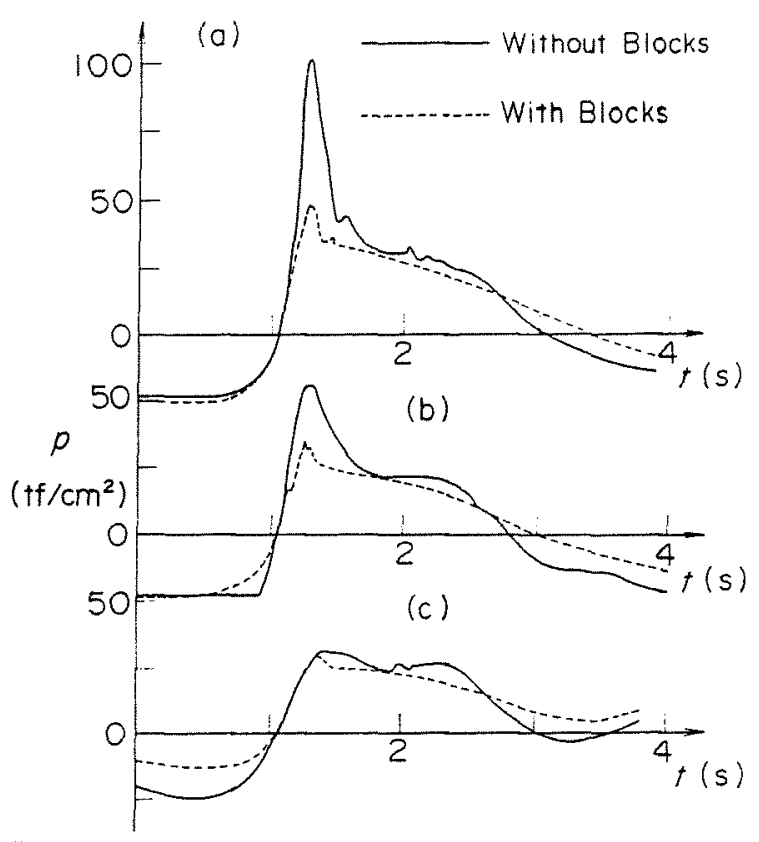

Fig. 6.4 Change in wave pressure profile by wave-dissipating blocks

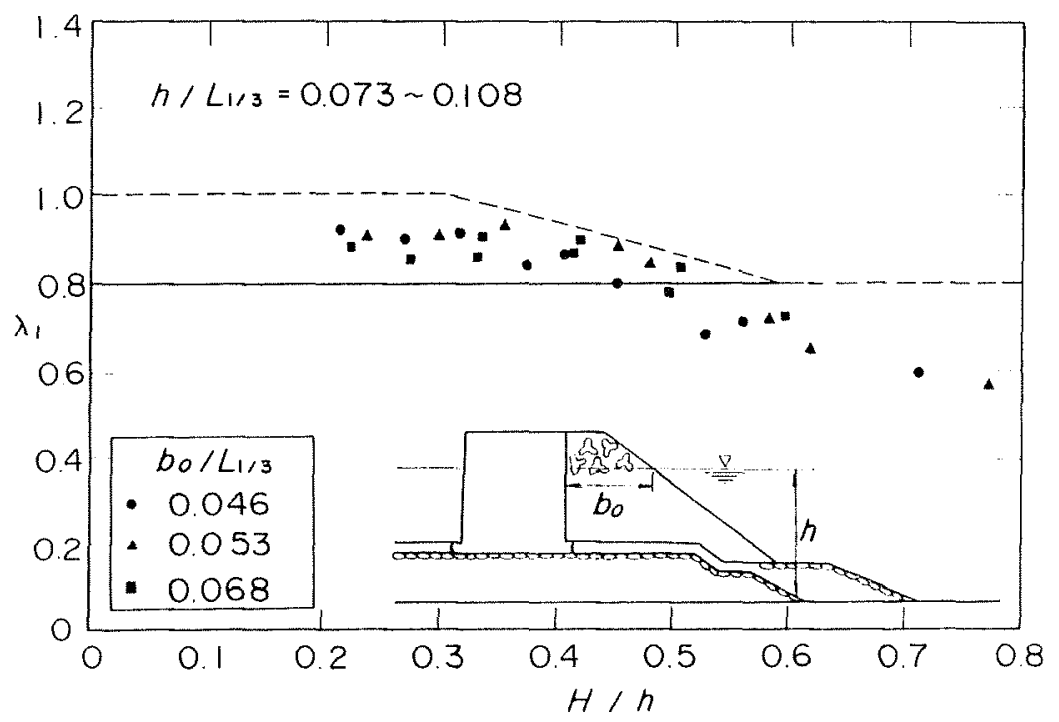

Fig. 6.5 Reduction of wave force on the vertical wall due to wave- dissipating blocks (Takahashi et al., 1990)

$$
\begin{array}{rlrl}
\lambda_{1}=\lambda_{3} & =1.0 & & : H / h<0.3 \\
& =1.2-2 / 3(H / h) & & : 0.3<H / h<0.6 \\
& =0.8 & & : H / h>0.6 \\
\lambda_{2}=0 & &
\end{array}
$$


When $\lambda_{1}-\lambda_{3}$ are applied to an ordinary block section, it becomes apparent that the wave force is significantly reduced by the covering blocks. If the covering width is enlarged, the wave force is reduced even more (Inagaki et al., 1987). On the other hand, strong impulsive pressures are generated if the covering is not sufficient (Kogami and Tokikawa, 1970).

(2) Block force on a vertical wall

When concrete blocks are installed in front of the vertical wall, the wall acts as a retaining wall supporting them. The resultant block force can be large, especially in deep water. However, as shown in Fig. 6.6, during wave action this force is greatly reduced by the movement of the upright section due to the wave force. Consequently, with the exception of breakwaters in deepwaters with relatively small wave heights, the block force can usually be neglected compared to the direct wave force.

\subsection{Stability of Wave-Dissipating Concrete Blocks}

(1) Block section

(a) Before Wave Action
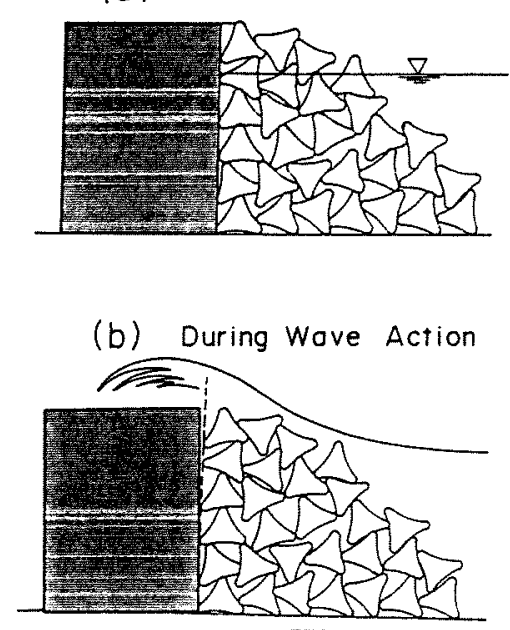

Fig. 6.6 Caisson displacement and block force

Many types of shape-designed concrete blocks have been used in horizontally composite breakwater as wave-dissipating blocks. The weight of a block varies from several to 80 tf (780 $\mathrm{KN}$ ), and most types are not reinforced with steel bars, though high interlocking blocks such as dolos blocks utilize steel reinforcement.

The blocks should completely cover the vertical wall to avoid impulsive breaking pressure on the wall. The top level of the blocks should therefore be at the same height as the crown of the vertical wall, while the width of the block section at the top should be at least twice the height of a block. The slope of the blocks $\alpha$ is usually steep, i.e., $\cot \alpha=4 / 3-1.5$, and a gentle slope (cot $\alpha>2$ ) is seldom employed in a design.

(2) Necessary weight of the blocks

Although the wave action on the wave-dissipating blocks of a horizontally composite breakwater is slightly different from that on the armor blocks of a rubble mound breakwater, the Hudson formula can still be employed to evaluate the necessary weight of the concrete blocks. Recently, van der Meer (1988b) modified the Hudson formula to include parameters such as the damage rate and number of waves.

The following aspects should be considered in the design of the block section:

1) A large design wave height requires a large weight, and therefore, the strength of block itself (integrity) becomes crucial as evidenced by the failure of the amor layer of the Sines breakwater. To avoid breakwater failure due to the breakage of blocks, the slope of blocks and their specific density can be changed instead of just using a large weight of them (see Section 7.)

2) The blocks at the breakwater head are relatively unstable compared to those at breakwater 
trunk.

3) The necessary weight of the wave-dissipating concrete blocks is probably less than that calculated by the Hudson or van der Meer formula. The reason for this is that the stability of such blocks in front of the vertical wall is higher than that of armor blocks on a rubble slope, being due to a higher permeability of the block section, also because these formulae are for armor blocks. Consequently, it is prudent to carry out model experiments to determine the optimum shape of the blocks section including their necessary mass, or to use experimental results in which similar conditions are employed. Tanimoto et al. (1985), Kajima (1994) Hanzawa et. al. (1996) conducted comprehensive studies on the stability of wave-dissipating blocks used for horizontally composite breakwaters. 


\section{PERFORMANCE DESIGN OF CAISSON BREAKWATERS}

\subsection{History and Definition of Performance Design}

While performance design started in Europe in 1960's, it became popular in the United States following the 1994 Northrige earthquake disaster. Stability performance of buildings and civil engineering structures is assessed in the performance design (SEACO,1995).

The concept of performance design is new and fluid, which allows researchers and engineers to create an integrated design framework for its development. Performance design can be considered as a design process that systematically and clearly defines performance requirements and respective performance evaluation methods. In other words, performance design allows the performance of a structure to be explicitly and concretely described.

\subsection{New Framework for Performance Design}

Table 7.1 lists five basic aspects that should comprise the basic frame of performance design: selection of adequate performance evaluation items, consideration of importance of structure, consideration of probabilistic nature, consideration of lifecycle, and inclusion of various functional design features. Regarding deformation-based reliability design, the first three aspects are applied and will be explained next, while the latter two be discussed in section 7.2.

Table 7.1 Necessary considerations for performance design

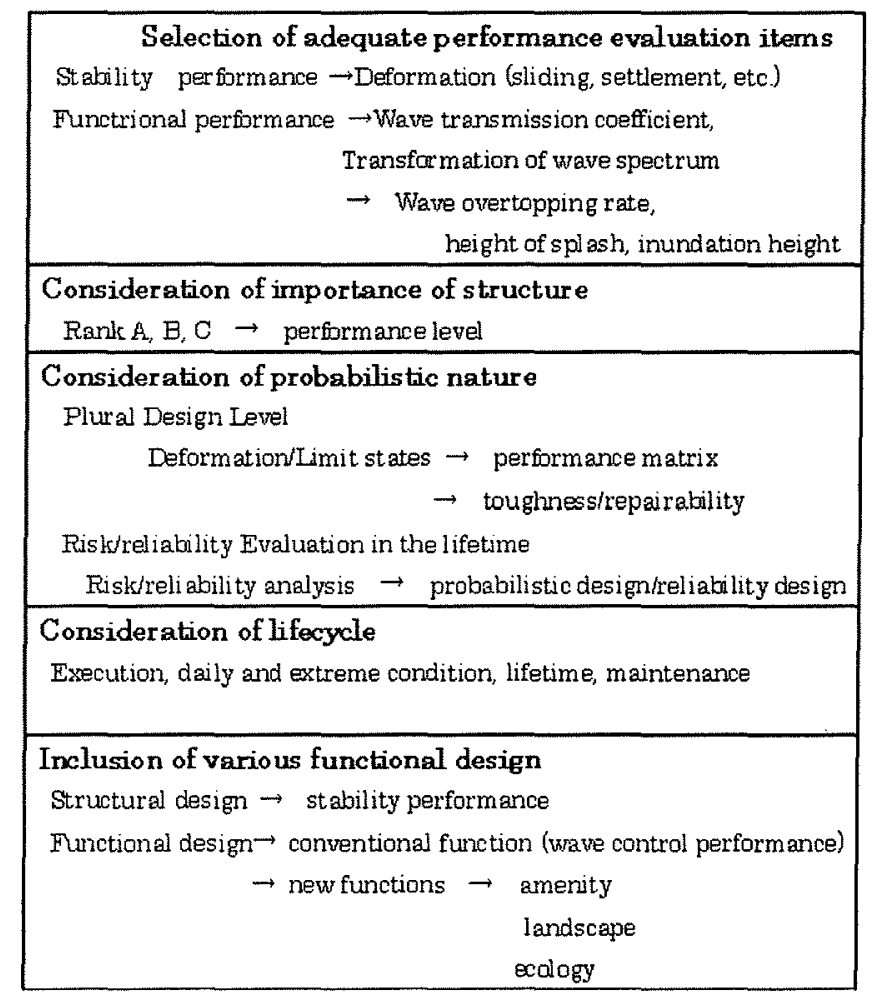

(1) Selection of adequate performance evaluation items

In the conventional design process, the stability of breakwater caissons is for example judged using safety factors of sliding and overturning, etc. based balancing external and resisting forces. Deformation such as sliding distance, however, more directly indicates a caisson's stability 
performance.

Design based on structure deformation is not new for maritime structures, i.e., in conventional design the deformation of the armor layer of a rubble mound is used as the damage rate or damage level. For example, van der Meer (1987) proposed a method to evaluate necessary weight of armor stones and blocks which can also evaluate the damage level of the armor, while Melby and Kobayashi (1998) proposed a method to evaluate the damage progression of armor stones, and we proposed one to determine the damage rate of concrete blocks of horizontally composite breakwaters (Takahashi et al., 1998).

\section{(2) Consideration of importance of structure}

Importance of the structure is considered even in current design. However, the performance design should deal with the structure's importance more systematically, and therefore the different levels of required performance should be defined in the performance design. The performance matrix can be formed considering the importance of the structure and probabilistic nature as will be described next.

(3) Consideration of probabilistic nature

Probabilistic nature should be considered in the performance design of maritime structures because waves have an irregular nature and wave actions fluctuate. "Two" methods now exist to consider probabilistic nature.

\section{a) Plural Design Levels}

Firstly, a design should include performance evaluation against external forces which exceed the deterministic design value, e.g., stability performance against a wave with a 500 -yr recurrence interval is valuable information leading to an advanced design considering robustness/toughness and reparability. This probabilistic consideration was examined after the Northridge earthquake which is the foundation of anti-earthquake performance design. Current design codes for harbor structures in Japan include two design levels: a $75^{-}$and several hundreds-yr recurrence intervals It is very important to have different design levels to consider probabilistic nature.

b) Risk/reliability evaluation in the lifetime

With regard to reliability design, three levels exist: Level 1 uses partial safety coefficients as the limit state design for concrete structures; Level 2, the next higher level, uses a reliability index which expresses the safety level in consideration of all probabilities; while Level 3, the highest level of reliability design, uses probability distributions at all design steps.

Although the partial safety coefficient and reliability index methods (levels 1 and 2) are easily employed in standard designs, the probability distribution method (level 3) more directly indicates a structure's safety probability. Research has been performed in this area. Brucharth (1993), Oumeraci et al. (1999), and Vrijling et al. (1999) proposed partial coefficients methods for caisson breakwaters, van der Meer (1988) discussed a level 3 reliability design method for armor layers of rubble mound breakwaters considering the damage level, and Takayama et al. (1994) discussed a level 3 reliability design method for caisson breakwaters that did not consider deformation (sliding). 


\subsection{PERFORMANCE DESIGN OF STABILITY OF BREAKWATER CAISSONS}

\subsubsection{Performance Evaluation Method}

(1) Fundamental considerations of deformation-based reliability design

A new performance design for the stability of breakwater caissons will be explained, being called deformation-based reliability design. Sliding distance is selected as the performance evaluation item and the probabilistic nature is fully considered. Performance design requires a reliable performance evaluation method. Thus, in deformation-based reliability design of a breakwater caisson, we developed a calculation method to determine the sliding distance due to wave actions, employing Monte Calro simulation to include the probabilistic nature of waves and response of the breakwater caisson.

(2) Calculation method of sliding distance

a) Deterministic value for a deepwater wave with recurrence interval

Table 7.2 shows the flow of the calculation method of sliding distance due to a deepwater wave with particular recurrence interval (Shimosako and Takahashi, 1999). After specifying the deepwater wave, the incident wave is calculated by the wave transformation method (Goda 1985), providing not only the significant wave height but also the wave height distribution. For each wave, wave pressure distribution is evaluated and total horizontal and vertical wave forces are obtained with components, i.e., the standing wave pressure component $\alpha_{1}$ and breaking/impulsive-breaking wave pressure component $\quad \alpha_{2} / \alpha_{\mathrm{I}}$ (Takahashi, 1996). The time profiles of these components are sinusoidal and triangle, respectively.

The resisting forces against sliding are easily obtained from its dimensions, and the resisting force due to the movement of the caisson, being called the wave-making resisting force, can be formulated using the caisson dimensions. The equation of motion of the caisson with the external and resisting forces gives the motion of the caisson and resultant sliding distance. The equation considers only two-dimensional phenomena and is solved numerically (See Chapter 4.5).

b) Probabilistic value for a deepwater wave of a recurrence interval

Even for a fixed deepwater wave condition, resultant sliding usually fluctuates due to the probabilistic nature of a group of waves and the response of the caisson. To obtain the probabilistic sliding distance for a given deepwater wave, fluctuation of the items denoted by @ should be considered. Table 7.3 shows parameters considered to reflect probabilistic nature in the present calculations and indicates bias of mean values and standard deviation (variance) of the probability distribution. The Monte Carlo simulation allows calculating the probability distribution of the sliding distance, with the calculation being repeated more than 5000 times from wave transformation to determination of the sliding distance for a fixed deepwater wave condition. From the probability distribution, the mean and 5\% exceedance value are selected to represent the calculated distribution. 
Table 7.2 Flowchart for calculating sliding distance

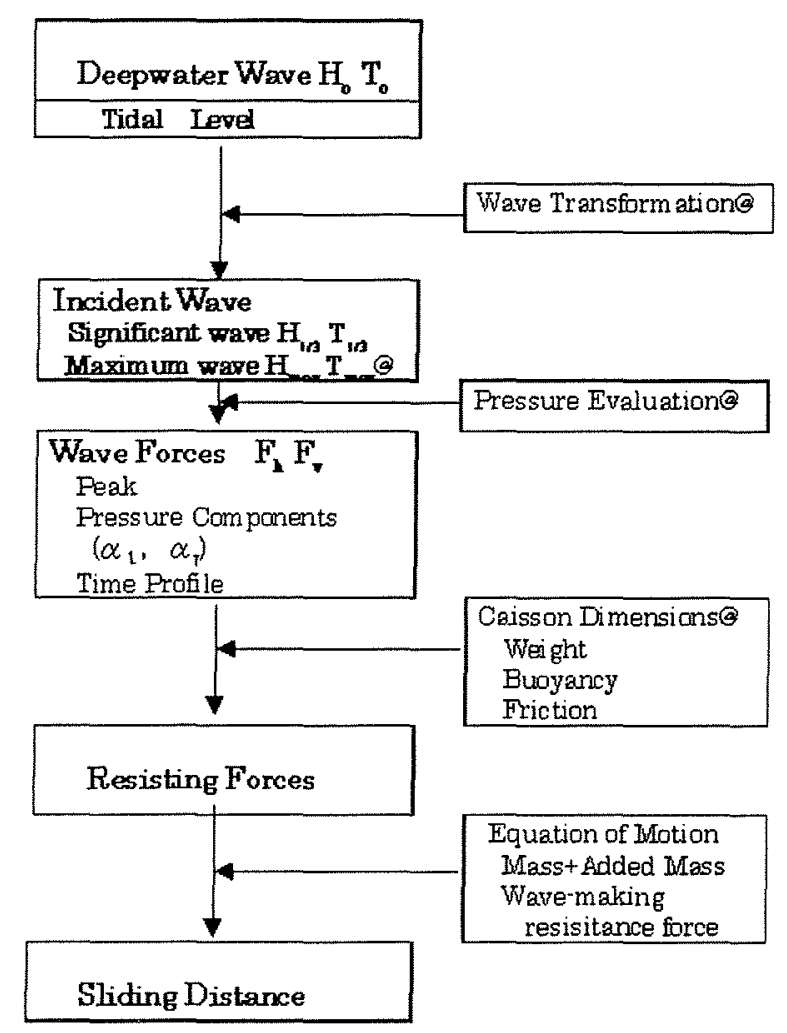

Table 7.3 Estimation errors for design parameters

\begin{tabular}{|c|c|c|}
\hline Lesignparametess & $\begin{array}{c}\text { Bas of } \\
\text { mean } \\
\text { value }\end{array}$ & Variande \\
\hline Weve Transfimation & 0 & 0.1 \\
\hline Werve Frnoes & 0 & 0.1 \\
\hline Friction Cofficiert. & 0 & 0.1 \\
\hline Cason Vid & $Q$ & 0 \\
\hline Deppuder wake & 0 & 0.1 \\
\hline Thdal level & 0 & 0.1 \\
\hline
\end{tabular}

c) Accumulated value during lifetime

To obtain the accumulated sliding distance during caisson lifetime ( $50 \mathrm{yr}$ ), one needs to consider the probabilistic nature of the deepwater wave and tidal level. The Weibull distribution with $\mathrm{k}=2.0$ is assumed as the extreme wave distribution with estimation error of $10 \%$ standard deviation. The tidal level is assumed as a triangle distribution between the L.W.L. and H.W.L. with error of $10 \%$ standard deviation. A total of 50 deepwater waves are sampled and the sliding distance is evaluated by the Monte Carlo simulation using the procedure in Table 2 . Total sliding distance due to the 50 
deepwater waves is the accumulated sliding distance for a 50.yr lifetime. The probability distribution of the accumulated sliding distance is obtained by repeating the calculations more than 5000 times.

\subsubsection{Example of Performance Evaluation}

(1) Design condition of a typical vertical breakwater

Figure 7.1 shows a cross section of a composite breakwater designed against a design deepwater wave of a 50-yr recurrence interval of $\mathrm{H}_{1 / 3}=9.2 \mathrm{~m}$ and $\mathrm{T}_{1 / 3}=14 \mathrm{~s}$ with water depth $\mathrm{h}=20 \mathrm{~m}$ (H.W.L. $=+2.0 \mathrm{~m}$ ). The caisson has width $\mathrm{B}=23.68 \mathrm{~m}$ corresponding to a sliding safety factor $\mathrm{SF}=$ 1.07. The stability performance of the caisson, considered the sliding distance here, is explained next.

(2) Deepwater wave and sliding distance (deterministic value)

Figure 7.2 shows caisson sliding distance produced by deepwater waves of different recurrence intervals, where the deterministic value of the sliding distance denoted by $\mathbf{m}$ is almost zero when the design wave with a 50-yr recurrence interval attacks. This result is considered quite reasonable since the safety factor for sliding is greater than 1.0. Note that even though deepwater wave height increases, sliding distance does not because the incident wave height is limited by wave breaking; i.e., the maximum incident wave height for a 50.yr recurrence interval deepwater wave is $15.07 \mathrm{~m}$ and only $10 \%$ higher at $16.56 \mathrm{~m}$ for a $5000-\mathrm{yr}$ one.

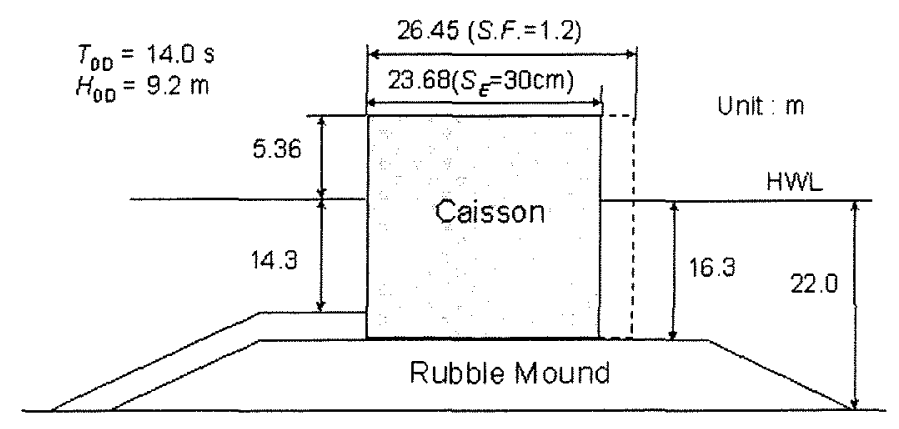

Fig. 7.1 Cross section of a composite breakwater for performance evaluation example

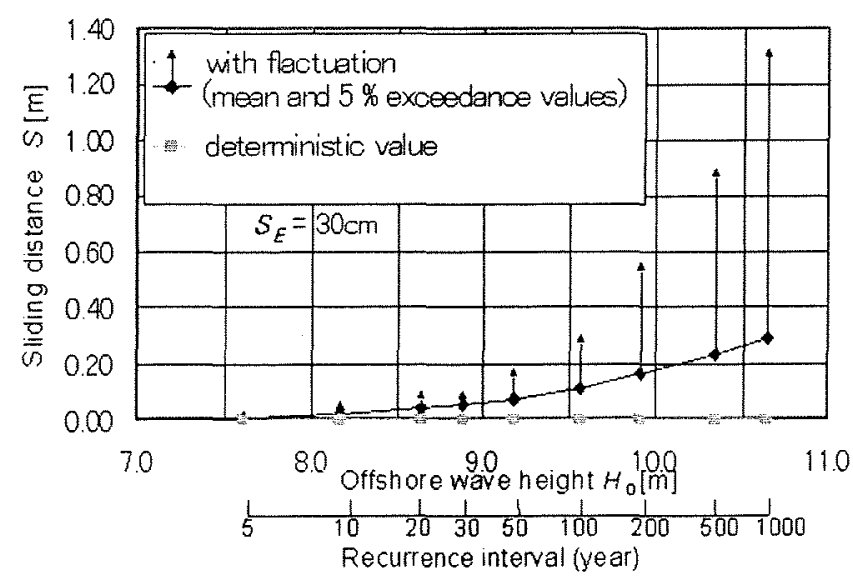

Fig. 7.2 Deepwater wave height/recurrence interval vs. sliding distance (deterministic value) 
(3) Deepwater wave and sliding distance (probabilistic value)

Figure 7.2 also shows sliding distance due to deepwater waves obtained from the Monte Carlo simulation that included fluctuation of waves and sliding response of the caisson, where the mean $(\checkmark)$ and $5 \%$ exceedance $(\uparrow)$ values of sliding distance are indicated. Due to the probabilistic nature, i.e., the occurrence of larger incident wave height and larger sliding, even the mean value of the sliding distance is greater than the deterministic values. In fact, the $5 \%$ exceedance value is much larger the mean value. For example, for a wave with a 50 -yr recurrence interval the mean value of the sliding distance is $7 \mathrm{~cm}$ and the $5 \%$ exceedance value is $17 \mathrm{~cm}$, whereas for a wave with a $500-y \mathrm{r}$ recurrence interval the values are 23 and $88 \mathrm{~cm}$, respectively. Obviously then, the probabilistic nature must be considered.

(4) Probability of exceedance for a deepwater wave of $\mathrm{N}$-yr recurrence interval over life time Figure 7.3 shows the probability of exceedance of the occurrence of the deepwater wave over a $50-y r$ lifetime (design working time) vs. the recurrence interval of the deepwater wave. Since the estimation error in the Weibull distribution is considered to be 0.1 (variance), the probability of exceedance for the wave of a $50 \mathrm{yr}$ recurrence interval is $>80 \%$, being high compared to the conventional value of $63 \%$. Even for the wave of a 500-yr recurrence interval the exceedance is still high, nearly $30 \%$. For this reason the design should (i) evaluate sliding performance due to waves with larger recurrence intervals, and (ii) investigate overall sliding performance over the entire lifetime of the structure.

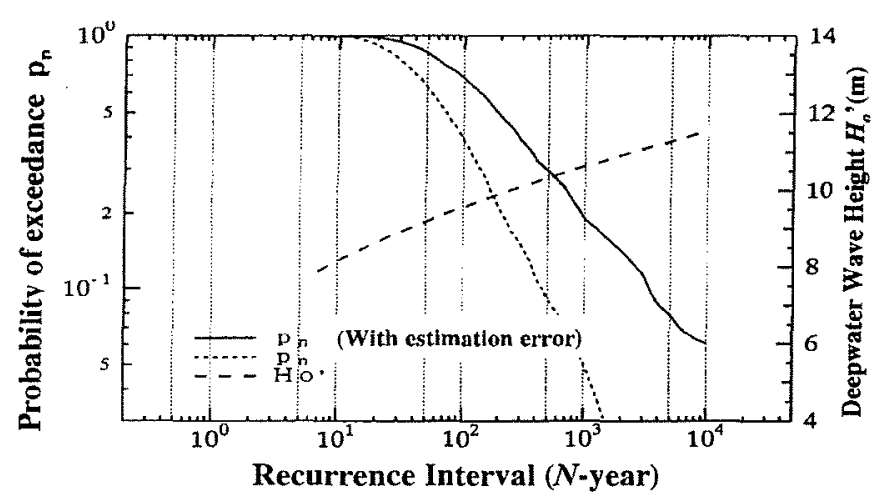

Fig. 7.3 Probability of exceedance for a wave with various recurrence intervals over a $50 \mathrm{yr}$ lifetime

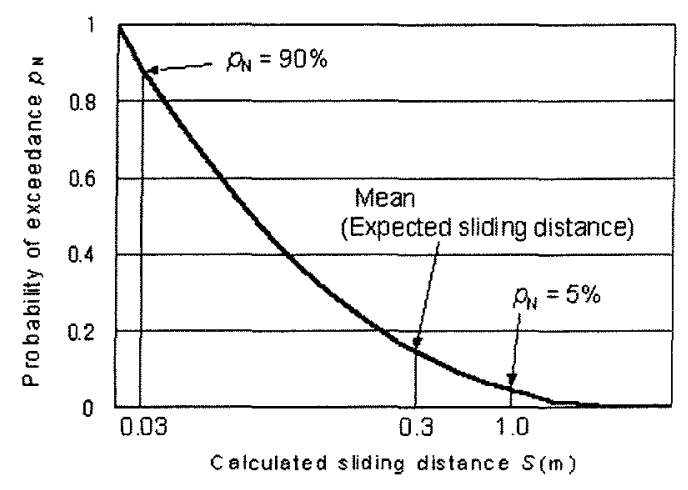

Fig. 7.4 Probability of exceedance of accumulated sliding distance over a $50 \mathrm{yr}$ lifetime

(5) Accumulated sliding distance over structure lifetime

Figure 7.4 shows the probability of exceedance of accumulated sliding distance over a $50 \cdot y r$ breakwater lifetime, where the mean value of the accumulated sliding distance, which we call the "expected sliding distance," is $30 \mathrm{~cm}$. The probability of exceedance for a sliding distance of $1 \mathrm{~m}$ is $5 \%$ and $0.5 \%$ for $10 \mathrm{~m}$. Note that the value of $30 \mathrm{~cm}$ corresponds to a $17 \%$ of probability of exceedance.

(6) Stability performance versus caisson width

Figure 7.5 shows caisson sliding distance vs. caisson width for four design levels, where expected sliding distance for a 50-yr lifetime is also shown. When caisson width $\mathrm{B}=22.1 \mathrm{~m}$, the conventional sliding $\mathrm{SF}=1.0$, and the mean value of sliding distance for a $50 \cdot \mathrm{yr}$ recurrence interval is $20 \mathrm{~cm}$ and 
the expected sliding distance is $81 \mathrm{~cm}$. In contrast, for $\mathrm{SF}=1.2(\mathrm{~B}=26.5 \mathrm{~m})$, the sliding distance is very small, i.e., the mean value for a $50 \cdot \mathrm{yr}$ recurrence interval wave is $1 \mathrm{~cm}$ and the expected sliding distance is $5 \mathrm{~cm}$.

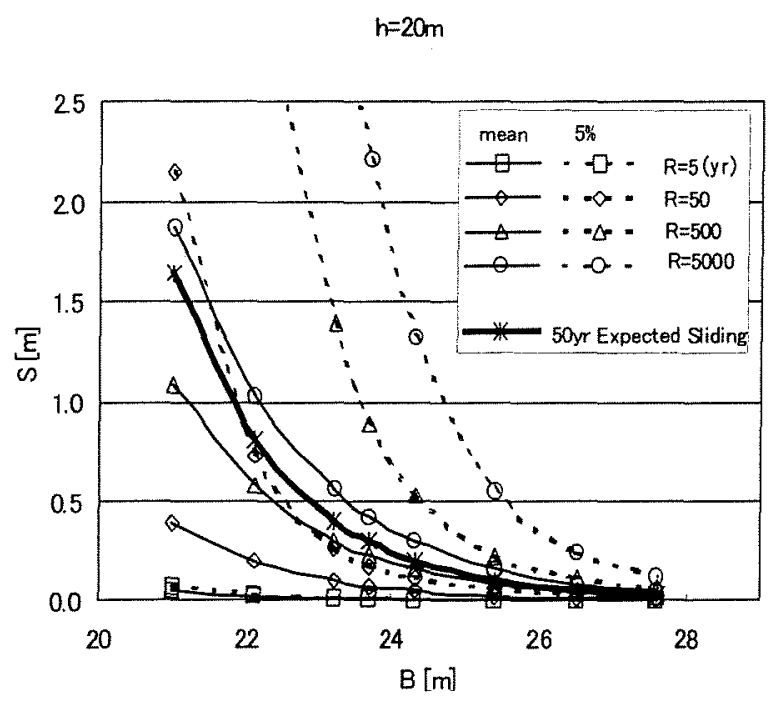

Fig. 7.5 Sliding distance vs. caisson width $(\mathrm{h}=20 \mathrm{~m})$

Table 7.4 Performance matrix of caisson

Performance Level

\begin{tabular}{|l|l|l|l|l|}
\hline \begin{tabular}{l} 
Limit states \\
\hline $5-$ year
\end{tabular} & $\begin{array}{c}\text { Serviceability } \\
(3 \mathrm{~cm})\end{array}$ & $\begin{array}{l}\text { Repairable } \\
(10 \mathrm{~cm})\end{array}$ & $\begin{array}{l}\text { Ultimate } \\
(30 \mathrm{~cm})\end{array}$ & $\begin{array}{c}\text { Collapse } \\
(100 \mathrm{~cm})\end{array}$ \\
\hline 50 -year & & $\mathrm{C}$ & & \\
\hline $500-$ year & $\mathrm{A}$ & $\mathrm{B}$ & $\mathrm{C}$ & \\
\hline 5000 -year & & $\mathrm{A}$ & & $\mathrm{B}$ \\
\hline
\end{tabular}

\subsubsection{New Design Method Based on Stability Performance}

Figure 7.5 allows us to determine the caisson width satisfying required performance (design criteria). Here, a new method is introduced to determine this parameter named "a performance matrix design method"

(1) Performance matrix design method with limit states

Table 7.4 shows a so-called performance matrix first introduced by earthquake engineers. The vertical axis is the design level corresponding to waves with four different recurrence intervals, while the horizontal axis is the performance level defined by four limit states; namely, serviceability limit, repairable limit, ultimate limit, and collapse limit, corresponding to the extent of deformation. Serviceability limit and ultimate limit are defined in the current limit states design, whereas we added the other two limit states to more quantitatively describe the change of performance. That is, the collapse limit state is defined as extremely large sliding such that the breakwater falls off the rubble foundation, while the repairable limit state is deformation that is repaired relatively easily. 
These limit states are defined by deformation, being the mean value of the sliding distance in this case. The values indicated here are so-called design criteria or allowable limits and are tentatively determined slightly conservatively, taking into account that the $5 \%$ exceedance value is 3 or 4 times larger than the mean value. Letters $\mathrm{A}, \mathrm{B}$, and $\mathrm{C}$ in Table 4 denote the importance of a breakwater, i.e., A are critical, $\mathrm{B}$ are ordinary, and $\mathrm{C}$ lesser degree. For example, if a breakwater is classified as $\mathrm{B}$, the necessary width of the caisson becomes less than $23.2 \mathrm{~m}$ for the sample breakwater.

Table 7.5 Design criteria using expected sliding distance

\begin{tabular}{|l|l|l|l}
\hline Importance of Structure & A & B & C \\
\hline Expected Sliding distance $(\mathrm{cm})$ & 3 & 30 & 100 \\
\hline
\end{tabular}

(2) Checking the design by the expected sliding distance in the lifetime

The caisson width can be checked by the expected sliding distance obtained from the probability distribution of the accumulated sliding distance. From Fig. 7.5 the sliding distance against the 500 yr recurrence interval wave is very similar to the $50 \mathrm{yr}$ expected sliding distance. Table 7.5 shows the allowable limit value of the expected sliding distance for breakwater classified as A, B, or C. which corresponds to that for 500yr recurrence interval wave in Table 7.4.

For example, if the breakwater is classified $B$, the design criteria for the expected sliding distance width is $30 \mathrm{~cm}$ and the resultant caisson width is $23.68 \mathrm{~m}$. By comparing the value of $23.2 \mathrm{~m}$ determined from the performance matrix design method, a width of $23.68 \mathrm{~m}$ can be obtained as the final design value. However, the difference of the width is only $2 \%$ and the $50 y$ r expected sliding distance for the caisson of $23.2 \mathrm{~m}$ witdth is $38 \mathrm{~cm}$, which is very close to $30 \mathrm{~cm}$. The allowable limit value of the expected sliding distance in Fig.7.5 is used only for checking, and therefore, we use the value of $23.2 \mathrm{~m}$ for the final design.

The determined width is more than $10 \%$ smaller than the conventional design value, i.e., the caisson width is reduced by clarifying its stability performance. For a breakwater in high importance category $\mathrm{A}$, the necessary caisson width is $26 \mathrm{~m}$ to ensure that the expected sliding distance is less than $3 \mathrm{~cm}$, while that for one in less importance category $\mathrm{C}$ is $21.2 \mathrm{~m}$ for an expected sliding distance of $100 \mathrm{~cm}$.

\section{(3) Deep water example}

Figure 7.6 shows the sliding distance versus caisson width for each design level in addition to the expected sliding distance. The water depth $\mathrm{h}$ is $30 \mathrm{~m}$ in this case, being quite deep compared to that in Fig. 7.5. Using the performance matrix (Table 7.4), the necessary caisson width for ordinary importance $B$ is $22 \mathrm{~m}$, while that determined by the expected sliding distance of $30 \mathrm{~cm}$ is $23.9 \mathrm{~m}$; a value that corresponds to a sliding SF of 1.3 , which exceeds a SF of 1.2 corresponding to a width of $22.1 \mathrm{~m}$. Obviously the maximum wave height in deep water is not limited by water depth and therefore the necessary width becomes larger than the conventional design value. Accordingly, deformation-based reliability design is capable of effectively evaluating stability performance, with 
the resultant width closely corresponding to stability performance.

For a caisson width of $23.9 \mathrm{~m}$ in which the expected sliding distance is $30 \mathrm{~cm}$, the sliding distance due to a wave with 500-year recurrence interval is $20 \mathrm{~cm}$ and that for one with a 50 -year recurrence interval is $4.6 \mathrm{~cm}$. The design criteria for expected sliding distance usually gives a larger width than that determined by the performance matrix; hence the expected sliding distance determines the necessary caisson width. This tendency is in fact intended when determining the design criteria for the performance matrix, although to confirm stability performance it is still necessary to check the caisson's sliding distance due to waves at each design level.

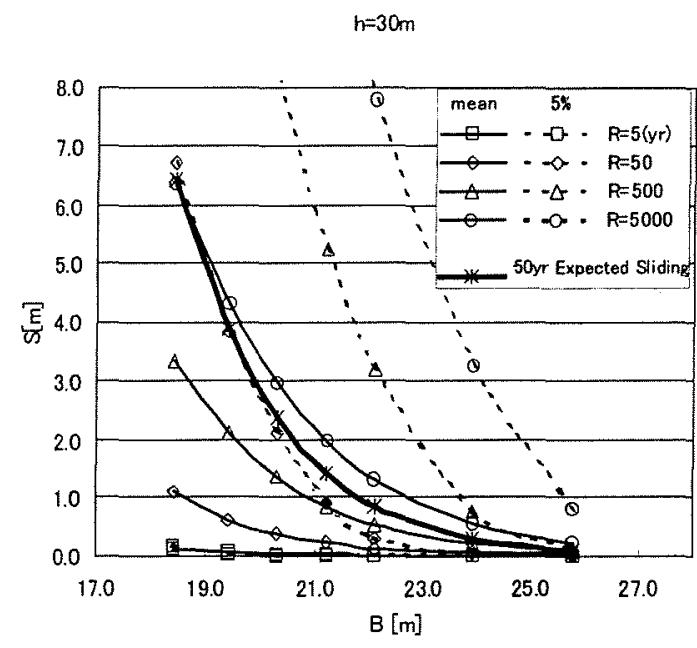

Fig. 7.6 Sliding distance vs. caisson width $(\mathrm{h}=30 \mathrm{~m})$

7.4 Extended Periurmance vesign

Table 7.1 in 7.1 presents new considerations to be included in performance design, i.e., the selection of appropriate performance items, consideration of importance of structure and consideration of probabilistic nature as discussed above.

In addition, new designs should be extended to include life-cycle considerations, and a performance design should elucidate all performance aspects over structure lifetime. In conventional maritime design, only a short period is considered for exceptional waves attacking a breakwater although the construction period is considered when necessary. Since a structure performs during its design working time (lifetime) and therefore its deterioration and maintenance should be considered in the design stage. While fatigue is included in the conventional design process, maintenance is not. Moreover, performance during the majority of time, or ordinary time, should be investigated in the design stage, e.g., even small waves reflected off a vertical breakwater disturbs the smooth entrance of fishery boats into a harbor.

The design process is usually divided into functional and structural designs. Structural design includes the stability of the entire structure and strength of its members, while functional design is related to objectives of the structure such as preventing wave-overtopping or damping of waves. In extended performance design, environmental considerations such as amenity, landscape, and ecology should be included in the functional design. 


\section{REFERENCES}

AHRENS, J. P. (1981) "Irregular wave run-up on smooth slopes," Technical paper, US Army Corps of Engrs., CERC, Fort Belvoir, Tech. Paper 81-17.

AHRENS, J. P. (1987) "Characteristics of reef breakwaters," USA Army Corps of Engrs., Vicksburg, Tech. Rep. CERC, pp. 87-17.

ALLSOP, N. W. H. (1983) "Low"crest breakwaters, studies in random waves," Proc. of Coastal Structures '83. ASCE.

ALLSOP, N. W. H., HAWKES, P. I., JACKSON, F. A. et al. (1985) "Wave run-up on steep slopes model tests under random waves," Hydraulics Res. Wallingford. Rep. SR 2.

ALLSOP, N. W. H. (1990) "Reflection performance of rock armoured slopes in random waves," Proc. of the 22nd Coastal Eng. Conf. Delft, The Netherlands.

ALLSOP, N. W. H. and MCBRIDE, N. W.(1994) "Reflections from vertical walls: the potential for improvement in vessel safety and wave disturbance," Proc. Int. Workshop on Wave Barriers in Deepwaters, Port and Harbor Res. Inst.

AMINTI, P. and FRANCO, L.(1988) "Wave overtopping on rubble mound breakwaters," Proc. of the 21st ICCE, Malaga, Spain.

ARAMI, A. and HATTORI., S. (1990) "A model of impulsive pressure" Proc. of Coastal Engg., Vol. 37, JSCE, pp. 629-633, (in Japanese).

BAGNOLD, R. A. (1939) "Interim report of wave pressure research," Jour. of Inst. Civil Engrs., Vol. 12 , pp. 202-226.

BAIRD, W. F. and HALL, K. R. (1984) "The design of breakwaters using quarried stones," Proc. of the 19th Coastal Eng., Houston, USA.

BARENDS, F. B. J. (1988), "Discussion on paper 5," Proc. of the Conf. on Breakwaters 1988, Eastbourne, UK, Inst. of Civil Engrs., London.

BATTJES, J. A. (1974), "Surf similarity," Proc. of the 14th Conf. on Coastal Engg, Copenhagen, Denmark, pp.466 480 .

BENEZIT, A. (1923) "Essai sur les digues maritimes verticales."

BEZUIJEN, A., KLEIN BRETTELER, M., and BAKKEN, K. I. (1987) "Design criteria for placed block revetments and granular filters," Proc. of the International Conf. on Coastal and Port Eng. in Developing Countries, Beijing, China.

BOTTIN, R., CHATHAM, C., and CARVER, R. (1976) "Waianae Small-Boat Harbor, Oahu, Hawaii, Design for Wave Protection," TR h-76-8, U.S. Army Engineer Waterways Experiment Station, Vicksburg, Miss.

BREBNER, A. and DONNELLY, D. (1962) "Laboratory study of rubble foundations for vertical breakwaters," Proc 8th Intl. Conf. on Coastal Engineering, New Mexico City, ASCE, pp. 406-429. BRADBURY, A. P., ALLSOP, N. W. H., and STEVENS, R. V. (1988) "Hydraulic performance of breakwater crown wall," Report No. SR 142, HRS.

BURCHARTH, H. F. (1983) "Material, structural design of armour units," Seminaral rubble mound breakwaters, Royal Inst. of Tech., Sweden, Bull. TRITA-VBI-120.

BURCHARTH, H. F. (1984) "Fatigue in breakwater armour units," Proc. of the 19th ICCE, Houston, USA.

BURCHARTH, H. F. and BREJNEGAARD-NIELSEN, T. (1986) "The influence of waist thickness of Dolosse on the hydraulic stability of Dolos armour," Proc. of the 20th ICCE, Taipei, Taiwan. 
BURCHARTH, H. F. and FRIGAARD, P. (1987) "Stability of roundheads and trunk erosion," Proc. of ASCE Conf. on Berm Breakwaters, Ottawa, Canada.

BURCHARTH, H. F. and FRIGAARD, P. (1988) "On 3-dimensional stability of reshaping breakwaters," Proc. of the 21st Coastal Eng. Conf., Malaga, Spain.

BURCHARTH, H. F. (1989) "Uncertainty related to environmental data and estimated extreme event," Rep. of sub-group B, working group 12, PTCII, PIANC, Brussels.

BURCHARTH, H. F. and LIU, Z. (1990) "A general discussion of problems related to the determination of concrete armour unit stress including specific results related to static and dynamic stresses in Dolosse," Proc. of the Seminaral Stresses in Concrete Armour Units, ASCE, Vicksburg, USA.

BURCHARTH, H. F. and LIU, Z. (1992) "Design formulae for hydraulic and structural stability of Dolos armour," Proc. of the 23th Coastal Eng. Conf., Venice.

BURCHARTH, H. F. (1993)" Development of a partial safety factor system for the design of rubble mound breakwaters," PIANC PTII working group 12, subgroup F, Final Report, pub-lished by PIANC, Brussels.

BURCHARTH, H. F. and FRIGAARD, P., BERENGUER, J. M., and MADRIGAL, B. G., (1995) "Design of the Cievana breakwater, Bilbao," Proc. of Coastal Structures and Breakwaters, Institution of Civil Engineers, London, U.K.

BURGER, W. W., OUMERACI, H. and PARTENSCKY, H. W. (1990) "Impact strain investigations on Tetrapods: Results of dry and hydraulic tests," Proc. of the Seminar Stresses in Concrete Armour Units, ASCE, Vicksburg, USA.

COOKER, M. J., and PEREGRINE, D. H., (1990) "A model for breaking wave impact pressure," Proceeding of 22nd International Conference on Coastal Eng., Delft, ASSCE, pp. 1473-1489.

CASTRO, E. (1933) "Diques de escollera," Revista de Obras Publicas.

CIRIA and CUR (1990) "Manual on the use of rock in coastal and shoreline engineering," London, UK.

DANEL, P. (1953) "Tetrapods," Proc. Fourth Int. Conf. Coastal Eng., ASCE, Chicago, pp. 390-398.

ENDO, K. and TAKAHASHI, S. (1994) "Numerically modeling personal danger due to overtopping waves on a promenade breakwater," Proc. 24th International Conference on Coastal Eng., Kobe, ASCE.

FOURNIER, C. P., SAYAO, O. J. and CALDAS, F. (1990) "Berm breakwater contamination study Sergipe Marine Terminal," Brazil. Proc. of the 22nd Coastal Eng. Conf., Delft, The Netherlands.

FUNAKOSHI, H., (1994) "Survey of long-term deformation of composite breakwaters along the Japan sea," pp. 239-266. Proceeding of the International Workshop on Wave Barriers in Deepwaters, PHRI, Yokosuka, Japan, PHRI, pp. 239-266.

GAILLARD, B. (1905) "Wave action in engineering structures," Eng. News, 23 Feb.

GIVLER, L. D. and SORENSEN, R. M. (1986) "An investigation of the stability of submerged homogeneous rubble mound structures under wave attack," H.R. IMBT Hydraulics, Lehigh Univ. Lehigh, USA. Rep. IHL 110·86.

GODA, Y. and KAKIZAKI, S. (1966) "Study on finite amplitude standing waves and their pressures upon a vertical wall," Rept. Port and Harbour Res. Inst., Vol. 5, No. 10, 57 p. (in Japanese) or Coastal Engg. in Japan, Vol. 10, 1967, pp. 1-11.

GODA, Y. (1967) "Wave forces on structures," JSCE Hydraulic Eng. Series 67-10, (in Japanese).

GODA, Y. and HARANAKA, S. (1967) "An experiment of the shock pressure of breaking waves," 
Tech. Note of the Port and Harbour Res. Inst., No. 32, pp. 1·18, (in Japanese).

GODA, Y. (1969) " Reanalysis of Laboratory Data on Wave Transmission over Breakwaters," Rept. Port and Harbour Res. Inst., Vol. 8, No. 3, pp. 3-18.

GODA, Y. and YOSHIMURA, T. (1971) "Wave force component for structures of large diameter isolated in offshore," Report of Port and Harbour Research Institute, Vol. 10, No. 4. pp. 3-52, (in Japanese).

GODA, Y. (1972) "Laboratory investigation of wave pressures exerted upon vertical and composite walls," Rept. Port and Harbour Res. Inst., Vol. 11, No. 2, pp. 3·45 (in Japanese) or GODA, Y. (1972): Experiments on the transition from nonbreaking to post breaking wave pressures. Coastal Eng. in Japan, 15, 81-90.

GODA, Y.(1973a) "Motion of composite breakwater on elastic foundation under the action of impulsive breaking wave pressure (in Japanese)," Rept. Portand Harbour Res. Inst., Vol. 12, No. 3, pp. 3-29, or Goda, Y. (1994) "Dynamic response of upright breakwater," Journal of Coastal Eng., Vol. 22.

GODA, Y. (1973b) "A new method of wave pressure calculation for the design of composite breakwater," Rept. Port and Harbour Res. Inst., Vol. 12, No. 3, pp. 31-70, (in Japanese) or Proc. 14th Conf. Coastal Eng., 1974, ASCE, Copenhagen, pp. 1702-1720.

GODA, Y. (1985) "Random seas and design of maritime structures," Univ. Tokyo Press.

GODA, Y. (1988) "On the methodology of selecting design wave height," Proc. 21st International Conference on Coastal Engineering, Spain, Malaga, pp. 899-913.

GODA, Y. and TAKAGI, H. (2000) "A reliability design method for caisson breakwaters with optimal wave heights," Coastal Engineering Journal, 42(4), pp. 357-387.

GRAAUW, A. F. F., VAN DER MEULEN, T., and DE BYE, D. (1984) "Granular filters: Design criteria. Journal of Waterways," Port, Coastal and Ocean Division, ASCE, 110(1).

GUNBAK, A. R.(1979) "Rubble Mound Breakwaters," Division of Port and Ocean Eng. Technical Univ. of Norway, Trondheim, Rep. 12/77.

HAYASHI, T., and IMAI, T. (1964) "Breaking wave pressure and sliding of caisson," Proc. of Coastal Eng., Vol. 11, JSCE, pp. 184-192, (in Japanese).

HEDAR, P. A.(1965) "Rules for the design of rock-fill breakwaters and revetments," XXI Internat Navig Congress, Section II-1, Stockholm.

HIROI, I.(1919) "On a method of estimating the force of waves," Journal of College of Engg., Tokyo Imperial Univ., Vol. 10, No. 1, pp. 1-19.

HITACHI, S. (1994) "Case study of breakwater damages - Mutsu-ogawara Port-" Proc. of Intl. Workshop on Wave Barriers in Deepwaters, PHRI,pp. 308-331.

HAMILTON, D. G. and HALL, K. R. (1992) "Preliminary analysis of the stbility of rubble mound breakwater crown wall," Proceeding of 23rd International Conference on Coastal Engineering, ASCE, pp. 1217-1230.

HORIKAWA, K. and NOGUCHI, Y. (1970) "Relation between the wave force and wave profile of breaking wave on vertical wall," Proc. of Coastal Engg. JSCE, Vol. 17, pp. 177-184, (in Japanese).

HORIKAWA, K., OZAWA, Y., and TAKAHASHI, K. (1975) "Expected sliding distance of high mound composite breakwater," Proc. of Coastal Engg. JSCE, Vol. 19, pp. 351-356, (in Japanese).

HOWELL, G. L. (ed.) (1985) "Proc. of workshop on measurement and analysis of structural response in concrete armor units," Waterways Experiment Station, Coastal Eng. Res. Center, Vicksburg, Mississippi, USA. 
HOWELL, G. L. (1988) "Measurement of forces on dolos armor units at prototype scale," Proc. of the 21 st Conf. on Coastal Eng. Malaga, Spain.

HUDSON, R. Y. (1958) "Design of quarry stone cover layers for rubble mound breakwaters," WES, Vicksburg, Res. Rep. 2.2.

HUDSON, R. Y. (1959) "Laboratory investigation of rubble mound breakwater," Journal of Waterways, Harbors Division, ASCE, 85 (WW3). pp. 93-121.

INAGASKI, K., TSUNEI, K., HATTORI, M., and ENDO, T. (1987) "Wave force on a breakwater with concrete block mound of energy dissipating type," Proceeding of Japanese Conference on Coastal Engineering, Vol. 34, (in Japanese).

IRIBARREN CAVANILLES, R. (1938) "Una formula para el calculo de diques de escollera," Revista de obras Publicas.

IRIE, I., KURIYAMA, Y., and ASAKAWA, H., (1986) "Study on scour in front of breakwaters by standing waves and protection method," Report of Port and Harbour Research Institute, Vol. 25, No. 1, pp. 3-86, (in Japanese).

ITO, Y., FUJISHIMA, M., and KITATANI, T. (1966) "On the stability of breakwaters," Rept. Port and Harbour Res. Inst., Vol. 5, No. 14, 134 p.(in Japanese) or Coastal Engg. in Japan, Vol.14, 1971, pp.53-61.

ITO, Y.(1969) "A treatise on historical development of breakwater design," Tech. Note of Port and Harbour Res. Inst., No.69, 78p., (in Japanese).

ITO, Y. and TANIMOTO, K.(1972) "Meandering Damages of Composite Type Breakwaters," Tech. Note of Port and Harbour Res. Inst., No. 112.(in Japanese).

JARLAN, G. E. (1961) "A perforated vertical breakwater," The Dock and Harbour Authority, Vol. 41, No. 488, pp. 394-398.

JENSEN, O. J. (1984) "A monograph on rubble mound breakwaters," Danish Hydraulic Inst. Horsholm, Denmark.

JUHL, J. (1994) "Danish experience and recent research on vertical breakwaters," Proc. of International Workshop on Wave Barriers in Deepwaters, PHRI, pp. 154·171.

KAJIMA, R. (1994) "A new method of structurally resistive design of very important seawalls against wave action," Proc. of Intl. Workshop on Wave Barriers in Deepwaters, PHRI, pp. 459-518.

KAKUNO, S. (1994) "Status and trends in the wave pressure calculations for coastal structures in Japan," Proc. of Intl. Workshop on Wave Barriers in Deepwaters, PHRI, pp. 519-537.

KAMPHUIS, J. W. and MOHAMED, N., (1978) "Run-up of Irregular Waves on Plane Smooth Slope," ASCE J. Waterw. Port Coastal Ocean Div., 104(WW2) pp.135-147.

KARMAN., Von, (1929) "The impact on sea plane floats during landing," NACA, TN321, pp. 1-8.

KATAOKA, S., and SAIDA, S. (1986) "Compilation of breakwater structures," Tech. Note of Port and Harbour Res. Inst., No. 556,150p., (in Japanese).

KIMURA, K., TAKAHASHI, S., and TANIMOTO, K. (1994) "Stability of rubble mound foundations of caisson breakwater under oblique wave attack," Proc. 24th Int. Conf. on Coastal Eng., Kobe, ASCE.

KIMURA, K., MIZUNO, Y., and HAYASHI, M. (1998): Wave force and stability of armor units for composite breakwaters, Proceedings 26th International Conference on Coastal Engineering, pp. 2193-2206.

KIRKGOZ, S. M. (1991) "Impact pressure of breaking waves on vertical and sloping walls," Ocean 
Eng, Vol. 18 , No. $1 / 2$, pp. 45•49.

KOBAYASHI, M., TERASHI, M., and TAKAHASHI, K. (1987) "Bearing capacity of a rubble mound supporting a gravity structure," Rept. Port and Harbour Res.Inst., Vol. 26, No. 5, pp. 215-252.

KOBUNE, K. and OSATO, M. (1976) "A Study of Wave Height Distribution Along a Breakwater with a Corner," Rept. of Port and Harbour Res. Inst., Vol. 15, No. 2, (in Japanese).

KONDO, H. and TAKEDA, H. (1983) "Wave Dissipating Structures," Morikita Publishing Co. Ltd. 275 p., (in Japanese).

KUO, C. T. (1994) "Recent researches and experinces on composite breakwaters in Taiwan," Proc. Intl. Workshop on Wave Barriers in Deepwaters, PHRI, pp. 200-217.

KOUGAMI, Y. and TOKIKAWA, K. (1970) "Experimental study on the reduction of wave force due to wave dissipating concrete blocks during construction," Proc. of Coastal Eng., Vol. 17, pp. 205-210, (in Japanese).

LAMBERTI, A. and FRANCO, L. (1994) "Italian experience on upright breakwaters," Proc. Intl. Conf. on Wave Barriers in Deepwaters, PHRI,pp. 25-73.

LARRAS, J. (1952) "L'equilibre sous-marin d'un massif de materiaux soumis a la houle," Le Genie Civil.

LARRAS, J. (1961) "Cours d'Hydrauiique Maritime et de Travaux Maritimes," Dunod, Paris, pp. 244-245.

LIGTERINGEN, H., ALTINK, H., and VAN ORCHOT, J. H. (1990) "Strength of concrete armour units, joint industry research," Proc. of a Seminar on Stresses in Concrete Armour Units, ASCE, Vicksburg, USA.

LIGTERINGEN, H. (1994) "Other European experiences on deepwater breakwaters," Proc. of Intl. Workshop on Wave Barriers in Deepwaters, PHRI, pp.185-199.

LOSADA, M. A. and GIMENEZ-CURTO, L. A. (1980) "Mound Breakwaters Under Wave Attack," Int. Seminar on Criteria for Design and Construction of Breakwaters and Coastal Structures. Dep. of Oceanographical and Ports Eng. Univ. of Santander, Santander, Spain. Sect. II, pp. 127-238.

LOSADA, M. A. (1990) "Recent development in the design of mound breakwaters," Chapter 21 in Handbook of Coastal and Ocean Engineering, edited by J. B. Herbich, Gulf Publishing Co., Houston

LUNDGREN, H. (1969) "Wave shock forces," Proc. Res. on Wave Action, Delft,Vol. II.

MADSEN, O. S., and WHITE, S. (1979) "Reflection and Transmission Characteristics of Porous Rubble-Mound Breakwaters," MR 76-5, Coastal Eng. Res. Center, U.S. Army Waterways Experiment Station, Vicksburg, Miss.

MAGOON, O. T. and BAIRD, W. F. (1977) "Breakage of Breakwater Armor Units," Proc. of the Symposium on Design Rubble-Mound Breakwaters, British Hovercraft Corporation, Isle of Wright.

MARKLE, R. G. (1990) "Crescent City instrumental model Dolos study," Proc. of a Seminar on Stresses in Concrete Armour Uits, ASCE, Vicksburg, USA.

MELBY, J. A. and KOBAYASHI, N. (1998) "Damage progression on breakwaters," Proc. 26th International Conference on Coastal Engineering, pp. 1884-1897.

MINIKIN, R. R. (1950) "Winds, Waves and Maritime Structures," Griffin, London, 294 p.

MITSUYASU, H. (1961) "Experimental study on wave force against a wall," Rept. Transp. Tech. Res. Inst., No. 47, 39 p, or Coastal Eng.,in Japan,Vol. 5, pp. 24-27.

MITSUYASU, H. (1966) "Shock pressure of breaking wave," Proc. of 10th Coastal Eng. Conf., ASCE, 
pp. 268-283.

MIZUNO, Y., SUGIMOTO, Y., KIMURA, K., YAMANAKA, K., and KIKUCHI,S. (1993) "Wave forces on breakwater with high crown," Proc. of Japanese Coastal Eng, Vol. 40, (in Japanese).

MONTGOMERY, R., HOFMEISTER, G. J., and BAIRD, W. F. (1987) "Implementation and performance of berm breakwater design at Rachine," Berm Breakwaters, ASCE.

MORIHIRA, H. and KUNITA, O. (1979) "Model experiments on hydraulic characteristics of sloped wall breakwater," Proc. Japanese Coastal Eng., Vol. 26, pp. 295-288.

NAGAI, S. and KURATA, K. (1974) "Investigations of wave pressure formulas due to damages of breakwaters," Proc. 14th Intl. Conf. on Coastal Eng., Copenhagen, ASCE, pp.1721-1740.

NAKADA, K., TERAUCHI, K., HISHIDA, H., and UMEKI, K. (1984) "Characteristic of low crown composite breakwaters," Proc. Japanese Conference on Coastal Engineering, Vol. 31, pp. 532-536, (in Japanese).

NUMATA, A. (1976) "Laboratory Formulation for Transmission and Reflection at Permeable Breakwaters of Artificial Blocks," Coastal Eng. In Japan, Vol. XIX. pp. 47-58.

OKADA,Y., WATANABE,T., SUGAWARA, T., and TANIMOTO,K. (1990) "Recent developments of new type breakwaters in Japan," PIANC 27th Inter. Congress, Osaka.

OUMERACI, H., PARTENSCKY, H. W., TAUTENHAIN, E., and NICKELS, H. (1991) "Large-scale model investigations: a contribution to the revival of vertical breakwaters," Proc. Conf. on Coastal Structures and Breakwaters, I.C.E., pp. 167-180.

OUMERACI, H. and KORTENHAUS, A. (1992) "Analysis of the dynamic response of caisson breakwaters," proc. 23rd ICCE, Venice, ASCE.

OUMERACI, H. (1994) "Scour in front of vertical breakwaters - Review of problems," Proceeding of International Workshop on Wave Barriers in Deepwaters, PHRI, pp. 281-317.

OUMERACI, H., ALLSOP, N. W. H., De GROOT, M. B., CROUCH, R. S., and VRIJILING, J. K. (1999) "Probabilistic design methods for vertical breakwaters," Proc. of Coastal Structures'99, pp. 585-594.

OWEN, M. W. (1980) "Design of seawalls allowing for wave overtopping," 294, Hydraulics Res., Wallingford. Rep. Ex 294.

OWEN, M. W. (1982) "The hydraulic design of seawall profiles," Proc.of the Conf. on Shoreline Protection, ICE, Southampton, UK.

PARTENSCKY, H. W. (1988) "Dynamic forces due to waves breaking at vertical coastal structure," Proc. of the 21st ICCE, pp. 2504-2518.

PIERRE, R. (1953) "La jetee de Mustapha au Port d'Alger," Ann. Ponts et Chaussees, Avr.-Mai.

POWELL, K. A. and ALLSOP, N. W. H. (1985) "Low•crest breakwaters, hydraulic performance and stability," Hydraulics Res., Wallingford, UK. Rep. SR57.

PRICE, A. W. (1979) "Static stability of rubble mound breakwaters," Rep.of Hydraulics Res. Station, Wallingford, UK.

RICHEY, E. P. and SOLLITT, C. K. (1970) "Wave attenuation by porous walled breakwater," Proc. ASCE, Vol. 96, WW3.

SAINFLOU, G. (1928) "Essai sur les digues maritimes verticales," Ann. Ponts et Chaussees, Vol. 98, No. 1, pp. 5-48.

SAKAMOTO, Y., MIYAJI, Y., UENISHI, T., and TAKEDA, H. (1984) "Experimental study on hydrodynamic function of rubble mound beakwaters," Rept. Civil Eng. Reseach Inst. of Hokkaido Development Brueau, No. 82, 31 p., (in Japanese). 
SATO, T., YAMAGATA, N., FURUKAWA, M., TAKAHASHI, S., and HOSOYAMADA, T. (1992) "Hydraulic characteristics of the sloping top caisson covered with wave dissipating blocks," Proc. Japanese Coastal Eng., Vol. 39, pp. 556-560, (in Japanese).

SAVILLE, T., Jr. (1963) "Wave Run-up on Composite Slopes," Proc. 6th Conf. on Coastal Eng., pp.691-699.

SCOTT et al. (1986), Delft Hydraulic 1980 Aalborg Univ.(1987), p. 53.

SEACO(1995) "Vision 2000-Performance-based seismic engineering of bridges".

SELLING, W. N. and AHRENS, J. (1981) "Estimation of wave reflection and energy dissipation coefficients for beaches, revetments and breakwaters," USA Army Crops of Engrs, Coastal Eng. Res. Center, Fort Belvoir, Va.

SEELIG, W. (1980) "Two-dimensional tests of wave transmission and reflection characteristics of laboratory breakwater," TR 80-1, CERC, WES, U.S. Army.

SELLING, W. N. (1983) "Wave reflection from coastal structures," Proc. of Conf. on Coastal Structures '83. Arlington, Va.

SHIMOSAKO, K. and TAKAHASHI, S. (1994) "Determination of the sliding distance of composite breakwaters due to wave forces inclusive of impulsive breaking wave forces," Proc. 24th Intl. Conf. on Coastal Engineering, Kobe, ASCE.

SHIMOSAKO, K. and TAKAHASHI, S. (1999) "Application of reliability design method for coastal structures-expected sliding distance method of composite breakwaters," Proc. of Coastal Structures '99, pp. 363-371.

SHIMOSAKO, K, MASUDA, S., and TAKAHASHI, S. (2000) "Effect of breakwater alignment on reliability design of composite breakwater using expected sliding distance," Proc. of Coastal Engineering, JSCE, pp. 821-825.

SOWERS, G. B. and SOWERS, G. F.(1970) "Introductory Soil Mechanics and Foundations," 3d ed., MacMillan, New York.

STEVENSON, TH. (1886) "The Design and Construction of Harbours (3rd Ed.)," Adam \& Charles Black.

SUZUKI, K., TAKAHASHI, S., and KANG, Y. H. (1998) "Experimental analysis of wave-induced liquefaction in a fine sand bed," Proc. 26th International Conference on Coastal Engineering, pp.3643-3654.

TAKAHASHI, S., TANIMOTO, K., and SUZUMURA, S. (1983) "Generation mechanism of impulsive pressure by breaking wave on a vertical wall" Rept. Port and Harbour Res. Inst., Vol. 22,No. 4, pp. 3-31, (in Japanese).

TAKAHASHI, S., TANIMOTO, K., and MIYANAGA, S. (1985) "Uplift force due to compression of enclosed air layer and their similitude law," Coastal Eng. in Japan, JSCE, Vol. 28, pp. 191-206.

TAKAHASHI, S., KIMURA, K., and TANIMOTO, K., (1990) "Stability of armor units of composite breakwater mound against oblique waves," Report of Port and Harbour Research Institute, Vol. 29, No. 2, (in Japanese).

TAKAHASHI, S. and SIMOSAKO, K. (1990) "Reduction of wave force on a long caisson of vertical breakwater and its stability," Technical Note of Port and Harbour Research Institute, No. 685, (in Japanese).

TAKAHASHI, S., TANIMOTO, K., and SHIMOSAKO, K. (1990) "Wave and block forces on a caisson covered with wave dissipating blocks," Rept.Port and Harbour Res. Inst., Vol. 29, No. 1, pp. 54-75, (in Japanese). 
TAKAHASHI, S., SHIMOSAKO, K., and SASAKI, H. (1991) "Experimental study on wave forces acting perforated wall caisson breakwaters," Rept. Port and Harbour Res. Inst., Vol. 30, No. 4, pp. 3-34, (in Japanese), or Takahashi, S. and Shimosako, K.(1994), Wave pressure on a perforated wall, Proc. of International Conference on Hydrotechnical Eng. for Port and Harbor Construction.

TAKAHASHI, S., NAKADA, H., OHNEDA, H. and SHIKAMIRI, M. (1992) "Wave power conversion by a prototype wave power extracting caisson in Sakata Port," Proc. 23rd Int. Conf. on Coastal Engineering, Venice, ASCE, pp. 3440-3543.

TAKAHASHI, S., TANIMOTO, K., and SHIMOSAKO, K. (1992) "Experimental study of impulsive pressures on composite breakwaters," Rept. Port and Harbour Res. Inst., Vol. 31, No. 5, or Takahashi, et al, (1994) "Dynamic response and sliding of breakwater caisson against impulsive breaing wave forces," Proceeding of International Workshop on Wave Barriers in Deepwaters, pp. 362-401.

TAKAHASHI, S., TANIMOTO, K. and SHIMOSAKO, K. (1994) "A proposal of impulsive pressure coefficient for design of composite breakwaters," Proc. of International Conference on Hydro-technical Eng. for Port and Harbor Construction, Port and Harbour Res. Inst.

TAKAHASHI, S. and HOSOYAMADA, S. (1994) "Hydrodynamic characteristics of sloping top caissons", Proc. of International Conference on Hydro-technical Eng. for Port and Harbor Construction.

TAKAHASHI, S., HANZAWA, M., SATO, K., GOMYO, M., SHIMOSAKO, K., TERAUCHI, K., TAKAYAMA, T., and TANIMOTO, K. (1998) "Lifetime damage estimation with a new stability formula for concrete blocks," Rpt. of Port and Harbour Research Institute, Vol. 37, No. 1, pp. 3-32 (in Japanese).

TAKAHASHI, S. and TSUDA, M. (1998) "Experimental and numerical evaluation on the dynamic response of a caisson wall subjected to breaking wave impulsive pressure," Proc. 26th International Conference on Coastal Engineering, pp.1986-1999.

TAKAHASHI, S., MIZUGUCHI, M., and GODA, Y. (1999) "Japanese technical standards for maritime facilities," Proc. of Coastal Structures '99, pp. 1049-1058.

TAKAHASHI, S., SHIMOSAKO, K., KIMURA, K., and SUZUKI, K. (2000) "Typical failures of composite breakwaters in Japan," Proc. 27th International Conference on Coastal Engineering. ASCE,pp.1885-1898.

TAKAYAMA, T. and FUJII, H. (1991) "Probabilistic estimation of stability of slide for caisson type breakwaters," Rept. Port and Harbour Res. Inst., Vol.30, No.4, pp.35-64 or Rept. of Port and Harbour Res. Inst. Vol. 31, No. 5.

TAKAYAMA, T., SUZUKI, Y., KAWAI, H., and FUJISAKU, H. (1994) "Approach to probabilistic design for a breakwater," Tech. Note Port and Harbour Research Institute, No. 785:1-36 (in Japanese).

TAKAYAMA, T., IKESUE, S., and SHIMOSAKO, K. (2000) "Effect of directional occurrence distribution of extreme waves on composite breakwater reliability in sliding failure," Proc. 27th International Conference on Coastal Engineering, ASCE (in press).

TANAKA, N. (1976) "Effects of Submerged Rubble-Mound Breakwater on Wave Attenuation and Shoreline Stabilization," Proc. 23rd Japanese Coastal Engg. Conf., pp.152-157, (in Japanese).

TANIMOTO, K., KOBUNE, K., and OHSATA, M. (1975) "Wave forces on a caisson and stress analysis of the wall for prototype breakwaters," Tech. Note of the Port and Harbour Res. Inst. No. 
224, 39 p., (in Japanese).

TANIMOTO, K., MOTO, K., ISHIZUKA, S., and GODA, Y.(1976) "An investigation on design wave force formulae of composite- type breakwaters," Proc. 23rd Japanese Conf. Coastal Engg., pp. 11-16, (in Japanese).

TANIMOTO, K. (1976) "Wave forces on a composite- type breakwater," Proc. of the 1976 Annual Res. Presentation of Port and Harbour Res. Inst., pp. 1-26, (in Japanese).

TANIMOTO, K., TAKAHASHI, S., and KITATANI, T. (1981) "Experimental study of impact breaking wave forces on a vertical-wall caisson of composite breakwater," Rept. Port and Harbour Res. Inst., Vol. 20 , No. 2, pp. 3-39, (in Japanese).

TANIMOTO,K., YAGYU,T., and GODA,Y. (1982) "Irregular wave tests for composite breakwater foundation," Proc. 18th Conf. Coastal Eng., Capetown, pp. 2144-2163.

TANIMOTO, K. and YOSHIMOTO, Y. (1982) "Theoretical and experimental study of reflection coefficient for wave dissipating caisson with a permeable front wall," Rept. Port and Harbour Res. Inst., Vol.21, No.3,in Japanese, or Proc of Coastal Structures and Breakwaters 1995.

TANIMOTO, K., and OJIMA, R. (1983) "Experimental study on wave forces acting on a superstructure of sloping breakwater and on block type composite breakwaters," Tech. Note of Port and Harbour Res. Inst., No.450, 32p., (in Japanese).

TANIMOTO, K., HARANAKA, S., and YAMAZAKI, K. (1985) "Experimental study of wave dissipating concrete blocks against irregular waves," Rept. Port and Harbour Res. Inst. Vol. 24, No. 2, pp. 85-121, (in Japanese).

TANIMOTO, K. and KIMURA, K.(1985) "A hydraulic experimental study on trapezoidal caisson breakwaters," Technical Note of Port and Harbour Res. Inst., No.528., 27p., (in Japanese).

TANIMOTO, K., TAKAHASHI, S., and KIMURA, K. (1987) "Structures and Hydraulic Characteristics of Breakwaters-The state of the Art of Breakwater Design in Japan," Rept. Port and Harbour Res. Inst., Vol. 26, No. 5, pp. 11-15.

TANIMOTO, K., ENDOH, H., AND TAKAHASHI, S. (1992) "Field experiments on a dual cylindrical caisson breakwater," 23rd Int. Conf. on Coastal Eng., ASCE, Venice.

TANIMOTO, K. and TAKAHASHI, S. (1994) "Design and construction of caisson breakwaters-the Japanese experience -," Journal of Coastal Engineering, Vol. 22, pp. 57-77.

TANIMOTO, K, FURUKAWA, K., and HIROAKI, N. (1996) "Fluid resistant forces during sliding of breakwater upright section and estimation model of sliding under wave forces," Proc. of Coastal Engineering, JSCE, pp. 846-850.

TAW (1974) "Wave run-up and overtopping," Technical Advisory Committee on Protection against Inundation.

TERRETT, F. L., OSORIO, J. D. C., and LEAN, G. H. (1968) "Model studies of a perforated breakwater," Proc. of 11th Conf. on Coastal Eng. TIMCO, G. W. and MANSARD, E. P. D. (1983) "On the interpretation of rubble-mound breakwater tests," Proc. of Coastal Structures '83, Arlington, Va. USAArmy, Coastal Eng. Res. Center (1984) "Shore Protection Manual."

TSUCHIDA, T. and TANG, Y. X. (1996) "The optimum safety factor for stability analysis of harbour structures by use of the circular arc slip method," Rpt. of Port and Harbour Research Institute, Vol. 35, No. 1, pp. 117-145 (in Japanese).

USHIJIMA, R., MIZUNO, R., and IMOTO, T.(1988) "Laboratory stability test of foot-protection blcoks for upright section of composite breakwaters," Rept. of Civil Engineering Research Institute, Hokkaido Development Bureau, No. 424, pp. 1-14, (in Japanese). 
VAN DER MEER, J. W. (1987) "Stability of breakwater armor layers-Design formulae," Coastal Eng, 11, pp. 219-239.

VAN DER MEER, J. W. (1988a) "Rock slopes and gravel beaches under wave attack," Doctoral thesis, Delft Univ. of Tech.

VAN DER MEER, J. W. (1988b) "Stability of cubes, Tetrapodes and Accropode," Proc. of Breakwater '88, Eastbourne, UK.

VAN DER MEER, J. W. (1988c) "Deterministic and probabilistic design of breakwater armor layers," Proc. American Society of Civil Engineers, J. of Waterways, Coastal and Ocean Engineering Division, 114, No. 1, pp. 66-80.

VAN DER MEER, J. W. (1991) "Stability and transmission at low-crested structures," Delft Hydraulics Rep. H-45.

VAN DER MEER, J. W. and ANGREMOND, K. (1991) "Wave transmission at low crested structures," Proc. of Conf. on Coastal Structures and Breakwaters, ICE, London.

VAN DER MEER, J. W. and HEYDRA, G. (1991) "Rocking armour units: number, location and impact velocity," Coastal Eng. 15, 21-39.

VRIJILING, J. K., VORRTMAN, H. G., BURCHARTH, H. F., and SORENSEN, J. D. (1999) "Design philosophy for a vertical breakwater," Proceedings of Coastal Structures '99, pp.631-635.

WAGNER, H. (1932) "Uber stoss-und Gleitvorgange an der Oberflache von Flussigkeiten," Zeishrift fur Angewandete Mathematik und Mechanik, Band 12, Heft 4, pp. 193-215.

WILLIS, D.H., BAIRD, W.F., and MAGOON, O.T. (1987) "Berm breakwaters," ASCE, 284p.

XIE, S. L. (1981) "Scouring patterns in front of vertical breakwaters and their influence on the stability of foundation of breakwaters," Rept. of Department of Civil Engineering, Delft University of Technology, $61 \mathrm{p}$.

XIE, S. L. (1994) "Recent research and experience on vertical and composite breakwaters in China," Proc. Intl. Conf. on Wave Barriers in Deepwaters, PHRI, pp. 129-153. 
